UNIVERSIDADE DE SÃO PAULO

FACULDADE DE ECONOMIA, ADMNISTRAÇÃO E CONTABILIDADE DEPARTAMENTO DE ADMINISTRAÇÃO PROGRAMA DE PÓS-GARDUAÇÃO EM ADMINISTRAÇÃO

DESENVOLVIMENTO E VALIDAÇÃO DE ESCALA DA IMPORTÂNCIA DA IMAGEM DO PAÍS DE ORIGEM (COI) COMO RECURSO NA ESTRATÉGIA

Mariana Bassi Sutter

Orientador: Prof. Dr. Edison Fernandes Polo

SÃO PAULO

2016 
Prof. Dr. Marco Antonio Zago

Reitor da Universidade de São Paulo

Prof. Dr. Adalberto Américo Fischmann

Diretor da Faculdade de Economia, Administração e Contabilidade

Prof. Dr. Roberto Sbragia

Chefe do Departamento de Administração

Prof. Dr. Moacir de Miranda Oliveira Junior Coordenador do Programa de Pós-Graduação em Administração 
MARIANA BASSI SUTTER

\section{DESENVOLVIMENTO E VALIDAÇÃO DE ESCALA DA IMPORTÂNCIA DA IMAGEM DO PAÍS DE ORIGEM (COI) COMO RECURSO NA ESTRATÉGIA}

Tese apresentada ao Programa de Pós-Graduação em Administração do Departamento de Administração da Faculdade de Economia, Administração e Contabilidade da Universidade de São Paulo, como requisito parcial para a obtenção do título de Doutor em Ciências.

Orientador: Prof. Dr. Edison Fernandes Polo

Versão Corrigida

(versão original disponível na Biblioteca da Faculdade de Economia, Administração e Contabilidade)

SÃO PAULO 
Autorizo a reprodução e divulgação total ou parcial deste trabalho, por qualquer meio convencional ou eletrônico, para fins de estudo e pesquisa, desde que citada a fonte.

Sutter, Mariana Bassi.

Desenvolvimento e validação de escala da importância da Imagem do País de Origem (COI) como recurso na estratégia / Mariana Bassi Sutter. São Paulo, 2016. $147 \mathrm{p}$.

Tese(Doutorado) - Universidade de São Paulo, 2016.

Orientador: Edison Fernandes Polo.

1. Administração estratégica. 2. Marketing internacional. 3. Teoria Baseada em Recursos (RBT). 4. Imagem do País de Origem (COI). 5. Country of Origin (COO). 6. Escala de Mensuração. 7. Marca. I. Universidade de São Paulo. Faculdade de Economia, Administração e Contabilidade. II. Título. 


\section{Dedicatória}

Aos meus Pais, aos meus familiares, aos meus colegas de "empreitada", aos meus mestres e, sobretudo, Àquele que me guia e me inspira. 



\section{AGRADECIMENTOS}

A finalização do curso de doutorado tem significado de extrema importância tanto na trajetória acadêmica quanto no desenvolvimento pessoal. É uma enorme conquista, marcada por desafios, pela construção de laços de amizade e de confiança e, sobretudo, pela superação diária. Estou certa de que para concluir esse ciclo da minha vida contei com a ajuda, inspiração, humildade e sabedoria de muitos que estiveram próximos de mim nesse período e em outros. Mais uma vez tive o apoio incondicional da minha família e tive a sorte de receber o suporte de amigos, de profissionais, de professores e de colegas que se tornaram parceiros de pesquisa e amigos, pessoas que, de alguma forma, cooperaram para o desenvolvimento deste estudo e para a minha formação como pesquisadora, professora e pessoa.

Em primeiro lugar, agradeço aos meus familiares, em especial meus Pais, que são grandes exemplos de superação, humildade e paciência. Eles me deram todo apoio e incentivo para realizar essa etapa. Agradeço ao Prof. Dr. Edison Fernandes Polo por novamente ter assumido o desafio de me orientar, por reafirmar sua crença no meu potencial e no tema de pesquisa sobre o qual eu escolhi desenvolver a minha tese. Agradeço aos Professores Felipe Borini e Janaina Giraldi, pela importante participação no decorrer desta tese (em especial no exame de qualificação) e pelos ensinamentos e recomendações que enriqueceram a pesquisa.

Ao longo desses anos cursei diversas disciplinas, monitorias, participei da organização de eventos acadêmicos (e sociais) e da representação discente. Tais experiências me aproximaram de professores e profissionais que colaboraram para a minha formação. Assim, agradeço: ao Edson Crescitelli, ao Geraldo Toledo, ao José Afonso Mazzon, ao Moacir Miranda, à Kavita Hamza, ao James Wright, à Renata Spers, à equipe do PPGA (Eloisa, Fabiana, Daniela e Cíntia) e à equipe da SPG (Cida, Ana e Francisco) pelos ensinamentos e paciência.

O doutorado na USP me trouxe a possibilidade de estudar em outras instituições, oportunidades nas quais fiz novas amizades e aprendi com excelentes professores que também me auxiliaram nessa trajetória. Agradeço aos Professores Vivian Strehlau, Thelma Valéria e Mateus Ponchio do PMDGI da ESPM, programa no qual tive os primeiros insights para desenvolver a minha pesquisa e os ensinamentos para realizar os ajustes finos para finalizá-la. Agradeço aos Professores Dirceu da Silva, Marcelo Moll e Diógenes de Souza Bido pelas discussões e recomendações de cunho metodológico.

Agradeço a compreensão e apoio dos colegas da FIA, em especial, à equipe de Professores Assistentes do Profuturo-FIA (Bruno, Lufe, Alexandre, Samantha, Andrea, Luiza, Nelson, Diogo), à equipe de apoio (Ivana, Karen, Paloma, Gisele, Juliana, Daniana, Joseph, Babi, Thiago, Elaine, 
Cristiane) e à coordenação (Prof. James, Profa. Renata e Prof. Daniel) que foram fundamentais nessa etapa.

Para atingir os objetivos desta tese mobilizei diversas pessoas em diferentes instituições. Sem a ajuda de todos, eu não conseguiria desenvolver e validar as assertivas da minha escala, tampouco levantar 457 casos válidos para realizar os testes estatísticos. Por isso, minha eterna gratidão aos colegas, aos amigos, aos professores, aos coordenadores de cursos, aos executivos e aos gestores de empresas que se disponibilizaram a me ajudar no processo de desenvolvimento da escala e na coleta de dados, em especial: ao Cesar Yokomizo, à Patrícia Krakauer, à Maria Cecília Galante, ao Leandro Morilhas, à Ivete Rodrigues, à Flávia Ghisi, ao Rodolfo Olivo, à Michele Candeloro, à Luciana Florencio, ao Almir Ferreira, à Mariana Bussab, ao Sergio Garrido, ao Helder Haddad, à Mariana Hammel, à Ana Puglia, ao Claudio Saito e ao Pedro Ferreira.

Agradeço às eternas acadêmicas da Maloca (Rê, Tia China, Carmela, Madalena e Mãe) que me ensinam e me inspiram com sua dedicação ao ofício e à amizade. Agradeço também aos amigos que o doutorado me propiciou, especialmente, à Rafaela Almeida, ao Tobias Parente, ao Vitor Nogami, à Elaine Mandotti, ao Ricardo Pitellli e à Simone Barakat com quem dividi angústias, frustrações, problemas de pesquisa, aprendizados e muitos momentos de alegria. Agradeço também aos amigos da FEA: Barbara Galleli, Gabriela Tiscoski, Laura MacLennan, Ângela Lucas, João Paulo Bittencourt, Luciana Lima, Tatiana Zuppani, Natani, Pilli, Alexandre Salvador e Bruno Mazzola.

Agradeço às amigas Gabriele Navarini, Ana Paula Melo, Daniella Rosenbaum que aturaram a minha ausência em "dias de tese" e tiveram muita paciência com as minhas inquietações acadêmicas. Agradeço às amigas Talita Sassaki, Silvia Hito, Rosa Janinni e Fernanda Figueiredo que sempre me encorajaram. Agradeço à Universidade de São Paulo e à Coordenação de Aperfeiçoamento de Pessoal de Nível Superior (CAPES) pela bolsa de estudos disponibilizada.

Agradeço à Professora Dinorá Floriani e aos demais professores convidados à banca (mencionados anteriormente), por participarem da defesa, pela leitura do estudo e pelas valiosas contribuições. Meus sinceros agradecimentos àqueles que, direta ou indiretamente, contribuíram para a conclusão deste importante ciclo. 
“[...] seria necessário resgatar como uma dimensão altamente positiva, como patrimônio realmente invejável, toda essa nossa capacidade de sintetizar, relacionar e conciliar, criando áreas e valores ligados à alegria, ao futuro e à esperança. Num mundo que cada vez mais se desencanta consigo mesmo e institui um individualismo sem limites, que reduz os valores coletivos a mero apêndice da felicidade pessoal e do mercado, a capacidade de deslumbrar-se com a sociedade é algo muito importante e positivo. $\mathbf{E}$ aqui, sem dúvida, podemos novamente sintetizar, de modo criativo e relacional, o indivíduo com as suas exigências e direitos fundamentais, com a sociedade, com a sua ordem, seus valores e necessidades.

Talvez a sociedade brasileira seja missionária dessa possibilidade que vai se esgotando no mundo ocidental. Digo missionária porque somo pioneiros no reconhecimento da ambiguidade como um elemento crítico de qualquer sociabilidade. Pois se descobrimos e adotamos o individualismo e o mercado, bem como as tecnologias que permitem criar mais riqueza, não nos esquecemos de um universo relacional, festivo e caseiro, que também tem o seu lugar. Assim, em vez de termos aquele célebre combate ocidental do Carnaval contra a Dona Quaresma, do qual o primeiro saiu como perdedor, teríamos um caminho entre a técnica, o individualismo, o mercado e essa modernidade fundada nos direitos individuais e em tudo o que vem de casa. Nem tanto o desencanto crítico que conduz a um primado igualmente cego da sociedade e do coletivo, que esmaga a criatividade humana e sufoca o conflito e a chama das contribuições pessoais. Talvez algo no meio. Algo que permita ter um pouco mais da casa na rua e da rua na casa". 



\section{RESUMO}

A área de estratégia, por meio da teoria baseada em recursos (RBT), desenvolve estudos que procuram compreender as características, recursos, capacidades e processos que levam algumas empresas, na mesma indústria, a terem um desempenho melhor que seus concorrentes. A RBT atingiu a maturidade teórica exigindo novos rumos para a sua revitalização. Simultaneamente, os estudiosos de marketing internacional afirmam que a teoria sobre a imagem do país de origem (COI) precisa ser revigorada e recomendam que ela seja analisada à luz da literatura de estratégia. É sob essa perspectiva que esta tese apresenta a sua contribuição, desenvolvendo e validando uma escala de importância de COI na perspectiva empresarial. O construto foi desenvolvido com base em uma capacidade específica da empresa: a construção e gestão da marca. Para isso, as bases teóricas sobre RBT, interface entre RBT e marketing, COI e marca foram revisadas e, ancorada nesta literatura, foi possível identificar os processos para incorporar a COI na estratégia da marca, os quais foram utilizados como dimensões da escala. Foram realizados diversos procedimentos psicométricos seguindo as recomendações de diversos psicometristas. O constructo foi definido como a capacidade de gestão da incorporação da COI à marca (BCOI), que reflete a importância conferida pela empresa para usar a COI como um recurso na construção da capacidade de marca. Após a etapa inicial, em que foram gerados e validados os itens com pesquisadores e com gestores, realizou-se um levantamento com 457 executivos. A amostra foi dividida em duas subamostras para aplicação de diferentes técnicas estatísticas. Na subamostra 1 foi realizada uma análise fatorial exploratória que confirmou o modelo inicial da escala delineado junto a pesquisadores e gestores no processo de geração de itens. Esse modelo foi testado na subamostra 2 por meio da análise fatorial confirmatória e da modelagem de equação estrutural. Os resultados indicaram que a BCOI se manifesta por meio de 26 itens organizados em cinco dimensões: elementos textuais e visuais, sentidos, recursos culturais, recursos naturais e empregados.

Palavras-chave: Recursos, Capacidades, Processos, Teoria baseada em recursos (RBT), Imagem do País de Origem (COI), Country of Origin, Escala de mensuração, Estratégia, Estratégia Internacional, Marketing Internacional, Marketing, Marca. 


\begin{abstract}
The strategy stream, through resource theory based (RBT), develops studies that seek to understand the characteristics, features, capabilities and processes that lead some companies in the same industry, to have a better performance compered to its competitors. The RBT has reached the theoretical maturity requiring new directions for its revitalization. Simultaneously, international marketing scholars claim that the theory about the country of origin image (COI) needs to be invigorated and recommend it to be examinated in the light of the strategy literature. It is from this perspective that this thesis presents its contribution by developing and validating a scale of importance of COI in business perspective. The construct was developed based on a specific capability of the company: building and manageming the brand (branding). For this, the theoretical basis of RBT, the interface between marketing and RBT, COI and branding were reviewed and anchored in this literature, it was possible to identify the processes to incorporate the COI in the brand strategy, which were used as scale dimensions. various psychometric procedures following the recommendations of several psychometricians were performed. The construct was defined as the branding capability of COI incorporation (BCOI), which reflects the importance given by the company to use the COI as a resource in brand building capability. After the initial stage, in which items were generated and evaluated with researchers and managers, a survey with 457 executives was held. The sample was divided into two subsamples for application of different statistical techniques. An exploratory factor analysis was performed with subsample 1. The EFA produced an initial scale model that was tested in subsample 2 through confirmatory factor analysis and structural equation modeling. The results indicated that the BCOI iis manifested through 26 items organized into five dimensions: textual and visual elements, senses, cultural resources, natural resources and employees.
\end{abstract}

Keywords: Resource, Capability, Process, Resource Based Theory (RBT), Country of Origin Image (COI), Country of Origin, Measurement scale, Strategy, International Strategy, International Marketing, Marketing, Branding. 


\section{SUMÁRIO}

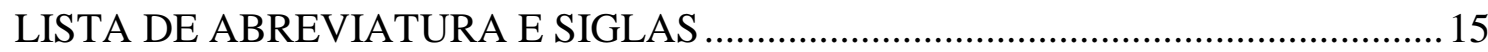

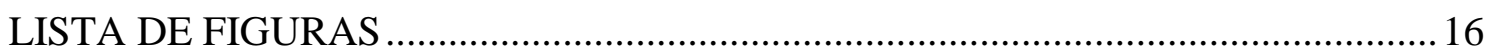

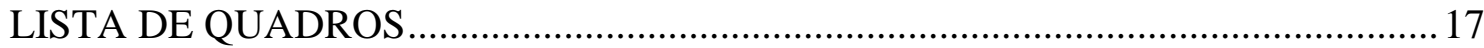

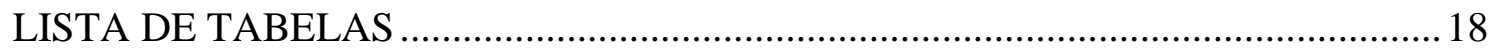

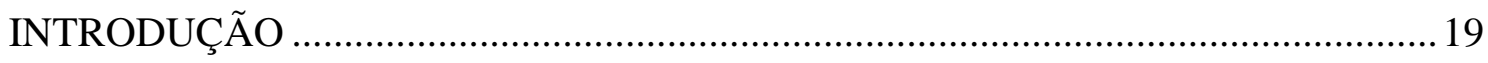

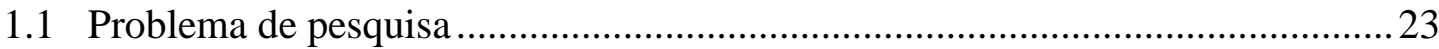

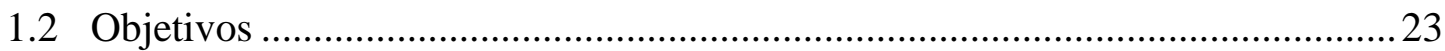

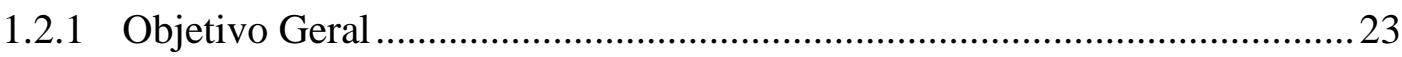

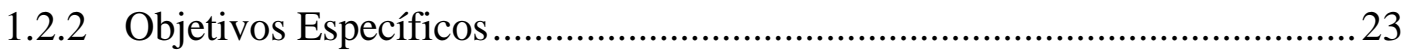

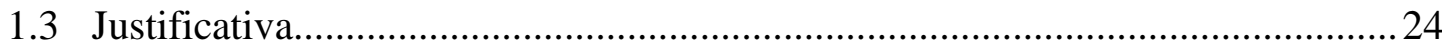

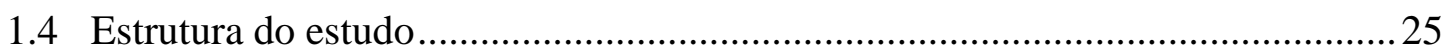

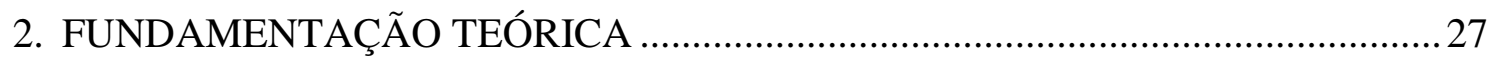

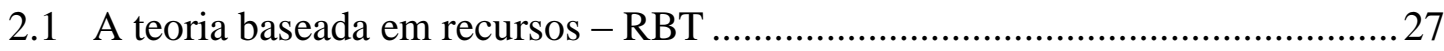

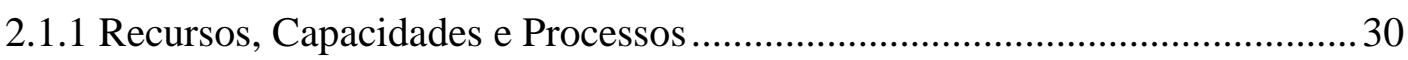

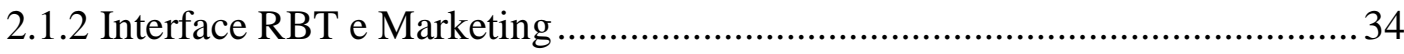

$2.2 \mathrm{O}$ papel do país de origem na empresa em processo de internacionalização ......... 38

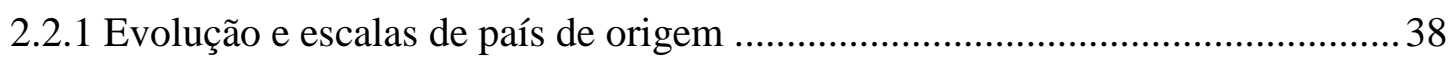

2.2.2 A COI como recurso na estratégia internacional .........................................4 47

2.2.3 Os processos de incorporação da COI e elaboração de hipóteses ..................52

3. ASPECTOS METODOLÓGICOS DA PESQUISA EMPÍRICA ............................66

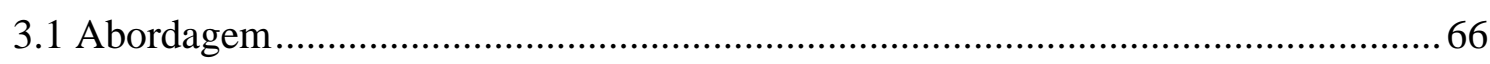

3.2 Procedimentos para o desenvolvimento e validação de escalas .............................67

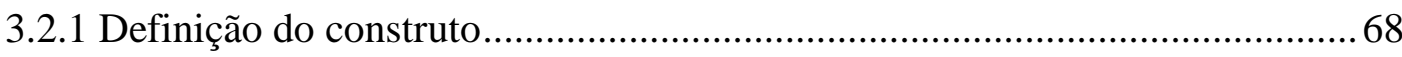

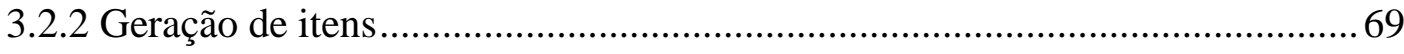

3.2.3 Amostra, coleta de dados e técnica de coleta de dados ................................81

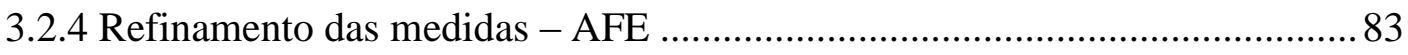

3.2.5 Análise de confiabilidade e validação estatística.......................................... 85

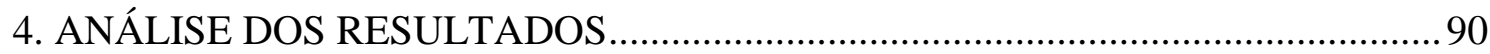

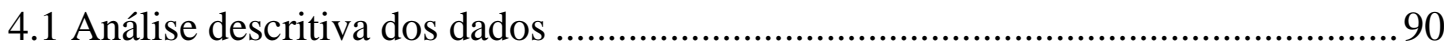




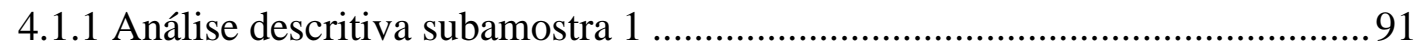

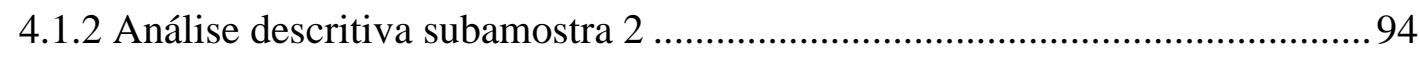

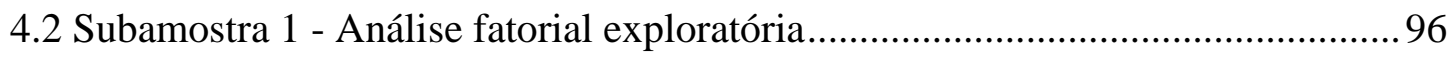

4.3 Subamostra 2 - Análise fatorial confirmatória e validação estatística ................ 102

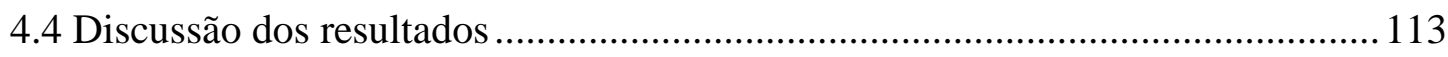

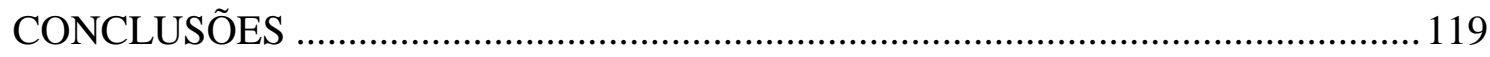

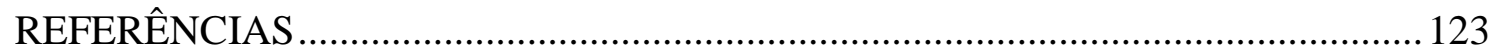

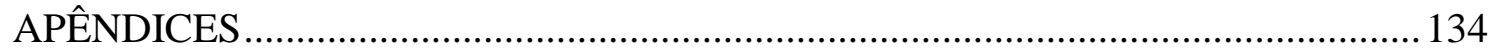

Apêndice A - Instrumento de coleta de dados ...................................................... 134

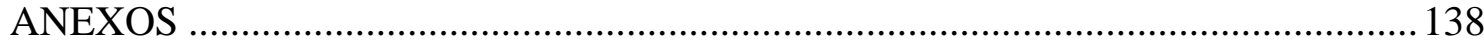

Anexo 1 - Resumo das principais escalas analisadas por Roth \& Diamantopoulos (2009) 138 


\section{LISTA DE ABREVIATURA E SIGLAS}

AFC - Análise Fatorial Confirmatória

AFE - Análise Fatorial Exploratória

BO - Brand Origin

BCOI - Branding capability of country of origin incorporation

BORA - Brand origin recognition accuracy

CI - Country Image

COA - Country-Of-Assembly

COB - Country-Of-Brand

COD - Country-of-Design

COE - Country-of-Origin-Effect

COI - Country-of-Origin-Image

COM - Country-of-Manufacture

$\mathrm{COO}$ - Country-of-Origin

COP - Country-of-Parts

ESPM - Escola Superior de Propaganda e Marketing

MEE - Modelagem de Equações Estruturais

PCI - Product-Country-Image

RBT - Resource based theory

RBV - Resource based view

VC - Vantagem Competitiva

VI - Variável Independente

VD - Variável Dependente 


\section{LISTA DE FIGURAS}

Figura 1 - Sequência Lógica do Estudo.......................................................................... 26

Figura 2 - A janela de transferência de valor ......................................................................... 50

Figura 3 - Classificação da origem da marca e associação favorabilidade (aceitação) ................ 51

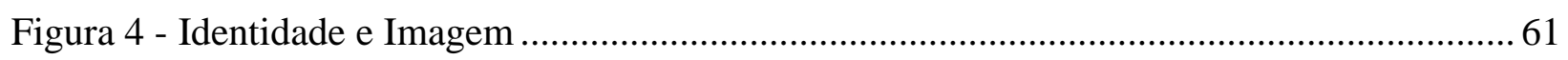

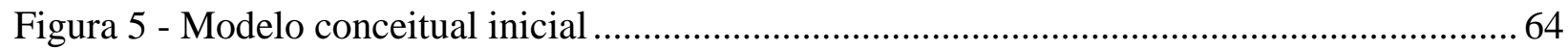

Figura 6 - Etapas do desenvolvimento e validação da escala ................................................. 68

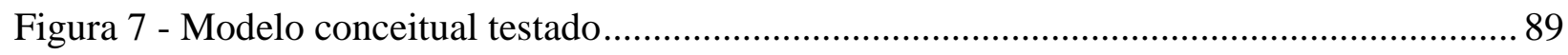

Figura 8 - Modelo de mensuração da escala ............................................................................ 102

Figura 9 - Cargas do modelo de mensuração .......................................................................... 103

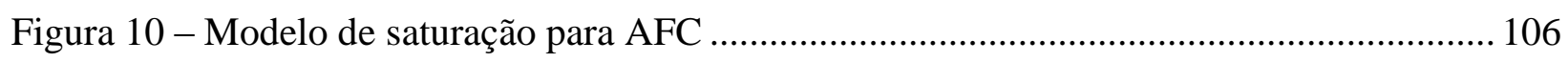

Figura 11 - Cargas das variáveis pelo método de saturação .................................................... 106

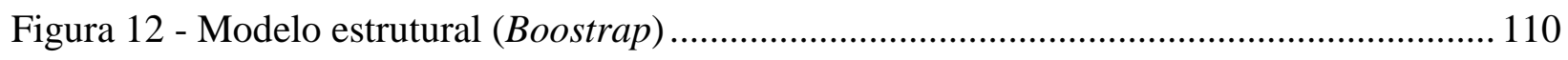

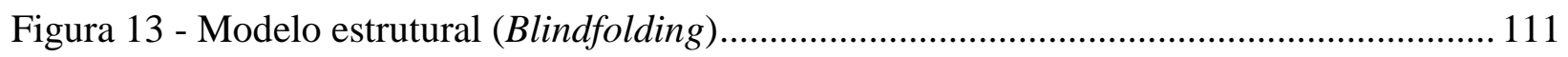

Figura 14 - MEE ajustada com coeficientes de caminho, R2 e cargas fatoriais ....................... 112

Figura 15 - A importância da incorporação da COI na construção da capacidade de marca

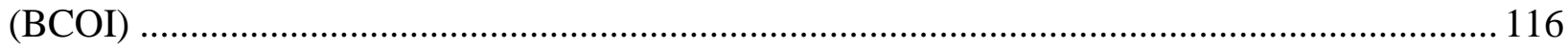

Figura 16 - Processo de desenvolvimento e validação da escala ............................................... 117 


\section{LISTA DE QUADROS}

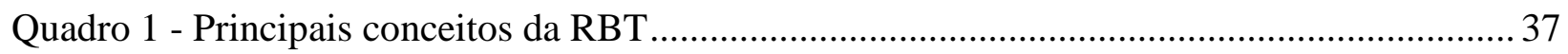

Quadro 2 - Escala de mensuração da COI ........................................................................... 40

Quadro 3 - Estudos que utilizaram a escala de Nagashima como base ...................................... 41

Quadro 4 - Resumo dos estudos do país de origem na década de 1990 .................................... 43

Quadro 5 - Evidências de incorporação da COI na estratégia da marca ...................................... 63

Quadro 6 - COI na estratégia: aplicação dos conceitos da RBT …............................................ 65

Quadro 7 - Processos de incorporação da COI na estratégia da marca...................................... 70

Quadro 8 - Dimensões e itens para desenvolvimento de escala de incorporação da COI como

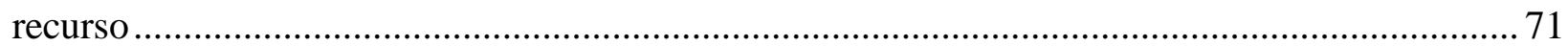

Quadro 9 - Itens após reunião com grupo de pesquisa …...................................................... 73

Quadro 10 - Pesquisadores que participaram da validação de conteúdo .................................... 73

Quadro 11 - Itens após validação de conteúdo com pesquisadores ............................................ 75

Quadro 12 - Gestores que participaram da validação de face .................................................. 76

Quadro 13 - Itens após validação de face com gestores ......................................................... 79

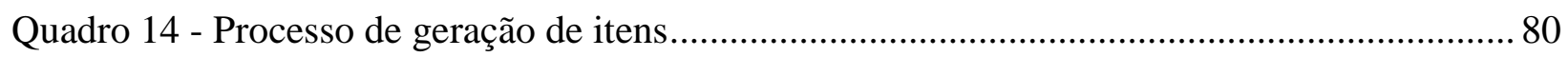

Quadro 15 - Indicadores e procedimentos AFC com PLS ..................................................... 86

Quadro 16 - Indicadores e procedimentos do modelo estrutural com PLS ............................... 87

Quadro 17 - Atividades do primeiro passo para construção de escala........................................ 88

Quadro 18 - Itens, fatores e indicadores de confiabilidade .................................................... 100

Quadro 19 - Especificação do modelo estrutural geral ............................................................ 104

Quadro 20 - Correlações entre as variáveis latentes e as raízes quadradas das AVEs .............. 104

Quadro 21 - Correlações entre as variáveis latentes e as raízes quadradas das AVEs ............... 107

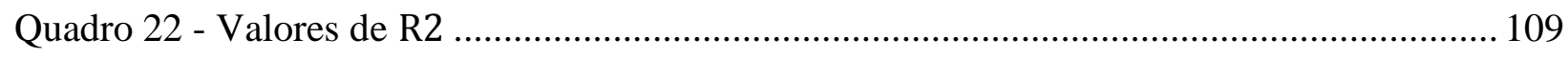

Quadro 23 - Valores t e p das relações causais entre os construtos do modelo ajustado............ 110

Quadro 24 - Valores dos tamanhos dos efeitos (f2) e das relevâncias preditivas (Q2)............. 111

Quadro 25 - Valores dos coeficientes de caminho do modelo ajustado ................................... 112

Quadro 26 - Valores t, valores p e coeficientes de caminho das relações causais entre os construtos do modelo ajustado..... 


\section{LISTA DE TABELAS}

Tabela 1 - Tipo de operação (subamostra 1) ........................................................................... 91

Tabela 2 - Distribuição do país de origem das empresas (subamostra 1) ................................... 93

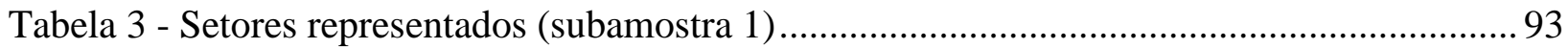

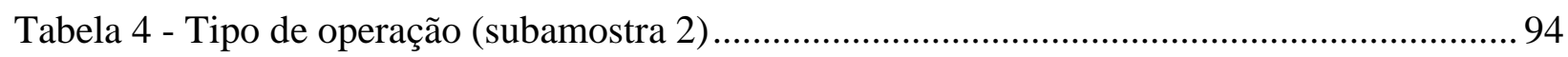

Tabela 5 - Distribuição do país de origem das empresas (subamostra 2) ................................... 95

Tabela 6 - Setores representados (subamostra 2) ..................................................................... 96

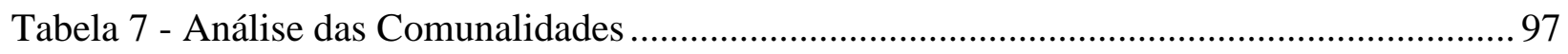

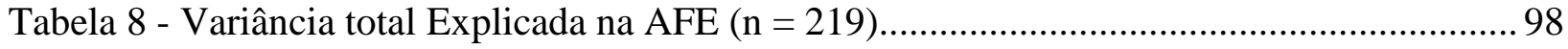

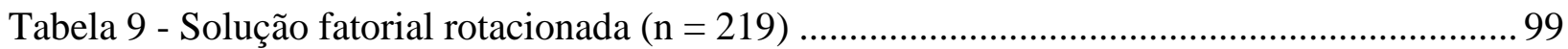

Tabela 10 - Análise de confiabilidade das dimensões no caso de exclusão de item................... 101

Tabela 11 - Valores das cargas cruzadas das variáveis observáveis nas variáveis latentes ........ 105

Tabela 12 - Resultados da análise de consistência interna pelos dois métodos de AFC pelo

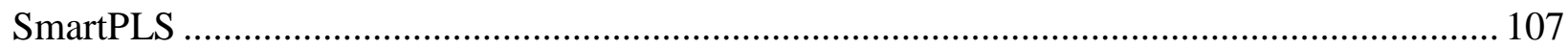

Tabela 13 - Resultados da análise das cargas cruzadas pelos dois métodos de AFC ................. 108 


\section{INTRODUÇÃO}

A teoria baseada em recursos (RBT) busca compreender o que leva algumas empresas na mesma indústria a terem desempenho superior e como podem sustentar a vantagem competitiva (VC) (Barney, 1991; Dierickx \& Cool, 1989; Peteraf, 1993; Wernerfelt, 1984), pois entende que as diferenças em termos de resultados financeiros não podem ser atribuídas somente às diferenças nas condições da indústria (Peteraf, 1993; Barney, Ketchen \& Wright, 2011). A RBT defende que a empresa é uma fonte de recursos (Penrose, 1959; Barney, 1991) e que a obtenção de VCs emerge da identificação, desenvolvimento e gestão do portfólio de recursos físicos, financeiros, intangíveis, organizacionais e humanos. Esse processo tem como resultado o desenvolvimento de capacidades e recursos internos que asseguram uma posição competitiva sustentável, dado que seus competidores não conseguem imitar tais recursos (Barney, 1991).

Segundo Barney, Wright \& Ketchen (2011) essa perspectiva atingiu a maturidade teórica, o que indica que o seu corpo teórico é robusto, contudo a abordagem precisa ser renovada, pois, do contrário, poderá entrar em declínio. Para que isso não aconteça novas direções devem ser utilizadas e novas perspectivas podem ser desenvolvidas com base em outras áreas de estudo (Barney et. al, 2011). Na área de marketing, a teoria baseada em recursos tem se mostrado de grande importância (Day, 2014; Kozlenkova, Samaha \& Palmatier, 2014) podendo contribuir ainda mais para a extensão da literatura de RBT (Barney, Wright \& Ketchen, 2001; Barney, 2014; Wernerfelt, 2014). Desde o final dos anos 1990, o número de artigos dessa área ancorados em RBT aumentaram expressivamente, sendo os principais temas que abordam a RBT: marketing estratégico, marketing internacional e inovação (Kozlenkova et al., 2014).

Especificamente na área de negócios internacionais, a RBT auxilia a apontar a natureza dos recursos necessários para superar a desvantagem do estrangeiro e estabelecer uma ponte para investigar os recursos que podem fornecer os alicerces para produto e diversificação internacional (Barney et al., 2001). Uma das literaturas mais investigadas em marketing internacional é o país de origem. Cuervo-Cazurra \& Un (2015) e Cuervo-Cazurra (2011) incentivam estudos sobre o país de origem à luz da estratégia, pois acreditam que o país de origem pode ser considerado um recurso capaz de oferecer vantagem ou desvantagem para a empresa, e não apenas uma funcionalidade do produto. Neste estudo, argumenta-se que o país 
de origem e sua imagem devem ser considerados ao se pensar a estratégia da empresa, o modo de operação nos mercados internacionais (Senthi \& Elango, 2000) e outras decisões da empresa (Cuervo-Cazurra \& Un, 2015), e acredita-se, sobretudo, que a imagem do país de origem pode representar um recurso capaz de gerar vantagem competitiva à empresa (Cuervo-Cazurra \& Un, 2015; Agrawal \& Kamakura, 1999; Baker \& Ballington, 2002).

O tema "país de origem" ou COO (Country-Of-Origin) é objeto de estudos na área de marketing internacional desde 1960 (Pharr, 2005; Roth \& Diamantopoulos, 2009), quando Schooler (1965) demonstrou empiricamente que consumidores diferenciam produtos com atributos idênticos, a não ser pelo seu país de origem. Desde então, acadêmicos de marketing internacional estudam a influência que o país de origem do produto exerce nas avaliações de consumidores internacionais com relação à qualidade do produto e à marca (Agrawal \& Kamakura, 1999; Gürhan-Canli \& Maheswara, 2000; Pharr, 2005; Roth \& Diamantopoulos, 2009; Diamantopoulos, Schlegelmilch \& Palihawadana, 2011; Herz \& Diamantopoulos, 2013a, 2013b; Magnusson, Westjohn, \& Zdravkovic, 2011a, 2011b). O conceito evoluiu e se ampliou para uma abordagem conhecida como imagem do país de origem - Country-Of-Origin-Image COI (Roth \& Diamantopoulos, 2009) ou imagem do produto/país que inclui também a imagem de lugares (Papadopoulos, 2004). Esse conceito refere-se à imagem do país com a qual o produto é associado pelos vendedores e/ou compradores (Papadopulos, 2004), podendo exercer uma influência tanto positiva quanto negativa, na percepção dos consumidores.

Da COI pode ainda derivar substancial proporção do valor da marca (Pappu, Quester \& Cooksey, 2007). No entanto, recentemente, a real importância sobre o construto foi colocada em debate buscando-se sua revitalização. Por um lado, estudiosos afirmam que as marcas das empresas são mais importantes do que seu país de origem, e, assim, o país de origem não apresenta mais relevância gerencial (Samiee, 2011; Usunier, 2011). Por outro lado, outros pesquisadores acreditam que o país de origem ainda influencia o processo de avaliação do produto (por exemplo, Herz \& Diamantopoulos 2013a; 2013b; Diamantopoulos et al., 2011; Magnusson et al., 2011a; 2011b) e novos métodos, novas variáveis e novos temas devem ser explorados em pesquisas para avaliar essa questão a partir de novas perspectivas (IMR, 2015).

Outros pesquisadores reforçam a importância de se estudar o país de origem chamando a atenção para diferentes perspectivas de investigações (Roth \& Diamantopoulos, 2009), tais como no processo de internacionalização de pequenas empresas (Spence \& Hamzaoui Essoussi, 2010), em empresas de serviços (La, Patterson \& Styles, 2009; Cheng, Chen, Lai \& Li, 2014), 
na avaliação da marca (Đorđević, 2008; Herstein, Berger \& Jaffe, 2014) e também para empresas de mercados emergentes que ainda estão em fase inicial de internacionalização (Ramamurti 2012), quando as características do país de origem ainda podem beneficiar ou desafiar a imagem da empresa no exterior (Cuervo-Cazurra, 2011). Além disso, Samiee (2010) argumenta que muitos estudos sobre o país de origem têm sido realizados com metodologias complexas, no entanto, no avanço da teoria para questões de gestão e estratégia têm recebido pouca atenção. Dessa forma, recomendam-se estudos sobre a temática, mas a partir da perspectiva de outras correntes de pesquisa (Roth \& Diamantopoulos, 2009).

Por meio de pesquisas em bases de dados internacionais podem ser encontradas centenas de estudos de marketing internacional que tratam o país de origem como destacam Cavusgil, Deligonul \& Yaprak (2005), Kotabe (1999) e Usunier (2006). Em 1970, Nagashima (1970) propôs a primeira escala para medir a percepção que executivos têm sobre determinado país de origem. Tal estudo serviu como base para vários outros estudos como relatado por Nebenzahl, Jaffe \& Usunier (2003). Desde então, outras escalas foram propostas por diversos acadêmicos da área, como: Papadopoulos (1986), Yaprak \& Parameswaran (1986), Pisharodi \& Parameswaran (1992), Chao \& Rajendran (1993), Verlegh (2001), Heslop, Papadopoulos, Dowdles, Wall \& Compeau (2004), Laroche, Papadopoulos, Heslop \& Mourali (2005), d'Astous \& Boujbel (2007), Pappu, Quester \& Cooksey (2007), entre outros. A análise desses estudos mostra a importância do país de origem em transações internacionais, contudo, a temática é abordada com foco, principalmente, no consumidor final (Usunier, 2006; Peterson \& Jolibert, 1995), em consumidores industriais (Nagashima, 1970; 1977; Cattin, Jolibert \& Lohnes , 1982; Ahmed \& d'Astous, 1995; d'Astous \& Ahmed, 1999; Quester, Dzever \& Chetty, 2000) e em serviços industriais (La, Patterson \& Styles, 2009; Cheng et al., 2014). Tais escalas incluem dimensões em relação à avaliação dos consumidores sobre o produto (a integridade do produto, preço, presença de mercado, sensibilidade, atributos gerais do produto, atributos negativos do produto, questões de distribuição, a imagem do produto, entre outros), marca (imagem, marca atributos) e do país (a imagem do país no que diz respeito a: a política, a aparência, a cultura, as pessoas, economia, sociedade, tecnologia).

Todavia, conforme as unidades de análise das escalas propostas têm foco no mercado consumidor final ou empresarial, não foi possível identificar dimensões ou itens dispostos a capturar a importância do país de origem na estratégia da empresa como um recurso. Essa é a razão pela qual o presente estudo advoga que as várias escalas de mensuração do país de origem 
estão direcionadas para a avaliação do consumidor sobre um produto ou uma marca originária de um país em particular. Buscas realizadas na base de dados Scopus, para o período de 2005 a 2015, com as palavras "Country of Origin", "Country of Origin Image," "Brand Origin" combinadas com as palavras "Resource Based Theory", "Resource Based View", "Capability" e "Resources" levaram à identificação de apenas doze artigos publicados relacionando, de algum modo, os termos. Esse baixo número de investigações acadêmicas ligando as duas teorias (país de origem e RBT) corrobora os resultados de Castro, Giraldi \& Galina (2014) de que ainda não existe um corpo teórico sólido argumentando como o COO representa um recurso para a empresa.

Dentre os estudos identificados, nenhum propõe, tampouco testa uma escala para medir a importância ou a forma de uso do país de origem como um recurso na estratégia da empresa, eles apenas fornecem uma avaliação exploratória do construto por meio de uma abordagem qualitativa ou conceitual (ver: Cuervo -Cazurra \& Un, 2015; Agrawal \& Kamakura, 1999; Baker \& Ballington, 2002; Đorđević, 2008; Herstein, Berger \& Jaffe, 2014; Kumar \& Steenkamp, 2013; Chattopadhyay, Batra \& Ozsomer, 2012; Paterlini, Giraldi \& Amui, 2012; Castro et al, 2014; Spence \& Hamzaoui Essoussi, 2010; D'Antone \& Merunka, 2015). Portanto, identificou-se que não há uma escala delineada e validada que mensure a importância da COI como recurso na estratégia da empresa em processo de internacionalização, sendo essa a problemática que o presente estudo buscou sanar.

Assim, esta tese amplia a literatura de RBT recorrendo à literatura de marketing internacional. Como o país de origem é considerado uma fonte de informação para a avaliação de marcas (Đorđević, 2008; Herstein, Berger \& Jaffe, 2014), parte-se da premissa de que a incorporação do país de origem pode tornar-se um recurso para a empresa por meio da sua capacidade de construção e gestão da marca. Logo, buscou-se mensurar a importância da COI como um recurso na construção de uma capacidade de gestão da marca. Isto é, o quanto é importante a incorporação de atributos da COI da empresa, tais como as suas representações, suas pessoas; suas imagens; seus recursos naturais e culturais (Kotler \& Gertner, 2002; Wang, Li, Barnes \& Ahn, 2011; Kumar \& Steenkamp, 2013) por meio de mensagens transmitidas pelos produtos, serviços e comunicações de marca (Kapferer, 2003).

O presente estudo inicia as investigações nessa linha de pesquisa que relaciona a RBT e a COI e parte do pressuposto de que a COI pode representar um recurso para empresas em 
processo de internacionalização. Nesta tese toma-se como referência o Brasil e o objeto de estudo são as empresas em processo de internacionalização.

\subsection{Problema de pesquisa}

Tendo em vista as informações apresentadas que destacam o contexto acadêmico envolvendo a COI, RBT, capacidade de marca e estratégia da empresa em processo de internacionalização, o problema de pesquisa identificado e que a tese se propôs a responder consiste na seguinte questão: A COI pode ser considerada um recurso a ser incorporado na constração da capacidade de marca de empresas em processo de internacionalização?

\subsection{Objetivos}

\subsubsection{Objetivo Geral}

A fim de corroborar a robustez de estudos com a temática de COI sob o enfoque de estratégia, o objetivo geral desta tese consistiu em propor e validar uma escala para mensurar a importância da COI como recurso na construção da capacidade de marca da empresa em processo de internacionalização.

\subsubsection{Objetivos Específicos}

Para atingir esse objetivo geral, foram definidos os seguintes objetivos específicos para o estudo empírico:

- OE1: Propor e refinar uma escala para mensurar a importância da incorporação da COI como recurso na construção da capacidade de marca da empresa em processo de internacionalização, definindo suas dimensões e respectivos indicadores.

- OE2: Testar e validar as escalas propostas para os constructos de $1^{\mathrm{a}}$ ordem e as relações deles com o construto de $2^{\mathrm{a}}$ ordem. 


\subsection{Justificativa}

A primeira justificativa da tese está em linha com a busca de novas perspectivas para análise do construto COI e na busca pela extensão da RBT considerando a COI como um recurso para a empresa em processo de internacionalização. Essa justificativa se apoia (i) no fato de que toda a literatura sobre o país de origem ter sido desenvolvida sob a percepção do consumidor final e no B2B, e não acerca do aspecto da $\mathrm{COI}$ como recurso na estratégia da empresa (Berveland \& Lingreen, 2002; Senthi \& Elango, 2000; Cuervo-Cazzura \& Un, 2015); (ii) da mesma maneira, a tese se justifica em função da demanda, por parte de acadêmicos da área de estratégia, para a revitalização da RBT, processo no qual a teoria de marketing pode ajudar a estender essa literatura (Barney et al., 2011).

Em função da escassez de investigações sobre a COI na perspectiva da estratégia empresarial, foram identificados somente alguns estudos sobre o uso da COI na estratégia da empresa, sendo esses de cunho qualitativo (Berveland \& Lingreen, 2002; Cuervo-Cazzura \& Un, 2015). E, em função disso, não foi desenvolvida uma escala para mensurar o uso ou a importância da COI na estratégia da empresa. Assim, a segunda justificativa do estudo reside na necessidade de se desenvolver uma escala para mensurar tal relação, sendo esse o objetivo geral desta tese.

Em terceiro, a literatura que trata o marketing internacional aponta que países emergentes devem omitir a COI em operações internacionais (Manrai, Lascu, Manrai, 1998; Pappu, Quester, \& Cooksey, 2007; Tallman \& Yip, 2009). Em contrapartida, Chattopadhyay, Batra \& Ozsomer (2012) e Kumar \& Steenkamp (2013) em estudos sobre construção de marcas de países emergentes no contexto internacional, apontam que elementos integrantes da COI, como atributos culturais e naturais, podem adicionar valor à marca. As marcas: Havaianas (Brasil), a Herborist, a Shangai Tang e a Shang Xia (Chinesas) utilizam atributos da cultura do seu país para competir internacionalmente, assim como as marcasCafé da Colombia (Colômbia), Concha y Toro (Chile), Premier Cosmetics (Israel) e Natura (Brasil), se apoiam em recursos naturais característicos do seu país de origem para construir suas marcas (Kumar e Steenkamp, 2013). Observando o valor dos atributos da COI de países emergentes, empresas estrangeiras começam a se beneficiar da COI de países emergente em suas estratégias. Berveland \& Lingreen (2002) citam que as empresas devem ter cautela ao utilizar a COI em sua estratégia. Nesse sentido, faz-se necessário compreender em quais situações utilizar a COI. 
Por isso, esta tese aprofunda o conhecimento acerca da utilização da COI na estratégia internacional.

A quarta justificativa refere-se à importância do aprofundamento de estudos na área de marketing internacional no contexto das empresas de mercados emergentes, dado que as empresas de países emergentes têm tanto comportamento quanto características diferentes das empresas de países desenvolvidos (Fan, 2008). De acordo com análise de conteúdo de Usunier (2006) - que considerou artigos publicados sobre a temática entre 1965 e 2002 - cerca de $26 \%$ dos estudos consideraram países emergentes nas investigações. O Brasil foi foco de apenas 2,06\% da amostra analisada. As justificativas apresentadas denotam a lacuna teórica nesse campo de estudos e mostram a originalidade deste projeto, que almeja contribuir para uma melhor compreensão da temática por meio de uma abordagem interdisciplinar (Cheng, Henisz, Roth \& Swaminathan, 2009).

\subsection{Estrutura do estudo}

Este estudo está estruturado em cinco partes. No primeiro capítulo, apresentou-se a introdução do tema, em que se contextualizou a sua relevância teórica e gerencial. Nesse capítulo também se desenvolveu e delimitou-se o problema de pesquisa, os objetivos e as justificativas que nortearam o trabalho, assim como, descreveu-se a sua organização.

No segundo capítulo desenvolveu-se o referencial teórico do estudo, que abrangeu a revisão de livros e artigos acadêmicos com o objetivo de estruturar o arcabouço teórico sobre as duas teorias que foram relacionadas nesta tese (COI e RBT). Esse capítulo também delineou o construto para o qual a tese se propôs a desenvolver um instrumento de mensuração, teceu as hipóteses do estudo e o modelo conceitual do estudo.

O terceiro capítulo dos aspectos metodológicos do estudo e contemplou desde a escolha do método, as etapas para desenvolvimento e validação de escala até o plano de coleta e análise dos dados.

As análises dos resultados e as fases do estudo de campo foram apresentadas no capítulo quatro. Por fim, o capítulo cinco reúne as conclusões geradas a partir da análise dos resultados, as contribuições acadêmicas e as implicações gerenciais dos achados, as limitações do estudo e as sugestões para estudos futuros. A Figura 1 mostra um esquema da organização do estudo: 


\section{Figura 1 - Sequência Lógica do Estudo}

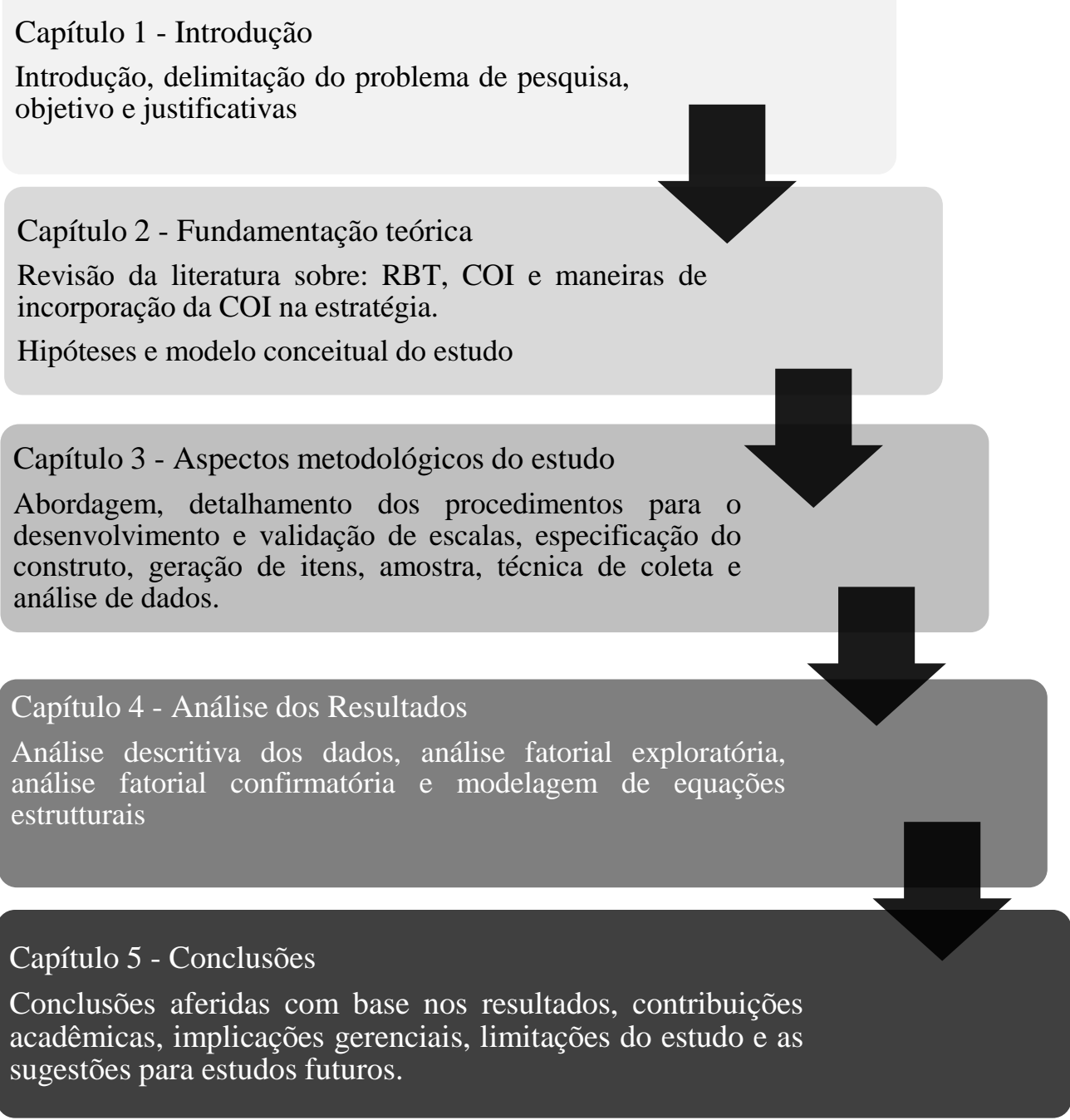

Figura 1. Sequência lógica do estudo Fonte: A autora. 


\section{FUNDAMENTAÇÃO TEÓRICA}

A fundamentação teórica desta tese se apoia em dois tópicos. No primeiro item se apresenta a revisão sobre a literatura que sustenta as argumentações do estudo, a RBT, e são tecidas as suas relações com o problema de pesquisa. A segunda parte desenvolve os conceitos sobre COI em que são relatadas as suas principais escalas, suas relações com a área de estratégia e as dimensões identificadas na literatura que integram a proposta da nova escala.

\subsection{A teoria baseada em recursos - RBT}

A análise das condições para sustentar uma vantagem competitiva (VC) e o desempenho superior da empresa constitui o principal tema de pesquisa na área de estratégia (Costa, Cool \& Dierickx, 2013) e é consenso nessa literatura que as organizações buscam VCs para manterem posição competitiva superior à de seus competidores. Para alcançar uma VC a empresa precisa portar recursos que gerem valor econômico superior ao de seus concorrentes (Barney \& Hesterly, 2007). Nesse sentido, a teoria baseada em recursos busca compreender o que leva algumas empresas na mesma indústria a terem desempenho superior e como podem sustentar a VC (Barney, 1991; Dierickx \& Cool, 1989; Peteraf, 1993; Sirmon, Hitt \& Ireland, 2007; Wernerfelt, 1984), pois entende que as diferenças em termos de resultados financeiros não podem ser atribuídas somente às diferenças nas condições da indústria (Peteraf, 1993; Barney et al., 2011). A RBT, então, defende que a empresa é uma fonte de recursos (Penrose, 1959; Barney, 1991) e que a obtenção de VCs emerge da identificação, desenvolvimento e gestão do portfólio de recursos físicos, financeiros, intangíveis, organizacionais e humanos. Esse processo tem como resultado o desenvolvimento de capacidades e recursos internos que asseguram uma posição competitiva sustentável, dado que seus competidores não conseguem imitar tais recursos (Barney, 1991; Barney \& Hesterly, 2007).

Portanto, a RBT assume que os recursos conduzem à competência da empresa em desenhar, produzir, vender e distribuir seus produtos e serviços (Theodosiou, Kehagias \& Katsikea, 2012). Essa teoria analisa a conexão entre as características internas e o desempenho da empresa (Barney, 1991) ao explorar ou adquirir recursos que possam ser ou se tornar VCs, por isso a RBT tem seu foco no interior da empresa (de Camargo Guerrazzi, Brandão, Campos 
Junior \& Lourenço, 2015, Kim \& Haskisson, 2015). Ademais, essa teoria é considerada proeminente pois descreve, explica e analisa as relações organizacionais (Barney et al, 2011). Seu desenvolvimento teve início em 1959 com o trabalho de Edith Penrose (1959) intitulado The Theory of the Growtth of the Firm no qual a autora advoga que uma empresa pode ser compreendida como um conjunto de recursos produtivos. Para Penrose (1959) os recursos são definidos como sendo o que a empresa compra, aluga ou mesmo produz para seu uso, assim como as pessoas que fazem parte de seu quadro de funcionários.

A partir dos trabalhos de Wernerfelt (1984) e Barney (1991), essa perspectiva teórica passou a receber mais ênfase do meio acadêmico, dado que esses autores apontaram que as análises das empresas deveriam ser realizadas com base em seus recursos internos, dando origem ao termo visão baseada em recursos (RBV). A RBV é compreendida como uma abordagem teórica em que os recursos organizacionais são interpretados no seu sentido estratégico, representando fontes de VCs sustentáveis (Wernerfelt, 1984; Barney, 1991; Barney et al, 2011). Nessa perspectiva teórica, os recursos são ativos estratégicos (Foss, 1998) ou um estoque de fatores disponíveis que são possuídos e controlados pela empresa (Amit \& Schoemaker, 1993), os quais podem representar uma força ou uma fraqueza da empresa (Wernerfelt, 1984). Alguns exemplos de recursos são: nome de marcas, conhecimento de tecnologia, capacidade do maquinário, lealdade do cliente, experiência de produção, colaboradores qualificados, entre outros (Wernerfelt, 1984, Barney, 1991). Wernerfelt (1984) aponta que é possível identificar categorias de recursos para os quais podem ser construídas barreiras à reprodução por parte dos concorrentes. Para esse autor as propriedades dos recursos e seu modo de aquisição são os fatores que permitem a construção de tais barreiras e as empresas precisam encontrar esse tipo de recursos para defenderem suas posições competitivas.

Junto aos recursos, passou-se a considerar também as habilidades superiores na busca pela vantagem competitiva. Penrose (1959) já havia destacado a importância de se considerar nos estudos as diferenças entre as empresas ao mencionar que, certamente, nem todas as organizações possuem as qualificações necessárias para tirarem proveito de seus recursos na busca da obtenção da VC. Day \& Wensley (1988) chamaram tais qualificações de habilidades superiores, que, ao serem combinadas com recursos superiores, resultam na capacidade de um negócio em fazer e entregar mais e melhor do que os negócios de seus competidores. As habilidades superiores são as capacidades distintivas do pessoal da empresa que a distanciam 
dos seus competidores, e os recursos superiores são requisitos mais tangíveis para vantagem, permitindo que a empresa exercite suas capacidades (Day \& Wensley; 1988).

Barney (1991; 1995) avançou a compreensão de Wernerfelt (1984) e de Day \& Wensley (1988) sobre a sustentabilidade do recurso em termos de VC e propôs um modelo de análise com duas premissas: 1) os recursos administrados pelas empresas dentro de uma indústria são heterogêneos, e 2) tais recursos podem não ser aplicáveis ou móveis entre as empresas, por isso a heterogeneidade pode existir. Barney (1991) considera como recursos da empresa todos os ativos (tangíveis e intangíveis), as capacidades, os processos e rotinas organizacionais, as informações, o conhecimento, entre outros, que são controlados pela empresa e podem ajudar a implementar estratégias. Seguindo o raciocínio de Barney (1991), a VC só será sustentável se a empresa tiver em sua posse recursos, habilidades e aptidões que respeitem os seguintes critérios: sejam valiosos, raros, únicos, difíceis de serem imitados pelos concorrentes (Barney, 1991) e que a empresa deve se organizar para poder explorar todo o potencial do recurso (Barney, 1995; Barney \& Hesterly, 2007) o modelo VRIO (V-valioso; R - raro; I - inimitável; $\mathrm{O}$ - organização).

Portanto, pela ótica da RBV, a VC pode ser alcançada por meio da implantação de mecanismos de isolamento para proteger a vantagem da imitação. Os mecanismos típicos de isolamento incluem a ambiguidade causal (dificuldade em identificar como uma vantagem foi criada), a complexidade (decorrente da interação de vários recursos), tacitividade (habilidades e conhecimentos intangíveis resultante da experiência), caminho dependente (a necessidade de se passar por estágios críticos para criar a vantagem), economia (o custo de imitação), e barreiras legais (tais como direitos de propriedade e patentes) (Lippman \& Rumelt, 1982; Dierickx \& Cool, 1989). A RBV passou a ser uma teoria dominante na qual periódicos acadêmicos e livros-texto se ancoram (Newbert, 2007). Para aprofundar no desenvolvimento dessa teoria, estudos começaram a abordar os tipos de processos que as empresas devem desenvolver para conseguir explorar o valor latente do recurso, pois havia necessidade de se compreender, com mais detalhes, a origem dos recursos e o modo de seu emprego (Wernerfelt, 1995).

Em 2001, Barney et al. (2001) sugeriram uma agenda com seis itens que mereciam ser investigados à luz da RBV: recursos, capacidades dinâmicas e conhecimento; governança corporativa; gestão de carteira e financiamento de capital de risco; ambiente institucional; empreendedorismo; assuntos metodológicos. Em 2011, duas décadas após o início do 
desenvolvimento da RBV, Barney et al. (2011) realizaram outro estudo, esse para a edição especial do periódico Journal of Management, no qual fizeram uma análise da abordagem teórica à luz do ciclo de vida do produto. Para os autores a abordagem alcançou seu estágio de maturidade e pode ser considerada uma teoria em função dos seguintes aspectos: (1) acadêmicos da área cada vez mais referenciam a abordagem usando o termo teoria baseada em recursos (RBT) em vez de visão baseada em recursos (RBV); (2) a partir da abordagem novas perspectivas teóricas emergiram, como por exemplo as capacidades dinâmicas e a visão baseada em conhecimento (Acedo, Barroso \& Galan, 2006); (3) as ideias da RBT foram integradas com as de outras teorias, como, por exemplo a teoria institucional.

Se, por um lado, o fato da RBT ter atingido a maturidade teórica indica que a literatura sobre a temática é robusta e, ao longo dos anos, foi explorada sob diversos prismas, tais como gestão de pessoas, economia e finanças, empreendedorismo, marketing e negócios internacionais (Barney et al., 2001), por outro lado, mostra que o modo como a RBT tem sido utilizada precisa ser renovado, do contrário, poderá entrar em declínio (Barney et. al, 2011). Para revitalizar a RBT os autores instigam novas direções em que a teoria ainda pode ser ampliada. São elas: inter-relacionamento com outras perspectivas; processos de aquisição e desenvolvimento de novos recursos; pesquisas voltadas para os fundamentos da RBT; pesquisas com foco na sustentabilidade e questões sobre método e medições (Barney et al., 2011). Na área de negócios internacionais, contexto competitivo ao qual as unidades de análise deste estudo estão sujeitas, a RBT auxilia a especificar a natureza dos recursos necessários para superar a desvantagem do estrangeiro e estabelecer uma ponte para investigar os recursos que podem fornecer os alicerces para produto e diversificação internacional (Barney et al., 2001; Barney \& Hesterly, 2007). Por isso, neste estudo, utiliza-se a perspectiva da RBT no contexto de negócios internacionais com foco na identificação de recursos que podem melhorar a competitividade de empresas em processo de internacionalização. O próximo item da fundamentação teórica dedica-se à compreensão de recursos.

\subsubsection{Recursos, Capacidades e Processos}

Como analisado no item anterior, a RBT postula que a empresa é constituída por recursos (Barney, 1991; Penrose, 1959;). Diversas definições sobre recursos são identificadas na literatura de estratégia (conforme já apresentado). Neste estudo compreende-se por recursos 
todos os ativos da empresa (tangíveis ou intangíveis), as capacidades e os processos organizacionais e, dentre os mais atrativos estão: capacidade do maquinário, lealdade do consumidor, gestão da marca, experiência de produção e liderança tecnológica (Barney, 1991). Os ativos podem ser tangíveis ou intangíveis. Os tangíveis referem-se aos ativos fixos atuais da organização que têm capacidade de execução relativamente longa (Wernerfelt, 1989), como a fábrica, equipamentos, maquinário, terrenos, estoque, depósitos bancários. Já os ativos intangíveis têm capacidade relativamente ilimitada, podendo ser utilizados internamente, alugados ou vendidos (Wernerfelt, 1989). Os ativos intangíveis incluem propriedade intelectual, a reputação da corporação e a marca (Barney \& Hesterly, 2007).

Outro recurso da empresa são as capacidades. A empresa é um repositório de capacidades (Kogut \& Zander, 1992), as quais envolvem habilidades que são incorporadas nas rotinas e práticas organizacionais e representam o conhecimento que a empresa acumula ao longo dos anos (Theodosiou, Kehagias \& Katsikea, 2012). As capacidades da empresa residem nos princípios de organização pelos quais as relações entre os indivíduos, dentro e entre os grupos, e entre as organizações são estruturadas (Kogut \& Zander, 1992).

Amit \& Schoemaker (1993) dividiram o construto recursos em recursos e capacidades e definiram esses termos. Para eles os recursos são convertidos em produtos finais ou serviços por meio da utilização de uma vasta gama de outros ativos da empresa e mecanismos de ligação como tecnologia, sistemas de gestão da informação, sistemas de incentivo, confiança entre gerência e empregados, entre outros. Esses recursos são constituídos em know-how que pode ser negociado (como patentes e licenças), ativos financeiros ou físicos (como propriedades, plantas e maquinário) e capital humano. Assim, os recursos de uma empresa são classificados em quatro amplas categorias: recursos físicos (planta, equipamentos, localização geográfica, acesso à matéria-prima), recursos financeiros (todo capital em dinheiro da empresa, lucros retidos), recursos humanos (treinamento, experiência, inteligência, relacionamentos) e recursos organizacionais (estrutura formal de reporte da empresa, cultura, reputação, controle e coordenação) (Barney \& Hesterly, 2007).

Em contraste, as capacidades referem-se às competências e habilidade da empresa em implantar os recursos, geralmente em combinação com processos organizacionais para atingir o fim desejado (Amit \& Schoemaker, 1993; Barney \& Hesterly, 2007), aumentando a produtividade de outros recursos de posse da empresa (Makadok, 2001). As capacidades são ativos invisíveis, tangíveis ou intangíveis baseadas em informação, são processos 
desenvolvidos pela empresa ao longo do tempo por meio de interações complexas entre os recursos da empresa (Amit \& Schoemaker, 1993) que não podem ser compradas, devem ser construídas (Teece, Pisano \& Shuen, 1997) e são responsáveis por unir os ativos organizacionais e implantá-los de modo vantajoso (Zhou, Zhou \& Su, 2008; Barney \& Hesterly, 2007).

As capacidades diferem dos ativos, pois não são observáveis, são difíceis de serem quantificadas e, a elas, não se pode atribuir um valor monetário como se faz a um equipamento tangível (Day, 1994). Ademais, as capacidades são tão enraizadas nas rotinas e práticas organizacionais que não podem ser comercializadas ou imitadas (Theodosiou et al., 2012). As capacidades são costumeiramente desenvolvidas em áreas funcionais da empresa como, por exemplo, gestão de marca no departamento de marketing, ou combinando recursos físicos, humanos e tecnológicos do nível corporativo (Amit \& Schoemaker, 1993). As capacidades podem incluir as competências de marketing, seu trabalho em equipe, assim como a cooperação entre gerências (Barney \& Hesterly, 2007).

Nesta tese, acredita-se que a VC é resultado do modo como a empresa combina e aplica suas capacidades e recursos superiores (Day \& Wensley, 1988). Outro aspecto considerado neste estudo, foi apontado por Winter (1995) na construção da VC e utilização do recurso, ele assinalou que recursos são importantes na busca pela VC, mas são insuficientes. Isto se deve ao fato da empresa precisar, também, possuir rotinas e estar apta a replicá-las de forma que os recursos sejam coordenados e implementados (Winter, 1995). Em linha, Cater (2003) defende que as empresas que buscam construir sua VC com base em suas capacidades devem focar-se em seus processos de negócios. Os processos de negócios são as ações com as quais a empresa se engaja para atingir seus propósitos ou objetivos de negócios, ou seja, a maneira como a empresa explora seus recursos (Ray, Barney \& Muhanna, 2004). Representam, portanto, o modo como o potencial competitivo dos recursos e capacidades de uma empresa são realizados, merecendo maior aprofundamento empírico segundo Ray et al. (2004).

As capacidades e os processos de negócios da empresa estão fortemente entrelaçados, pois são as capacidades que permitem que as atividades no processo de negócio sejam realizadas (Day, 1994). Logo, o fato de a empresa deter um recurso por si só não significa que ela conseguirá tirar proveito desse recurso. Ela deve se organizar (Barney, 1995) para desenvolver suas capacidades e processos/rotinas com objetivo de explorar adequadamente o recurso para então obter uma VC. 
Day (1994) classificou as capacidades da organização em três categorias em função da orientação e foco dos processos que definem cada capacidade: 1) Inside-out: são implantadas a partir de processos de dentro para fora (inside out) e são acionados por exigências do mercado, desafios competitivos e oportunidades externas. Exemplos de processos inside-out são atividades de transformação, logística, gestão de recursos humanos, manufatura, controle de custos; 2) Outside-in: tem como propósito conectar os processos que definem as outras capacidades organizacionais ao ambiente externo, permitindo que a empresa compita antecipando as necessidades do mercado antes dos concorrentes, assim como, criando relações duradouras com os clientes, os membros do canal e os fornecedores. Exemplos de processos outside-in são compreensão do mercado, vínculo com o cliente, ligação de canais e monitoramento da tecnologia; 3) Abrangedoras (spanning): são os processos necessários para integrar os processos e capacidades inside-out às out-side, como por exemplo, processos de precificação, desenvolvimento de estratégia, desenvolvimento de novo produto/serviço (Day, 1994).

Observa-se que as capacidades outside-in (Day, 1994) monitoram e buscam transformar informações obtidas no ambiente externo em recursos competitivos. Dyer \& Singh (1998) acreditam que o recurso crítico de uma empresa pode estar fora dos domínios da empresa, em rotinas de compartilhamento de conhecimento entre empresas e parcerias. Corroborando essa visão, Krush, Sohi \& Saini (2015), defendem que o ambiente competitivo atual demanda que as empresas busquem recursos em toda a organização e além de suas fronteiras.

Agrawal \& Kamakura (1999) lembram que o país de origem, uma variável externa à empresa, tem sido apontado pela literatura como um importante indicador que pode ser utilizado por empresas operando em mercados internacionais para influenciar a avaliação do consumidor com relação à marca. Seguindo esse raciocínio, neste estudo acredita-se que o país de origem, um aspecto externo à organização, também possa ser utilizado como recurso pela empresa no processo de busca de VC, sendo o foco central desta tese. No contexto de negócios internacionais, alguns acadêmicos relacionaram o país de origem à estratégia da empresa (por exemplo: Cuervo-Cazurra \& Un, 2015; Baker \& Ballington, 2002; Florek \& Insch, 2008; Morrish \& Lee, 2011; Herstein, Berger \& Jaffe, 2014; Castro, Giraldi \& Galina, 2014; Beverland \& Lindgreen, 2002; Agrawal \& Kamakura, 1999).

Noo entanto, a teoria sobre o país de origem foi desenvolvida pela perspectiva do marketing internacional. Por isso, a unidade de análise de grande parte dos estudos é o 
consumidor, seja no B2B ou no B2C. Resultados do estudo de Castro et al. (2014) reforçam a escassez de estudos que conectem país de origem e estratégia.

Pelo fato de muitos recursos serem gerados e sustentados pelas atividades de marketing (Hooley, Greenley, Cadogan \& Fahy, 2005) e, em função da COO ter suas raízes teóricas na área de marketing, representando importante atributo capaz de influenciar o consumidor internacional na escolha por um produto ou marca (como se verá em detalhes adiante), acreditase que o uso estratégico desse recurso por parte da empresa, seja realizado pela área de marketing. O item seguinte detalha a RBT no contexto do marketing, uma área de estudos que faz interface com a de estratégia, seguindo a solicitação de Barney et. al (2011) para revitalizar a RBT.

\subsubsection{Interface RBT e Marketing}

A teoria baseada em recursos tem se mostrado de grande importância para a área de marketing (Day, 2014; Kozlenkova et al., 2014), tem contribuído e pode contribuir para a extensão da literatura de RBT (Barney et al., 2001; Barney, 2014; Wernerfelt, 2014). Ao longo das últimas décadas (desde os anos 1990), as aplicações da lógica baseada em recursos têm crescido exponencialmente no campo de marketing. Nos anos 1990 somente 19 artigos em marketing explicitamente faziam referência a RBT ou RBV, ao passo que nos anos 2000, esse número atingiu 104 e, entre 2010 e 2012, mais de 50 artigos de marketing ancorados em RBT foram publicados (Kozlenkova et al., 2014). Nesse período, a RBT foi utilizada pelos acadêmicos de marketing com maior ênfase em três domínios: marketing estratégico, marketing internacional e inovação (Kozlenkova et al., 2014).

Como a área de marketing foca-se na criação de demanda e em como oferecer aos consumidores uma proposta de valor única (Nath, Nachiappan \& Ramanathan, 2010), as capacidades e recursos de marketing devem estar relacionadas às habilidades únicas da empresa em adquirir conhecimento sobre os consumidores e oferecer os benefícios procurados por eles (Woodside, Sullivan \& Trappey III, 1999). Os recursos de marketing podem ser definidos como qualquer atributo, tangível ou intangível, físico ou humano, intelectual ou relacional, que pode ser implantado pela empresa para alcançar uma vantagem competitiva em seus mercados (Hooley et al., 2005). 
Hooley et al. (2005) distinguem os recursos de marketing em recursos baseados no mercado e recursos de marketing de suporte. Para os autores, os recursos baseados no mercado são aqueles recursos que podem ser implantados imediatamente no mercado para criar ou manter uma vantagem competitiva. Os recursos de marketing de suporte, por outro lado, servem essencialmente para atividades de marketing de apoio e, consequentemente, contribuem indiretamente para a vantagem competitiva (Hooley et al., 2005).

Acredita-se que as capacidades, recursos e processos de marketing estão alinhados com as capacidades outside-in apresentadas por Day (1994). Nessa perspectiva, os gestores devem olhar primeiro para fora dos limites e restrições da empresa, ou seja, para o mercado, onde podem encontrar um conjunto de ricas oportunidades para alcançar vantagens competitivas e de crescimento (Day, 2014). Por isso, grande parte dos estudos relacionando RTB e marketing investigam os recursos baseados no mercado (Srivastava, Fahey \& Christensen, 2001; Kozlenkova et al., 2014).

Os recursos baseados no mercado referem-se ao subconjunto de recursos da empresa relacionados com as atividades e processos de marketing (Kozlenkova et al., 2014). Dentre os principais estão: capacidade de relacionamento com os clientes; construção de marca por meio da reputação e credibilidade da empresa perante os stakeholders; habilidade de inovar no mercado; qualificação dos recursos humanos (Hooley et al., 2005; Kozlenkova et al., 2014).

Srivastava et al. (2001) ajudam na compreensão dos recursos de marketing ao distinguirem os recursos baseados em mercado entre ativos, processos e capacidades. Os ativos são atributos organizacionais que uma organização adquire, desenvolve, cria e alavanca para propósitos internos (organizacionais) e externos (mercado) (Barney, 1991; Hunt \& Morgan, 1995; Srivastava, Shervani \& Fahey, 1998). De acordo com Srivastava et al. (2001) há dois tipos de ativos baseados no mercado, os relacionais e os intelectuais. Os ativos relacionais são os de relacionamento, são ativos intangíveis, difíceis de serem mensurados, pois são construídos por meio de associações com organizações externas. Esses ativos são baseados em fatores como confiança e reputação, portanto, raros e difíceis de serem imitados. Exemplos de ativos relacionais incluem o relacionamento com: clientes, canais, parceiros estratégicos, fornecedores, rede entre outros (Srivastava et al., 2001).

$\mathrm{O}$ ativo intelectual baseado no mercado são ativos que se referem ao tipo de conhecimento que a empresa detém sobre seu ambiente competitivo. É um ativo intangível e interno, pois é produzido dentro da empresa. Exemplos de ativos intelectuais são: conhecimento 
sobre o ambiente interno e externo, conhecimento para alavancar as relações entre organizações, entre outros (Srivastava et al., 2001).

Como já discorrido, os processos são as atividades e rotinas inter-relacionadas que a empresa articula para transformar seus ativos e recursos em produtos ou soluções para o cliente. Consideram-se exemplos de processos baseados no mercado para criar valor ao cliente: a gestão de inovação de produto, a gestão da cadeia de suprimentos e a gestão do relacionamento com o consumidor (Srivastava et al., 2001).

Por fim, as capacidades de marketing baseadas no mercado são aquelas que capturam e refletem quão bem a empresa desempenha cada um dos processos de conexão com o cliente (Day, 1994), assim como aquelas que se referem ao resultado da articulação e gestão de subprocessos dentro do processo de gestão do relacionamento com o cliente (Srivastava, Shervani \& Fahey, 1999). A capacidade de marketing, portanto, pode ser compreendida como a integração entre os processos em que a empresa utiliza recursos tangíveis e intangíveis para: entender as necessidades do consumidor, ter um produto diferenciado em relação ao do concorrente, atingir valor de marca superior (Nath et al., 2010; Day, 2000), desenvolver a marca, desenvolver o relacionamento com o cliente e detectar alterações ambientais (Day, 2014; Kozlenkova et al., 2014).

Assume-se para fins deste estudo, que os recursos da empresa são representados por um conjunto composto por todos os seus ativos (tangíveis ou intangíveis), as suas capacidades e os processos de negócios (Barney, 1991; Sethi \& Elango, 2000). Dado que cada negócio desenvolve a própria configuração das capacidades que estão vinculadas a sua realidade competitiva de mercado (Day, 1994), acredita-se que cada área da empresa desenvolve seus recursos (ativos, capacidades e processos). $\mathrm{Na}$ área de marketing, área que tem maior influência sobre a gestão de marca e relacionamento com o cliente, considera-se a definição de recursos baseados em mercado (Kozlenkova et al., 2014; Hooley et al., 2005; Woodside et al., 1999). Considera-se a definição de Srivastava et al. (2001) sobre os ativos de marketing, que são divididos em intelectuais e relacionais, no entanto, considera-se também que a área de marketing pode ser dotada de ativos físicos, como matéria-prima e equipamentos que, quando utilizados em conjunto com processos de marketing, podem gerar capacidades de marketing. $\mathrm{O}$ quadro 1 reúne os principais conceitos aqui discutidos. 
Quadro 1 - Principais conceitos da RBT

\begin{tabular}{|c|c|}
\hline Principais conceitos de RBT & $\begin{array}{c}\text { Principais conceitos de RBT aplicados ao } \\
\text { marketing }\end{array}$ \\
\hline $\begin{array}{l}\text { Recursos: } \\
\text { Todos os ativos da empresa (tangíveis ou } \\
\text { intangíveis), as capacidades e os processos } \\
\text { organizacionais (Barney, 1991). Os recursos são } \\
\text { convertidos em produtos finais ou serviços por meio } \\
\text { da utilização dos ativos da empresa e processos de } \\
\text { negócios (Amit \& Schoemaker, 1993). }\end{array}$ & $\begin{array}{l}\text { Recursos de marketing: } \\
\text { Os recursos baseados no mercado referem-se ao sub- } \\
\text { conjunto de recursos e habilidades da empresa } \\
\text { relacionados com as atividades e processos de } \\
\text { marketing (Kozlenkova et al., 2014) para criar valor } \\
\text { no mercado (Hooley, Greenley, Codagan \& Fahy, } \\
\text { 2005; Woodside, Sullivan \& Trappey III, 1999). }\end{array}$ \\
\hline $\begin{array}{l}\text { Ativos: } \\
\text { Tangíveis: ativos fixos atuais da organização que têm } \\
\text { capacidade de execução relativamente longa } \\
\text { (Wernerfelt, 1989), como a planta, equipamentos, } \\
\text { maquinário, terrenos, estoque, depósitos bancários. } \\
\text { Intangíveis: têm capacidade relativamente ilimitada, } \\
\text { podendo ser utilizados internamente, alugados ou } \\
\text { vendidos (Wernerfelt, 1989). Exemplo: propriedade } \\
\text { intelectual, a reputação da corporação e a marca } \\
\text { (Hall, 1992). }\end{array}$ & $\begin{array}{l}\text { Ativos de marketing: } \\
\text { Relacionais: são ativos de relacionamento, são } \\
\text { intangíveis, de relacionamento com organizações } \\
\text { externas e que não são de posse da empresa. } \\
\text { Exemplo: relacionamento com clientes, canais, } \\
\text { parceiros estratégicos, fornecedores, rede entre outros } \\
\text { (Srivastava et al., 2001). } \\
\text { Intelectuais: são ativos que se referem ao tipo de } \\
\text { conhecimento que a empresa detém sobre seu } \\
\text { ambiente competitivo. É um ativo intangível e } \\
\text { interno. Exemplo: conhecimento sobre o ambiente } \\
\text { interno e externo, conhecimento para alavancar as } \\
\text { relações entre organizações, entre outros (Srivastava } \\
\text { et al., 2001). }\end{array}$ \\
\hline $\begin{array}{l}\text { Capacidades: } \\
\text { A capacidade da empresa em implantar os recursos, } \\
\text { geralmente em combinação com processos } \\
\text { organizacionais para atingir o fim desejado (Amit \& } \\
\text { Schoemaker, 1993). As capacidades podem ser: } \\
\text { inside-out (de dentro para fora), outside-in (de fora } \\
\text { para dentro) e abrangedoras (ligam os outros dois } \\
\text { tipos de capacidades) (Day, 1994). } \\
\text { Exemplo: gestão de marca no departamento de } \\
\text { marketing (Amit \& Schoemaker, 1993). }\end{array}$ & $\begin{array}{l}\text { Capacidades de marketing: } \\
\text { São aquelas que capturam e refletem quão bem a } \\
\text { empresa desempenha cada um dos processos de } \\
\text { conexão com o cliente (Day, 1994, 2001). Em sua } \\
\text { maioria são do tipo outside-in. Refletem o resultado } \\
\text { da articulação e gestão de subprocessos dentro do } \\
\text { processo de gestão do relacionamento com o cliente } \\
\text { (Srivastava, Shervani \& Fahey, 1999). Exemplo: } \\
\text { Capacidade de relacionamento com os clientes; } \\
\text { construção de marca por meio da reputação e } \\
\text { credibilidade da empresa perante os stakeholders; } \\
\text { habilidade de inovar no mercado (Hooley et al., 2005; } \\
\text { Kozlenkova et al., 2014). }\end{array}$ \\
\hline $\begin{array}{l}\text { Processos: } \\
\text { Ações, atividades e rotinas da empresa para atingir } \\
\text { seus propósitos ou objetivos de negócios, ou seja, a } \\
\text { maneira que a empresa utiliza para explorar seus } \\
\text { recursos (Ray, Barney \& Muhanna, 2004). }\end{array}$ & $\begin{array}{l}\text { Processos de marketing: } \\
\text { São as atividades e rotinas inter-relacionadas de } \\
\text { marketing que a empresa articula para transformar } \\
\text { seus ativos e recursos em produtos ou soluções para } \\
\text { cliente. São processos de gestão de inovação de } \\
\text { produto, de gestão da cadeia de suprimentos e da } \\
\text { gestão do relacionamento com o consumidor } \\
\text { (Srivastava et al., 2001). }\end{array}$ \\
\hline
\end{tabular}

Fonte: Autora

Observa-se que a maioria dos recursos estudados em marketing são intangíveis e essa característica oferece benefícios, como a dificuldade de imitação (Kozlenkova et al., 2014). Por exemplo, a marca representa importante fonte de informação para o cliente (Caroll, 2009) e é um ativo da empresa desenvolvido por meio das capacidades de marketing. A natureza intangível da marca a torna difícil de ser imitada (Srivasta et al, 1998), pois a imagem e o significado da marca são custosos e difíceis de serem construídos ou alterados (Aaker \& Joachimsthaler, 2000). 
Em linha, Barney (2014) aponta que a marca de uma empresa pode ser um recurso complexo, portanto, pode representar fonte de vantagem competitiva sustentável. Para ele a informação sobre como a empresa desenvolve sua marca pode gerar ideias sobre a construção de um recurso particularmente importante, heterogêneo e custoso de imitar. Com relação ao modo como os recursos são desenvolvidos, Foss (1998) já apontava desde o final dos anos 1990 para a carência de pesquisas que mostrassem os mecanismos de criação de novos recursos. Por isso, acredita-se que a literatura sobre RBT e a de marketing minimizou os processos fundamentais pelos quais recursos são transformados em algo de valor para o cliente (Srivastava et al., 2001; Day, 2011). O próximo item da fundamentação teórica dedica-se a explicar o modo como o COI pode ser utilizado por empresas em processo de internacionalização.

\subsection{O papel do país de origem na empresa em processo de internacionalização}

Esse item da fundamentação teórica dedica-se ao entendimento sobre o país de origem em diversos aspectos. No primeiro momento apresenta-se a evolução do construto, o seu papel em negócios internacionais e, por fim, as dimensões identificadas na literatura para mensurar a COI dentro da perspectiva proposta neste estudo.

\subsubsection{Evolução e escalas de país de origem}

O construto sobre o país de origem (COO - Country-of-Origin) vem sendo estudado desde 1965 (Schooler, 1965). Desde então a área de marketing internacional estuda a influência que o país de origem do produto exerce nas avaliações do consumidor com relação à qualidade do produto, às crenças sobre atributos individuais de um produto, à atitude em relação à marca e ao comportamento das pessoas (Agrawal \& Kamakura, 1999; Gürhan-Canli \& Maheswara, 2000; Pharr, 2005; Roth \& Diamantopoulos, 2009; Diamantopoulos et al., 2011; Herz \& Diamantopoulos, 2013a; 2013b; Magnusson, Westjohn, \& Zdravkovic, 2011a, 2011b). Com isso, o país de origem tornou-se parte do repertório de pistas extrínsecas que o consumidor utiliza para avaliar produtos junto à marca, o preço, a embalagem e o vendedor (Bilkey \& Nes, 1982; Hakala; Lemmetyinen; Kantola, 2013; Niss, 1996; Peterson \& Jolibert, 1995; Pharr, 
2005). Giraldi, Giraldi \& Scaduto (2011) defendem que os efeitos derivados das informações sobre o país de origem são diretamente afetados pela imagem do país.

Ao longo das décadas subsequentes à de 1960 o construto foi utilizado em diversos estudos, sob distintas óticas - em sua maioria com foco no consumidor, seja no consumidor organizacional (Nagashima, 1970; 1977; White, 1979; Cattin, Jolibert \& Lohnes, 1982; Ahmed \& d'Astous, 1995; d'Astous \& Ahmed, 1999; Quester, Dzever \& Chetty, 2000; La, Patterson \& Styles, 2005), no consumidor final (Peterson \& Jolibert, 1995) e em serviços industriais (La, Patterson \& Styles, 2009; Cheng, Chen, Lai, \& Li, 2014) - e recebeu diferentes definições. É considerado um dos temas mais estudados em marketing internacional (Pharr, 2005). Até 2006 o número de estudos sobre a temática, de acordo com Usunier (2006), passou dos 1000, dos quais pelo menos 400 deles foram publicados em periódicos. Por isso, o construto gradualmente mudou seu foco de analisar as diferenças de avaliações de produtos e preferências com base na noção da origem de um produto para um construto mais complexo, considerando a imagem dos países sob investigação (Roth \& Diamantopoulos, 2009). Giraldi et al. (2011) lembram que o foco da abordagem dos estudos naturalmente migrou de exploratório e descritivo para trabalhos com aplicações dos conceitos teóricos.

Em 1970, Nagashima (1970) propôs a primeira escala para medir a imagem de país. Para o autor a imagem do país significa a representação, a reputação e os estereótipos que os consumidores e os empreendedores têm sobre um produto feito em um país específico. Essa imagem é criada a partir de variáveis relacionadas ao produto, tais como recursos nacionais, sistema econômico e político, história e tradições (Nagashima, 1970). Em 1977 Nagashima replicou o estudo de 1970, com o intuito de verificar supostas alterações nas avaliações da imagem do país de origem ao longo do tempo. A escala desenvolvida por Nagashima (1970, 1977) abarca 20 itens distribuídos em 5 dimensões. O autor trabalha com uma escala numérica de 7 pontos de diferencial semântico, conforme pode ser analisado no quadro 2. 
Quadro 2 - Escala de mensuração da COI

\begin{tabular}{|c|c|c|}
\hline \multicolumn{3}{|c|}{ Dimensão: Preço e Valor } \\
\hline Barato & $\overline{(1)} ; \frac{}{(2)} ; \overline{(3)} ; \overline{(4)} ; \frac{}{(5)} ; \overline{(6)} ; \overline{(7)}$ & Caro \\
\hline Preço razoável & $\overline{(1)} ; \frac{}{(2)} ; \overline{(3)} ; \overline{(4)} ; \overline{(5)} ; \overline{(6)} \overline{(7)}$ & Preço injusto \\
\hline Confiável & $\overline{(1)} ; \frac{}{(2)} ; \overline{(3)} ; \overline{(4)} ; \frac{}{(5)} ; \overline{(6)} \overline{(7)}$ & Duvidoso \\
\hline Artigos de luxo & $\overline{(1)} ; \frac{}{(2)} ; \overline{(3)} ; \overline{(4)} ; \overline{(5)} ; \overline{(6)} \overline{(7)}$ & $\begin{array}{r}\text { Artigos de primeira } \\
\text { necessidade }\end{array}$ \\
\hline Exclusivo & $\overline{(1)} ; \underset{(2)}{7} \overline{(3)} ; \underset{(4)}{ } ; \overline{(5)} ; \overline{(6)} ; \overline{(7)}$ & Comum \\
\hline Produtos de indústria pesada & $\overline{(1)}_{(2)} ; \frac{}{(3)} ; \overline{(4)} ; \overline{(5)} ; \overline{(6)} \overline{(7)}$ & Produtos de indústria leve \\
\hline \multicolumn{3}{|c|}{ Dimensão: Serviço e engenharia } \\
\hline $\begin{array}{lll}\text { Trabalho } & \text { cuidadoso } & \mathrm{e} \\
\text { meticuloso } & & \\
\end{array}$ & $\overline{(1)} ; \frac{}{(2)} ; \overline{(3)} ; \overline{(4)} ; \overline{(5)} ; \overline{(6)} ; \overline{(7)}$ & $\begin{array}{r}\text { Trabalho não cuidadoso nem } \\
\text { meticuloso }\end{array}$ \\
\hline Tecnicamente avançado & $\overline{(1)} ; \frac{}{(2)} ; \overline{(3)} ; \overline{(4)} ; \overline{(5)} ; \overline{(6)} ; \overline{(7)}$ & Tecnicamente retrógrado \\
\hline Produção em massa & $\overline{(1)} ; \frac{}{(2)} ; \frac{}{(3)} ; \overline{(4)} ; \frac{}{(5)} ; \overline{(6)} ; \overline{(7)}$ & Feito à mão/artesanalmente \\
\hline Distribuição mundial & ${ }_{(1)} ; \underset{(2)}{ } ; \underset{(3)}{ } ; \overline{(4)} ; \overline{(5)} ; \overline{(6)} ; \overline{(7)}$ & $\begin{array}{r}\begin{array}{r}\text { Distribuição principalmente } \\
\text { doméstica }\end{array}\end{array}$ \\
\hline Inventivo & $\overline{(1)} ; \frac{}{(2)} ; \overline{(3)} ; \overline{(4)} ; \overline{(5)} ; \overline{(6)} ; \overline{(7)}$ & Imitativo \\
\hline \multicolumn{3}{|c|}{ Dimensão: Publicidade e reputação } \\
\hline Orgulho de propriedade & $\overline{(1)} ; \frac{}{(2)} ; \overline{(3)} ; \overline{(4)} ; \overline{(5)} ; \overline{(6)} ; \overline{(7)}$ & $\begin{array}{r}\text { Não muito orgulho de } \\
\text { propriedade }\end{array}$ \\
\hline Muita propaganda & $\overline{(1)}_{(2)} ; \overline{(3)} ; \overline{(4)} ; \overline{(5)} ; \overline{(6)} ; \overline{(7)}$ & Pouca propaganda \\
\hline Marcas reconhecíveis & $\overline{(1)} ; \overline{(2)} ; \overline{(3)} ; \underset{(4)}{ } ; \overline{(5)} ; \overline{(6)} ; \overline{(7)}$ & Marcas irreconhecíveis \\
\hline \multicolumn{3}{|c|}{ Dimensão: Design e estilo } \\
\hline $\begin{array}{l}\text { Grande escolha do tamanho e } \\
\text { modelo }\end{array}$ & $\overline{(1)} ; \frac{}{(2)} ; \frac{}{(3)} ; \overline{(4)} ; \frac{}{(5)} ; \frac{}{(6)} ; \overline{(7)}$ & $\begin{array}{r}\text { Escolha do tamanho e modelo } \\
\text { limitada }\end{array}$ \\
\hline $\begin{array}{l}\text { Mais preocupados com a } \\
\text { aparência exterior }\end{array}$ & ${ }_{(1)} ; \underset{(2)}{ } ; \underset{(3)}{ } ; \frac{}{(4)} ; \frac{}{(5)} ; \overline{(6)} ; \overline{(7)}$ & $\begin{array}{r}\text { Mais preocupados com o } \\
\text { desempenho }\end{array}$ \\
\hline Uso inteligente da cor & $\overline{(1)} ; \frac{}{(2)} ; \overline{(3)} ; \overline{(4)} ; \overline{(5)} ; \overline{(6)} ; \overline{(7)}$ & Uso não inteligente da cor \\
\hline \multicolumn{3}{|c|}{ Dimensão: Perfil do consumidor } \\
\hline Mais para os jovens & $\overline{(1)} ; \frac{}{(2)} ; \overline{(3)} ; \overline{(4)} ; \overline{(5)} ; \overline{(6)} ; \overline{(7)}$ & Mais para as pessoas idosas \\
\hline Mais para homem & $\overline{(1)} ; \frac{}{(2)} ; \frac{}{(3)} ; \overline{(4)} ; \frac{}{(5)} ; \overline{(6)} \overline{(7)}$ & Mais para mulher \\
\hline Classe alta & $\overline{(1)} ; \overline{(2)} ; \overline{(3)} ; \underset{(4)}{ } ; \overline{(5)} ; \overline{(6)} ; \overline{(7)}$ & Classe baixa \\
\hline
\end{tabular}

Fonte: Nagashima (1970, 1977).

Posteriormente, outros autores apontaram que a escala de Nagashima $(1970,1977)$ tinha como foco a avaliação da imagem dos produtos e não do país em si. Para Martin \& Eroglu (1993), a escala proposta por Nagashima (1970, 1977) não distinguia claramente se media a imagem do país ou a imagem do produto. De acordo com Bacha Lopes \& Giraldi (2014), que realizaram uma revisão da literatura sobre as principais escalas para mensurar a imagem de 
país, a partir de 1980, vários outros pesquisadores passaram a desenvolver estudos e escalas embasadas na proposta apresentada por Nagashima (1970, 1977). O trabalho de Nebenzahl, Jaffe \& Usunier (2003) reforça os apontamentos de Bacha Lopes \& Giraldi (2014). Nebenzahl et al (2003) ao proporem uma nova escala, reuniram os domínios das escalas sobre país de origem anteriormente desenvolvidos e, dentre os trinta e três estudos investigados por eles, oito se ancoraram na escala desenvolvida por Nagashima (1970) conforme mostra o quadro 3. Logo, essa escala pode ser considerada a mais utilizada dentre os estudos investigados pelos autores.

Quadro 3 - Estudos que utilizaram a escala de Nagashima como base

\begin{tabular}{|c|c|c|c|}
\hline Autor & Dimensão & Mensuração & Origem \\
\hline $\begin{array}{l}\text { Johansson } \& \\
\text { Nebenzhal (1986) }\end{array}$ & Produto & $\begin{array}{l}10 \text { atributos do produto; } 3 \text { sociais; } 7 \\
\text { pontos da escala likert }\end{array}$ & Nagashima (1970) \\
\hline $\begin{array}{l}\text { Chasin \& Jaffe } \\
\text { (1987) }\end{array}$ & Produto & $\begin{array}{l}12 \text { atributos de produto e de marketing } \\
\text { medidos com } 9 \text { pontos da escala likert. }\end{array}$ & $\begin{array}{l}\text { Nagashima } \quad(1970, \\
1977)\end{array}$ \\
\hline $\begin{array}{l}\text { Johansson \& } \\
\text { Nebenzhal (1987) }\end{array}$ & $\begin{array}{l}\text { Produto e } \\
\text { marca }\end{array}$ & $\begin{array}{l}9 \text { atributos do produto; } 3 \text { de normas } \\
\text { sociais; } 1 \text { geral com escala de sete itens. }\end{array}$ & $\begin{array}{l}\text { Nagashima (1970); } \\
\text { Agarwal } \quad \& \\
\text { Ratchford (1980) }\end{array}$ \\
\hline $\begin{array}{l}\text { Han \& Terpstra } \\
(1988)\end{array}$ & $\begin{array}{l}\text { Produto e } \\
\text { marca }\end{array}$ & $\begin{array}{l}6 \text { atributos do produto com escala likert } \\
\text { de } 7 \text { pontos. }\end{array}$ & $\begin{array}{l}\text { Nagashima } \quad(1970, \\
1977)\end{array}$ \\
\hline $\begin{array}{l}\text { Papadopoulus, } \\
\text { Heslop \& } \\
\text { Bamossy (1990) } \\
\end{array}$ & Produto & $\begin{array}{l}21 \text { atributos do produto e } 11 \text { do país, } \\
\text { medidos por escala de diferencial } \\
\text { semântico }\end{array}$ & $\begin{array}{lr}\text { Nagashima } & (1970) \text {; } \\
\text { Darling \& Kraft } \\
(1977)\end{array}$ \\
\hline $\begin{array}{l}\text { Papadopoulus, } \\
\text { Heslop \& Beracs } \\
\text { (1990) }\end{array}$ & Produto & $\begin{array}{l}21 \text { atributos do produto; } 11 \text { atributos do } \\
\text { país; escala de diferencial semântico de } \\
7 \text { pontos. }\end{array}$ & $\begin{array}{lr}\text { Nagashima } & (1970) \text {; } \\
\text { Darling \& } & \text { Kraft } \\
(1977) & \end{array}$ \\
\hline $\begin{array}{l}\text { Wood \& Darling } \\
\text { (1992) }\end{array}$ & Produto & $\begin{array}{l}19 \text { atributos do produto; } 6 \text { atributos de } \\
\text { marketing; } 6 \text { atributos de compra e de } \\
\text { uso do produto medidos com escala do } \\
\text { tipo likert. }\end{array}$ & $\begin{array}{l}\text { Nagashima (1970); } \\
\text { Rierson (1960) }\end{array}$ \\
\hline $\begin{array}{l}\text { Roth \& Romeo } \\
(1992)\end{array}$ & Produto & $\begin{array}{l}4 \text { dimensões de produto medidas com } \\
\text { escala likert de } 7 \text { pontos }\end{array}$ & $\begin{array}{l}\text { Nagashima (1970); } \\
\text { Cattin, Jolibert \& } \\
\text { Lohnes (1982); Jaffe } \\
\text { \& Nebenzahl (1984) }\end{array}$ \\
\hline
\end{tabular}

Fonte: Elaborado pelo autor a partir de Nebenzahl et al. (2003)

O quadro 3 mostra também que a maioria dos estudos que se basearam na escala desenvolvida por Nagashima (1970) fizeram pequenas modificações. Desse modo, Bacha Lopes \& Giraldi (2014) apontam que tanto as escalas com atributos univariados como multivariados nas investigações sobre o país de origem tiveram como foco, quase que unicamente, o produto analisado e não os componentes da imagem de um país.

Na década de 1980, Bilkey \& Nes (1982) realizaram uma revisão da literatura sobre os estudos precedentes e, por meio da análise dos trabalhos, compreenderam que o objetivo inicial das pesquisas sobre o país de origem era o de demonstrar que a informação sobre o país de 
origem de fato influenciava na avaliação do consumidor. No entanto, o estudo de Bilkey \& Nes (1982) trouxe um novo argumento que deveria ser considerado na discussão da temática. Esses autores apontaram que as informações sobre o país de origem apoiavam-se em apenas um atributo dentre outras características que o produto possuía. Contudo, sabe-se que um produto é composto por atributos intrínsecos (tamanho, cor e qualidade) e extrínsecos (preço) (Usunier, 2006). Na ausência de outras informações, o consumidor pode usar a informação sobre o país de origem para avaliar o produto, ou seja, os estudos que utilizavam somente o país de origem como informação influenciadora do comportamento do consumidor superestimavam o seu impacto no processo de avaliação (Bilkey \& Nes, 1982). Logo, Bilkey \& Nes (1982), assinalaram a necessidade de realizar estudos com mais informações do produto além da sua origem. Dessa forma, a partir de 1983, grande parte da literatura sobre a temática passou a ser desenvolvida com base em estudo com mais variáveis junto ao produto, acrescentando-se preço, loja, qualidade, entre outros (Usunier, 2006).

Considerando as críticas à escala de Nagashima, Papadopoulos (1986) desenvolveu a $2^{\mathrm{a}}$ escala sobre o construto, a qual apresentava 21 itens, sendo que 14 haviam sido retirados da escala de Nagashima (1977). Papadopoulos (1986) aponta que os principais itens da escala de Nagashima (1977) permaneceram. O autor adicionou sete itens para medir a atitude. Outra escala desenvolvida na década de 1980 e que foi utilizada por diversos estudos é a de Yaprak \& Parameswaran (1986). Para mensurar a imagem do país os autores trabalharam com uma escala de três dimensões: GCA (General Country Attributes - atributos gerais do país) com doze itens; GPA (General Product Attributes - Atributos gerais do produto) com 17 itens e SPA (Specific Product Attributes - Atributos específicos do produto) com 10 itens. Todos os itens foram medidos utilizando-se uma escala de 10 pontos, em que 1 indicava que o a declaração não era de todo adequada, e 10 indicava que a declaração era mais adequada.

No entanto, os pesquisadores da área passaram a compreender que o construto do país de origem não se restringe às influencias geradas pelas crenças cognitivas a respeito dos aspectos técnicos do produto, mas abarcava também a influência da imagem que os consumidores têm das pessoas que produzem esses produtos (Papadopoulus, Heslop \& Bamossy, 1990). Portanto, a partir de 1990, as investigações sobre a temática passaram a ter compreensões mais abrangentes do que o prisma proposto por Nagashima (1970) (Bacha Lopes \& Giraldi, 2014). Novas escalas foram propostas com novas dimensões como a marca e o país 
além do produto. As dimensões e modo de mensuração das principais escalas propostas na década de 1990 estão disponíveis no quadro 4.

Quadro 4 - Resumo dos estudos do país de origem na década de 1990

\begin{tabular}{|c|c|c|c|}
\hline Autor & Dimensão & Mensuração & Origem \\
\hline $\begin{array}{l}\text { Wall, Liefeld \& } \\
\text { Heslop (1991) }\end{array}$ & Produto e marca & $\begin{array}{l}\text { Indeterminado número de } \\
\text { atributos de produto; risco e } \\
\text { propensão à compra; escalas } \\
\text { bipolares. }\end{array}$ & N.I. \\
\hline $\begin{array}{l}\text { Sauer, Young \& } \\
\text { Unnava (1991) }\end{array}$ & Produto e marca & $\begin{array}{l}6 \text { atributos de atitude; } 2 \text { de } \\
\text { intenção de compra; escala } \\
\text { de diferencial semântico de } 7 \\
\text { pontos }\end{array}$ & N.I. \\
\hline $\begin{array}{lll}\text { Witt } & \& & \text { Rao } \\
(1992) & & \end{array}$ & Produto e marca & N.I. & N.I. \\
\hline Tse \& Gorn & Produto e marca & $\begin{array}{l}5 \text { atributos de produto; } 4 \\
\text { gerais; } 6 \text { pontos escala likert }\end{array}$ & N.I. \\
\hline $\begin{array}{l}\text { Wood \& Darling } \\
\text { (1992) }\end{array}$ & Produto & $\begin{array}{l}19 \text { atributos do produto; } 6 \\
\text { atributos de marketing; } 6 \\
\text { atributos de compra e de uso } \\
\text { do produto medidos com } \\
\text { escala do tipo likert. }\end{array}$ & $\begin{array}{l}\text { Nagashima } \\
\text { Rierson (1960) }\end{array}$ \\
\hline $\begin{array}{l}\text { Roth \& Romeo } \\
(1992)\end{array}$ & Produto & $\begin{array}{l}4 \text { dimensões de produto } \\
\text { medidas com escala likert de } \\
7 \text { pontos }\end{array}$ & $\begin{array}{l}\text { Nagashima (1970); } \\
\text { Cattin, Jolibert \& } \\
\text { Lohnes (1982); Jaffe \& } \\
\text { Nebenzahl (1984) }\end{array}$ \\
\hline $\begin{array}{l}\text { Martin \& Eroglu } \\
(1993)\end{array}$ & País & $\begin{array}{l}14 \text { atributos de país; escala } \\
\text { likert de } 7 \text { pontos }\end{array}$ & Pré-teste \\
\hline $\begin{array}{l}\text { Johansson, } \\
\text { Ronkainen \& } \\
\text { Czinkota (1994) } \\
\end{array}$ & Produto & $\begin{array}{l}\text { Atributos de produto; escala } \\
\text { likert de } 7 \text { pontos }\end{array}$ & N.I. \\
\hline $\begin{array}{l}\text { Thakor \& } \\
\text { Pacheco (1997) }\end{array}$ & Marcas & $\begin{array}{l}\text { Atributos de marca e de } \\
\text { produto; escala likert de } 7 \\
\text { pontos }\end{array}$ & $\begin{array}{l}\text { Papadopoulos, Heslop \& } \\
\text { Bamossy (1990) }\end{array}$ \\
\hline
\end{tabular}

Fonte: Elaborado pelo autor a partir de Nebemzahl, Jaffe \& Usunier (2003); Roth \& Diamantopoulus (2009); Bacha Bacha Lopes \& Giraldi (2014)

Os estudos realizados até meados da década de 1990 conduziam à conclusão de que o país de origem de um produto poderia influenciar na avaliação e no julgamento do consumidor com relação ao produto (Pharr, 2005). Contudo, o contexto de pesquisa havia se alterado. Mudanças estruturais nos modelos de comércio e de marketing internacional, num mercado em que várias empresas passam a desenvolver atividade em diversas partes do globo, levaram pesquisadores a indagar sobre a real relevância do país de origem no novo contexto (Pharr, 2005). 
O conceito de país de origem que era originalmente considerado como o de "feito em" (made-in-country) ou país de manufatura (country-of-manufacture COM), que era o país que aparecia no rótulo como "feito em" (Usunier, 2006), passou a ser decomposto em uma medida ou categoria de tratamento para uma operacionalização multidimensional (Pharr, 2005). Por isso, novos conceitos passaram a progressivamente integrar a literatura sobre país de origem, como o país de design (Country-of-Design COD) - consiste no país em que o produto é desenhado e desenvolvido - e o país de montagem (Country-Of-Assembly COA) (Pharr, 2005; Usunier, 2006). Usunier (2006) aponta que a produção das multinacionais em âmbito global teve como consequência o aumento da discrepância entre país de manufatura e de design, como pode ser exemplificado analisando a empresa Nike, que desenvolve seus produtos nos EUA e fabrica em diversos países.

Além disso, identificou-se que as companhias globais tendem a manipular os nomes de suas marcas para sugerir origens específicas, trazendo outro componente para a literatura de COO, o de país da marca (Country-Of-Brand COB) (Usunier, 2006). Pharr (2005) e Papadopoulos (2004) acrescentam ainda à literatura de país de origem os componentes: país de proveniência de componentes importantes para a manufatura (COP) e país sede da marca corporativa. Assim, o país de origem é considerado como o país com o qual os consumidores tipicamente associam o produto ou a marca (Usunier, 2006). Outros termos também passaram a fazer parte do construto COO, como: imagem do país (Country Image - CI) ou ainda imagem do país de origem (Country-of-Origin-Image - COI) (Usunier, 2006), e, imagem do produto do país (Product-Country-Image PCI) (Papadopoulos, 2004). Estudos com esses termos passaram a ser mais utilizados a partir de 2000 .

Roth \& Diamantopoulos (2009) relatam diferentes modos pelos quais o construto é definido na literatura. Segundo eles, muitos estudos definem imagem de país como percepções, ou esquemas, ao passo que outros se referem à imagem do país como estereótipos. E, com base nas definições conceituais, os autores classificaram os estudos em três grupos, a saber: 1) estudos com definições sobre imagem do país (Country-of-Origin Image - COI); 2) estudos com definições sobre imagem de país e seus produtos (Product-Country-Image-PCI), ou seja, estudos que relacionam a imagem do país e os produtos nele fabricados e, 3 ) estudos referentes à imagem dos produtos de um país (Product Image - PI) (Roth \& Diamantopoulos, 2009).

De acordo com a classificação proposta por Roth e Diamantopoulos (2009), o presente estudo apoia-se no termo Imagem de País de Origem (COI). A imagem do país refere-se à 
representação mental de um país e de seu povo, envolvendo as crenças cognitivas com relação aos estágios de desenvolvimento tecnológico e econômico do país, e as avaliações afetivas do sistema social e político (Wang, Li, Barnes \& Ahn, 2012).

Verlegh \& Steenkamp (1999) citam que além de representar uma informação cognitiva sobre a qualidade do produto, a COI também se refere à emoções, identidade, orgulho e memórias autobibliográficas. Manrai et al. (1998), Al-Sulait e Baker (1998), assim como, Hakala et al., (2013) apontam que a imagem do país representa importante estímulo extrínseco nas avaliações de produtos, pois provoca associações e assim, pode influenciar as decisões de compra. Logo, Hakala et al. (2013) assumem que a imagem positiva do país pode gerar uma reputação positiva para toda uma categoria de produtos.

Por fim, mais recentemente, novamente em função do contexto em que as empresas estão vivendo, uma linha de pesquisadores aponta que estudos sobre imagem do país de origem são menos relevantes (Samiee, Shimp \& Sharma, 2005; Martin \& Cerviño, 2011; Samiee, 2011 Usunier, 2011). Isso decorre da crescente dificuldade que os consumidores apresentam em avaliar a informação sobre o país de origem, em parte em função das mudanças nas regras de rotulagem, mas, principalmente pelo fato da terceirização passar a ser global, e, pela globalização da cadeia de suprimentos. Nesse sentido, empresas globais preferem não enfatizar a sua origem (Usunier, 2006).

Usunier (2006) reconhece que o país de origem está sendo cada vez mais considerado como aquele país com o qual os consumidores normalmente associam um produto ou uma marca, independentemente de onde ele está sendo de fato fabricado. Passando, portanto, a ótica de COO a analisar o país de origem da marca. A origem da marca (Brand Origin - BO) é compreendida como o país em que se localiza a sede da empresa (Samiee, 2011). Achados do estudo de Samiee et al. (2005) corroboram Usunier (2006). Esses resultados de estudos com consumidores americanos indicam que de fato os consumidores têm dificuldade em reconhecer o país de origem do produto, mas têm conhecimento sobre as origens da marca. Além disso, os consumidores têm a capacidade de reconhecer as origens de marcas estrangeiras por meio de variáveis como: status socioeconômico, viagens internacionais realizadas no passado, habilidades com línguas e gênero.

Os resultados do estudo de Samiee et al. (2005) apontaram ainda que reconhecimento da origem da marca é amplamente embasado nas associações que os consumidores fazem entre os nomes das marcas e linguagens sugerindo a origem do país. Usunier (2011) define esse 
movimento sobre a análise do país de origem como um processo de deslocamento do país de origem de manufatura para o país de origem da marca. Ainda de acordo com esse autor, na temática sobre o país de origem a ótica do país da marca mostra-se mais importante de ser estudada do que COD (Country-of-Origin-Design) e COM (Country-of-OriginManufacturing).

De modo geral, neste estudo assume-se que a COI é um construto que influencia a informação sobre o país de origem de um produto ou marca nas atitudes e comportamentos das pessoas. A concepção da imagem que o consumidor tem do produto ou marca originário de um dado país é resultado das percepções primárias que ele tem sobre as forças e fraquezas de produção e de marketing daquele país (Roth \& Romeo, 1992), somadas ao sentimento que ele tem em relação ao país (Pharr, 2005).

Como foi analisado, diversas escalas foram desenvolvidas para mensurar o país de origem desde 1965. Em 1970, Nagashima (1970) propôs a primeira escala para medir a imagem de país. Esse estudo serviu de base para diversos outros trabalhos científicos conforme relatam Nebenzahl, Jaffe \& Usunier (2003). Outras escalas foram propostas por Papadopoulos (1986), Yaprak \& Parameswaran (1986), Pisharodi \& Parameswaran (1992), Chao \& Rajendran (1993), Verlegh (2001), Heslop et al. (2004), Laroche et al. (2005), d'Astous \& Boujbel (2007), Pappu, Quester \& Cooksey (2007) entre outros.

As escalas desses estudos apresentam, em sua maioria, duas dimensões; alguns tem somente uma. Tais dimensões variam entre produto (integridade do produto, preço, presença de mercado, sensibilidade, atributos gerais do produto atributos negativos do produto, aspectos de distribuição, imagem do produto, entre outros), marca (imagem, atributos da marca) e país (imagem do país com relação a: política, aparência, cultura, pessoas, economia, sociedade, tecnologia). Esses apontamentos encontram apoio nos argumentos de Roth e Diamantopoulos (2009) que reuniram em um trabalho as principais pesquisas com propostas de escalas para medir a imagem do país (anexo 1). Por meio da análise do estudo desses autores, é possível observar que todas as escalas propostas apresentam ferramentas de mensuração para a avaliação do consumidor com relação a imagem de onde o produto provém, a imagem do país, a imagem do produto e a imagem de origem da marca. Ou seja, as dimensões apresentadas nos estudos foram operacionalizadas para capturar a ótica do consumidor com relação ao produto ou ao país, por isso, não foi possível identificar uma escala para mensurar o uso, a incorporação ou mesmo a importância da COI na estratégia da empresa. Por isso, Roth e Diamantopoulos (2009) 
incentivam que escalas sobre a COI sejam desenvolvidas sob outras perspectivas que conectem diferentes áreas do conhecimento.

Assim, apesar de uma corrente de pesquisadores de marketing internacional defender que a discussão sobre COI perde importância, por utilizar métodos falhos e por não apresentar relevância gerencial, dado que muitas empresas realizam diferentes etapas dos seus processos produtivos em outros países (conforme já analisado nesse item) por isso suas as marcas se sobressaem às marcas país de origem (Samiee et al., 2005; Samiee, 2011; Usunier, 2011). Outra linha de pesquisadores acredita que o país de origem ainda exerce influência no processo de avaliação de produto (por exemplo: Herz \& Diamantopoulos; 2013; Diamantopoulos, Schlegelmilch \& Palihawadana 2011; Magnusson, Westjohn \& Zdravkovic, 2011a; 2011b), como por exemplo, em empresas de países emergentes (Cuervo-Cazurra \& Un, 2015; Magnusson, Haas \& Zhao, 2008), no processo de internacionalização de marcas de pequenas empresas (Spence \& Hamzaoui Essoussi, 2010), em empresas de serviços (La et al., 2009; Cheng et al., 2014), na avaliação da marca (Đorđević, 2008; Herstein, Berger \& Jaffe, 2014).

Contudo, apesar de muitos estudos sobre a COI estarem sendo conduzidos com metodologias complexas, observa-se que, no avanço da teoria, as questões de gestão e estratégias têm recebido pouca atenção (Samiee, 2010). Em linha com essa visão, o presente estudo assume que a COI ainda se mostra pertinente e pode servir como recurso na estratégia de marca internacional, pois as empresas de mercados emergentes ainda estão na etapa inicial do processo de internacionalização (Ramamurti, 2008). Assim, acredita-se que suas marcas ainda não estão consolidadas no mercado externo e o país de origem exerce influência no processo de comercialização.

O próximo item da fundamentação dedica-se ao aprofundamento da COI na perspectiva da estratégia da empresa.

\subsubsection{A COI como recurso na estratégia internacional}

Sob o prisma de negócios internacionais, estudos incentivam a investigação sobre o país de origem, pois entende-se que ele interfere na estratégia da organização em mercados internacionais (Senthi \& Elango, 2000; Ramamurti, 2012), uma vez que a COI pode ser reconhecida como recurso gerador de vantagem ou desvantagem competitiva (Cuervo-Cazurra 
\& Un, 2015; Agrawal \& Kamakura, 1999; Baker \& Ballington). Diante disso, o país de origem pode explicar parte da variância do desempenho observado entre as empresas de diferentes setores e ramos de negócios (Brito \& Vasconcelos, 2005).

No entanto, observa-se que não há um arcabouço consistente mostrando que a COI representa um recurso para a empresa (Castro et al., 2014). Buscas realizadas na base de dados Scopus com as palavras: "Country of Origin", "Country of Origin Image", "Brand Origin" juntamente com as palavras "Resource Based Theory", "Resource Based View", "Capability" e "Resources" levaram à identificação de apenas doze artigos publicados relacionando os termos entre 2005 e 2015. Esse baixo número de trabalhos acadêmicos confirma os resultados encontrados por Castro et al. (2014) em revisão sistemática de estudos científicos internacionais sobre país de origem como fonte de vantagem competitiva.

Cuervo-Cazurra \& Un (2015) em ensaio teórico, apontam que, apesar da COI ter sua raridade limitada e de haver a possibilidade de ela ser imitada por outras empresas, ela ainda pode ser considerada um recurso valioso. Os autores argumentam que a COI representa mais do que uma característica da oferta, ela mostra-se um recurso para a empresa ao interferir nos níveis de investimento externo, que podem variar, em função do modo como o consumidor do país de destino e o seu governo a avaliam.

Sob a perspectiva de serviços, La, Patterson \& Styles (2009) buscaram identificar o que explica o valor percebido pelo cliente na prestação de serviço no B2B no contexto internacional. No estudo incluíram dimensões do país de origem para verificar se a imagem do país de origem do prestador de serviços influenciava na percepção geral do serviço. Os resultados indicam que os efeitos de interação entre antecedentes de desempenho percebido e os moderadores, em especial a COI, podem alterar as percepções do cliente com relação ao desempenho global da empresa e o seu valor. Por exemplo, se o cliente tem uma imagem negativa das pessoas do país (do prestador de serviços) e, mesmo que o prestador de serviço apresente nível moderado de habilidades técnicas, o pessoal de serviço não irá produzir um grande impacto sobre o desempenho percebido pelo cliente. Por outro lado, quando o cliente tem uma imagem positiva das pessoas do país de origem do prestador de serviços e ele apresente habilidades técnicas excelentes, o desempenho geral da empresa é percebido de modo superior (La et al., 2009). Os autores chamam atenção para aspectos de gestão de pessoas em relações B2B, e sugerem que os gestores de marketing devem promover não só o que a empresa tem de bom a oferecer, mas também devem mostrar as qualidades do seu país. 
Os estudos de marketing internacional fazem a ligação, não explícita, entre a COI e recursos da empresa por meio da construção e gestão da marca. Diamantopoulos et al. (2011) chamam atenção para que diferentes perspectivas sob país de origem sejam investigadas e que os novos estudos devem considerar não só o papel do país de origem como direcionador da imagem de um produto, mas também como norteador da imagem da marca capturada por meio da imagem do país de origem. Nesse sentido, faz-se necessário compreender quando e como é favorável utilizar a COI na marca.

Entende-se que essa vertente de estudos, dentro da linha de pesquisa sobre país de origem, começou a ganhar espaço no meio acadêmico em função do aumento da competição de empresas internacionais. Nesse contexto, a sensibilidade do consumidor ao país de origem do produto aumentou. Assim, o tema passou a ser relevante para os gestores de marca (Agrawal \& Kamakura, 1999). Na medida que a COI é considerada fonte de informação para avaliação de marcas, a empresa pode se beneficiar da imagem do seu país para desenvolver sua estratégia de marca (Đorđević, 2008; Herstein, Berger \& Jaffe, 2014). Para Baker \& Ballington (2002) a COI pode ser um recurso para a empresa tanto no mercado interno quanto no externo. Os gestores de marketing podem utilizar indicações sobre o país de origem para adicionar valor aos seus produtos e diferenciá-los por meio de um posicionamento específico, ao utilizar, por exemplo, informações úteis do país de origem nas propagandas, na embalagem e na marca (Baker \& Ballington, 2002).

Đorđević acredita que as associações entre imagem do país e da marca podem ser positivas quando a imagem do país é forte. Duas variáveis devem ser consideradas para compreender se a imagem do país pode ser explorada pela marca da empresa: 1) a consciência por parte da empresa sobre o valor da imagem do país, ou seja, as relações entre a marca da empresa e a imagem do país e 2) as associações feitas pelo público alvo da marca com relação à marca da empresa e à imagem do país. Esses dois elementos originam uma matriz proposta pelo autor para explicar quando a transferência de valor da marca país para a marca da empresa se justifica, conforme pode ser analisado na figura 2 . 
Consciência da empresa sobre os beneficios que os valores da marca país carrega

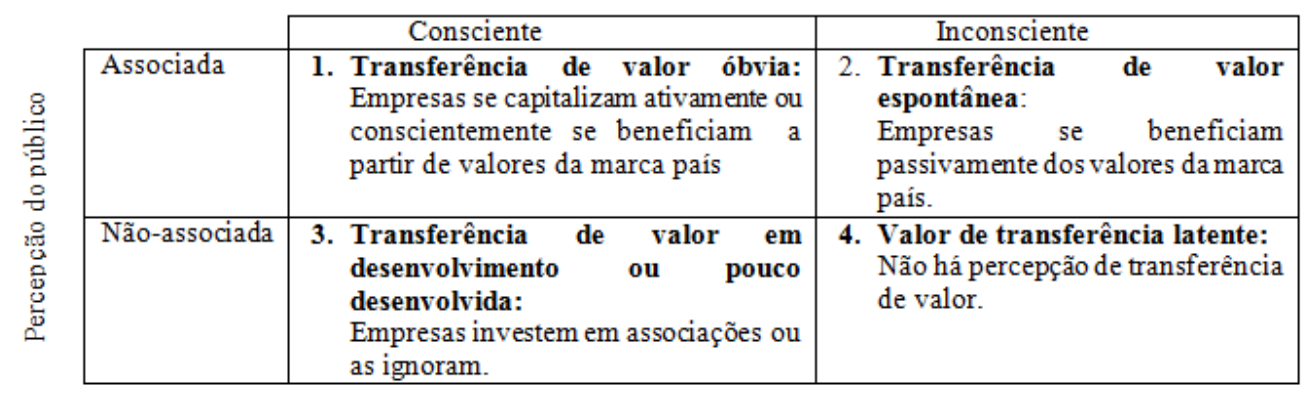

Figura 2 - A janela de transferência de valor Fonte: Adaptado de Đorđević (2008)

No quadrante 1 ocorre o a transferência de valor óbvia, pois a empresa tem consciência de que os valores da imagem do país de origem podem contribuir para o desenvolvimento da sua marca. E, ao mesmo tempo, o público da empresa associa esses valores do país à marca (Đorđević, 2008). Exemplos dessa associação ocorrem na indústria automotiva (as empresas Mercedes e Audi associam conscientemente suas marcas à imagem do país), assim como marcas de café colombiano, a vodca russa, o vinho francês, as sandálias havaianas do Brasil, entre outros.

No quadrante 2 a empresa não tem consciência sobre como os valores do país podem ser benéficos para a construção da sua marca, ou seja, a empresa é cega em relação aos benefícios que os atributos do país de origem podem lhe proporcionar. Por outro lado, o público alvo faz associações entre a imagem do país de origem e a empresa, por isso, a transferência é espontânea.

A situação em que a empresa tem consciência sobre os valores do país de origem, mas o seu público alvo não tem é chamada de valor de transferência em desenvolvimento ou não desenvolvida (Đorđević, 2008). No quadrante (3), as empresas devem investir na construção da marca com atributos do país de origem e explicar ao seu público alvo essa associação, ou simplesmente ignorar a possibilidade de ter benefícios com a imagem do país. Por fim, no quarto quadrante Đorđević (2008) cita que tanto a empresa quanto o consumidor não percebem a transferência de valor dos atributos da imagem do país para a empresa, embora a transferência ainda ocorra em um nível oculto e latente.

Três anos mais tarde, em 2011, Usunier (2011) realizou um comentário ao artigo de Magnusson et al. (2011a) em que apresentou argumentos similares aos de Đorđević (2008) com 
relação a utilização da COI na estratégia (ver figura 3). Para Usunier (2011), há quatro formas de administrar as pistas sobre o país de origem da marca: não tomar nenhuma atitude; evitar ação inapropriada; mudar o nome da marca e mudar a percepção da marca. Para Usunier (2011), a célula 1 corresponde a situação perfeita, em que o país de origem e a marca são corretamente percebidos e a associação entre os dois é favorável, similar ao quadrante 1 de Đorđević (2008). Diante dessa situação, Usunier (2011) recomenda que a empresa não deva tomar nenhuma atitude. Um exemplo dessa situação pode ser verificado com as marcas de carros alemãs Audi e Volkswagen. Os consumidores associam positivamente a categoria de produto carro com a imagem da Alemanha (Magnusson et al., 2011a). Nesse exemplo, Usunier (2011) recomenda que a empresa mantenha ou, se possível, reforce a percepção favorável da sua origem.

A segunda situação (célula 2), mostra que a combinação da classificação errada com e marca de origem favorável também corresponde a uma situação gerencialmente positiva, seja ela intencional ou não intencional. A questão em jogo é entender como proteger a classificação incorreta entre marca e país de origem. O conselho é evitar quaisquer sinais de informação que levem as pessoas à correta classificação da origem da marca (Usunier, 2011).

\begin{tabular}{l|cc|}
$\begin{array}{l}\text { Classificação } \rightarrow \begin{array}{c}\text { Favorabilidade } \\
\text { (aceitação) }\end{array} \\
\text { Associação favorável }\end{array}$ & $\begin{array}{c}\text { Corretamente } \\
\text { classificada }\end{array}$ & $\begin{array}{c}\text { Não classifica ou incorretamente } \\
\text { classificada }\end{array}$ \\
Associação desfavorável & 1 & 2 \\
\hline
\end{tabular}

Figura 3 - Classificação da origem da marca e associação favorabilidade (aceitação) Fonte: Adaptado de Usunier (2011)

A terceira célula corresponde à situação frequente de um nome de marca estabelecido que carrega uma imagem bastante desfavorável. Uma recomendação para esse caso seria a alteração do nome da marca.

Por fim, o pior cenário consiste na situação 4, em que não há aderência entre a imagem do país da marca com sua categoria de produto, ou seja, a classificação é inadequada e a imagem do país de origem da marca é desfavorável nessa categoria de produto (Usunier, 2011). Nesse caso, recomenda-se associação entre a empresa com a imagem de um país que seja forte na categoria.

Samiee (2011) argumenta que as empresas devem ter um entendimento correto sobre suas origens e como ela é reconhecida pelo seu público alvo. A partir disso, esse autor, cita que 
a empresa tem a opção de usar a COI no seu plano de marketing se identificar que essa incorporação pode conferir uma estratégia melhor e, portanto, ser benéfica para atingir os objetivos da empresa. Na situação em que o consumidor não possuir conhecimento ou não for sensível às informações da origem da marca e ao país de origem, o uso de atributos da COI na estratégia de marketing fará pouco sentido.

Os apontamentos de Đorđević (2008) indicam as situações em que é interessante transferir a COI para a empresa. Usunier (2006; 2011) complementa lembrando que muitas empresas operando internacionalmente tendem a manipular o nome da marca para sugestionar sua a origem. Isso pode ocorrer quando a empresa deseja associar sua marca à imagem de um país que tenha uma imagem forte na categoria de produto em que ela opera em função das associações que são feitas pelos consumidores entre o produto e o país de origem (Usunier \& Cestre, 2007).

Até esta parte deste item da revisão da literatura só se discutiu se a empresa pode ou não utilizar a COI e o que utilizar da COI. Acredita-se que para mensurar a importância da incorporação da COI na capacidade de marca é necessário compreender o modo como a empresa utiliza os elementos da COI na sua estratégia por meio da construção da marca. Conforme discorrido anteriormente, a marca é um ativo valioso, por isso exerce importante papel na busca pela obtenção de VC em decisões estratégicas da empresa (Moradi \& Zarei, 2012; Spence \& Hamzaoui Essoussi, 2010). A área de marketing, por meio de suas capacidades, desenvolve e gerencia a marca e faz isso por meio de processos.

O item seguinte apresenta os processos estratégicos pelos quais a empresa pode incorporar a COI como recurso na estratégia de marca.

\subsubsection{Os processos de incorporação da COI e elaboração de hipóteses}

Compreende-se que a importância da COI como recurso na construção da capacidade de marca da empresa pode ser identificada ao se verificar a sua incorporação à marca. Por sua vez, a incorporação da COI na estratégia acontece por meio da identidade da marca mediante associações com o país de origem (Spence \& Hamzaoui Essoussi, 2010). Tal construção demanda capacidades específicas da área de marketing que devem capturar e refletir quão bem a empresa desempenha cada um dos processos de conexão com o cliente (Day, 1994, 2000). 
Nesta tese, defende-se que a incorporação da COI na marca pode ser manifestada por diversos processos, cabendo a empresa transformar a COI num recurso por meio da sua capacidade de gestão e construção de marca. A utilização de todos os elementos da COI não é necessária para que a empresa se valha da COI como recurso em sua estratégia. Isso se deve ao fato de que os profissionais de marketing devem compreender os valores da marca e sua identidade para identificarem os processos mais aderentes à marca pelos quais a COI possa ser incorporada. Por isso, argumenta-se que a empresa pode usar a(s) dimensão(ões), ou processo(s), que se mostrar(em) mais coerente(s) para o conceito da marca (Pappu, Quester \& Cooksey, 2006).

Para identificar os processos de incorporação na COI na estratégia por meio da construção da marca, foi necessário recorrer à literatura sobre: COI, mais especificamente a que relata a imagem do país de origem para empresas de mercados emergentes, o arcabouço sobre construção de marcas e, novamente, a RBT.

A literatura sobre a COI indica que o viés estereotipado contra países emergentes faz com que os consumidores avaliem de modo desfavorável os produtos desses países (Nagashima, 1970; Roth \& Romeo, 1992), como sendo produtos commoditizados, com preço baixo e de qualidade inferior (Herstein et al., 2014; Manrai et al., 1998; Papadopoulus, 2004; Pappu, Quester, \& Cooksey, 2007; Kumar \& Steenkamp, 2013). Por isso, muitas empresas de países emergentes ao explorar economias avançadas podem ocultar seu país de origem: mostrando-se ser uma empresa local (Tallman \& Yip, 2009); comprando uma marca local (Demirbag, Sahadev \& Mellahi, 2010) ou construindo sua identidade a partir de um terceiro país (Tallman \& Yip, 2009; Magnusson et al., 2008) escolhendo um nome ocidental para a marca (Herstein, et al., 2014).

No entanto, a COI do país emergente pode mostrar-se um recurso valioso em operações internacionais (Cuervo-Cazurra \& Un, 2015; Kumar \& Steenkamp, 2013; Chattopadhyay et al., 2012; Magnusson et al., 2008), dependendo da maneira como a empresa emprega esse recurso na marca (Magnusson et al., 2008) e no modo como o país de destino (consumidores e governo) percebe a imagem do país de origem da empresa (Cuervo-Cazurra \& Un, 2015). Para Kumar \& Steenkamp (2013) as empresas de mercados emergentes podem tornar suas marcas globais. Para isso, sugerem oito estratégias:

- A rota da tartaruga Asiática: a migração para melhor qualidade e marca premium. A lógica dessa estratégia consiste em estabelecer uma ponte em um país ocidental com a venda 
de um bom produto com preço muito baixo para um nicho de mercado, e, em seguida, tomar medidas convergentes em uma espiral ascendente para aumentar a qualidade da nova versão do produto para precificar de forma superior, atingindo o segmento acima, fazendo o mesmo mecanismo até que a marca atinja presença dominante no mercado em toda faixa de preço e qualidade. Exemplos de empresas que seguem essa estratégia são Haier (China), Pearl River Piano (China) e Wanli (China);

- A rota do negócio para consumidor: alavancando a força do B2B em mercados B2C. Essa estratégia é utilizada por algumas empresas que se veem evoluindo para uma marca de consumo, talvez em uma categoria de produto adjacente ou em um negócio de maior valor agregado. Incluem-se nesse caso as marcas ASD (China), Huawei (China) e ZTE (China);

- A rota da diáspora: seguindo os emigrantes pelo mundo. O princípio dessa estratégia está em seguir os fluxos de imigrantes que vivem fora do seu país de origem. Corona (México), Dabur (Índia) e Jollibee (Filipinas) são exemplos de empresas que empregam essa estratégia;

- A rota da aquisição de marcas: compra de marcas globais por multinacionais ocidentais para expandirem-se rapidamente e de forma agressiva em mercados ocidentais. Fazem isso por meio da aquisição de ativos críticos de multinacionais ocidentais maduras nesses territórios. Por exemplo: Bimbo (México), Lenovo (China), Tata Motors (Índia) e TCL (China);

- Rota da campanha positiva: por meio dessa estratégia busca-se superar as associações negativas do país de origem. Para tanto sete caminhos podem ser trilhados: 1) disfarçar a origem na escolha do nome da marca; 2) confrontar associações negativas, associando a marca a elementos positivos; 3) focar em atributos positivos da imagem do país; 4) oferecer garantias extras; 5) enfatizar a estética; 6) trabalhar com manufatura reversa e 7) investir fortemente em marketing. As empresas e os governos também podem unir forças e lançar campanhas nacionais ou regionais de marca, como feito pela Índia INcredable India e por Taiwan com "The future Made by Taiwan”. As Chinesas Ospop, Roewe, Shangai Vive e a Tailandesa Chang peer utilizam essa estratégia;

- A rota do recurso cultural: essa estratégia visa construir a identidade de marca da empresa com base em mitos culturais positivos, ou seja, a apropriação de aspectos culturais do país de origem que podem adicionar valor à marca. A cultura de um país refere-se a todas as crenças, atitudes, aspirações, valores e mitos mantidos por grande parte da sua sociedade, bem como os traços comportamentais, as regras, costumes e normas que as pessoas seguem. Inclui também aspectos sociais, do ambiente físico, as instituições, os objetos e a história do país. A 
marca Havaianas é citada para exemplificar a incorporação da COI do Brasil por parte da empresa. A marca faz uso positivo da COI do Brasil, que transmite jovialidade, alegria e diversão, elementos amplamente associados à cultura brasileira como se verá no item da fundamentação que trata sobre atributos da imagem do Brasil. Na China as marcas Herborist, Shanghai Tang e Shang Xi também incorporam os atributos culturais do país na estratégia de marca;

- A rota do recurso natural: essa estratégia versa sobre a utilização de recursos naturais no processo produtivo para transformar commodities em produtos com valor agregado. Para fazer isso, deve-se implementar um processo dividido em quatro etapas: 1) definição de uma região geográfica que seja conhecida como única e cuja matéria prima de qualidade deve ser promovida; 2) realizar a especificação da produção com transparência, aumentando as barreiras de entrada e de forma elaborada para resultar em qualidade; 3) autenticação da produção por meio de auditores regulares e independentes e conquistar selos de qualidade; 4) branding internacional: divulgar que a área geográfica é protegida, restrita e que possui características únicas, assim como comunicar ao consumidor o valor do produto com recurso natural. Exemplos dessa estratégia são as marcas Natura (Brasil), o café da Colômbia (Colômbia) e o vinho Concha Y Toro (Chile).

- A rota do campeão nacional: a marca é alavancada com um forte apoio do Estado. Essa estratégia encontra apoio e segurança no Estado, tanto por meio direto (via subsidiárias) ou indireto (tratamento preferencial, barreiras de entrada para competidores). Esses recursos e a proteção são utilizados para a empresa se tornar um grande player no mercado doméstico, para depois expandir-se aos mercados internacionais. Por vezes, o apoio do estado ocorre somente no perído inicial da gestão, depois a empresa é privatizada, embora a marca continue estreitamente alinhada aos interesses do Estado. Exemplos dessa estratégia são identificadas nas marcas: China Mobile e Comac da China, Embrarer (Brasil), Emirates Airlines (Dubai), Embrarer (Brasil) e Proton (Malásia).

Observa-se que, das oito estratégias de marca sugeridas por Kumar \& Steenkamp (2013) para empresas de países emergentes, três envolvem aspectos da COI: campanha positiva, recursos culturais e recursos culturais. Magnusson et al. (2008) corroboram com a estratégia campanha positiva proposta por Kumar \& Steenkamp (2013), apontando que uma boa alternativa para reduzir os efeitos negativos do país de origem consiste na associação da marca da empresa a imagens positivas que encantem o consumidor. Essa estratégia tem sido utilizada 
por empresas de mercados desenvolvidos, como a Nokia, do setor de telecomunicações, de origem finlandesa, cujo nome soa como japonesa. Assim os consumidores associavam a marca à imagem de tecnologia dos produtos japoneses. Outro exemplo é o da Häagen-Dazs, empresa norte-americana, mas que transmite por meio de sua marca, a identidade de um país europeu, como Alemanha ou Suíça.

Ratificando essa discussão, Chattopadhyay et al. (2012) também contribuem com a estratégia de campanha positiva. Esses autores, em estudo qualitativo com 39 multinacionais de países emergentes, identificaram que muitos dos países de origem das empresas pesquisadas, embora tenham COI positiva e reconhecida em algumas categorias de produtos, ainda apresentam a imagem de serem subdesenvolvidos, pobres com baixa competência em tecnologia e controle de qualidade. Para superar essa deficiência, Chattopadhyay et al. (2012) sugerem 1) que a empresa estipule como alvo os países que tenham uma imagem positiva sobre a COI dela, 2) que construa uma imagem de marca global ou regional ou 3) construa sua identidade de marca desvinculada da sua COI.

Os recursos naturais são utilizados para mensurar a atitude do consumidor com relação ao produto ou marca de um país, por isso, acredita-se que essa seja uma das características exploradas pela capacidade de gestão da marca para incorporar a COI na estratégia de marca da empresa. Diversas escalas de avaliação da COI utilizam aspectos respaldados nos recursos naturais de um país para mensurar a atitude do consumidor: a geo-cultura (Brijs, 2006), a paisagem natural (Verlegh, 2001), o clima (Verlegh, 2001; Van Ittersum, Candel \& Meulenberg, 2003), a natureza e o ambiente (Van Ittersum et al., 2003). Quando o produto comercializado se apoia na capacidade da empresa em extrair, processar e promover as qualidades dos recursos naturais do país, esses podem estender a imagem do país para a marca da empresa.

Observa-se também que grande parte dos estudos sobre COI mensuram o modo como os consumidores analisam o produto com base na imagem que têm da cultura de um país (Papadopoulos, Heslop \& Bamossy, 1990; Laroche et al., 2005; Brijs, 2006). A cultura de um país refere-se às crenças, atitudes, aspirações, valores e mitos da sociedade de um país, bem como ao comportamento, às regras, aos hábitos e costumes vigentes que as pessoas respeitam e seguem. Kumar \& Steenkamp (2013) também evidenciam esse aspecto para construção de marcas de mercados emergentes. Assim, a propõe-se que, os elementos da cultura de um país são incorporados à estratégia da marca quando os marketers evidenciam aspectos como: as artes 
produzidas por cidadãos do país, a literatura nacional, as pessoas, as suas expressões culturais, os hábitos e costumes de seu povo.

Nota-se também que as estratégias de recursos naturais e de recursos culturais propostas por Kumar \& Steenkamp (2013) são reforçadas por Paterlini et al. (2012). Os resultados de estudo realizado por estes autores com relação ao uso de informações da COI do Brasil por empresas de cosméticos brasileiras em processo de internacionalização indicam que a biodiversidade e a mistura cultural brasileira ajudam a manter uma COI positiva para cosméticos que tenham origem na Amazônia.

Os achados de Sutter, Polo \& Maclennan (2014) e de Sutter, Barakat, Massaini \& Marinho (2015b) confirmam o uso de recursos culturais e naturais na estratégia de marca internacional de empresas de mercados emergentes. Ambos os estudos foram realizados no segmento da moda e indicam que os recursos naturais do Brasil - como por exemplo fibras, gemas, metais, semente, penas, escamas, conchas, pedras, contas de madeira, fios de palha, artesanato produzido à base de fibras de buriti, tecidos ecológicos, algodão natural, fibra de buriti, juta - podem fazer parte do produto e da marca (Sutter et al., 2014; 2015b). Para esses autores, os recursos culturais do Brasil podem ser incorporados na marca de moda por meio de duas dimensões, o estilo de vida (ousadia; diversidade de tradições culturais, miscigenação transferida aos produtos, ironia, jovialidade e alegria de viver) e pelas representações do Brasil e símbolos nacionais (utilização de imagens de flora e fauna nas estampas, frutas, coqueiros, flores, onça, papagaios, tucanos, inspiração em encadernação, tipografia, gravura, entalhe, cerâmica, culinária, práticas religiosas e folclóricas, conciliação das referências da cultura nacional com à modernidade nos elementos que fazem menção à geográfica do país, como natureza, uso das cores verde e amarela, elementos que estabelecem relação direta com o Brasil - praias, coqueiros, favelas, samba, cultura indígena e africada, religiosidade e imagens de Carmen Miranda).

Ademais, a estratégia de recursos naturais e culturais de Kumar \& Steenkamp (2013) tem relação com o uso de indicações geográficas. As Indicações Geográficas (IGs) referem-se à indicação de procedência e/ou denominação de origem do produto (Castro \& Giraldi, 2015), similar às marcas comerciais e marcas corporativas, as IGs suscitam a identidade e imagem geográfica (Brodie \& Benson-Rea, 2016). À princípio, IGs foram desenvolvidas para constituir mecanismos inibidores de fraudes e adulterações. Atualmente, em função do novo contexto de mercado, as IGs passaram figurar como componente expressivo de diferenciação em termos 
qualitativos (Castro \& Giraldi, 2015; Brodie \& Benson-Rea, 2016). A mudança na acepção das IGs permitiu aos produtores a criação de nichos de mercado ao transformar a região de origem do produto em um atributo, fazendo isso por meio da ênfase na conexão da marca com o seu local de origem (Brodie \& Benson-Rea, 2016). Por isso, as GIs, são reconhecidas, cada vez mais, como dispositivos para comunicar aos consumidores (B2C) e produtores (B2B) princípios qualitativos específicos (Niederle, 2012).

Castro \& Giraldi (2015) apontam que a IG pode ser obtida mediante o reconhecimento do saber-fazer de um determinado produto ou de um território específico. Por exemplo, a IG de café e de vinho. O café brasileiro e o colombiano são reconhecidos internacionalmente. Notase que nos trabalhos de Sutter et al (2014a; 2015b) os resultados apontam para o uso de IGs, como praias específicas brasileiras (como estampa do calçadão de Copacabana), a natureza exuberante e a miscigenação que são referências no Brasil.

Seguindo os apontamentos analisados anteriormente e tomando como exemplo o de Sutter et al (2014) sobre os atributos da COI do Brasil no setor da moda, uma marca como a Havaianas ou outra empresa de moda, cujos produtos e identidade da marca sejam pautados pela cultura brasileira, podem incorporar a COI do Brasil enfatizando os recursos culturais brasileiros, indo ao encontro dos apontamentos de Kumar \& Steenkamp (2013). Assim:

H1 A importância da COI como recurso como recurso na construção da capacidade de marca da empresa em processo de internacionalização é manifestada por meio da incorporação de recursos culturais do país de origem na marca.

Já empresas cujos valores estejam apoiados na sustentabilidade, ou que utilizam muitos recursos naturais como a natura e a L'Occitane au Brésil (Sutter, Carmago, Strehlau \& Crescitelli, 2016a) podem incorporar a COI destacando a Natureza, fazendo referência aos recursos naturais do país, como a Amazônia ou florestas tropicais (Kumar \& Steenkamp, 2013) ou mesmo às IGs (Brodie \& Benson-Rea, 2016).

H2 A importância da COI como recurso na construção da capacidade de marca da empresa em processo de internacionalização é manifestada por meio da incorporação de recursos naturais do país de origem na marca.

Outros processos de incorporação da COI na estratégia são relatados na literatura. Samiee et al. (2005) em estudo para identificar se os consumidores reconheciam o país de origem de 84 marcas, inseriram no instrumento de coleta de dados perguntas com associação 
de linguagem, ou seja, os respondentes deveriam atribuir a cada nome de marca um idioma que estivesse mais próximo do idioma dela. Samiee et al. (2005), apontaram, portanto, um dos processos de incorporação da COI na marca, por meio da identificação do idioma. Em linha, Magnusson, Westjohn \& Zdravkovic (2011a) também apontam que uma forma de conectar a origem da marca ocorre por meio do entendimento sobre o idioma utilizado pela marca, ou seja, a ortografia, a pronúncia, assim como a utilização de um nome de marca que remeta a outro país de origem, conforme discorrido anteriormente (Magnusson et al., 2011a) também podem ser utilizados. Usunier (2011) acrescenta ao idioma as siglas, que, às vezes, podem ser desenvolvidas intencionalmente para omitir associações. Samiee (2011) adicionou outros processos para incorporação da COI como uso de referências do país de origem no logo e em expressões. Esses elementos são chamados de processos textuais.

Os processos textuais são muitas vezes considerados como a única forma de se incorporar a COI na marca (Usunier, 2011; Papadopoulos \& Heslop, 1993; Thakor \& Kohli, 1996). Contudo, pistas visuais também são importantes para a transmissão de informações sobre a origem que podem ser inferidas a partir da embalagem, ao se utilizar, por exemplo, ícones, símbolos, emblemas, brasões, planta específica, bandeiras, cores ou cenários típicos que remetam ao país (Usunier, 2011; Samiee, 2011; Florek \& Insch, 2008; Insch \& Florek, 2009; Papadopoulos \& Heslop, 1993; Thakor \& Kohli, 1996; Thakor \& Lavack, 2003). Assim como, em alguns casos, integrar o design do produto e a própria gestão da marca (Samiee, 2011). A incorporação da COI pode ser reforçada com propagandas endossadas por celebridades, artistas ou empresários de nacionalidade igual à da marca e que sejam reconhecidos internacionalmente (Usunier, 2011).

Com isso, acredita-se que a associação da linguagem e de aspectos visuais do país de origem também represente uma forma de manifestação da incorporação da COI na estratégia conforme apontaram Thakor \& Kohli (1996), Samiee et al. (2005), Samiee (2011), Magnusson et al. (2011) e Usunier (2011).

Com base nesses apontamentos, as seguintes hipóteses foram levantadas:

H3 A importância da COI como recurso na construção da capacidade de marca da empresa em processo de internacionalização é manifestada por meio da incorporação de elementos textuais do país de origem na marca. 
H4 A importância da COI como recurso na construção da capacidade de marca da empresa em processo de internacionalização é manifestada por meio da incorporação de elementos visuais do país de origem na marca.

Mais recentemente, D’Antone \& Merunka (2015) publicaram estudo conceitual no qual exploraram como os atributos referentes à origem da marca (BO) afetam a associação do consumidor com uma marca nova que utiliza a COI. Os autores propõem uma perspectiva teórica, com base na semiótica, que permita a compreensão do processo pelo qual os consumidores identificam a origem da marca, como por exemplo, por pistas e mecanismos que levam os consumidores a associar a marca com uma origem. Após a identificação da origem da marca, o modelo propõe a transferência do significado da origem para a marca. D’Antone \& Merunka (2015) deram a esse processo o nome de modelo de transferência de significado da origem da marca (Brand origin meaning transfer model - BOMT).

As considerações do estudo apontam que a influência das características da marca na identificação da sua origem é particularmente relevante para entrada em novos mercados. Por isso, D’Antone \& Merunka (2015) chamam atenção dos gestores de marketing para que monitorem cuidadosamente quais impressões a COI da marca desperta e, então, selecionem sinais específicos para incluir na comunicação com o mercado e evitar pistas que podem evocar procedência desfavorável à marca.

Outro aspecto relevante apontado por D’Antone \& Merunka (2015) é que, nesse processo de incorporação da COI na marca, os gestores devem estabelecer uma conexão direta com o local de origem da marca, mas essa associação pode ser feita de modo mais experiencial, como por meio da atmosfera de vendas, do estilo do produto, do uso de celebridades do país de origem, eventos ou outras alianças. Com uma associação experiencial, o uso da COI mostra-se uma opção viável para as marcas explicitamente ligadas à sua origem geográfica que estejam buscando estabelecer exclusividade perante seus competidores (D’Antone \& Merunka, 2015). A utilização da dimensão experiencial da COI na marca ajudará os consumidores a sentirem e viverem a proveniência marca e percebê-la como mais genuína ou autêntica ( $D^{\prime}$ Antone \& Merunka, 2015). Os apontamentos de D’Antone \& Merunka (2015) vão ao encontro dos de Herz \& Diamantopoulos (2013b) que defendem a importância de se enfatizar os atributos emocionais específicos do país, por meio de ferramentas de comunicação de marca.

Em linha, Sutter, MacLennan, Giraldi, Crescitelli \& Polo (2016b), em estudo qualitativo com duas empresas do ramo de cosméticos que utilizam a imagem do Brasil em suas estratégias 
de marca, apontaram evidências de como os sentidos podem ser trabalhados no processo experiencial ligando o país de origem à marca. Os autores relataram que as duas marcas utilizam aromas, fragrâncias e músicas que remetam ao país de origem em pontos de contato com o cliente. Tais evidências encontram amparo teórico nas citações de D’Antone \& Merunka (2015) e de Herz \& Diamantopoulos (2013b), por isso, formula-se a hipótese de que:

H5 A importância da COI como recurso na construção da capacidade de marca da empresa em processo de internacionalização é manifestada por meio da incorporação de sentidos associados ao país de origem na marca.

Por fim, defende-se o uso dos funcionários como embaixadores da COI. Isto porque os funcionários são essencias para a gestão dos esforços da marca, pois desenvolvem relacionamento com diversos steakholders externos. Eles têm a responsabilidade de entregar a promessa da marca aos clientes (Piehler, Burmann \& Xiong, 2016). Desempenham, portanto, relevante papel de mensageiros na comunicação da marca do emissor para o receptor, conforme aponta Kapferer (2003) (ver figura 4).

Figura 4 - Identidade e Imagem

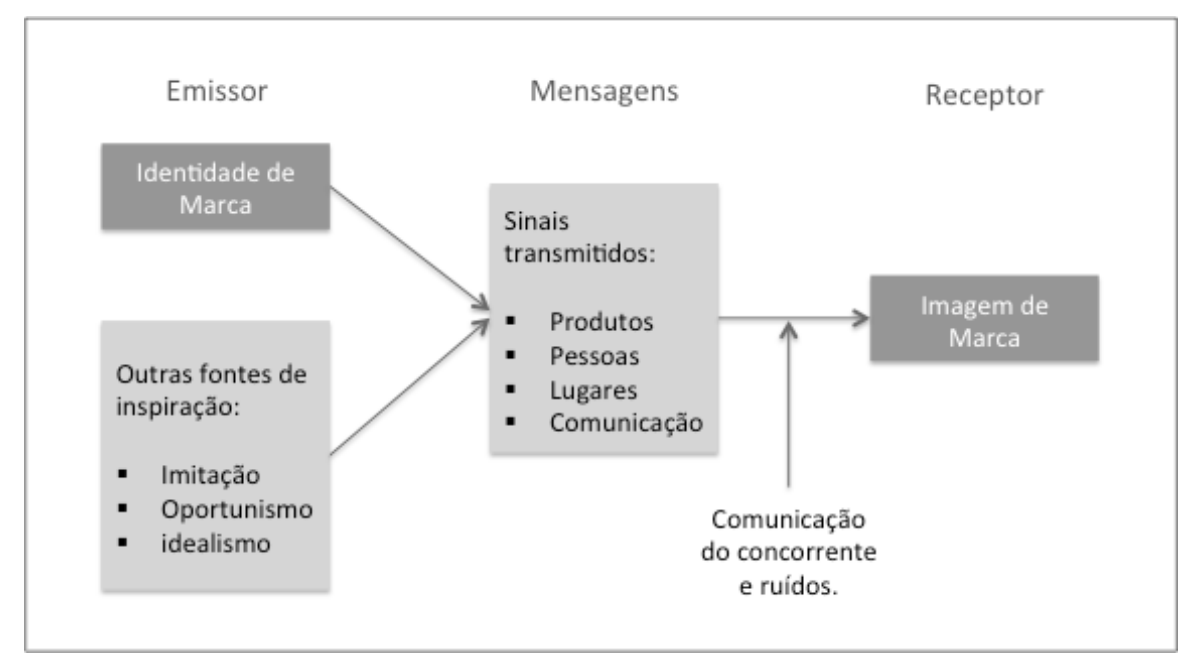

Fonte: Adaptado a partir de Kapferer (2003).

Dessa forma, o modo como os funcionários estão engajados e preparados para falar sobre a marca e as características do país de origem articuladas na marca, mostra-se essencial para que a COI seja incorporada à marca. É nesse sentido que se faz necessária a capacitação deles, por meio de treinamentos sobre a importância da COI para a empresa. Ademais, sabe-se 
que os funcionários representam um recurso para a empresa à medida que constroem uma cultura organizacional difícil de ser imitada, por isso, representam um recurso para a empresa (Penrose, 1959; Barney \& Hesterly, 2007). Por isso, a qualificação dos funcionários (Hooley, Greenley, Cadogan \& Fahy, 2005; Kozlenkova et al., 2014) é um dos recursos de mercado capaz de gerar vantagens competitivas para as empresas.

Por meio da observação da figura 4, fica clara a importância das mensagens para efetivar a transmissão da identidade da marca do emissor para o receptor. Assim, seguindo o que foi sugerido por Kapferer (2003), os sinais transmitidos pela marca - produtos, pessoas, lugares e comunicação - podem servir como processos para incorporação da COI na estratégia. Dentre tais mensagens do sistema de decodificação da identidade da marca, todos estão relacionados a dimensões já identificadas na literatura para incorporação da COI na estratégia, o único sinal que não foi abordado ainda é o de pessoas. As pessoas, que na empresa desempenham o papel de funcionários, além de carregarem e disseminarem a identidade da marca, representam o principal ponto de contato entre uma marca e seu cliente. Ademais, elas representam um recurso para a empresa tendo em vista que constroem uma cultura organizacional difícil de ser imitada.

O estudo de Sutter et al. (2016) mostra a importância dos funcionários na transmissão da COI ao mercado. De acordo com os achados do estudo (detalhados no quadro 5), as empresas podem treinar e capacitar seus funcionários sobre as especificidades e importância sobre o país na estratégia da marca. Tais resultados estão em linha com as citações de Kapferer (2003) sobre a importância do papel desempenhado pelas pessoas na transmissão de mensagens entre a marca e o mercado. 
Quadro 5 - Evidências de incorporação da COI na estratégia da marca

\begin{tabular}{|c|c|c|}
\hline \multirow[t]{2}{*}{ Dimensão } & \multicolumn{2}{|c|}{ Evidências identificadas em campo } \\
\hline & Natura & L’Occitane \\
\hline $\begin{array}{l}\text { Elementos } \\
\text { textuais }\end{array}$ & $\begin{array}{l}\text { Sim - Nome do Brasil na loja } \\
\text { da Natura em Paris. }\end{array}$ & $\begin{array}{l}\text { Sim - Nome do Brasil na marca L'Occitane au Brèsil } \\
\text { e utilização de linguagem, expressões, sinais, do } \\
\text { Brasil, por exemplo: xilografia, informação de preços } \\
\text { em quadro negro escrito à giz remetendo à feiras livre. }\end{array}$ \\
\hline Elementos visuais & $\begin{array}{l}\text { Sim - algumas imagens que } \\
\text { rementem ao Brasil na } \\
\text { comunicação. Refroça na } \\
\text { linha Ekos. }\end{array}$ & $\begin{array}{l}\text { Sim- Imagens do Brasil e de matéria-prima brasileira. } \\
\text { Utilização de cores do Brasil, cenário, imagens, } \\
\text { símbolos típicos do país (como animais), cenários } \\
\text { naturais ao fundo. Endosso com artistas brasileiros } \\
\text { para construção da identidade visual de cada linha da } \\
\text { marca e da identidade da loja e da marca. Uso de } \\
\text { fotografias do Brasil, nome no país no uniforme dos } \\
\text { funcionários. }\end{array}$ \\
\hline $\begin{array}{l}\text { Sentidos: audição, } \\
\text { olfato e tato. }\end{array}$ & $\begin{array}{l}\text { Sim - uso de música } \\
\text { brasileira no site. }\end{array}$ & $\begin{array}{l}\text { Sim - uso de música brasileira no site e no ponto de } \\
\text { vendas. Olfato por meio da matéria-prima dos } \\
\text { produtos; tato mediante o alto-relevo nas embalagens. }\end{array}$ \\
\hline Funcionários & $\begin{array}{lll}\text { Sim }- & \text { enfatiza } & \text { os } \\
\text { relacionamentos entre } & \text { as } \\
\text { consultoras e os clientes, a } \\
\text { alegria de } & \text { viver } & \text { a } \\
\text { receptividade } & & \end{array}$ & $\begin{array}{l}\text { Sim- Capacitação e treinamento dos funcionários, } \\
\text { explicando a origem de cada linha de produto com } \\
\text { atributos da COI do Brasil, os benefícios } \\
\text { proporcionados pelos recursos naturais e a história de } \\
\text { cada artista que desenvolveu a identidade visual de } \\
\text { cada uma das linhas da marca. }\end{array}$ \\
\hline Recursos naturais & $\begin{array}{l}\text { Sim -_Utilização de matérias- } \\
\text { primas típicas do país }\end{array}$ & Sim- Utilização de matérias-primas típicas do país. \\
\hline Recursos culturais & $\begin{array}{l}\text { Sim - } 4 \text { Explora a } \\
\text { miscigenação da cultura } \\
\text { Brasileira para compor e } \\
\text { promover seu portfólio de } \\
\text { produtos. }\end{array}$ & $\begin{array}{l}\text { Sim - Contratou artistas Brasileiros para construção da } \\
\text { marca, explorando o estilo de vida e aspectos culturais } \\
\text { da região originária dos recursos naturais brasileiros } \\
\text { utilizados nas linhas da marca. }\end{array}$ \\
\hline
\end{tabular}

Fonte: Sutter et al. (2016)

Assim, acredita-se que:

H6 A importância da COI como recurso na construção da capacidade de marca da empresa em processo de internacionalização é manifestada por meio da incorporação de treinamentos e capacitação dos funcionários sobre o país de origem na marca.

A figura 5 ilustra o modelo conceitual da escala pautado na revisão da literatura. 


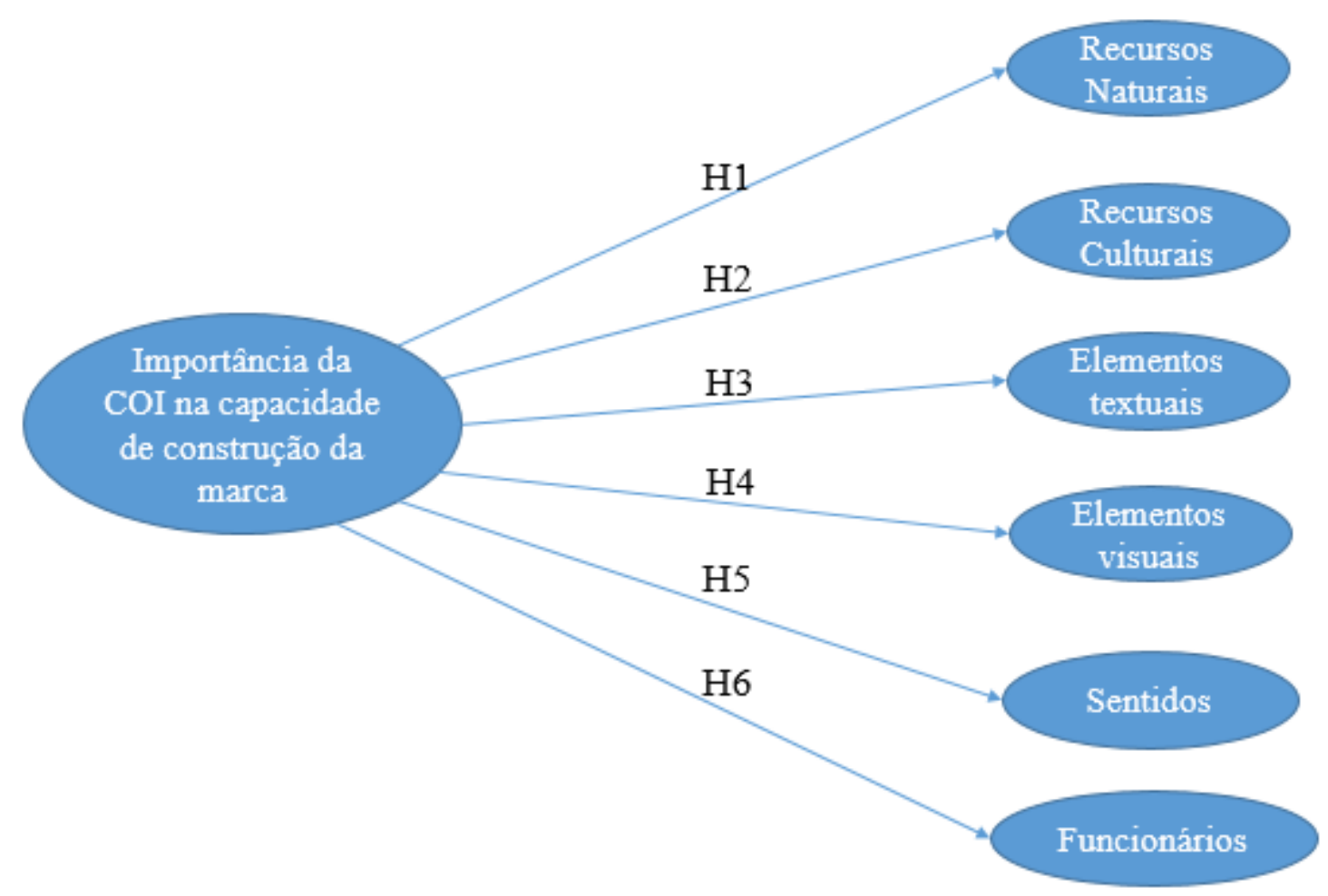

Fonte: Autora

Neste estudo, defende-se que uma empresa pode articular seus recursos em conjunto com a COI para a construção da capacidade de gestão da marca. Para isso, as marcas podem se valer da articulação de diversos elementos associados à COI que foram apresentados ao longo da fundamentação teórica. Tais processos foram utilizados para alicerçar as questões referentes ao uso de COI por parte da empresa e serviram como dimensões para a proposta de escala. A figura 5 ilustra o modelo conceitual inicial para a elaboração da escala. O quadro 6 apresenta os principais conceitos de RBT e sua aplicação que alicerçaram este estudo. 
Quadro 6 - COI na estratégia: aplicação dos conceitos da RBT

\begin{tabular}{|c|c|c|}
\hline RBT & RBT em Marketing & $\begin{array}{c}\text { RBT em marketing - análise } \\
\text { deste estudo }\end{array}$ \\
\hline $\begin{array}{l}\text { Recursos: } \\
\text { Todos os ativos da empresa } \\
\text { (tangíveis ou intangíveis), as } \\
\text { capacidades e os processos } \\
\text { organizacionais (Barney, 1991). }\end{array}$ & $\begin{array}{l}\text { Recursos em marketing: } \\
\text { Geralmente são baseados no } \\
\text { mercado. É o subconjunto de } \\
\text { recursos e habilidades da } \\
\text { empresa relacionados com as } \\
\text { atividades e processos de } \\
\text { marketing (Kozlenkova et al., } \\
\text { 2014) para criar valor no } \\
\text { mercado (Hooley et al., 2005; } \\
\text { Woodside et al., 1999). }\end{array}$ & $\begin{array}{l}\text { Recurso: } \\
\text { Imagem do País de Origem }\end{array}$ \\
\hline $\begin{array}{l}\text { Capacidade: habilidade da } \\
\text { empresa em implantar os } \\
\text { recursos, geralmente em } \\
\text { combinação com processos } \\
\text { organizacionais para atingir o } \\
\text { fim desejado (Amit \& } \\
\text { Schoemaker, 1993). }\end{array}$ & $\begin{array}{l}\text { Capacidades de marketing: } \\
\text { São aquelas que capturam o quão } \\
\text { bem a empresa desempenha cada } \\
\text { um dos processos de conexão } \\
\text { com o cliente (Day, 1994, 2001). } \\
\text { Em sua maioria são do tipo } \\
\text { outside-in. A construção de } \\
\text { marca é uma capacidade de } \\
\text { marketing (Hooley et al., 2005; } \\
\text { Kozlenkova et al., 2014). }\end{array}$ & $\begin{array}{l}\text { Capacidade: } \\
\text { Construção da identidade da } \\
\text { marca utilizando atributos da } \\
\text { COI. }\end{array}$ \\
\hline $\begin{array}{l}\text { Processo: } \\
\text { Ações, atividades e rotinas da } \\
\text { empresa para atingir seus } \\
\text { propósitos ou objetivos de } \\
\text { negócios, ou seja, a maneira que } \\
\text { a empresa utiliza para explorar } \\
\text { seus recursos (Ray, Barney \& } \\
\text { Muhanna, 2004). }\end{array}$ & $\begin{array}{l}\text { Processos de marketing: } \\
\text { São as atividades e rotinas inter- } \\
\text { relacionadas de marketing que a } \\
\text { empresa articula para } \\
\text { transformar seus ativos e } \\
\text { recursos em produtos, soluções } \\
\text { e valor para o cliente } \\
\text { (Srivastava et al., 2001). }\end{array}$ & $\begin{array}{l}\text { Processos: } \\
\text { - Para incorporação da COI na } \\
\text { Marca: elementos textuais, } \\
\text { elementos visuais, sentidos, } \\
\text { funcionários, recursos naturais e } \\
\text { recursos culturais. }\end{array}$ \\
\hline
\end{tabular}

Fonte: Autora

O desenvolvimento de escalas demanda diversos processos e cuidados. No capítulo seguinte, serão detalhadas as etapas para construção e validação da escala aqui proposta. 


\section{ASPECTOS METODOLÓGICOS DA PESQUISA EMPÍRICA}

Após a realização da revisão da literatura existente sobre os temas e variáveis relacionadas ao problema de pesquisa, o pesquisador poderá julgar se é valido realizar uma pesquisa de campo sobre a temática estudada (Sampieri, Collado \& Lucio, 2006). Conforme justificado no primeiro capítulo desta tese, há uma lacuna na literatura, ou seja, os estudos disponíveis - apresentados no segundo capítulo - não respondem ao problema de pesquisa aqui levantado. Logo, julga-se pertinente o desenvolvimento de um estudo empírico para atingir os objetivos propostos. Para tal, faz-se necessário o detalhamento do método que será empregado.

O método consiste em uma série de regulamentos organizados para explicar um fenômeno ou resolver determinado problema por meio de teorias ou hipóteses que devem ser testadas e que podem ser comprovadas ou refutadas sempre com o objetivo de gerar conhecimento (Hair, Babin, Money \& Samouel, 2005). Este capítulo dedica-se à apresentação dos procedimentos metodológicos da investigação.

\subsection{Abordagem}

Existem dois enfoques de pesquisa, o quantitativo e o qualitativo (Sampieri et al., 2006). Enquanto o estudo qualitativo busca descobrir, aprofundar, analisar, interpretar e refinar aspectos mais profundos (Sampieri et al., 2006), a abordagem quantitativa almeja responder às questões de pesquisa, assim como testar hipóteses previamente constituídas, delimitando intencionalmente a informação (Sampieri et al., 2006). Por isso, o método qualitativo difere do quantitativo não somente por não utilizar instrumentos estatísticos, mas também pelos instrumentos de coleta de dados (Martins \& Theóphilo, 2009).

A abordagem do estudo deve ser escolhida em função da situação, dos recursos que o pesquisador dispõe, dos objetivos e, principalmente, do problema do estudo em questão (Sampieri et al., 2006). Este estudo tem como objetivo geral o de propor uma escala para mensurar a importância da COI como recurso na estratégia de marca da empresa em processo de internacionalização. Uma escala pode ser definida como um instrumento de mensuração composto por itens que combinados resultam num escore composto e destina-se a revelar níveis 
de variáveis teóricas que não são facilmente observáveis por meios diretos (DeVellis, 2016). Por isso, a abordagem que se mostra adequada para este estudo é a quantitativa.

\subsection{Procedimentos para o desenvolvimento e validação de escalas}

O desenvolvimento de escalas envolve diversos procedimentos desde a especificação do domínio do construto, a geração de itens, o julgamento por especialistas, a validação dos itens, estudos exploratórios, testes piloto, coletas de dados, dentre outros (Churchill, 1979; Mackenzie, Podsakoff \& Podsakoff, 2011) até a aplicação de técnicas estatísticas multivariadas, como análises fatoriais exploratória - AFE - (Lee \& Hooley, 2005) e confirmatória - AFC (Mackenzie et al., 2011). Tais procedimentos apresentam propriedades psicométricas e têm como objetivo assegurar que a nova proposta esteja estruturada com as dimensões adequadas ao construto a que se pretende medir, assim como, garantir que ela seja confiável e válida (Churchill, 1979; Lee \& Hooley, 2005).

Roth \& Diamantopoulos (2009) destacam que muitos estudos de escala envolvendo o construto imagem do país de origem têm executado poucas avaliações de validade e confiabilidade. Dessa maneira, esta tese segue os procedimentos psicométricos recomendados por diversos acadêmicos tais como DeVellis (2017), Churchill (1979), Netemeyer, Bearden \& Sharma (2003), Mackenzie et al. (2011) entre outros.

Churchill (1979) indica 8 passos para desenvolvimento de uma escala: 1) especificação do domínio do construto; 2) geração de uma amostra de itens; 3) primeira coleta de dados; 4) purificação das medidas; 5) nova coleta de dados; 6) análise de confiabilidade; 7) avaliação da validade estatística e 8) desenvolvimento de normas. Optou-se por adaptar e reduzir as etapas propostas por Churchill (1979), por isso, o desenvolvimento da escala contemplou cinco etapas, conforme ilustra a figura 6 . 


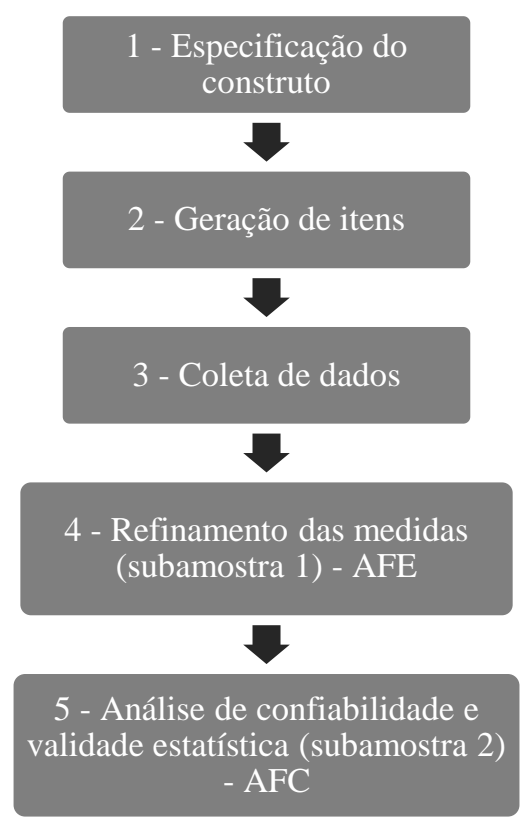

Figura 6 - Etapas do desenvolvimento e validação da escala Fonte: autora com base em Churchill (1979) e Hair et al. (2016)

\subsubsection{Definição do construto}

O passo 1 na construção da escala consiste na definição do conceito, ou seja, o estabelecimento teórico do que se busca mensurar (Churchill, 1979; Mackenzie et al., 2011; DeVellis, 2016). No caso desta tese, é a definição do que se compreende por importância da COI como recurso na estratégia de marca da empresa.

Neste estudo o objetivo é mensurar o construto capacidade de gestão da incorporação da COI à marca, doravante BCOI (branding capability of country of origin incorporation), que reflete a importância conferida pela empresa para usar a COI como um recurso na construção da capacidade de marca. Logo, a BCOI é reflexo da importância que a empresa confere aos elementos visuais, textuais, de sentido, naturais e culturais que se referem a COI, assim como a importância do engajamento dos funcionários na promoção desses elementos. Sua incorporação é realizada mediante os sinais transmitidos na comunicação da identidade da marca em todos os pontos de contato com clientes (site, folhetos, escritórios, show room, estande em feiras), nos produtos (embalagem, matéria-prima e design) (Kapferer, 2003). Como 
a proposta da escala é voltada para verificação da importância do COI na construção da capacidade de gestão da marca, a unidade de análise da escala é a empresa representada por seus gestores (nível tático e estratégico).

\subsubsection{Geração de itens}

Após a definição da proposta do que se pretende mensurar, DeVellis (2017) indica que o pesquisador pode desenvolver o próximo passo. Tal passo versa sobre a construção do instrumento que, por sua vez, deve ser realizado por meio da geração de um grande conjunto de itens que pode fazer parte da escala. Para isso, fez-se necessária a profunda revisão da literatura (Churchill, 1979) permitindo estruturar um quadro com os processos de incorporação do COI que, neste estudo, são também compreendidos como as dimensões da escala de mensuração de importância da COI na estratégia (ver quadro 7).

Com base no quadro 7, foi elaborada a primeira versão de itens para mensurar o construto composta por 6 dimensões e 22 itens. Logo, considera-se o construto para medir a importância da COI na estratégia uma variável latente de $2^{\mathrm{a}}$ ordem que pode ser medida por outros construtos de $1^{\mathrm{a}}$ ordem. Por isso, é um construto multidimensional. Assume-se que a relação entre os construtos e os itens é refletiva, dado que os construtos de $1^{\text {a }}$ ordem são manifestações do uso do COI na estratégia, por isso, espera-se que tais medidas sejam correlacionadas (Jarvis, Mackenzie \& Podsakoff, 2003) e impulsionadas pelo construto latente (DeVellis, 2016). 
Quadro 7 - Processos de incorporação da COI na estratégia da marca

\begin{tabular}{|c|c|c|}
\hline $\begin{array}{l}\text { Processos } \\
\text { (dimensões) }\end{array}$ & $\begin{array}{l}\text { Elementos } \\
\text { (indicadores) }\end{array}$ & Aporte teórico \\
\hline $\begin{array}{lr}\text { Elementos } & \text { textuais: } \\
\text { associação } & \text { de } \\
\text { linguagem } & \end{array}$ & $\begin{array}{l}\text { Idioma, ortografia, pronúncia, siglas, nome } \\
\text { do país, nomes que remetam ao país, } \\
\text { expressões, sinais, grafismos, logo. }\end{array}$ & $\begin{array}{l}\text { Thakor \& Kohli (1996); } \\
\text { Samiee et al. (2005); Florek \& } \\
\text { Insch (2008); Insch \& Florek } \\
\text { (2009); Samiee (2011); } \\
\text { Magnusson et al. (2011a); } \\
\text { Sutter et al. (2014); Sutter et al. } \\
\text { (2015c) Sutter et al (2016a;b) }\end{array}$ \\
\hline $\begin{array}{lr}\text { Elementos visuais: na } \\
\text { comunicação } \\
\text { empresa, por meio da } \\
\text { embalagem } \\
\text { produtos, no design } \\
\text { do produto, na } \\
\text { propaganda } \\
\text { empresa. }\end{array}$ & $\begin{array}{l}\text { Cores, bandeira nacional, cenário, imagens, } \\
\text { símbolos típicos do país (como animais), } \\
\text { cenários naturais ao fundo, endosso com } \\
\text { celebridades ou artista, fotografias, } \\
\text { uniforme dos funcionários. }\end{array}$ & $\begin{array}{l}\text { Thakor \& Kohli (1996); Florek } \\
\text { \& Insch (2008); Insch \& Florek } \\
\text { (2009); Usunier (2011); } \\
\text { Samiee (2011); Sutter et al. } \\
\text { (2014); Sutter et al. (2015c); } \\
\text { Sutter et al. (2016b); } \\
\text { D'Antone \& Merunka (2015). }\end{array}$ \\
\hline Recursos naturais & $\begin{array}{l}\text { Utilização de matérias-primas típicas do } \\
\text { país de origem no processo produtivo, } \\
\text { podendo transformar commodities em } \\
\text { produtos com valor agregado. }\end{array}$ & $\begin{array}{l}\text { Kumar \& Steenkamp (2013); } \\
\text { Florek \& Insch (2008); } \\
\text { Paterlini et al. (2012); Sutter et } \\
\text { al (2014); Sutter et al. (2015b); } \\
\text { Sutter et al. (2016a). }\end{array}$ \\
\hline Recursos culturais & $\begin{array}{l}\text { Construir a identidade de marca da empresa } \\
\text { com base em mitos culturais positivos, } \\
\text { incorporando aspectos culturais do país de } \\
\text { origem que podem adicionar valor à marca. } \\
\text { A cultura de um país refere-se a todas as } \\
\text { crenças, atitudes, aspirações, valores e } \\
\text { mitos mantidos por grande parte da } \\
\text { sociedade de um país, bem como os traços } \\
\text { comportamentais, as regras, costumes e } \\
\text { normas que as pessoas seguem. }\end{array}$ & $\begin{array}{l}\text { Kumar \& Steenkamp (2013); ); } \\
\text { Sutter et al (2014); Paterlini, } \\
\text { Giraldi \& Amui (2012). }\end{array}$ \\
\hline $\begin{array}{l}\text { Sentidos: audição, } \\
\text { olfato e tato }\end{array}$ & $\begin{array}{l}\text { Músicas nacionais no site das duas marcas; } \\
\text { olfato por meio da matéria-prima dos } \\
\text { produtos; tato mediante o alto-relevo nas } \\
\text { embalagens. }\end{array}$ & $\begin{array}{l}\text { Sutter et al. (2016b); D’Antone } \\
\text { \& Merunka (2015); Herz \& } \\
\text { Diamantopoulos (2013b). }\end{array}$ \\
\hline Funcionários & $\begin{array}{l}\text { Capacitação e treinamento dos funcionários } \\
\text { para falar sobre o país de origem da marca. }\end{array}$ & $\begin{array}{l}\text { Kapferer (2003); Usunier } \\
\text { (2011); Sutter et al. (2016a;b). }\end{array}$ \\
\hline
\end{tabular}

Fonte: Autora

A primeira versão de itens para mensurar o construto utilizava uma escala de frequência, em que todos os itens deveriam ser respondidos conforme a seguinte indagação: Com qual frequência a sua empresa... (atribua $1=$ nunca; 7 = sempre). Para tanto, utilizou-se uma escala do tipo likert de 7 pontos. 
Quadro 8 - Dimensões e itens para desenvolvimento de escala de incorporação da COI como recurso

\begin{tabular}{|c|c|}
\hline Dimensão & Item \\
\hline \multirow{4}{*}{ 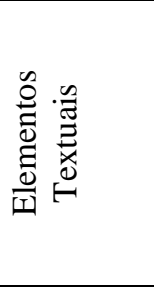 } & $\begin{array}{l}\text { Utiliza nomes de lugares, de pontos turísticos típicos do país de origem ou mesmo bairros } \\
\text { de cidades famosas de seu país (ex.: Ipanema, Copacabana, Foz do Iguaçu, Pantanal, } \\
\text { Amazônia, entre outros) na embalagens de produtos ou no nome dos produtos. }\end{array}$ \\
\hline & $\begin{array}{l}\text { Utiliza expressões tipicamente brasileiras (samba, Cristo Redentor, Axé, jeitinho } \\
\text { brasileiro, carnaval, ....)na comunicação e nos produtos da empresa. }\end{array}$ \\
\hline & Associa o nome de seus produtos a lugares do país de origem da empresa. \\
\hline & Destaca, de forma escrita, atributos que remetem ao Brasil na comunicação do produto. \\
\hline \multirow{5}{*}{ 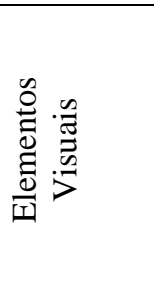 } & Utiliza bandeira brasileira na comunicação do produto. \\
\hline & Utiliza as cores da bandeira brasileira na comunicação ou embalagem do produto. \\
\hline & Utiliza imagens, figuras ou paisagens brasileiras na comunicação do produto. \\
\hline & $\begin{array}{l}\text { Utiliza celebridades, esportistas ou artistas brasileiros (reconhecidos mundialmente) nas } \\
\text { campanhas da empresa. }\end{array}$ \\
\hline & $\begin{array}{l}\text { Utiliza cores do Brasil e/ou figuras que remetam ao Brasil nos uniformes dos funcionários } \\
\text { que fazem contato com os clientes internacionais (em feiras). }\end{array}$ \\
\hline \multirow{3}{*}{ 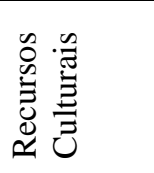 } & Utiliza na comunicação aspectos relacionados à cultura Brasileira. \\
\hline & $\begin{array}{l}\text { Utiliza na comunicação a diversidade de manifestações culturais do Brasil (Ex. o forró, o } \\
\text { carnaval, as celebrações de rua na Bahia, o Círio de Nazaré em Belém). }\end{array}$ \\
\hline & Utiliza no produto aspectos relacionados à miscigenação do povo brasileiro. \\
\hline \multirow{3}{*}{ 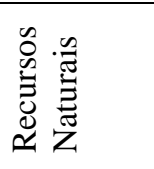 } & Utiliza matéria prima cultivada no país de origem no produto comercializado no exterior. \\
\hline & Promove a utilização dos recursos naturais do seu país na comunicação dos produtos. \\
\hline & $\begin{array}{l}\text { Destaca na comunicação as propriedades específicas proporcionadas pela utilização de } \\
\text { recursos naturais nos produtos. }\end{array}$ \\
\hline \multirow{4}{*}{$\stackrel{\substack{0 \\
:}}{\stackrel{0}{0}}$} & Utiliza músicas nacionais no site institucional. \\
\hline & $\begin{array}{l}\text { Utiliza músicas nacionais no local de contato com o cliente internacional (show room, } \\
\text { escritório ou stading em feira). }\end{array}$ \\
\hline & Estampa em alto-relevo aspectos relacionados a fauna e flora do Brasil no seu produto. \\
\hline & $\begin{array}{l}\text { Utiliza o aroma de essências brasileiras para perfumar os pontos de contato com o cliente } \\
\text { (no produto e no local de comercialização). }\end{array}$ \\
\hline \multirow{3}{*}{ 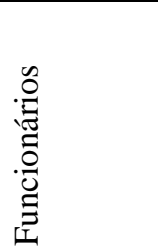 } & $\begin{array}{l}\text { Treina seus funcionários para explicar aos clientes aspectos relacionados à origem do } \\
\text { produto. }\end{array}$ \\
\hline & $\begin{array}{l}\text { Recebem informações sobre a importância dos atributos nacionais na estratégia da } \\
\text { empresa }\end{array}$ \\
\hline & $\begin{array}{l}\text { Os funcionários são motivamos a promover aos clientes o contexto em que os produtos } \\
\text { foram desenvolvidos e fabricados. }\end{array}$ \\
\hline
\end{tabular}

Fonte: Elaborado pela autora.

A primeira versão da escala era composta por 6 dimensões e 22 itens no total (conforme pode ser observado no quadro 8). Ela foi analisada numa reunião do grupo de pesquisas em marketing internacional da ESPM (Escola Superior de Propaganda e Marketing) no dia 23.10.2015. Nessa reunião, estavam presentes 10 pesquisadores dentre eles 1 doutor, 5 doutorandos, 3 mestres e um mestrando. Um dos doutorandos é gestor de projetos da Apex, por isso, tem experiência prática com o uso da COI por empresas em processo de internacionalização.

Os pesquisadores discutiram e analisaram em conjunto todos os itens da escala. Eles indicaram frases que poderiam ser reescritas, ajustes estruturais, de semântica e de significado 
das frases que foram feitos para melhor compreensão por parte do respondente e para diminuir a redundância dos itens (DeVellis, 2016). O grupo participou de forma bastante ativa e contribuiu de forma expressiva para a melhoria da escala. Um ponto que foi discutido referiase à decisão de indicação de exemplos nos itens. Enquanto alguns pesquisadores acharam que deveriam ser excluídos, outros consideraram importante deixar os exemplos, para que os respondentes não tivessem dúvidas. Por isso, os exemplos permaneceram em alguns itens.

Na dimensão elementos visuais, verificou-se que não havia um item que abordasse a imagem de celebridades e personalidades do país. Portanto, adicionou-se o seguinte item “associa o nome de seus produtos com nome de personalidades/ícones do país (Ex.: Café Pelé)". Itens foram adicionados nas dimensões: recursos culturais (1), recursos naturais (2), sentidos (1), funcionários (2) e elementos textuais (1). A escala passou a ter 29 itens. Os novos itens e os que foram modificados estão destacados no quadro 9.

Foi realizada uma nova rodada de análise das assertivas e de seu conteúdo entre 04.11.2015 e 10.11.2015. Dessa rodada participaram 15 estudantes de doutorado que sugeriram a simplificação das frases. Eles também apontaram que as dimensões elementos textuais e elementos visuais se confundiam, pois, uma empresa pode utilizar tanto os aspectos visuais quanto textuais de uma mesma imagem. De acordo com a maioria deles, as duas dimensões poderiam ser unificadas para não confundir os respondentes.

Realizou-se também um estudo com experts da área, pesquisadores e especialistas no tema para realizar a validação de face das dimensões identificadas e acrescentar, ou mesmo excluir, indicadores que não tinham sido identificados na literatura. Em estudos que se propõem a construir e validar uma escala, é indispensável a etapa de validação de face e conteúdo antes do desenvolvimento da escala. Isso ocorre em função da necessidade de se garantir que os itens da escala representem adequadamente o construto que se pretende medir (Rossiter, 2002). Assim, recorreu-se ao auxílio de quatro especialistas que são pesquisadores da área de marketing habituados a desenvolver escalas em seus estudos. O objetivo dessa consulta foi realizar a necessária validação de conteúdo dos itens e dimensões. 
Quadro 9 - Itens após reunião com grupo de pesquisa

\begin{tabular}{|c|c|}
\hline Dimensão & Itens - Com qual frequência a sua empresa (atribua 1 = nunca; 7 = sempre) \\
\hline \multirow{5}{*}{ 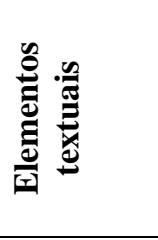 } & $\begin{array}{l}\text { Utiliza nomes de lugares, de pontos turísticos típicos do país de origem ou mesmo bairros de cidades } \\
\text { famosas de seu país. }\end{array}$ \\
\hline & Utiliza expressões tipicamente brasileiras na comunicação e nos produtos da empresa. \\
\hline & Associa o nome de seus produtos a lugares do país de origem da empresa. \\
\hline & Destaca, de forma escrita, atributos que remetem ao Brasil na comunicação do produto. \\
\hline & Associa o nome de seus produtos com nome de personalidades/ícones do país (Ex.: Café Pelé). \\
\hline \multirow{5}{*}{ 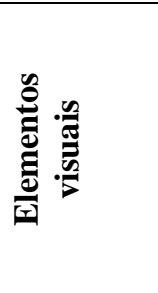 } & Utiliza bandeira brasileira na comunicação do produto. \\
\hline & Utiliza as cores da bandeira brasileira no produto. \\
\hline & Utiliza imagens, figuras ou paisagens do Brasil. \\
\hline & $\begin{array}{l}\text { Utiliza celebridades, esportistas ou artistas brasileiros (reconhecidos mundialmente) nas } \\
\text { campanhas da empresa. }\end{array}$ \\
\hline & $\begin{array}{l}\text { Utiliza cores do Brasil e/ou figuras que remetam ao Brasil nos uniformes dos funcionários que } \\
\text { fazem contato com os clientes internacionais (em feiras). }\end{array}$ \\
\hline \multirow{4}{*}{ U } & Utiliza aspectos relacionados à cultura Brasileira. \\
\hline & Utiliza a diversidade de manifestações culturais do Brasil. \\
\hline & Utiliza aspectos relacionados à miscigenação do povo brasileiro. \\
\hline & Utiliza aspectos relacionados à literatura do país de origem da en \\
\hline \multirow{5}{*}{ 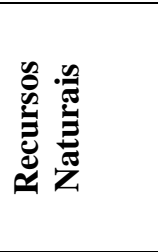 } & Utiliza no produto recursos naturais do Brasil. \\
\hline & Utiliza na comunicação recursos naturais do Brasil. \\
\hline & Divulga na comunicação a utilização de recursos naturais brasileiras. \\
\hline & $\begin{array}{l}\text { Destaca na comunicação benefícios proporcionados pela utilização de recursos naturais brasileiras nos } \\
\text { produtos. }\end{array}$ \\
\hline & Reforça como fator de diferenciação dos produtos a utilização de recursos naturais brasileiras. \\
\hline \multirow{5}{*}{ : } & Utiliza músicas nacionais no site institucional. \\
\hline & Utiliza músicas nacionais no local de contato com o cliente internacional. \\
\hline & Estampa em alto-relevo aspectos relacionados a fauna e flora do Brasil no seu produto. \\
\hline & $\begin{array}{l}\text { É importante utilizar o aroma de essências do país de origem para perfumar o local de } \\
\text { comercialização dos produtos (loja, show room, stand em feira, escritório) }\end{array}$ \\
\hline & $\begin{array}{l}\text { É importante utilizar aroma e essências do país de origem da empresa para perfumar } \\
\text { o produto. }\end{array}$ \\
\hline \multirow{5}{*}{ } & Treina seus funcionários para explicar aos clientes aspectos relacionados à origem do produto. \\
\hline & $\begin{array}{l}\text { Passa informações aos funcionários sobre a importância dos atributos brasileiros na estratégia } \\
\text { da empresa. }\end{array}$ \\
\hline & $\begin{array}{l}\text { Motiva os funcionários para falar aos clientes sobre especificidades do local em que os produtos } \\
\text { foram desenvolvidos e fabricados. }\end{array}$ \\
\hline & $\begin{array}{l}\text { Reconhece a importância dos funcionários transmitirem informações aos clientes sobre aspectos } \\
\text { relacionados ao Brasil. }\end{array}$ \\
\hline & Considera importante que o funcionário conheça a cultura brasileira. \\
\hline
\end{tabular}

Fonte: Autora

Os pesquisadores de marketing receberam a $3^{\text {a }}$ versão da escala com 29 itens entre 11.11.2015 e 23.11.2015 e teceram seus comentários com sobre o conteúdo da escala. O quadro 10 apresenta a instituição de ensino de cada pesquisador.

Quadro 10 - Pesquisadores que participaram da validação de conteúdo

\begin{tabular}{|c|c|c|}
\hline Pesquisador & Instituição & Tempo de experiência com pesquisa quantitativa \\
\hline A & ESPM & 10 anos \\
\hline B & Uninove & 41 anos \\
\hline C & Uninove & 11 anos \\
\hline D & FEA-USP & 40 anos \\
\hline
\end{tabular}

Fonte: Autora. 
O pesquisador A não fez comentário sobre os itens, mas chamou atenção para a importância de se decidir e explicitar quem serão os raters (os juízes) e quem serão as unidades de análise para aplicação da escala. No entendimento dele, em conformidade com que se almeja neste estudo, as unidades de análise serão as empresas. No entanto, o pesquisador A apontou que as empresas podem ter diversas divisões de negócios, ou mesmo diferentes linhas de produto com variabilidade na incorporação da COI. Nesse sentido, caso a escala seja aplicada em uma empresa multinacional o pesquisador recomendou que se especifique ao gestor para responder a pesquisa tomando como referência a principal linha de produtos comercializada internacionalmente.

De acordo com análise do pesquisador B, "parece que a escala está muito legal e bem fundamentada". Ele sugeriu algumas mudanças, como a inclusão da frase "de forma escrita" em alguns itens da dimensão elementos textuais, por exemplo: "utiliza na comunicação, de forma escrita, nomes de lugares, pontos turísticos do Brasil ou bairros famosos (por exemplo: Ipanema, Copacabana, Cristo Redentor, Pantanal, Amazônia, entre outros)" e a unificação das dimensões elementos visuais e textuais.

O pesquisador $C$ sugeriu alguns ajustes na redação das assertivas e recomendou que se realizasse a validade de face com, pelo menos, 3 gestores de empresas (potenciais respondentes). O pesquisador D também alertou para a importância de se consultar gestores para fazer a validade de face, assim como alertou que algumas assertivas da escala estavam redigidas como dicotômicas e não poderiam ser respondidas por meio de frequência. Ele sugeriu que se fizesse a pergunta de forma dicotômica, ou seja, se a empresa usa o elemento e responder sim ou não, depois perguntar quão importante é tal utilização para a estratégia da empresa. Para tanto, ele sugeriu a utilização de escala de diferencial semântico, em que 1 significa nada importante (desimportante) e 7, extremamente importante.

Para dar confiabilidade ao processo de desenvolvimento da escala, o pesquisador D sugeriu a realização da validade de conteúdo e de face com potenciais respondentes (gestores de empresas em processo de internacionalização), por meio de entrevistas com o questionário em mãos, para verificar a apresentação dos itens e a coerência entre os temas da escala. Ele recomendou que as dimensões fossem explicadas aos gestores e que se acompanhasse seu preenchimento para auxiliar o respondente no caso de dúvidas e anotar os comentários feitos por eles. Os apontamentos do pesquisador D e C sobre a validade de face e conteúdo, estão em linha com os postulados de Rossiter (2002) e foram aplicados neste estudo. 
Após validação de conteúdo (Hair et al., 2005), a pesquisadora revisou os apontamentos recomendados pelos pesquisadores e optou por juntar as dimensões elementos textuais e elementos visuais. Outra decisão tomada foi a modificação das assertivas para que fosse utilizada uma escala de discordância. As dimensões e itens também foram ajustados para se trabalhar com uma versão aplicável com gestores de empresas em processo de internacionalização de qualquer nacionalidade, conforme pode ser analisado no quadro 11. Portanto, a escala foi reduzida e passou de 29 para 27 itens.

\section{Quadro 11 - Itens após validação de conteúdo com pesquisadores}

\begin{tabular}{|c|c|}
\hline Dimensão & $\begin{array}{l}\text { Pensando na principal linha de produto comercializada pela sua empresa internacionalmente, indique } \\
\text { o grau de concordância atribuído às afirmações abaixo. Considerando a escala de } 1 \text { até } 7 \text {, onde } 1 \\
\text { significa Discorda Fortemente e } 7 \text { Concorda Fortemente com a afirmação. }\end{array}$ \\
\hline \multirow{8}{*}{ 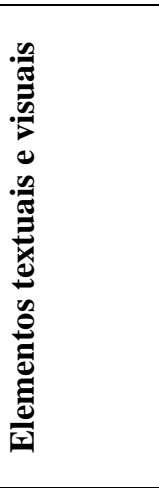 } & $\begin{array}{l}\text { É importante utilizar nome de lugares, pontos turísticos ou bairros famosos do país de origem da } \\
\text { empresa. }\end{array}$ \\
\hline & É importante utilizar expressões tipicamente do país na comunicação e nos produtos da empresa. \\
\hline & É importante associar o nome de seus produtos a lugares do país de origem da empresa. \\
\hline & $\begin{array}{l}\text { É importante destacar, de forma escrita, atributos que remetem ao país de origem na comunicação do } \\
\text { produto. }\end{array}$ \\
\hline & É importante utilizar desenho da bandeira do país de origem da empresa. \\
\hline & $\begin{array}{l}\text { É importante utilizar cores da bandeira do país de origem da empresa nos pontos de contato com os } \\
\text { clientes. }\end{array}$ \\
\hline & É importante utilizar imagens, figuras ou paisagens do país de origem da empresa. \\
\hline & $\begin{array}{l}\text { É importante utilizar imagem de pessoas famosas do país de origem da empresa que são reconhecidas } \\
\text { mundialmente. }\end{array}$ \\
\hline \multirow{4}{*}{ 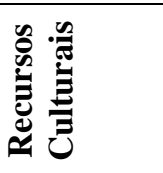 } & É importante utilizar aspectos relacionados aos hábitos e costumes do país de origem da empresa. \\
\hline & É importante utilizar a diversidade de manifestações culturais do país de origem da empresa. \\
\hline & É importante utilizar aspectos relacionados ao povo do país de origem da empresa. \\
\hline & É importante utilizar aspectos relacionados à literatura do país de origem da empresa. \\
\hline \multirow{5}{*}{ 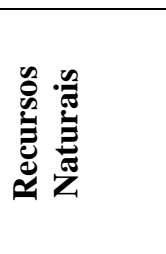 } & É importante utilizar recursos naturais do país de origem da empresa. \\
\hline & É importante destacar os recursos naturais típicos do país de origem da empresa. \\
\hline & É importante utilizar recursos da naturais típicos do país de origem da empresa. \\
\hline & $\begin{array}{l}\text { É importante destacar os benefícios proporcionados pela utilização de recursos naturais típicos do } \\
\text { país de origem da empresa. }\end{array}$ \\
\hline & É importante destacar recursos naturais do país de origem da empresa como fator de diferenciação. \\
\hline \multirow{5}{*}{ 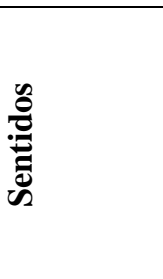 } & É importante utilizar músicas do país de origem da empresa no site internacional \\
\hline & É importante utilizar músicas do país de origem da empresa nas propagandas internacionais. \\
\hline & $\begin{array}{l}\text { É importante utilizar músicas do país de origem da empresa no local de contato com o cliente (show } \\
\text { room, escritório ou stand em feira). }\end{array}$ \\
\hline & $\begin{array}{l}\text { É importante utilizar o aroma de essências do país de origem para perfumar o local de } \\
\text { comercialização dos produtos (loja, show room, stand em feira, escritório) }\end{array}$ \\
\hline & É importante utilizar aroma e essências do país de origem da empresa para perfumar o produto. \\
\hline \multirow{5}{*}{ : } & $\begin{array}{l}\text { É importante treinar sua equipe de vendas para explicar aos clientes aspectos relacionados ao do país } \\
\text { de origem da empresa. }\end{array}$ \\
\hline & $\begin{array}{l}\text { É importante transmitir informações aos funcionários sobre a importância das características do país } \\
\text { de origem da empresa que são incorporadas à oferta. }\end{array}$ \\
\hline & $\begin{array}{l}\text { É importante motivar os funcionários a falar aos clientes sobre especificidades do país de origem da } \\
\text { empresa. }\end{array}$ \\
\hline & $\begin{array}{l}\text { É importante reconhecer a importância dos funcionários transmitirem informações aos clientes sobre } \\
\text { aspectos relacionados ao do país de origem da empresa }\end{array}$ \\
\hline & É importante analisar se o funcionário conhece a cultura do país de origem da empresa. \\
\hline
\end{tabular}


Deu-se continuidade ao processo de geração de itens por meio da validação de face com gestores. Entre 22.11.2015 e 07.12.2015 foram realizados 20 contatos com gestores de projetos setoriais e de empresas em processo de internacionalização. Desses contatos, 8 atenderam à pesquisadora e destacaram pontos importantes para o desenvolvimento da escala.

Quadro 12 - Gestores que participaram da validação de face

\begin{tabular}{|c|l|l|}
\hline Gestor & \multicolumn{1}{|c|}{ Setor } & \multicolumn{1}{c|}{ Cargo } \\
\hline A & Serviços - consultor de marcas & Consultor \\
\hline B & Alimentos - cereais & Proprietário \\
\hline C & $\begin{array}{l}\text { Alimentos - Abicab (indústria } \\
\text { Brasileira de chocolates, cacau, } \\
\text { amendoim, balas e derivados). }\end{array}$ & Gestor de Exportação \\
\hline D & Alimentos - Chocolate & Gestor de vendas \\
\hline E & Moda - Acessórios & Proprietário - designer \\
\hline F & $\begin{array}{l}\text { Alimentos - Biscoitos, café, } \\
\text { chocolates. }\end{array}$ & Gestor de Exportação \\
\hline G & Cosméticos & Gestor de logística \\
\hline H & Cosméticos & Gestor de inovação \\
\hline
\end{tabular}

Fonte: Autora.

O gestor A é consultor de marca e já desenvolveu dois projetos de marcas setoriais para a Apex-Brasil. Ele não apresentou dúvidas ao responder as assertivas e sugeriu acrescentar dois itens na dimensão elementos textuais e visuais, a saber: "É importante utilizar a sigla do país de origem da empresa" e "É importante destacar a frase made-in". No último item, ele empregou o verbo destacar em vez de utilizar, pois todos os produtos feitos no Brasil são obrigados por lei a especificar sua origem.

$\mathrm{O}$ gestor $\mathrm{B}$ conseguiu responder às questões em 6 minutos. Ele apontou como sugestão inserir perguntas para, no caso de a empresa utilizar os atributos da COI, indagar os motivos que levaram a empresa a fazer tal movimento, como chegou a decisão de incorporação da COI e qual tem sido o valor disso no processo de exportação. Tais questionamentos mostram-se relevantes, no entanto, são de cunho qualitativo e não estão dentro do escopo do que a escala se propõe a medir, por isso, não foram incorporados.

O gestor C não conseguiu cronometrar o tempo de resposta, pois ao ler cada item, fez diversas observações e deu inúmeros exemplos de empresas no setor em que trabalha que utilizam a COI de acordo com as assertivas. Por exemplo, na dimensão outros sentidos, no item "É importante utilizar o aroma de essências brasileiras para perfumar o local de comercialização dos produtos (loja, show room, stand em feira, escritório)", ele mencionou a Aquim 
gastronomia como exemplo. Quanto ao item da dimensão recursos culturais "É importante utilizar a diversidade de manifestações culturais do país de origem da empresa", ele apontou algumas empresas que começam a fazer essa comunicação (Nugali e Harald) que começam a fazer, com o cacau, esse tipo de comunicação.

O gestor D respondeu ao questionário em 8 minutos. Não apresentou dificuldades em suas respostas e também não sugeriu novos itens. Mas apresentou diversos exemplos das dimensões de incorporação na COI que identificou na estratégia da empresa em que trabalha, como na dimensão recursos naturais, o tipo e a procedência do cacau utilizado, e, na dimensão funcionários, os treinamentos que recebem para orientar os clientes sobre as origens do produto, entre outros.

O gestor E gerencia e desenvolve produtos para uma rede de acessórios de moda. Ele demorou 9 minutos para responder ao questionário e não apresentou dúvidas, tampouco sugeriu novos itens para a escala.

O gestor $\mathrm{F}$ também não apresentou dificuldades para responder os itens da escala e fez diversas observações quanto à veracidade dos itens. Por exemplo, no item de recursos naturais "É importante destacar os benefícios proporcionados pela utilização de recursos naturais típicos do país de origem da empresa", comentou que muitas empresas fazem a comunicação dos benefícios do processo de produção, do cultivo e das propriedades terapêuticas dos recursos naturais brasileiros por meio de certificações, remetendo às IGs, conceito que foi analisado na revisão da literatura.

O gestor $\mathrm{G}$ algumas sugestões. Para ele, as seguintes assertivas da dimensão elementos textuais e visuais são redundantes: "É importante utilizar expressões tipicamente do país na comunicação e nos produtos da empresa"; "É importante associar o nome de seus produtos a lugares do país de origem da empresa" e "É importante destacar, de forma escrita, atributos que remetem ao país de origem na comunicação do produto". Elas já são representadas pela assertiva: "É importante utilizar nome de lugares, pontos turísticos ou bairros famosos do país de origem da empresa". Na dimensão sentidos (auditivo, tátil e olfativo), o gestor G sugeriu substituir o termo aroma de essências por fragrâncias e essências, pois, de acordo com ele, utiliza-se o termo aroma para cheiros relacionados ao paladar. Já o termo essência é utilizado para a concentração de um determinado extrato. As recomendações foram consideradas.

A última contribuição do gestor $\mathrm{G}$ foi feita para a dimensão recursos culturais no item "É importante utilizar a diversidade de manifestações culturais do país de origem da empresa". 
Para o gestor, seria interessante explorar o conceito de conhecimento tradicional na escala. Tal conceito refere-se ao saber fazer específico e ao conhecimento contidos no estilo de vida de uma comunidade local. Ou seja, o conhecimento tradicional versa sobre a informação ou prática individual ou coletiva de uma comunidade indígena ou de uma comunidade local, com valor real ou potencial, associada ao patrimônio genético (Medida Provisória, 2001).

Essa foi uma recomendação valiosa, mas muito específica para setores, como o de cosméticos, em que o conhecimento tradicional está presente. Sobretudo, acredita-se que poucos respondentes de outros setores reconheceriam o significado do termo. Por isso, decidiuse manter a estrutura dos itens da dimensão recursos culturais. Mesmo assim, o gestor G sugeriu inserir um item para a dimensão de recursos culturais relacionado às peças de artes produzidas pelos cidadãos do país.

De acordo com o gestor $\mathrm{H}$, a empresa em que ele trabalha não faz menção explícita ao nome do País, mas se apoia no termo "biodiversidade brasileira" e Amazônia. Ele sugeriu incluir um item com o termo "biodiversidade brasileira". Por exemplo: "É importante utilizar no produto recursos da biodiversidade brasileira". Para essa dimensão a sugestão de utilizar o termo biodiversidade mostrou-se pertinente. Por isso, um dos itens da dimensão de recursos naturais foi alterado para biodiversidade do país de origem.

No que diz respeito à dimensão outros sentidos, o gestor $\mathrm{H}$ indicou que os itens se mostram bastante pertinentes e comentou que a empresa em que ele trabalha sempre investiu em projetos de cultura exclusivamente brasileira, projetos Musicais, teatro, entre outros. Ele mencionou que em 2015, a empresa contratou uma cantora brasileira para compor a trilha sonora para a nova campanha publicitaria. $\mathrm{O}$ gestor $\mathrm{H}$ recomendou a inclusão do seguinte item na dimensão sentidos: "é importante utilizar ferramentas que remetem ao sensorial olfativo de produtos, fragrância ou essências típicas do Brasil”. Tal sugestão está alinhada com um comentário que o gestor $\mathrm{G}$ fez sobre a substituição do termo aroma de essências por fragrâncias e essências. Como a sugestão do gestor $\mathrm{G}$ foi acatada, não se identificou a necessidade de gerar um novo item. Com relação à dimensão funcionários, o gestor $\mathrm{H}$ reconheceu a importância das assertivas para verificar se a empresa reconhece a importância da COI na sua cultura organizacional e se isso está firmado dentro da sua estratégia. Ele sugeriu questões, que cabem, no entanto, em estudos qualitativos.

Com base nos apontamentos dos gestores, alguns ajustes foram realizados. Na dimensão elementos textuais e visuais, foram retirados os itens: "É importante utilizar expressões 
tipicamente do país na comunicação e nos produtos da empresa"; "É importante associar o nome de seus produtos a lugares do país de origem da empresa" e "É importante destacar, de forma escrita, atributos que remetem ao país de origem na comunicação do produto”. Esses itens estavam, de acordo com alguns gestores e pesquisadores, repetitivos. Decidiu-se revisá-los antes da primeira coleta de dados para evitar redundância conforme recomendam Lee \& Hooley (2005). Como resultado das recomendações, adicionou-se o item “ É importante utilizar a sigla ou nome do país de origem da empresa".

Quadro 13 - Itens após validação de face com gestores

\begin{tabular}{|c|c|}
\hline & Assertivas \\
\hline \multirow{6}{*}{ 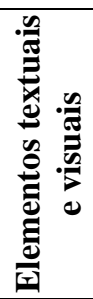 } & Utilizar nome de lugares, pontos turísticos ou bairros famosos do país de origem da empresa. \\
\hline & Utilizar a sigla ou nome do país de origem da empresa. \\
\hline & Utilizar desenho da bandeira do país de origem da empresa. \\
\hline & Utilizar cores da bandeira do país de origem da empresa nos pontos de contato com os clientes. \\
\hline & Utilizar imagens, figuras ou paisagens do país de origem da empresa. \\
\hline & $\begin{array}{l}\text { Utilizar imagem de pessoas famosas do país de origem da empresa que são reconhecidas } \\
\text { mundialmente. }\end{array}$ \\
\hline \multirow{5}{*}{ U气 } & Utilizar aspectos relacionados aos hábitos e costumes do país de origem da empresa. \\
\hline & Utilizar a diversidade de manifestações culturais do país de origem da empresa. \\
\hline & Utilizar aspectos relacionados ao povo do país de origem da empresa. \\
\hline & Utilizar aspectos relacionados à literatura do país de origem da empresa. \\
\hline & Utilizar aspectos relacionados às artes produzidas por cidadãos do país de origem da empresa. \\
\hline \multirow{5}{*}{ 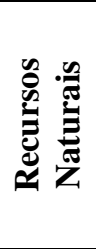 } & Utilizar recursos naturais do país de origem da empresa. \\
\hline & Destacar os recursos naturais típicos do país de origem da empresa. \\
\hline & Utilizar recursos da biodiversidade do país de origem da empresa. \\
\hline & $\begin{array}{l}\text { Destacar os benefícios proporcionados pela utilização de recursos naturais típicos do país de origem } \\
\text { da empresa. }\end{array}$ \\
\hline & Destacar recursos naturais do país de origem da empresa como fator de diferenciação. \\
\hline \multirow{5}{*}{ 告 } & Utilizar músicas do país de origem da empresa no site internacional \\
\hline & Utilizar músicas do país de origem da empresa nas propagandas internacionais. \\
\hline & $\begin{array}{l}\text { Utilizar músicas do país de origem da empresa no local de contato com o cliente (show room, } \\
\text { escritório ou stand em feira). }\end{array}$ \\
\hline & $\begin{array}{l}\text { Utilizar fragrâncias e essências do país de origem da empresa para perfumar o ponto de contato com } \\
\text { o cliente (loja, show room, stand em feira, escritório). }\end{array}$ \\
\hline & Utilizar fragrâncias e essências do país de origem da empresa para perfumar o produto. \\
\hline \multirow{5}{*}{ 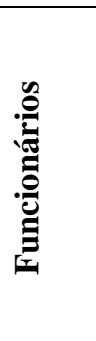 } & $\begin{array}{l}\text { Treinar sua equipe de vendas para explicar aos clientes aspectos relacionados ao do país de origem da } \\
\text { empresa. }\end{array}$ \\
\hline & $\begin{array}{l}\text { Transmitir informações aos funcionários sobre a importância das características do país de origem } \\
\text { da empresa que são incorporadas à oferta. }\end{array}$ \\
\hline & Motivar os funcionários a falar aos clientes sobre especificidades do país de origem da empresa. \\
\hline & $\begin{array}{l}\text { Reconhecer a importância dos funcionários transmitirem informações aos clientes sobre aspectos } \\
\text { relacionados ao do país de origem da empresa }\end{array}$ \\
\hline & Analisar se o funcionário conhece a cultura do país de origem da empresa. \\
\hline
\end{tabular}


O item "É importante utilizar aspectos relacionados às artes produzidas por cidadãos do país de origem da empresa" foi acrescentado na dimensão de recursos culturais. Em um item da dimensão recursos culturais, substituiu-se o termo recursos naturais por biodiversidade e, nas assertivas da dimensão sentidos, substituiu-se termo aroma de essências por fragrâncias e essências. Com esses ajustes, foi possível verificar que a escala estava coerente com os propósitos almejados.

O quadro 14 apresenta o processo de geração de itens da escala desde a revisão da literatura até a validação de face com gestores. O processo mostrou-se bastante enriquecedor, dado que no início a escala era composta por 6 dimensões e 22 itens, e, ao final dessa etapa passou a ser constituída por 5 dimensões e 26 itens.

Quadro 14 - Processo de geração de itens

\begin{tabular}{|l|l|l|l|}
\hline Etapa de geração de itens & $\begin{array}{l}\text { No de } \\
\text { dimensões }\end{array}$ & $\begin{array}{l}\text { No de } \\
\text { itens }\end{array}$ & Dimensões e total de itens por dimensão \\
\hline $\begin{array}{l}\text { Pela pesquisadora, com base em } \\
\text { estudo exploratório (estudo de caso) } \\
\text { e revisão da literatura. }\end{array}$ & 6 & 22 & $\begin{array}{l}\text { - Elementos Textuais (4); } \\
\text { - Elementos Visuais (5); } \\
\text { - Recursos Culturais (3); } \\
\text { - Recursos Naturais (3); } \\
\text { - Sentidos: auditivo, olfativo e de tato (4); } \\
\text { - Funcionários (3). }\end{array}$ \\
\hline $\begin{array}{l}\text { Após reunião com grupo de } \\
\text { pesquisadores - 10 pesquisadores. }\end{array}$ & 6 & 29 & $\begin{array}{l}\text { - Elementos Textuais (5); } \\
\text { - Elementos Visuais (5); } \\
\text { - Recursos Culturais (4); } \\
\text { - Recursos Naturais (5); } \\
\text { - Sentidos: auditivo, olfativo e de tato (5); } \\
\text { - Funcionários (5). }\end{array}$ \\
\hline $\begin{array}{l}\text { Após recomendação de 15 } \\
\text { doutorandos }\end{array}$ & 6 & & \\
- Elementos Textuais (5); \\
- Elementos Visuais (5); \\
- Recursos Culturais (4); \\
- Recursos Naturais (5); \\
- Sentidos: auditivo, olfativo e de tato (5); \\
- Funcionários (5).
\end{tabular}

Fonte: Autora. 
Cabe destacar que, após o desenvolvimento dos itens, duas dimensões foram unificadas. Logo, as hipóteses H5 (A importância da COI como recurso na estratégia da empresa é manifestada por meio da incorporação de elementos textuais do país de origem na marca) e H6 (A importância da COI como recurso na estratégia da empresa é manifestada por meio da incorporação de elementos visuais do país de origem na marca) passaram a ser representadas pela H5: A importância da COI como recurso na estratégia da empresa é manifestada por meio da incorporação de elementos textuais e visuais do país de origem na marca.

Decidiu-se partir para o estudo quantitativo a fim de testar a escala e refinar os itens, por meio de avaliações estatísticas e análise de possíveis exclusões de assertivas. O item seguinte detalha o processo de amostragem e coleta de dados.

\subsubsection{Amostra, coleta de dados e técnica de coleta de dados}

População, ou universo, é o conjunto de indivíduos ou objetos que apresentam características em comum, e amostra é um subconjunto da população (Martins \& Theóphilo, 2007). Nesta tese, a população é composta por executivos que trabalham em empresas em processo de internacionalização e que têm condições para representa-las. Logo, o executivo, para ser apto a participar do estudo, precisava trabalhar numa empresa com algum tipo de operação internacional (exportação, ponto de distribuição, manufatura, subsidiária) e ter conhecimento sobre tal operação.

Sabe-se que a amostra é uma parcela convenientemente selecionada do universo, ou seja, é um subconjunto da população. O processo de amostragem desta tese foi feito de forma não probabilística e por conveniência. Malhotra (2012), sustenta que apesar de não utilizar a seleção aleatória, a amostra por conveniência procura obter uma seleção de elementos que apresente uma boa estimativa das características da população.

Para a realização deste estudo, foi necessária uma coleta em uma população que atingisse um número amostral suficiente para ser dividido em duas subamostras para realizar testes exploratórios e confirmatórios (DeVellis, 2016). Seguindo os procedimentos psicométricos, a subamostra 1 foi utilizada a fim de realizar a análise fatorial exploratória e com a subamostra 2 realizou-se a análise fatorial confirmatória e a modelagem de equações estruturais. Segundo Hair, Black, Babin, Anderson \& Tatham (2009), a regra geral para realizar 
a AFE é que a amostra tenha no mínimo cinco e no máximo dez vezes mais observações do que o número de itens a serem analisados.

Com o processo de desenvolvimento dos itens, validação de face e de conteúdo, chegouse a 26 itens para mensurar a variável latente almejada. Logo, a amostra mínima para realizar a AFE seria de 130 e a máxima de 260.

Para estimar o tamanho amostral mínimo para a subamostra 2, a qual foi utilizada para realizar a AFC e a MEE no PLS-PM, empregou-se o software G*POWER 3.1.9.2 (Faul, Erdfelder, Buchner \& Lang, 2009). Como critério, adotou-se tamanho do efeito grande $(0,05)$, poder do teste $(1-\beta)=0,95$ (Cohen, 1998) e apenas um preditor (todos os construtos de $1^{\mathrm{a}}$ ordem - as dimensões - recebem apenas uma seta). O G*POWER 3.1.9.2 indicou que a amostra mínima para a subamsotra 2 é de 89 casos. No entanto, para se ter um modelo mais consistente, pode-se trabalhar com uma amostra duas ou três vezes maior que a indicada pelo $\mathrm{G}^{*}$ Power (Ringle, Silva \& Bido, 2014), pois amostras maiores podem aumentar a generalização das conclusões atingidas por meio da análise fatorial (DeVellis, 2016). Assim, a amostra mínima adequada para análise de dados desta pesquisa deveria contemplar 140 casos para a AFE, somados a 89 casos para a AFC e MEE, totalizando 229 casos.

O instrumento utilizado para coleta de dados neste estudo é o levantamento ou survey, que se trata de um conjunto ordenado e consistente de perguntas a respeito das variáveis do estudo (Martins \& Theóphilo, 2007; Forza, 2002). Ademais, o levantamento mostra-se apropriado para os casos em que o pesquisador deseja responder questões sobre a distribuição de uma variável ou das relações entre características de pessoas ou grupos (Martins e Theóphilo, 2007). Dessa forma, tal estratégia de pesquisa mostrou-se apropriada para os propósitos desta tese.

O método de coleta de dados primários ocorreu por meio de aplicação de um questionário. Os executivos foram acessados em MBAs da FIA, ESPM e FGV. Para tanto, utilizou-se um questionário estruturado visando, de maneira geral, padronizar o processo de coleta de dados (Malhotra, 2012). Grande parte das questões do questionário tiveram como proposta mensurar as variáveis de interesse, algumas categorizar e outras qualificar o objeto sob investigação (Sampieri et al., 2006). O instrumento foi elaborado com base nos seguintes preceitos de Forza (2002): a) definição da forma como as perguntas devem ser feitas para coletar as informações para cada conceito específico; b) decisão sobre a escala em que as 
respostas devem ser colocadas; c) identificação do entrevistado apropriado para responder o instrumento.

As questões formuladas foram predominantemente fechadas - com alternativas fixas do tipo: nominal ou intervalar com a utilização da escala Likert de 7 pontos. Optou-se pela escala Likert, cujo emprego, em procedimentos que envolvem muitos itens, como é o caso do instrumento desta tese, é recomendado para a redução do tamanho dos questionários e para facilitar ao respondente apontar seu grau de concordância com a afirmação (Costa, 2011). O apêndice A mostra o instrumento que foi aplicado.

Foram realizadas 3 rodadas de pré-teste para ajustar a formatação do instrumento (layout e linguagem da pesquisa) na plataforma Qualtrics com o intuito de facilitar o processo de resposta. Cada rodada de pré-teste foi conduzida com pesquisadores e gestores de empresas com operações internacionais: a primeira rodada 5 pesquisadores; a segunda, com 6 pesquisadores; a terceira com 10 gestores de empresas.

Depois do pré-teste, deu-se início à coleta de dados, que foi realizada entre 01.04.2016 a 28.04.2016, com executivos de empresas em processo de internacionalização atuando em áreas de nível tático ou estratégico. Dos 612 questionários respondidos, 457 foram considerados válidos. Os demais questionários não haviam sido integralmente preenchimentos, razão pela qual foram descartados. A amostra foi dividida em duas subamostras (subamostra $1 \mathrm{n}=219$ observações; subamostra $2 \mathrm{n}=238$ ) para concretização das análises multivariadas.

\subsubsection{Refinamento das medidas - AFE}

Para purificar os dados e verificar a dimensionalidade das variáveis, a literatura indica a utilização de um método multivariado de análise de interdependência (Hair et al., 2009): a análise fatorial exploratória. Tal análise identifica, dentre as assertivas, categorias com significados similares (DeVellis, 2016), pois verifica a correlação entre os itens relevantes (Lee \& Hooley, 2005). A AFE, portanto, busca analisar a estrutura de um conjunto de variáveis, para refinar a escala, apurar a confiabilidade dos fatores e examinar as relações entre as variáveis com o objetivo de propor uma estrutura fatorial inicial (Gerbing \& Anderson, 1988; Netemeyer et al, 2003). 
Assim, a AFE permite ao pesquisador determinar o número de fatores (dimensões) subjacentes a um conjunto de itens para que procedimentos, como o alpha de cronbach, possam ser realizados corretamente (DeVellis, 2016). Logo, a AFE é uma técnica essencial na construção de escalas (Gerbing \& Anderson, 1988; DeVellis, 2016). Além de ajudar a reduzir o número de itens da escala, é indicada para estudos como este, em que análises preliminares devem ser realizadas em função do escasso corpo teórico mostrando as relações entre os itens e o construto (Gerbing \& Anderson, 1988), pois não há um modelo fatorial previsto pela teoria.

Para execução da AFE, foi utilizado o software estatístico SPSS. O primeiro passo foi a adoção do método de extração de Análise de Componentes Principais, a qual tem o objetivo de utilizar a variância observada no conjunto de dados para criar novas variáveis que são compostas dos itens originais (Lee \& Hooley, 2005), ou seja, busca formar combinações lineares não correlacionadas das variáveis observadas e eliminar a multicolinearidade. O método de rotação empregado foi o Varimax, que busca simplificar a interpretação dos fatores ao maximizar a soma de variâncias de cargas demandadas pela matriz fatorial (Hair et al., 2009). Em seguida, avaliaram-se os seguintes indicadores:

- Teste de KMO (Kaiser-Meyer-Olkin) ou MSA (medida de adequação da amostra): índice que aponta se o tamanho da amostra é adequado para o teste geral e para cada variável individualmente. Esse índice pode variar de 0 a 1, sendo que para resultados iguais ou acima de 0,5 considera-se a medida ruim; igual ou acima de 0,6 medíocre; 0,7 ou acima, mediano; 0,8 ou acima, admirável (Hair et al.; 2009);

- Teste de esfericidade de Bartlett: um teste estatístico que mensura a presença de correlações entre as variáveis (Hair et al., 2009). É estatisticamente significante quando < 0,05, indicando que existem correlações suficientes entre as vaiáveis para se dar sequência à análise;

- Matriz de correlação anti-imagem: apresenta o valor negativo da correlação parcial. O valor do KMO para cada variável nessa matriz deve ser superior a 0,5 (Hair et al., 2009).

Como se verá no capítulo de resultados, todos os indicadores apresentaram índices dentro dos critérios aceitáveis. Por isso, deu-se sequência à análise dos demais critérios da AFE. O passo seguinte foi a avaliação das comunalidades. Hair et al. (2009, p. 112) definem a comunalidade de uma variável como sendo "a estimativa de sua variância compartilhada, ou em comum, entre as variáveis como representadas pelos fatores obtidos”. Isto é, o quanto cada variável está presente no modelo. O critério de aceitação para é de $h^{2}>0,5$ (Hair et al., 2009). 
Continuando a análise, verificarm-se as cargas fatoriais de cada variável dentro dos fatores para nomeá-los de acordo com o que foi delineado a partir da revisão da literatura. Depois, calculou-se o alpha de Cronbach para cada fator (dimensão), respeitando-se o critério de aceitação - acima de 0,6 - (Hair et al., 2009).

\subsubsection{Análise de confiabilidade e validação estatística}

Com o instrumento tendo passado pela AFE, partiu-se para a análise conclusiva apoiada na análise fatorial confirmatória (AFC), utilizando-se a subamostra 2 para aplicar os testes. A AFC é uma análise que busca avaliar e, se preciso, ajustar o modelo da escala (Gerbing \& Anderson, 1988) para confirmar um determinado padrão previsão em relação aos resultados anteriores (DeVellis, 2016). Ademais, a análise fatorial confirmatória (CFA) é um tipo de modelagem de equações estruturais que trata especificamente de modelos de mensuração, isto é, trata das relações entre as medidas observadas (indicadores) e variáveis latentes (fatores ou dimensões) (Brown \& Moore, 2012). Assim, a AFC utiliza técnicas estatísticas mais rigorosas para confirmar ou desaprovar os resultados obtidos na AFE (Ohanian, 1990).

O objetivo dessa fase consistiu em avaliar se o modelo de mensuração se ajustava e se apresentava validade de construto para respaldar a escala de importância da COI como recurso na estratégia da empresa (Hair et al., 2005). Foram analisadas as medidas descritivas básicas (médias, medidas de dispersão e medidas de forma). Depois realizou-se o teste de aderência a curva normal - teste de Kolmogorov-Smirnov (Hair et al., 2009). Contudo, nenhuma das variáveis apresentou distribuição normal.

Para atender ao objetivo central da análise de dados da segunda subamostra - o de validar o modelo da escala por meio de uma AFC - optou-se pela utilização do software SmartPLS 2.0. Tomou-se tal decisão, pois em casos em que os dados não são aderentes a uma distribuição normal, que o modelo do estudo seja pouco explorado na literatura (Mackenzie et al, 2011) e complexo (que envolva muitos construtos) recomenda-se a utilização de modelagem de equação estrutural baseada em variância (VB-MEE) ou em modelos de estimação de ajuste de mínimos quadrados parciais (partial least square) (Hair, Sarstedt, Ringle \& Mena, 2012). Ademais, observa-se que a utilização da metodologia do PLS é crescente em estudo de marketing internacional (Henseler, Ringle \& Sinkovics, 2009). 
Assume-se que a escala de importância da COI na estratégia (BCOI) é uma escala com um modelo complexo (envolve 5 construtos de primeira ordem e 26 itens) e exploratório, pois não há uma escala previamente desenvolvida para mensurar tal construto. Além do que os dados não apresentam normalidade. Por isso, optou-se pela utilização do software SmartPLS 2.0 para a validação do modelo de mensuração e do modelo estrutural aqui proposto. A AFC contempla os testes que analisam o modelo de mensuração envolvendo a análise de diversos indicadores e procedimentos para assegurar a validade da escala (MacKenzie et al., 2011; Ringle et al, 2014; Hair et al., 2017).

Os indicadores que foram utilizados como referência para analisar os resultados da AFC obtidos na subamostra 2 são: consistência interna (alpha de cronbach e confiabilidade composta), validade convergente (indicador de confiabilidade e variância média extraída) e validade discriminante (Hair et al., 2016). Eles são detalhados no quadro 15.

Quadro 15 - Indicadores e procedimentos AFC com PLS

\begin{tabular}{|c|c|c|c|}
\hline Indicador/Procedimento & Objetivo & $\begin{array}{l}\text { Valores referenciais/ } \\
\text { critérios de análise }\end{array}$ & Aporte teórico \\
\hline $\begin{array}{l}\text { AVE (variância média } \\
\text { extraída) }\end{array}$ & Validade convergente & $\mathrm{AVE}>0,50$ & $\begin{array}{l}\text { Henseler, } \\
\text { Ringle \& } \\
\text { Sinkovics } \\
(2009)\end{array}$ \\
\hline $\begin{array}{l}\text { Alfa de Cronbach (AC) e } \\
\text { Confiabilidade Composta } \\
\text { (CC) }\end{array}$ & $\begin{array}{l}\text { Confiabilidade do } \\
\text { modelo }\end{array}$ & $\begin{array}{l}\mathrm{AC}>0,70 \\
\mathrm{CC}>0,70\end{array}$ & $\begin{array}{l}\text { Hair et al. } \\
(2016)\end{array}$ \\
\hline Cargas cruzadas & $\begin{array}{l}\text { Validade } \\
\text { discriminante }\end{array}$ & $\begin{array}{l}\text { Valores das cargas maiores } \\
\text { nas variáveis latentes } \\
\text { originais do que nas outras }\end{array}$ & Chin (1998) \\
\hline $\begin{array}{llll}\text { Critério } & \text { de } & \text { Fornell } & \text { e } \\
\text { Larcker } & & & \\
\end{array}$ & $\begin{array}{l}\text { Validade } \\
\text { discriminante }\end{array}$ & $\begin{array}{l}\text { Comparação entre as raízes } \\
\text { quadradas dos valores das } \\
\text { AVE de cada variável latente } \\
\text { com as correlações de } \\
\text { Pearson entre as variáveis } \\
\text { latentes. Os valores das } \\
\sqrt{A V E} \text { s devem ser maiores } \\
\text { que as correlações das VLs. }\end{array}$ & $\begin{array}{c}\text { Fornell \& } \\
\text { Larcker (1981) }\end{array}$ \\
\hline
\end{tabular}

Fonte: elaborado pela autora

O smartpls permite a realização da AFC por meio de dois métodos, sendo que ambos abarcam a análise de consistência interna, validade convergente e validade discriminante. Um deles é pelo método de saturação e o outro como variável de $2^{\mathrm{a}}$ ordem. Ambos apresentam os mesmos resultados, conforme pode ser analisado no capítulo de resultados. 
A etapa confirmatória buscou validar o modelo de mensuração da escala que resultou da AFE. Ela representa a o primeiro estágio no processo de desenvolvimento da MEE, que tem dois passos. Assim, depois de ajustado o modelo de mensuração, ou seja, depois de analisados os indicadores de validade do construto e confiabilidade do modelo de mensuração, passou-se para a avaliação do modelo estrutural da escala proposta por meio do método de mínimos quadrados (Hair et al., 2009). Tal método envolve a capacidade do modelo para prever a variação nas variáveis dependentes (Hair et al., 2016).

A primeira análise feita foi a avaliação dos coeficientes de determinação de Pearson $\left(R^{2}\right)$, a qual indica a qualidade do modelo ajustado, pois avalia a variância das variáveis endógenas, que é explicada pelo modelo estrutural (Cohen, 1988). Cohen (1988) recomenda que, para a área de ciências sociais, o $R^{2}=2 \%$ deve ser classificado como efeito pequeno; $R^{2}=13 \%$ como efeito médio e $R^{2}=26 \%$ como efeito grande. Deu-se continuidade à análise do modelo estrutural com auxílio do recurso de reamostragem (bootstrap) do SmartPLS, com objetivo de estimar a validade das relações entre os construtos e as variáveis dos modelos de mensuração e dos coeficientes de regressão do modelo estrutural. Ou seja, o objetivo era de avaliar as significâncias das correlações e regressões (Hair et al., 2016).

Quadro 16 - Indicadores e procedimentos do modelo estrutural com PLS

\begin{tabular}{|c|c|c|c|}
\hline $\begin{array}{l}\text { Indicador/ } \\
\text { Procedimento }\end{array}$ & Objetivo & $\begin{array}{l}\text { Valores referenciais/ } \\
\text { critérios de análise }\end{array}$ & Aporte teórico \\
\hline $\begin{array}{lr}\text { Avaliação } & \text { dos } \\
\text { coeficientes } & \text { de } \\
\text { determinação } & \text { de } \\
\text { Pearson }\left(R^{2}\right) & \\
\end{array}$ & $\begin{array}{l}\text { Avalia a variância das } \\
\text { variáveis endógenas que é } \\
\text { explicada pelo modelo } \\
\text { estrutural }\end{array}$ & $\begin{array}{l}R^{2}=2 \% \text { efeito pequeno } \\
R^{2}=13 \% \text { efeito médio } \\
R^{2}=26 \% \text { efeito grande }\end{array}$ & $\begin{array}{l}\text { Cohen (1988); } \\
\text { Hair et al. } \\
\text { (2017) }\end{array}$ \\
\hline Teste T de Student & $\begin{array}{l}\text { Avaliação das significâncias } \\
\text { das correlações e regressões }\end{array}$ & $t>1,96$ & $\begin{array}{l}\text { Hair et al. } \\
\quad(2016)\end{array}$ \\
\hline $\begin{array}{l}\text { Tamanho do efeito } \\
\left(f^{2}\right)\end{array}$ & $\begin{array}{l}\text { Avalia quanto cada variável } \\
\text { latente contribui para o } \\
\text { ajuste do modelo }\end{array}$ & $\begin{array}{c}f^{2}>=0,02 \text { pequeno } \\
f^{2}>=0,15 \text { médio } \\
f^{2}>=0,35 \text { grande }\end{array}$ & $\begin{array}{l}\text { Hair et al. } \\
(2014 ; 2016)\end{array}$ \\
\hline $\begin{array}{l}\text { Relevância preditiva } \\
\left(Q^{2}\right)\end{array}$ & $\begin{array}{l}\text { Avalia a acurácia do modelo } \\
\text { ajustado }\end{array}$ & $Q^{2}>0$ & $\begin{array}{c}\text { Hair et al. } \\
(2014 ; 2016)\end{array}$ \\
\hline $\begin{array}{l}\text { Coeficiente } \mathrm{de} \\
\text { caminho }\end{array}$ & $\begin{array}{l}\begin{array}{l}\text { Avaliação } \\
\text { causais }\end{array} \\
\end{array}$ & $\begin{array}{l}\text { Devem-se interpretar os } \\
\text { valores à luz da teoria }\end{array}$ & $\begin{array}{c}\text { Hair et al. } \\
(2014 ; 2016)\end{array}$ \\
\hline
\end{tabular}

Fonte: elaborado pela autora

Para estimar a qualidade de ajuste do modelo, foram utilizados dois indicadores: a) o de validade preditiva $\left(Q^{2}\right)$, que avalia a acurácia do modelo ajustado, ou seja, tem como objetivo avaliar o quanto o modelo se aproxima do esperado (Hair et al., 2016), e b) o tamanho do efeito 
$\left(f^{2}\right)$, que avalia quanto cada variável latente contribui para o ajuste do modelo (Hair et al., 2016). Os resultados de ambos indicadores foram obtidos empregando-se o módulo Blindfolding do SmartPLS. Com a finalização da avaliação da qualidade de ajuste do modelo, recorreu-se ao último procedimento de validação do modelo: a interpretação dos coeficientes de caminho que tem como objetivo analisar a intensidades das relações causais (Hair et al., 2016).

Importante destacar que, neste estudo, não se calculou o GoF (Godness of Fit), uma vez que esse teste, segundo Hair et al. (2016), apresenta diversas deficiências estatísticas e não pode ser aplicado para o contexto de modelagem de equações estruturais utilizando-se a metodologia de mínimos quadrados. O quadro 16 detalha os procedimentos e os critérios analisados para o desenvolvimento da MEE.

Quadro 17 - Atividades do primeiro passo para construção de escala

\begin{tabular}{|c|c|}
\hline $\begin{array}{c}\text { Construto } \\
\text { latente }\end{array}$ & Capacidade de incorporação da COI na gestão da marca \\
\hline Definição & $\begin{array}{l}\text { Constui a importância conferida pela empresa para usar a COI como um } \\
\text { recurso na construção da capacidade de marca. Logo, a COI é reflexo da } \\
\text { importância que a empresa confere aos elementos visuais, textuais, de sentido, } \\
\text { naturais e culturais que se referem a COI, assim como a importância do } \\
\text { engajamento dos funcionários na promoção desses elementos. Sua } \\
\text { incorporação é realizada mediante os sinais transmitidos na comunicação da } \\
\text { identidade da marca em todos os pontos de contato com clientes (site, } \\
\text { folhetos, escritórios, show room, estande em feiras), nos produtos } \\
\text { (embalagem, matéria-prima e design) (Kapferer, 2003). Como a proposta da } \\
\text { escala é voltada para verificação da importância do COI na construção da } \\
\text { capacidade de gestão da marca, a unidade de análise da escala é a empresa } \\
\text { representada por seus gestores (nível tático e estratégico). }\end{array}$ \\
\hline $\begin{array}{ll}\text { Verificação } & \text { da } \\
\text { necessidade } & \text { de } \\
\text { nova escala } & \\
\end{array}$ & Não há escalas que mensurem esse construto, apenas estudo qualitativos. \\
\hline $\begin{array}{l}\text { Análise da } \\
\text { dimensionalidade }\end{array}$ & $\begin{array}{l}\text { Multidimensional - } 5 \text { dimensões: } \\
\text { - Elementos textuais e visuais; } \\
\text { - Recursos Naturais; } \\
\text { - Recursos Culturais; } \\
\text { - Sentidos; } \\
\text { - Funcionários. }\end{array}$ \\
\hline $\begin{array}{l}\text { Natureza } \\
\text { construto }\end{array}$ & Reflexivo - as dimensões são manifestações do construto de $1^{\text {a }}$ ordem. \\
\hline
\end{tabular}

Fonte: elaborado pela autora.

Para realizar a modelagem de equações estruturais, seguiram-se os passos recomendados por Hair et al. (2009): desenvolveu-se um modelo teórico (com base da literatura analisada e explorado com auxílio da AFE); construiu-se um diagrama de caminhos de relações 
causais; converteu-se o diagrama de caminhos construído anteriormente em um conjunto de modelos mensuração e estrutural; escolheu-se o tipo de matriz dos dados e estimação do modelo proposto; avaliou-se a identificação do modelo estrutural; avaliou-se os critérios de qualidade do ajuste e, por fim, interpretou-se o modelo.

O quadro 17 resume os principais aspectos de especificação da escala proposta e a figura 7 ilustra o modelo conceitual ajustado após a validade de face e conteúdo. O capítulo seguinte relata os resultados das análises estatísticas do desenvolvimento da escala.

Figura 7 - Modelo conceitual testado

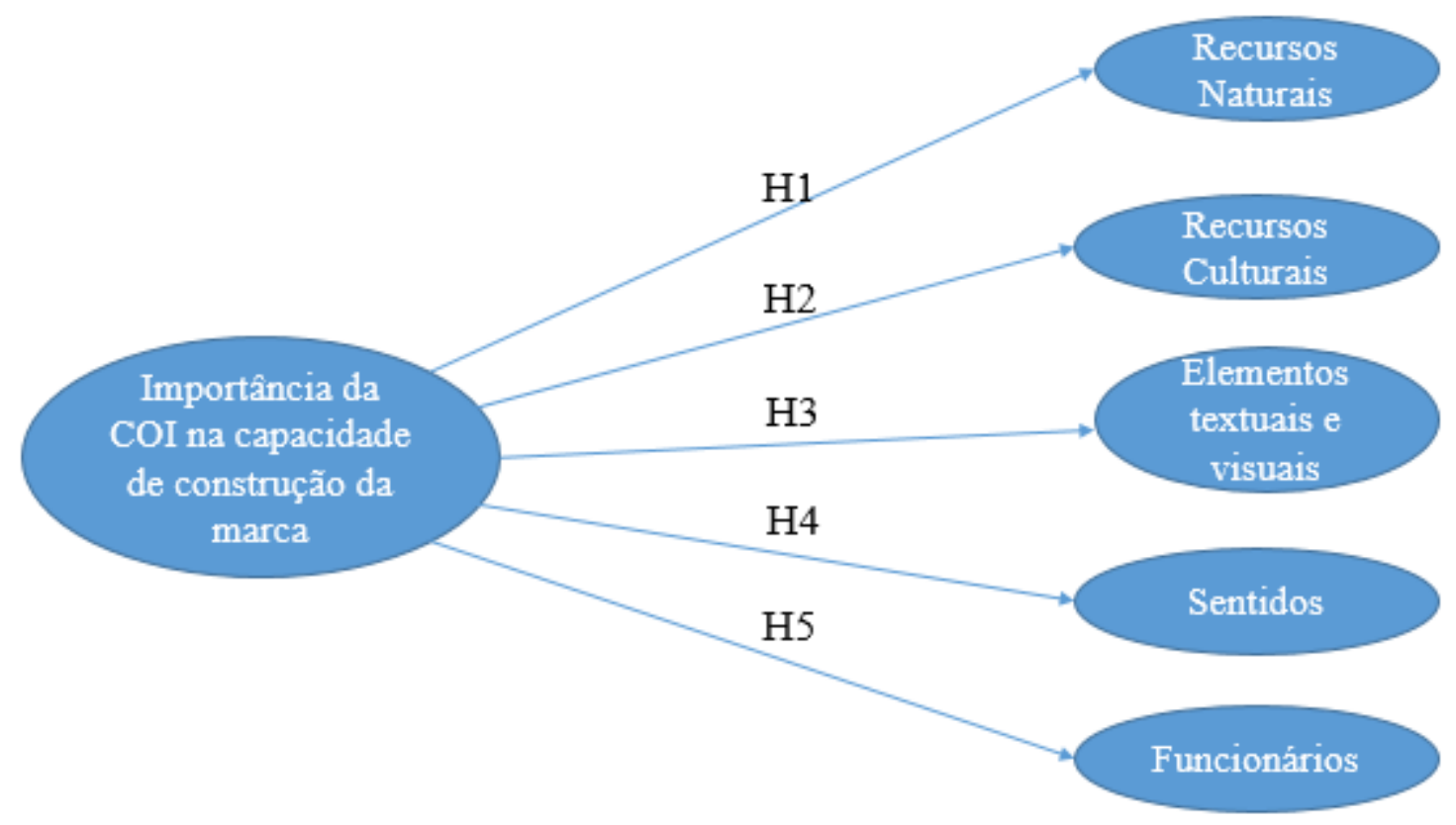

Fonte: elaborado pela autora. 


\section{ANÁLISE DOS RESULTADOS}

As análises dos resultados do estudo de campo dividem-se em três blocos: o primeiro mostra a análise descritiva das duas subamostras; o segundo apresenta a análise fatorial exploratória (subamostra 1) e o terceiro analisa os resultados da análise fatorial confirmatória (modelo de mensuração) e a validade estatística sobre as relações entre as variáveis latentes (subamostra 2).

Antes de dar início às análises estatísticas, preparou-se o banco de dados. Para tanto, verificaram-se os dados colhidos em campo e eliminaram-se do banco de dados os casos em que o respondente preencheu parcialmente o questionário ou os casos em que se verificaram inconsistências nas respostas. Seguiram-se as recomendações de Hair et al. (2005), para eliminar os questionários com mais de $15 \%$ de respostas em branco. Em seguida, foram excluídos os casos em que se observaram problemas com o preenchimento, como respostas repetidas com frequência suspeita e inadequação do perfil do respondente à pesquisa. Após tais análises, foram descartados do banco de dados 155 casos e 457 foram considerados válidos. A amostra foi dividida em duas subamostras (subamostra $1 \mathrm{n}=219$, subamostra $2 \mathrm{n}=238$ ) para concretização das análises univariadas e multivariadas.

Para as duas subamostras, realizou-se um exame da distribuição dos dados considerando-se apenas uma variável. Após a análise crítica da consistência das respostas, calcularam-se as seguintes estatísticas descritivas: médias, medidas de dispersão e medidas de forma. Testou-se também a normalidade dos dados por meio do teste de Kolmogorov-Smirnov (Hair et al., 2009), no entanto, nenhuma das variáveis apresentou distribuição normal.

\subsection{Análise descritiva dos dados}

A análise descritiva da amostra compreende a caracterização da unidade de análise pesquisada (a empresa) representada por gestores. Realizou-se esse procedimento para compreender se as duas amostras utilizadas para aferir as análises multivariadas apresentavam perfil semelhante. Para tanto, foram analisados os seguintes aspectos: tipo de operação da empresa em processo de internacionalização, país de origem da empresa e setor. 


\subsubsection{Análise descritiva subamostra 1}

A subamostra 1 compreendeu 219 respondentes que representaram 219 empresas. Grande parte dessa subamostra $(35,6 \%)$ é representada por empresas operando no Brasil por meio de subsidiária. Mais da metade de toda a subamostra é composta por empresas Brasileiras $(56,6 \%)$ que operam em mercados internacionais por meio de centros próprios de distribuição (5\%), escritórios de comercialização $(9,6 \%)$, exportação direta $(7,8 \%)$, exportação indireta $(14,2 \%)$, representante exclusivo no exterior $(2,7 \%)$ ou mesmo, por meio de subsidiária em outros países $(6,4 \%)$.

A tabela 1 detalha o tipo de operação das empresas da subamostral e o gráfico 1 apresenta a distribuição de frequência.

Tabela 1 - Tipo de operação (subamostra 1)

\begin{tabular}{|c|c|c|c|c|}
\hline & Frequência & Percentual & $\begin{array}{l}\text { Percentual } \\
\text { Válido }\end{array}$ & $\begin{array}{l}\text { Percentual } \\
\text { cumulativo }\end{array}$ \\
\hline Centros de distribuição próprios. & 11 & 5,0 & 5,0 & 5,0 \\
\hline É nacional & 25 & 11,4 & 11,4 & 16,4 \\
\hline $\begin{array}{l}\text { Escritórios de comercialização } \\
\text { próprios. }\end{array}$ & 21 & 9,6 & 9,6 & 26,0 \\
\hline Exportação direta & 17 & 7,8 & 7,8 & 33,8 \\
\hline Exportação indireta & 31 & 14,2 & 14,2 & 47,9 \\
\hline Outro (especifique). & 16 & 7,3 & 7,3 & 55,3 \\
\hline Representante exclusivo no exterior & 6 & 2,7 & 2,7 & 58,0 \\
\hline $\begin{array}{l}\text { Subsidiária de uma multinacional } \\
\text { estrangeira }\end{array}$ & 78 & 35,6 & 35,6 & 93,6 \\
\hline Subsidiárias em outros países. & 14 & 6,4 & 6,4 & 100,0 \\
\hline Total & 219 & 100,0 & 100,0 & \\
\hline
\end{tabular}

Fonte: Extraído do SPSS 
Gráfico 1 - Distribuição do tipo de operação (subamostra 1)

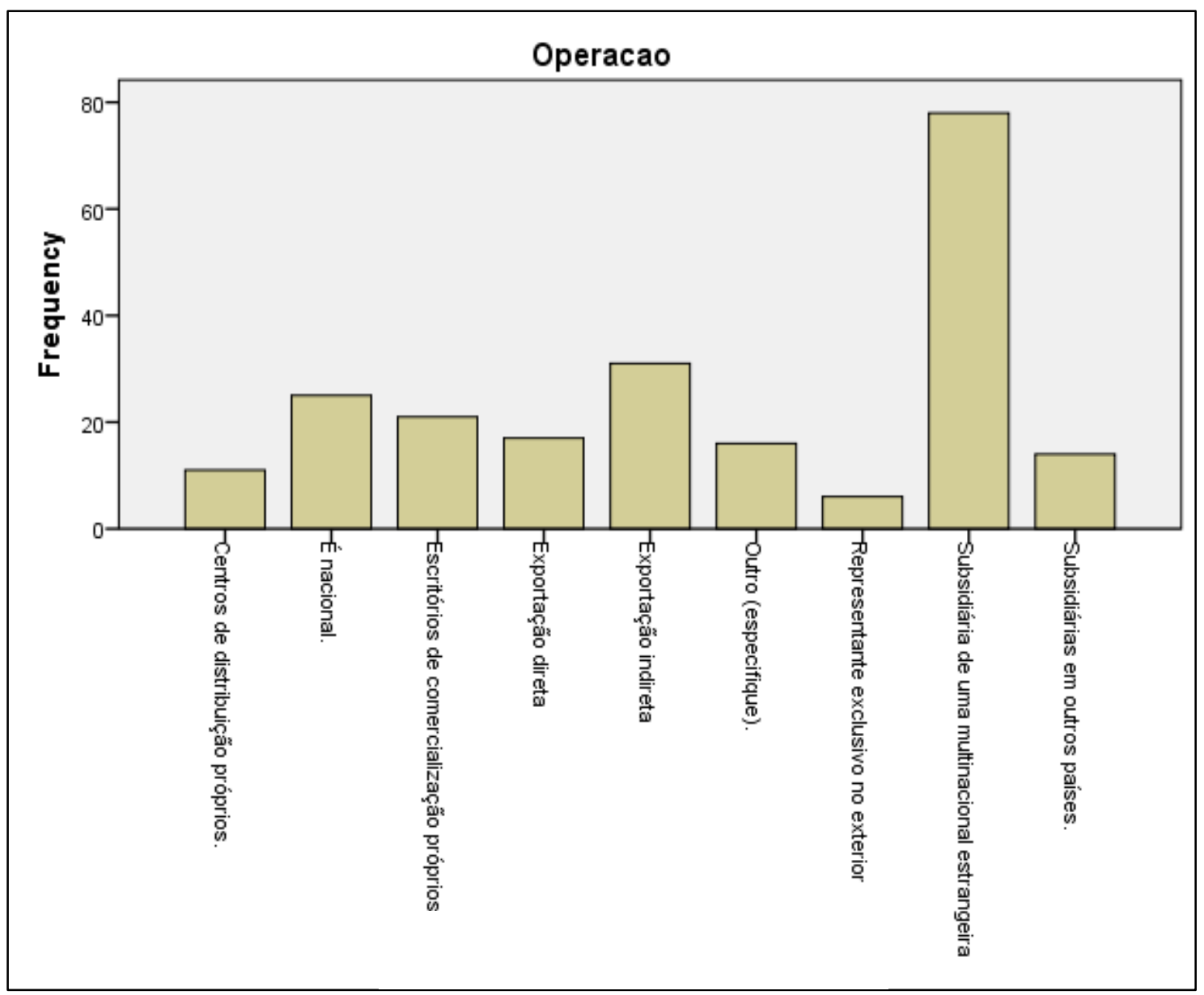

Fonte: Extraído do SPSS

Além do Brasil, outras nacionalidades foram representadas pela subamostra 1. Apesar de a maioria das empresas ser nacional $(56,6 \%)$, a subamostra 1 também continha empresas europeias $(21,2 \%)$, norte-americanas $(15,5 \%)$ e latino-americanas $(3,7 \%)$, além de empresas Japonesas $(1,8 \%)$. Ademais, o setor de atuação das empresas mostrou uma distribuição bastante heterogênea, destacando-se a presença de empresas da indústria de transformação $(11,9)$, de atividades financeiras $(8,2 \%)$ e de saúde $(8,2 \%)$. A tabela 2 detalha a origem das empresas, e a tabela 3 , o setor de atuação. 
Tabela 2 - Distribuição do país de origem das empresas (subamostra 1)

\begin{tabular}{|l|r|r|r|r|}
\hline & & Percentual & Percentual \\
cumulativo
\end{tabular}

Fonte: Extraído do SPSS

Tabela 3 - Setores representados (subamostra 1)

\begin{tabular}{|c|c|c|c|c|}
\hline & Frequência & Percentual & $\begin{array}{l}\text { Percentual } \\
\text { Válido }\end{array}$ & $\begin{array}{l}\text { Percentual } \\
\text { cumulativo }\end{array}$ \\
\hline Agricultura & 14 & 6,4 & 6,4 & 6,4 \\
\hline Alimentação & 16 & 7,3 & 7,3 & 13,7 \\
\hline Armazenagem & 1 &, 5 &, 5 & 14,2 \\
\hline Artes e Cultura & 2 & ,9 & ,9 & 15,1 \\
\hline Atividades financeiras & 18 & 8,2 & 8,2 & 23,3 \\
\hline Atividades imobiliárias & 1 &, 5 &, 5 & 23,7 \\
\hline Comércio & 17 & 7,8 & 7,8 & 31,5 \\
\hline Construção & 6 & 2,7 & 2,7 & 34,2 \\
\hline Correio & 2 & ,9 & ,9 & 35,2 \\
\hline Educação & 6 & 2,7 & 2,7 & 37,9 \\
\hline Eletricidade e gás & 4 & 1,8 & 1,8 & 39,7 \\
\hline Indústria de transformação & 26 & 11,9 & 11,9 & 51,6 \\
\hline Indústria extrativa & 6 & 2,7 & 2,7 & 54,3 \\
\hline Informação e comunicação & 17 & 7,8 & 7,8 & 62,1 \\
\hline Moda & 6 & 2,7 & 2,7 & 64,8 \\
\hline Outro & 53 & 24,2 & 24,2 & 89,0 \\
\hline Reparação de veículos e motocicleta & 2 & ,9 & ,9 & 90,0 \\
\hline Saúde & 18 & 8,2 & 8,2 & 98,2 \\
\hline Transporte & 4 & 1,8 & 1,8 & 100,0 \\
\hline Total & 219 & 100,0 & 100,0 & \\
\hline
\end{tabular}

Fonte: Extraído do SPSS 


\subsubsection{Análise descritiva subamostra 2}

A subamostra 2 foi comporta por 238 respondentes representando 238 empresas. Do mesmo modo que na subamostra 1, grande parte da subamostra $2(37 \%)$ é representada por empresas multinacionais operando no Brasil por meio de subsidiária. Mais da metade de toda a subamostra 2 é composta por empresas Brasileiras (52,1\%) que operam em mercados internacionais por meio de centros próprios de distribuição $(1,7 \%)$, escritórios de comercialização $(8,4 \%)$, exportação direta $(7,6 \%)$, exportação indireta $(2,5 \%)$, representante exclusivo no exterior $(4,2 \%)$ ou mesmo, por meio de subsidiária em outros países $(7,1 \%)$.

A tabela 4 detalha o tipo de operação das empresas da subamostra 2.

Tabela 4 - Tipo de operação (subamostra 2)

\begin{tabular}{|c|c|c|c|c|}
\hline & Frequência & Percentual & $\begin{array}{l}\text { Percentual } \\
\text { Válido }\end{array}$ & $\begin{array}{l}\text { Percentual } \\
\text { cumulativo }\end{array}$ \\
\hline Centros de distribuição próprios. & 4 & 1,7 & 1,7 & 1,7 \\
\hline É nacional & 63 & 26,5 & 26,5 & 28,2 \\
\hline $\begin{array}{l}\text { Escritórios de comercialização } \\
\text { próprios. }\end{array}$ & 20 & 8,4 & 8,4 & 36,6 \\
\hline Exportação direta & 18 & 7,6 & 7,6 & 44,1 \\
\hline Exportação indireta & 6 & 2,5 & 2,5 & 46,6 \\
\hline Outro (especifique). & 12 & 5,0 & 5,0 & 51,7 \\
\hline Representante exclusivo no exterior & 10 & 4,2 & 4,2 & 55,9 \\
\hline $\begin{array}{l}\text { Subsidiária de uma multinacional } \\
\text { estrangeira }\end{array}$ & 88 & 37,0 & 37,0 & 92,9 \\
\hline Subsidiárias em outros países. & 17 & 7,1 & 7,1 & 100,0 \\
\hline Total & 238 & 100,0 & 100,0 & \\
\hline
\end{tabular}

Fonte: Extraído do SPSS

A subamostra 2 também foi representada por mais empresas brasileiras $(52,1 \%)$ e a distribuição da representatividade das empresas estrangeiras mostrou-se ligeiramente diferente. $\mathrm{Na}$ subamostra 1, as empresas europeias representavam $21,2 \%$, enquanto na subamostra 2 a presença europeia foi da ordem de 23,8\%. Na subamostra 1, 15,5\% das empresas eram norteamericanas e na subamostra 2 esse percentual foi um pouco maior, 16,8\%. A representatividade de empresas latino-americanas na subamostra 1 era de $3,7 \%$ e diminuiu para $2,1 \%$ na subamostra 2. O percentual de empresas japonesas na segunda subamostra foi maior, passou de 
$1,8 \%$ para 2,5\%. Ademais, na subamostra 2 , observou-se a presença de uma empresa chinesa e uma australiana (países que não foram representados na subamostra 1).

Tabela 5 - Distribuição do país de origem das empresas (subamostra 2)

\begin{tabular}{|l|r|r|r|r|}
\hline & & & Percentual & \multicolumn{2}{|c|}{$\begin{array}{c}\text { Percentual } \\
\text { cumulativo }\end{array}$} \\
\hline Alemanha & Frequência & Percentual & Vado & 6,3 \\
Argentina & 15 & 6,3 & 6,3 & 7,6 \\
Austrália & 3 & 1,3 & 1,3 & 8,0 \\
Bélgica & 1 &, 4 &, 4 & 8,8 \\
Brasil & 2 &, 8 &, 8 & 60,9 \\
Chile & 124 & 52,1 & 52,1 & 61,3 \\
China & 1 &, 4 &, 4 & 61,8 \\
Dinamarca & 1 &, 4 &, 4 & 62,2 \\
Espanha & 1 &, 4 &, 4 & 65,1 \\
Estados Unidos & 7 & 2,9 & 2,9 & 81,9 \\
França & 40 & 16,8 & 16,8 & 86,6 \\
Holanda & 11 & 4,6 & 4,6 & 88,7 \\
Itália & 5 & 2,1 & 2,1 & 90,8 \\
Japão & 5 & 2,1 & 2,1 & 93,3 \\
Outro (especifique) & 6 & 2,5 & 2,5 & 95,0 \\
Peru & 4 & 1,7 & 1,7 & 95,4 \\
Reino Unido & 1 &, 4 &, 4 & 98,3 \\
Suécia & 7 & 2,9 & 98,7 \\
Suíça & 1 &, 4 & 1,4 & 100,0 \\
Total & 3 & 1,3 & 100,0 & \\
\hline
\end{tabular}

Fonte: Extraído do SPSS

O setor de atuação das empresas, assim como na subamostra 1, mostrou uma distribuição bastante heterogênea e, novamente, destacou-se a presença de empresas da indústria de transformação $(11,3 \%)$, do setor financeiro $(7,1 \%)$ e de saúde $(5 \%)$. A tabela 5 detalha a origem das empresas, e a tabela 6, o setor de atuação. 
Tabela 6 - Setores representados (subamostra 2)

\begin{tabular}{|l|r|r|r|r|}
\hline & Frequência & Percentual & $\begin{array}{c}\text { Percentual } \\
\text { Válido }\end{array}$ & $\begin{array}{c}\text { Percentual } \\
\text { cumulativo }\end{array}$ \\
\hline Agricultura & 5 & 2,1 & 2,1 & 2,1 \\
Água, esgoto, atividade de gestão de & 1 &, 4 &, 4 & 2,5 \\
resíduos e descontinua & 1 & 5,9 & 5,9 & 8,4 \\
Alimentação & 14 & 5,9 & 1,3 & 9,7 \\
Artes e Cultura & 3 & 1,3 & 7,1 & 16,8 \\
Atividades financeiras & 17 & 7,1 &, 8 & 17,6 \\
Atividades imobiliárias & 2 &, 8 & 11,8 & 29,4 \\
Comércio & 28 & 11,8 & 2,1 & 31,5 \\
Construção & 5 & 2,1 & 3,4 & 34,9 \\
Educação & 8 & 3,4 & 1,3 & 36,1 \\
Esporte e recreação & 3 & 1,3 & 11,3 & 47,5 \\
Indústria de transformação & 27 & 11,3 & 1,7 & 49,2 \\
Indústria extrativa & 4 & 1,7 & 9,7 & 58,8 \\
Informação e comunicação & 23 & 9,7 & 4,2 & 63,0 \\
Moda & 10 & 4,2 & 27,7 & 90,8 \\
Outro & 66 & 27,7 &, 4 & 91,2 \\
Produção Florestal & 1 &, 4 & 5,0 & 96,2 \\
Saúde & 12 & 5,0 & 3,4 & 96,6 \\
Serviços Sociais & 1 &, 4 & 100,0 \\
Transporte & 8 & 3,4 & 100,0 & \\
Total & 238 & & \\
\hline
\end{tabular}

Fonte: Extraído do SPSS

Os resultados das análises descritivas das duas amostras mostraram que ambas têm perfil semelhante. Por isso, decidiu-se seguir com as etapas de construção e validação da escala utilizando-se a subamostra 1 para a etapa exploratória e a subamostra 2 para a etapa confirmatória e de validação estatística.

\subsection{Subamostra 1 - Análise fatorial exploratória}

Na primeira subamostra ( $\mathrm{n}=219$ observações), realizou-se análise fatorial exploratória (AFE) e análise de consistência interna. Para acessar a estrutura da escala de importância da COI como recurso na estratégia, os 26 itens do questionário passaram então pela análise fatorial, com o método de extração de Análise de Componentes Principais e método Varimax. A princípio, analisou-se a matriz de correlações seguindo as heurísticas aconselhadas por Hair et al. (2005). Os resultados apontaram adequação para análise fatorial da amostra $(\mathrm{KMO}=0,925$; teste de Bartlett: qui-quadrado aprox.. = 4178,176; g.l. = 325; sig < 0,0000). Analisou-se o 
KMO da matriz anti-imagem de correlação que apresentou números acima de 0,881 (acima do valor de referência 0,500). Verificaram-se também os valores das comunalidades entre as variáveis observáveis, e todas apresentaram cargas acima de 0,500 (como pode ser observado na tabela 7).

Tabela 7 - Análise das Comunalidades

\begin{tabular}{|c|c|c|}
\hline Itens & Inicial & Extração \\
\hline SMEAN(Q7) & 1,000 &, 713 \\
\hline SMEAN(Q8) & 1,000 & ,838 \\
\hline SMEAN(Q9) & 1,000 & ,726 \\
\hline SMEAN(Q10) & 1,000 & ,835 \\
\hline SMEAN(Q11) & 1,000 &, 783 \\
\hline SMEAN(Q12) & 1,000 & ,684 \\
\hline SMEAN(Q13) & 1,000 & ,769 \\
\hline SMEAN(Q14) & 1,000 & ,769 \\
\hline SMEAN(Q15) & 1,000 &, 568 \\
\hline SMEAN(Q16) & 1,000 &, 521 \\
\hline SMEAN(Q17) & 1,000 & ,666 \\
\hline SMEAN(Q18) & 1,000 &, 774 \\
\hline SMEAN(Q19) & 1,000 & ,748 \\
\hline SMEAN(Q20) & 1,000 & ,778 \\
\hline SMEAN(Q21) & 1,000 & ,768 \\
\hline SMEAN(Q22) & 1,000 & ,778 \\
\hline SMEAN(Q23) & 1,000 & ,725 \\
\hline SMEAN(Q24) & 1,000 &, 770 \\
\hline SMEAN(Q25) & 1,000 & ,742 \\
\hline SMEAN(Q26) & 1,000 & ,653 \\
\hline SMEAN(Q1) & 1,000 & ,589 \\
\hline SMEAN(Q2) & 1,000 & ,518 \\
\hline SMEAN(Q3) & 1,000 & ,658 \\
\hline SMEAN(Q4) & 1,000 & ,671 \\
\hline SMEAN(Q5) & 1,000 & ,634 \\
\hline SMEAN(Q6) & 1,000 &, 524 \\
\hline
\end{tabular}

Extraction Method: Principal Component

Analysis.

Fonte: Extraído do SPSS

O critério de Kaiser foi aplicado e cinco fatores foram retidos (tabela 8). A solução fatorial correspondendo a aproximadamente $70 \%$ da variância dos dados é apresentada na tabela 9. Nenhum dos itens apresentou carga fatorial inferior a 0,510. Por isso, identificou-se que não 
havia necessidade de exclusão de item algum. Ademais, a análise fatorial mostrou que todos os itens estavam adequados às dimensões previamente designadas ancoradas na literatura.

Tabela 8 - Variância total Explicada na AFE $(n=219)$

\begin{tabular}{|c|c|c|c|c|c|c|c|c|c|}
\hline \multirow[b]{2}{*}{$\begin{array}{l}\text { Compon } \\
\text { ente }\end{array}$} & \multicolumn{3}{|c|}{ Valores próprios iniciais } & \multicolumn{3}{|c|}{$\begin{array}{c}\text { Soma da extração das cargas } \\
\text { elevadas ao quadrado }\end{array}$} & \multicolumn{3}{|c|}{$\begin{array}{c}\text { Soma da rotação das cargas } \\
\text { elevadas ao quadrado }\end{array}$} \\
\hline & Total & $\begin{array}{c}\% \text { de } \\
\text { Variânci } \\
\text { a }\end{array}$ & $\begin{array}{c}\% \\
\text { Cumulativo }\end{array}$ & Total & $\begin{array}{c}\% \text { de } \\
\text { Variância }\end{array}$ & $\begin{array}{c}\% \\
\text { Cumulativ } \\
\text { o }\end{array}$ & Total & $\begin{array}{c}\% \text { de } \\
\text { Variância }\end{array}$ & $\begin{array}{c}\% \\
\text { Cumulativo }\end{array}$ \\
\hline 1 & 12,092 & 46,508 & 46,508 & 12,092 & 46,508 & 46,508 & 4,181 & 16,083 & 16,083 \\
\hline 2 & 1,799 & 6,920 & 53,428 & 1,799 & 6,920 & 53,428 & 4,142 & 15,931 & 32,014 \\
\hline 3 & 1,715 & 6,597 & 60,026 & 1,715 & 6,597 & 60,026 & 3,493 & 13,435 & 45,448 \\
\hline 4 & 1,572 & 6,045 & 66,070 & 1,572 & 6,045 & 66,070 & 3,429 & 13,187 & 58,635 \\
\hline 5 & 1,022 & 3,931 & 70,002 & 1,022 & 3,931 & 70,002 & 2,955 & 11,367 & 70,002 \\
\hline 6 & ,867 & 3,333 & 73,335 & & & & & & \\
\hline 7 & ,771 & 2,964 & 76,299 & & & & & & \\
\hline 8 & ,716 & 2,755 & 79,054 & & & & & & \\
\hline 9 &, 579 & 2,226 & 81,280 & & & & & & \\
\hline 10 &, 548 & 2,107 & 83,387 & & & & & & \\
\hline 11 & ,471 & 1,813 & 85,200 & & & & & & \\
\hline 12 & ,416 & 1,601 & 86,801 & & & & & & \\
\hline 13 & ,412 & 1,585 & 88,386 & & & & & & \\
\hline 14 & ,386 & 1,485 & 89,871 & & & & & & \\
\hline 15 &, 323 & 1,242 & 91,113 & & & & & & \\
\hline 16 &, 312 & 1,199 & 92,312 & & & & & & \\
\hline 17 & 299 & 1,149 & 93,461 & & & & & & \\
\hline 18 & ,262 & 1,006 & 94,467 & & & & & & \\
\hline 19 & ,240 & ,924 & 95,391 & & & & & & \\
\hline 20 & ,226 & ,868 & 96,259 & & & & & & \\
\hline 21 & ,213 & ,818 & 97,077 & & & & & & \\
\hline 22 &, 176 & 676 & 97,753 & & & & & & \\
\hline 23 & ,172 & ,662 & 98,415 & & & & & & \\
\hline 24 & , 156 & 602 & 99,017 & & & & & & \\
\hline 25 &, 140 &, 540 & 99,556 & & & & & & \\
\hline 26 & ,115 & ,444 & 100,000 & & & & & & \\
\hline
\end{tabular}

Extraction Method: Principal Component Analysis. 
Tabela 9 - Solução fatorial rotacionada $(n=219)$

\begin{tabular}{|c|c|c|c|c|c|}
\hline \multirow[b]{2}{*}{ Itens } & \multicolumn{5}{|c|}{ Componentes (dimensões) } \\
\hline & 1 & 2 & 3 & 4 & 5 \\
\hline $\mathrm{Q} 23$ & 0,790 &, 272 &, 166 &, 157 &, 138 \\
\hline Q24 & 0,773 & 175 & ,206 & 197 & 124 \\
\hline Q25 & 0,728 & 244 & 153 & ,236 & 269 \\
\hline Q26 & 0,656 & 288 & 181 & ,216 & ,246 \\
\hline Q10 & ,196 & ,832 &, 186 & ,191 & , 181 \\
\hline Q8 & 249 &, 814 & 265 &, 182 & 103 \\
\hline Q11 & 251 & ,774 & 235 & 210 & 150 \\
\hline Q7 & 210 & ,759 &, 150 &, 118 & 237 \\
\hline Q9 & ,269 & ,751 &, 180 &, 149 & , 186 \\
\hline Q13 & 143 & 232 & ,797 &, 122 & 210 \\
\hline Q14 &, 175 & , 196 & ,767 &, 174 & 285 \\
\hline Q12 & 255 & ,210 & ,723 & ,200 & 112 \\
\hline Q15 & ,240 & , 129 & ,640 & , 190 & ,220 \\
\hline Q16 &, 118 & ,326 & ,511 &, 180 & 327 \\
\hline Q18 & ,202 & ,046 &, 070 & ,783 & ,337 \\
\hline Q20 & 280 & ,310 & ,253 & ,732 &,- 059 \\
\hline Q21 & 230 & ,299 & ,290 & ,728 &,- 105 \\
\hline Q17 &, 184 &, 153 &, 127 & ,702 & ,315 \\
\hline Q19 & 217 & 157 & 238 & 686 & ,386 \\
\hline Q4 & ,500 & 143 &, 175 &, 051 & 607 \\
\hline Q1 & ,054 & , 172 & ,314 & ,317 & ,598 \\
\hline Q5 & ,236 & 195 & ,401 &, 167 & ,592 \\
\hline Q3 & ,457 & 296 & 208 & 030 & ,563 \\
\hline Q2 & ,355 & 178 & , 190 & , 148 & ,550 \\
\hline Q6 &,- 005 & ,245 & ,334 & ,304 & ,510 \\
\hline
\end{tabular}

Extraction Method: Principal Component Analysis.

Rotation Method: Varimax with Kaiser Normalization.

a. Rotation converged in 7 iterations.

Partiu-se para a análise de consistência interna dos fatores (dimensões da escala). Para tanto avaliou-se: o alfa de cronbach para cada fator e a média das correlações interitens. Todos os índices (quadro 18) mostraram-se aceitáveis. 
Quadro 18 - Itens, fatores e indicadores de confiabilidade

\begin{tabular}{|c|c|c|c|}
\hline \multicolumn{2}{|c|}{ Fatores } & Itens & Correlação item-total \\
\hline \multirow{6}{*}{ 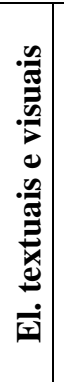 } & \multirow{6}{*}{$\begin{array}{l}\text { AC } 0,845 \\
\text { MII } 0,626\end{array}$} & Q1 & $\begin{array}{l}\text { Utilizar nome de lugares, pontos turísticos ou bairros famosos do país de } \\
\text { origem da empresa. }\end{array}$ \\
\hline & & Q2 & Utilizar a sigla ou nome do país de origem da empresa. \\
\hline & & Q3 & Utilizar desenho da bandeira do país de origem da empresa. \\
\hline & & Q4 & $\begin{array}{l}\text { Utilizar cores da bandeira do país de origem da empresa nos pontos de contato } \\
\text { com os clientes. }\end{array}$ \\
\hline & & Q5 & Utilizar imagens, figuras ou paisagens do país de origem da empresa. \\
\hline & & Q6 & $\begin{array}{l}\text { Utilizar imagem de pessoas famosas do país de origem da empresa que são } \\
\text { reconhecidas mundialmente. }\end{array}$ \\
\hline \multirow{5}{*}{ 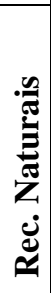 } & \multirow{5}{*}{$\begin{array}{l}\text { AC } 0,927 \\
\text { MII } 0,811\end{array}$} & Q7 & Utilizar recursos naturais do país de origem da empresa. \\
\hline & & Q8 & Destacar os recursos naturais típicos do país de origem da empresa. \\
\hline & & Q9 & Utilizar recursos da biodiversidade do país de origem da empresa. \\
\hline & & Q10 & $\begin{array}{l}\text { Destacar os benefícios proporcionados pela utilização } \\
\text { naturais típicos do país de origem da empresa. }\end{array}$ \\
\hline & & Q11 & $\begin{array}{l}\text { Destacar recursos naturais do país de origem da empresa como fator de } \\
\text { diferenciação. }\end{array}$ \\
\hline \multirow{5}{*}{ 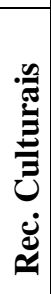 } & \multirow{5}{*}{$\begin{array}{l}\text { AC } 0,867 \\
\text { MII } 0,691\end{array}$} & Q12 & $\begin{array}{l}\text { Utilizar aspectos relacionados aos hábitos e costumes do país de origem da } \\
\text { empresa. }\end{array}$ \\
\hline & & Q13 & Utilizar a diversidade de manifestações culturais do país de origem da empresa. \\
\hline & & Q14 & Utilizar aspectos relacionados ao povo do país de origem da empresa. \\
\hline & & Q15 & Utilizar aspectos relacionados à literatura do país de origem da empresa. \\
\hline & & Q16 & $\begin{array}{l}\text { Utilizar aspectos relacionados às artes produzidas por cidadãos do país de origem } \\
\text { da empresa. }\end{array}$ \\
\hline \multirow{5}{*}{ 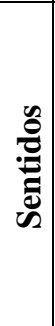 } & \multirow{5}{*}{$\begin{array}{l}\text { AC } 0,888 \\
\text { MII } 0,729\end{array}$} & Q17 & Utilizar músicas do país de origem da empresa no site internacional \\
\hline & & Q18 & Utilizar músicas do país de origem da empresa nas propagandas internacionais. \\
\hline & & Q19 & $\begin{array}{l}\text { Utilizar músicas do país de origem da empresa no local de contato com o cliente } \\
\text { (show room, escritório ou stand em feira). }\end{array}$ \\
\hline & & Q20 & $\begin{array}{l}\text { Utilizar fragrâncias e essências do país de origem da empresa para perfumar } \\
\text { o ponto de contato com o cliente (loja, show room, stand em feira, escritório). }\end{array}$ \\
\hline & & Q21 & $\begin{array}{l}\text { Utilizar fragrâncias e essências do país de origem da empresa para perfumar } \\
\text { o produto. }\end{array}$ \\
\hline \multirow{5}{*}{ 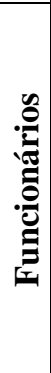 } & \multirow{5}{*}{$\begin{array}{l}\text { AC } 0,912 \\
\text { MII } 0,778\end{array}$} & Q22 & $\begin{array}{l}\text { Treinar sua equipe de vendas para explicar aos clientes aspectos relacionados ao } \\
\text { do país de origem da empresa. }\end{array}$ \\
\hline & & Q23 & $\begin{array}{l}\text { Transmitir informações aos } \quad \text { funcionários } \\
\text { características do país de origem da empresa que são incorporadas à oferta. }\end{array}$ \\
\hline & & Q24 & $\begin{array}{l}\text { Motivar os funcionários a falar aos clientes sobre especificidades do país de } \\
\text { origem da empresa. }\end{array}$ \\
\hline & & Q25 & $\begin{array}{l}\text { Reconhecer a importância dos funcionários transmitirem informações aos } \\
\text { clientes sobre aspectos relacionados ao do país de origem da empresa }\end{array}$ \\
\hline & & Q26 & Analisar se o funcionário conhece a cultura do país de origem da empresa. \\
\hline
\end{tabular}

Nota: $\mathrm{AC}=$ Alfa de Cronbach; MII = Média de Correlações Inter-itens.

Calcularam-se também os valores de alfa de cronbach para cada dimensão caso um item fosse eliminado dela. Observou-se que o alfa de cronbach de nenhuma das dimensões aumentou com a possível retirada de um item (tabela 10). Dessa maneira, não foram encontrados indícios para se eliminar itens. Assim, novamente decidiu-se manter a estrutura da escala com os 26 itens. 
Tabela 10 - Análise de confiabilidade das dimensões no caso de exclusão de item

\begin{tabular}{|c|c|c|c|c|}
\hline Dimensões & $\begin{array}{c}\text { Média da escala } \\
\text { se item for } \\
\text { excluído }\end{array}$ & $\begin{array}{c}\text { Variância da } \\
\text { escala se item } \\
\text { for excluído }\end{array}$ & $\begin{array}{c}\text { Correlação item- } \\
\text { total corrigida }\end{array}$ & $\begin{array}{l}\text { Alpha de Cronbach } \\
\text { se item for excluído }\end{array}$ \\
\hline \multicolumn{2}{|c|}{ Elementos textuais e visuais } & \multicolumn{2}{|c|}{ AC 0,845 sem eliminar item } & \\
\hline SMEAN(Q1) & 14,620 & 57,601 & ,586 &, 828 \\
\hline SMEAN(Q2) & 14,740 & 57,360 & 625 & ,820 \\
\hline SMEAN(Q3) & 14,883 & 56,305 & ,662 & ,813 \\
\hline SMEAN(Q4) & 15,003 & 58,206 & ,643 & ,817 \\
\hline SMEAN(Q5) & 14,737 & 56,999 & ,688 & ,808 \\
\hline SMEAN(Q6) & 15,049 & 60,619 &, 553 & ,833 \\
\hline \multicolumn{2}{|l|}{ Recursos Naturais } & \multicolumn{2}{|c|}{ AC 0,927 sem eliminar item } & \\
\hline SMEAN(Q7) & 11,147 & 50,222 & ,752 & ,923 \\
\hline SMEAN(Q8) & 11,491 & 50,794 & 849 & ,904 \\
\hline SMEAN(Q9) & 11,308 & 51,236 & ,771 & ,918 \\
\hline SMEAN(Q10) & 11,415 & 49,074 & ,859 & ,901 \\
\hline SMEAN(Q11) & 11,392 & 50,437 & ,822 & ,908 \\
\hline \multicolumn{2}{|l|}{ Recursos Culturais } & \multicolumn{2}{|c|}{ AC 0,867 sem eliminar item } & \\
\hline SMEAN(Q12) & 11,264 & 39,233 & 679 &, 842 \\
\hline SMEAN(Q13) & 11,475 & 37,589 & ,763 & 820 \\
\hline SMEAN(Q14) & 11,649 & 38,010 & ,776 & ,816 \\
\hline SMEAN(Q15) & 12,280 & 43,445 & 639 &, 851 \\
\hline SMEAN(Q16) & 12,067 & 43,064 & ,597 &, 860 \\
\hline \multicolumn{2}{|l|}{ Sentidos } & \multicolumn{2}{|c|}{ AC 0,888 sem eliminar item } & \\
\hline$\overline{\text { SMEAN(Q17) }}$ & 8,728 & 31,123 & ,699 & 871 \\
\hline SMEAN(Q18) & 8,527 & 29,521 & ,733 &, 862 \\
\hline SMEAN(Q19) & 8,396 & 27,702 & ,749 & ,859 \\
\hline SMEAN(Q20) & 8,615 & 28,779 & ,741 &, 860 \\
\hline SMEAN(Q21) & 8,611 & 29,318 & ,723 &, 865 \\
\hline \multicolumn{2}{|l|}{ Funcionários } & \multicolumn{2}{|c|}{ AC 0,912 sem eliminar item } & \\
\hline SMEAN(Q22) & 12,418 & 50,533 & ,792 & 890 \\
\hline SMEAN(Q23) & 12,400 & 51,931 & ,767 & ,895 \\
\hline SMEAN(Q24) & 12,795 & 53,048 & ,803 & ,888 \\
\hline SMEAN(Q25) & 12,591 & 52,997 &, 787 & ,891 \\
\hline SMEAN(Q26) & 12,754 & 53,253 & ,738 & ,901 \\
\hline
\end{tabular}

Fonte: elaborado com base os relatórios do SPSS.

Como as análises não indicaram a exclusão de item algum nessa etapa do estudo, o modelo conceitual delineado ao longo da etapa de geração de itens e validação de conteúdo permaneceu válido, assim como os itens de cada dimensão. Seguiu-se para a etapa de análise de confiabilidade do estudo. 


\subsection{Subamostra 2 - Análise fatorial confirmatória e validação estatística}

Após a verificação da adequação do tamanho da amostra, delineou-se o modelo de mensuração dentro do software smartPLS, conforme modelo conceitual proposto, e deu-se início ao cálculo e análise de diversos indicadores (Ringle et al., 2014; Garson, 2012; Henseler et al., 2009; Henseler, Hubona \& Ray, 2016). O estudo confirmatório com base no modelo de mensuração foi realizado de duas maneiras: primeiro, por meio de MEE, com análise fatorial confirmatória de segunda ordem, em que o construto importância da COI como recurso na estratégia não teve mensuração, mas se valeu dele para constituir as relações causais para as variáveis latentes do estudo (como realizado por Neto, Avrichir, Silva e Figueiredo, 2016); depois realizou-se a AFC pelo método de saturação das variáveis seguindo as recomendações de Gefen \& Straub (2005). A figura 8 mostra o modelo de mensuração em linha com o modelo delineado previamente, validado pela AFE e que foi utilizado para realizar a AFC por meio da MEE de $2^{\mathrm{a}}$ ordem.

Figura 8 - Modelo de mensuração da escala

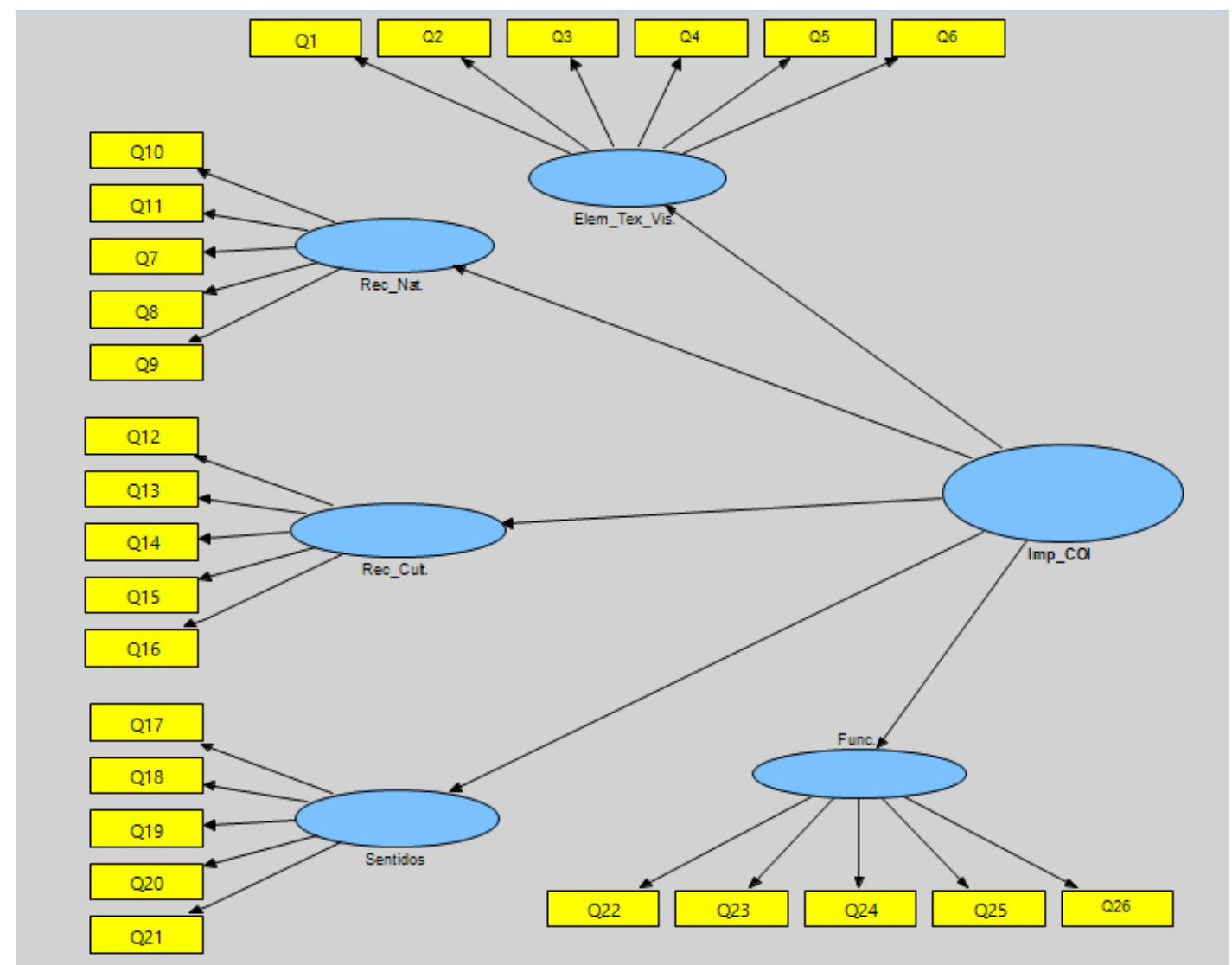

Fonte: SmartPLS 
Utilizou-se o algoritmo do PLS para calcular e verificar os primeiros indicadores. A figura 9 mostra o modelo de mensuração após esse processo. Por meio da observação de tal figura, analisou-se que as cargas fatoriais de cada item estão acima de 0,5, respeitando os critérios analisados previamente. Partiu-se para a análise dos relatórios gerados pelo smartPLS.

Figura 9 - Cargas do modelo de mensuração

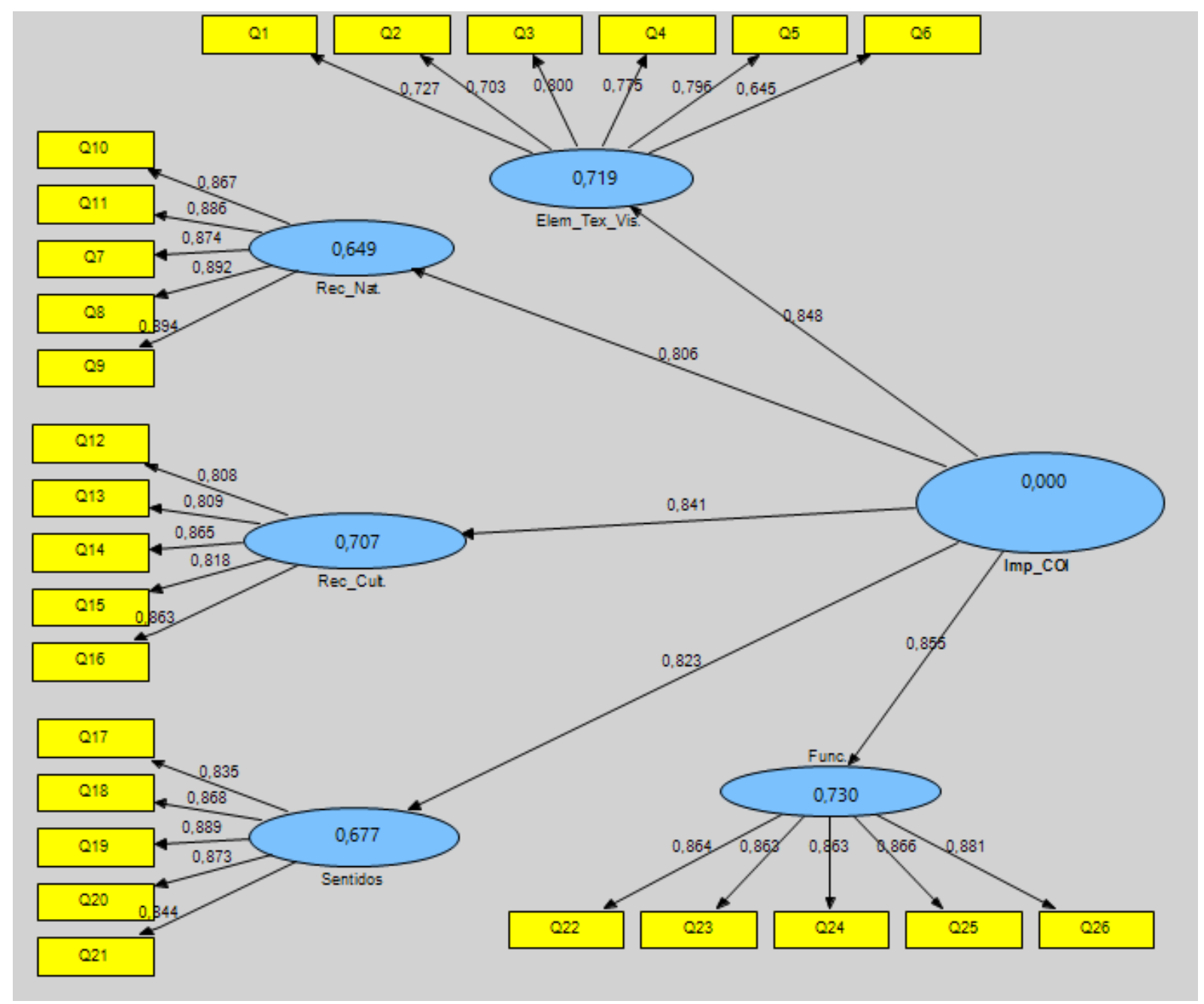

Fonte: Resultados gerados pelo SmartPLS

O cálculo do primeiro indicador avaliou a variância média extraída de cada construto. AVE é utilizada para verificar a validade convergente dos construtos, ou seja, é um dos critérios para de construto (Henseler et al, 2009). O valor das AVEs de todos os construtos foram acima (de 0,50) do valor de referência (Henseler et al, 2009) conforme dados apresentados no quadro 19. 
Quadro 19 - Especificação do modelo estrutural geral

\begin{tabular}{|c|r|r|r|}
\hline Construtos & AVE & \multicolumn{1}{c|}{$\begin{array}{l}\text { Composite } \\
\text { Reliability }\end{array}$} & Cronbachs Alpha \\
\hline BCOI & 0,555 & 0,839 & 0,957 \\
\hline Elementos & 0,552 & 0,880 & 0,836 \\
\hline Funcionários & 0,753 & 0,938 & 0,918 \\
\hline Recursos Culturais & 0,694 & 0,919 & 0,890 \\
\hline Recursos Naturais & 0,779 & 0,946 & 0,929 \\
\hline Sentidos & 0,743 & 0,935 & 0,913 \\
\hline Valor de referência & AVE $>\mathbf{0 , 5 0}$ & CC > 0,70 & AC > 0,70 \\
\hline Aporte teórico & Henseler et al. (2009) & Hair et al. (2014) & Hair et al. (2014) \\
\hline
\end{tabular}

Fonte: Elaborado pela autora a partir dos relatórios gerados pelo PLS

Para verificar a confiabilidade do modelo e consistência interna, dois indicadores foram analisados: o alfa de cronbach e a confiabilidade composta (Hair et al., 2014). Tais indicadores devem apresentar valores acima de 0,70 . Conforme se pode verificar no quadro 19 , todos os construtos apresentam valores superiores ao de referência para os dois indicadores.

Como os resultados de validade convergente e da confiabilidade do modelo mostraramse adequados, deu-se sequência ao processo de validação sem necessidade de retirada de item algum até esse momento da análise. O procedimento seguinte, denominado validade discriminante, teve como objetivo avaliar se os construtos são independentes entre si (Hair et al., 2016). Para tanto, dois métodos foram utilizados (Ringle et al, 2014; Henseler et al, 2016): a) o critério de Fornell \& Larcker (1981), em que se comparam as raízes quadradas dos valores de cada construto com as correlações (de Pearson) entre os construtos, e b) análise das cargas cruzadas, método que verifica se as cargas fatoriais mais altas pertencem ao construto previamente designado com base na literatura (Chin, 1998).

Para verificar a validade discriminante por meio do critério de Fornell e Larcker (1981), calcularam-se os valores das raízes quadradas das AVEs. Tais valores foram comparados com os coeficientes de correlação de Pearson (r) entre as variáveis latentes, conforme pode ser observado na diagonal principal do quadro 20.

Quadro 20 - Correlações entre as variáveis latentes e as raízes quadradas das AVEs

\begin{tabular}{|c|r|r|r|r|r|}
\hline $\begin{array}{l}\text { Dimensões da escala } \\
\text { (construtos de 1 }\end{array}$ ordem) & Elementos & Funcionários & $\begin{array}{l}\text { Recursos } \\
\text { Culturais }\end{array}$ & $\begin{array}{l}\text { Recursos } \\
\text { Naturais }\end{array}$ & Sentidos \\
\hline Elementos & $\mathbf{0 , 7 4 3}$ & & & & \\
\hline Funcionários & 0,630 & $\mathbf{0 , 8 6 8}$ & & & \\
\hline Recursos Culturais & 0,712 & 0,645 & $\mathbf{0 , 8 3 3}$ & & \\
\hline Recursos Naturais & 0,610 & 0,586 & 0,596 & $\mathbf{0 , 8 8 3}$ & \\
\hline Sentidos & 0,612 & 0,683 & 0,571 & 0,560 & $\mathbf{0 , 8 6 2}$ \\
\hline
\end{tabular}

Fonte: Elaborado pela autora a partir dos relatórios gerados pelo PLS 
O quadro 20 mostra que o modelo atende ao critério de Fornell \& Larcker (1981), pois os valores das raízes quadradas das AVEs (em destaque) são maiores do que os valores dos coeficientes de correlação de Pearson (r). Adicionalmente ao critério de Fornell \& Larcker (1981), confirmou-se a validade discriminante do modelo por meio da análise das cargas cruzadas (Chin, 1988), pois, ao se analisar a tabela 11, percebeu-se que as cargas fatoriais das variáveis observáveis têm valores maiores dentro dos construtos originais (do modelo). Assim, interpretando-se de forma conjunta os resultados do quadro 20 e da tabela 11, garante-se a validade discriminante do modelo.

Tabela 11 - Valores das cargas cruzadas das variáveis observáveis nas variáveis latentes

\begin{tabular}{|c|r|r|r|r|r|}
\hline Itens/Dimensões & Elementos & Funcionários & R. Culturais & R. Naturais & \multicolumn{1}{l|}{ Sentidos } \\
\hline Q1 & 0,727 & 0,446 & 0,517 & 0,442 & 0,501 \\
\hline Q2 & 0,703 & 0,471 & 0,507 & 0,420 & 0,404 \\
\hline Q3 & 0,800 & 0,424 & 0,466 & 0,436 & 0,460 \\
\hline Q4 & 0,775 & 0,412 & 0,501 & 0,415 & 0,398 \\
\hline Q5 & 0,796 & 0,555 & 0,636 & 0,624 & 0,522 \\
\hline Q6 & 0,645 & 0,486 & 0,527 & 0,340 & 0,426 \\
\hline Q22 & 0,566 & 0,864 & 0,542 & 0,508 & 0,603 \\
\hline Q23 & 0,543 & 0,863 & 0,574 & 0,539 & 0,558 \\
\hline Q24 & 0,507 & 0,863 & 0,577 & 0,521 & 0,625 \\
\hline Q25 & 0,537 & 0,866 & 0,543 & 0,468 & 0,592 \\
\hline Q26 & 0,580 & 0,881 & 0,559 & 0,507 & 0,583 \\
\hline Q12 & 0,579 & 0,527 & 0,808 & 0,462 & 0,468 \\
\hline Q13 & 0,516 & 0,446 & 0,809 & 0,457 & 0,405 \\
\hline Q14 & 0,621 & 0,614 & 0,865 & 0,569 & 0,479 \\
\hline Q15 & 0,596 & 0,514 & 0,818 & 0,465 & 0,464 \\
\hline Q16 & 0,645 & 0,570 & 0,864 & 0,520 & 0,553 \\
\hline Q7 & 0,510 & 0,445 & 0,505 & 0,874 & 0,456 \\
\hline Q8 & 0,577 & 0,531 & 0,527 & 0,892 & 0,500 \\
\hline Q9 & 0,554 & 0,524 & 0,497 & 0,894 & 0,512 \\
\hline Q10 & 0,491 & 0,508 & 0,483 & 0,867 & 0,499 \\
\hline Q11 & 0,555 & 0,573 & 0,610 & 0,886 & 0,501 \\
\hline Q17 & 0,570 & 0,572 & 0,483 & 0,448 & 0,835 \\
\hline Q18 & 0,536 & 0,578 & 0,461 & 0,456 & 0,868 \\
\hline Q19 & 0,570 & 0,587 & 0,503 & 0,448 & 0,889 \\
\hline Q20 & 0,485 & 0,616 & 0,537 & 0,572 & 0,873 \\
\hline Q21 & 0,478 & 0,588 & 0,477 & 0,483 & 0,844 \\
\hline
\end{tabular}

Fonte: Elaborado pelos autores a partir dos relatórios gerados pelo PLS

Em seguida, foram realizados os mesmos testes, mas, pelo método de saturação das variáveis. O modelo para rodar os testes por meio da saturação das variáveis é demonstrado na figura 10. 
Figura 10 - Modelo de saturação para AFC

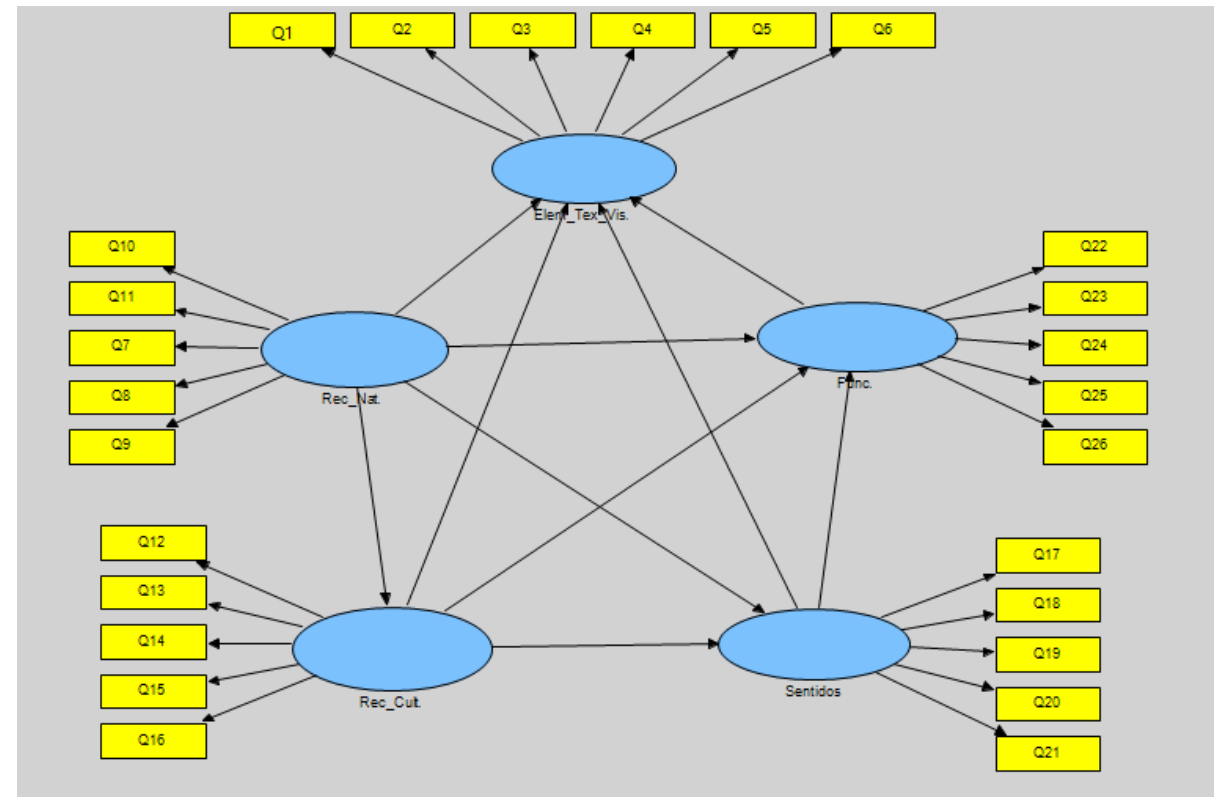

Fonte: SmartPLS

Após o estabelecimento das relações entre todos os construtos para saturar o modelo, utilizou-se o algoritmo PLS para obter os resultados de indicadores para avaliar a consistência interna, a validade convergente e a validade discriminante.

Figura 11 - Cargas das variáveis pelo método de saturação

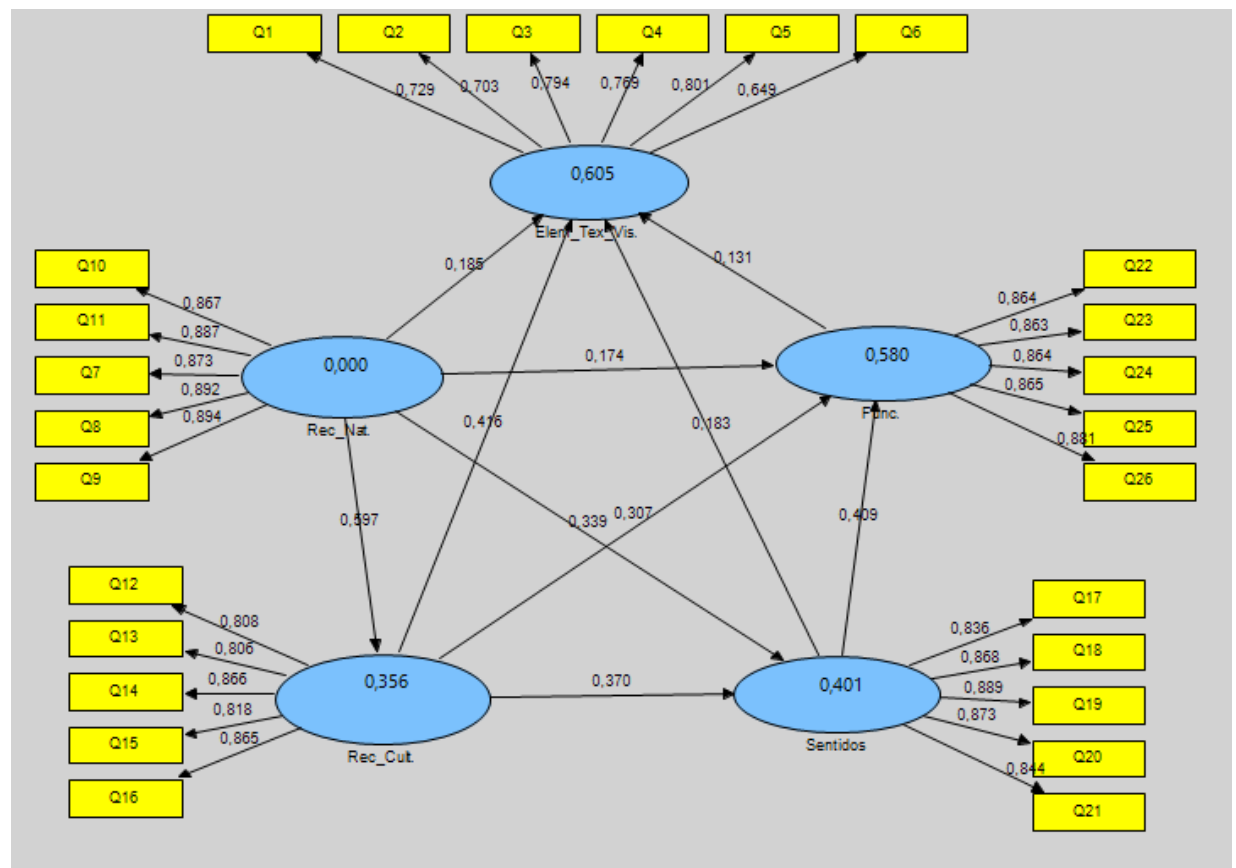

Fonte: Resultados gerados pelo SmartPLS 
Observa-se que os resultados obtidos para os indicadores de consistência interna apresentam os mesmos valores para os dois métodos de AFC conforme pode ser analisado pelos dados expostos na tabela 12 .

Tabela 12 - Resultados da análise de consistência interna pelos dois métodos de AFC pelo SmartPLS

\begin{tabular}{|c|c|c|c|c|r|r|}
\hline $\begin{array}{c}\text { Indicadores de } \\
\text { confiabilidade }\end{array}$ & \multicolumn{4}{|c|}{ AFC - método MEE 2a ordem } & \multicolumn{2}{|c|}{ AFC - método de saturação } \\
\hline Dimensões & AVE & C C & AC & AVE & C C & \multicolumn{1}{c|}{ AC } \\
\hline Elem_Tex_Vis. & 0,552 & 0,880 & 0,836 & 0,552 & 0,880 & 0,836 \\
\hline Func. & 0,753 & 0,938 & 0,918 & 0,753 & 0,938 & 0,918 \\
\hline Rec_Cult. & 0,694 & 0,919 & 0,890 & 0,694 & 0,919 & 0,890 \\
\hline Rec_Nat. & 0,779 & 0,946 & 0,929 & 0,779 & 0,946 & 0,929 \\
\hline Sentidos & 0,743 & 0,935 & 0,913 & 0,743 & 0,935 & 0,913 \\
\hline
\end{tabular}

Fonte: Resultados gerados pelo SmartPLS

Os resultados das correlações entre as variáveis latentes e as raízes quadradas da variância média extraída pelos dois métodos também se mostram muito parecidos e dentro do critério recomendado. Os resultados de ambos os métodos para um dos indicadores de validade discriminante podem ser comparados por meio da observação do quadro21.

Quadro 21 - Correlações entre as variáveis latentes e as raízes quadradas das AVEs

\begin{tabular}{|c|c|c|c|c|c|}
\hline \multicolumn{6}{|c|}{ Método MEE $2^{\text {a }}$ ordem } \\
\hline Dimensões da escala & Elem_Tex_Vis. & Func. & Rec_Cult. & Rec_Nat. & Sentidos \\
\hline Elem_Tex_Vis. & 0,743 & & & & \\
\hline Func. & 0,63 & 0,868 & & & \\
\hline Rec_Cult. & 0,712 & 0,645 & $\mathbf{0 , 8 3 3}$ & & \\
\hline Rec_Nat. & 0,61 & 0,586 & 0,596 & 0,883 & \\
\hline Sentidos & 0,612 & 0,683 & 0,571 & 0,56 & 0,862 \\
\hline \multicolumn{6}{|c|}{ Método de saturação } \\
\hline Elem_Tex_Vis. & 0,743 & & & & \\
\hline Func. & 0,632 & 0,868 & & & \\
\hline Rec_Cult. & 0,715 & 0,645 & 0,833 & & \\
\hline Rec_Nat. & 0,612 & 0,587 & 0,597 & 0,883 & \\
\hline Sentidos & 0,613 & 0,683 & 0,572 & 0,560 & 0,862 \\
\hline
\end{tabular}

Fonte: Resultados gerados pelo SmartPLS 
Por fim, analisaram-se as cargas cruzadas e, novamente, os resultados foram muito semelhantes com relação aos dois métodos de AFC. Isto é, as cargas fatoriais mais altas para cada item estavam relacionadas com o fator (dimensão) previamente determinado (literatura e AFE). Alguns itens apresentam cargas fatoriais altas em outros fatores também, mas isso é comum para modelos reflexivos, pois se espera que os fatores estejam correlacionados. A tabela 13 mostra os resultados das cargas cruzadas para os dois métodos por dimensão.

Tabela 13 - Resultados da análise das cargas cruzadas pelos dois métodos de AFC

\begin{tabular}{|c|c|c|c|c|c|c|c|c|c|c|}
\hline $\begin{array}{l}\text { Método da } \\
\text { AFC }\end{array}$ & MEE & Saturado & MEE & Saturado & MEE & Saturado & MEE & Saturado & MEE & Saturado \\
\hline Dimensão/itens & \multicolumn{2}{|c|}{ Elem_Tex_Vis. } & \multicolumn{2}{|c|}{ Func. } & \multicolumn{2}{|c|}{ Rec_Cult. } & \multicolumn{2}{|c|}{ Rec_Nat. } & \multicolumn{2}{|c|}{ Sentidos } \\
\hline Q1 & 0,727 & 0,729 & 0,446 & 0,446 & 0,517 & 0,518 & 0,442 & 0,442 & 0,501 & 0,501 \\
\hline Q2 & 0,703 & 0,703 & 0,471 & 0,471 & 0,507 & 0,507 & 0,42 & 0,420 & 0,404 & 0,404 \\
\hline Q3 & 0,800 & 0,794 & 0,424 & 0,424 & 0,466 & 0,467 & 0,436 & 0,436 & 0,46 & 0,460 \\
\hline Q4 & 0,775 & 0,769 & 0,412 & 0,412 & 0,501 & 0,502 & 0,415 & 0,415 & 0,398 & 0,398 \\
\hline Q5 & 0,796 & $\mathbf{0 , 8 0 1}$ & 0,555 & 0,555 & 0,636 & 0,636 & 0,624 & 0,624 & 0,522 & 0,522 \\
\hline Q6 & 0,645 & 0,649 & 0,486 & 0,486 & 0,527 & 0,527 & 0,34 & 0,340 & 0,426 & 0,426 \\
\hline Q22 & 0,566 & 0,568 & 0,864 & 0,864 & 0,542 & 0,543 & 0,508 & 0,508 & 0,603 & 0,603 \\
\hline Q23 & 0,543 & 0,545 & 0,863 & 0,863 & 0,574 & 0,574 & 0,539 & 0,540 & 0,558 & 0,558 \\
\hline Q24 & 0,507 & 0,508 & 0,863 & $\mathbf{0 , 8 6 4}$ & 0,577 & 0,578 & 0,521 & 0,521 & 0,625 & 0,625 \\
\hline Q25 & 0,537 & 0,539 & 0,866 & 0,865 & 0,543 & 0,544 & 0,468 & 0,469 & 0,592 & 0,592 \\
\hline Q26 & 0,580 & 0,581 & $\mathbf{0 , 8 8 1}$ & $\mathbf{0 , 8 8 1}$ & 0,559 & 0,560 & 0,507 & 0,507 & 0,583 & 0,584 \\
\hline Q12 & 0,579 & 0,580 & 0,527 & 0,526 & $\mathbf{0 , 8 0 8}$ & 0,808 & 0,462 & 0,463 & 0,468 & 0,468 \\
\hline Q13 & 0,516 & 0,518 & 0,446 & 0,446 & $\mathbf{0 , 8 0 9}$ & 0,806 & 0,457 & 0,458 & 0,405 & 0,405 \\
\hline Q14 & 0,621 & 0,624 & 0,614 & 0,614 & 0,865 & 0,866 & 0,569 & 0,569 & 0,479 & 0,479 \\
\hline Q15 & 0,596 & 0,598 & 0,514 & 0,514 & $\mathbf{0 , 8 1 8}$ & 0,818 & 0,465 & 0,465 & 0,464 & 0,464 \\
\hline Q16 & 0,645 & 0,646 & 0,57 & 0,570 & 0,864 & 0,865 & 0,52 & 0,520 & 0,553 & 0,554 \\
\hline Q7 & 0,510 & 0,511 & 0,445 & 0,445 & 0,505 & 0,505 & $\mathbf{0 , 8 7 4}$ & $\mathbf{0 , 8 7 3}$ & 0,456 & 0,456 \\
\hline Q8 & 0,577 & 0,579 & 0,531 & 0,531 & 0,527 & 0,528 & $\mathbf{0 , 8 9 2}$ & $\mathbf{0 , 8 9 2}$ & 0,5 & 0,500 \\
\hline Q9 & 0,554 & 0,556 & 0,524 & 0,524 & 0,497 & 0,498 & $\mathbf{0 , 8 9 4}$ & 0,894 & 0,512 & 0,512 \\
\hline Q10 & 0,491 & 0,493 & 0,508 & 0,508 & 0,483 & 0,483 & $\mathbf{0 , 8 6 7}$ & 0,867 & 0,499 & 0,499 \\
\hline Q11 & 0,555 & 0,556 & 0,573 & 0,573 & 0,61 & 0,611 & 0,886 & $\mathbf{0 , 8 8 7}$ & 0,501 & 0,501 \\
\hline Q17 & 0,570 & 0,570 & 0,572 & 0,572 & 0,483 & 0,483 & 0,448 & 0,449 & $\mathbf{0 , 8 3 5}$ & $\mathbf{0 , 8 3 6}$ \\
\hline Q18 & 0,536 & 0,536 & 0,578 & 0,578 & 0,461 & 0,461 & 0,456 & 0,456 & $\mathbf{0 , 8 6 8}$ & $\mathbf{0 , 8 6 8}$ \\
\hline Q19 & 0,570 & 0,572 & 0,587 & 0,587 & 0,503 & 0,504 & 0,448 & 0,448 & $\mathbf{0 , 8 8 9}$ & $\mathbf{0 , 8 8 9}$ \\
\hline Q20 & 0,485 & 0,487 & 0,616 & 0,616 & 0,537 & 0,537 & 0,572 & 0,572 & $\mathbf{0 , 8 7 3}$ & 0,873 \\
\hline Q21 & 0,478 & 0,480 & 0,588 & 0,588 & 0,477 & 0,476 & 0,483 & 0,483 & 0,844 & 0,844 \\
\hline
\end{tabular}

Fonte: Resultados gerados pelo SmartPLS 
Os resultados obtidos para os índices de consistência interna, validade convergente e a validade discriminante para os itens de cada uma das dimensões (construtos de $1^{\mathrm{a}}$ ordem) pelos dois métodos, quando não iguais, mostram-se extremamente próximos. Isso demonstrou que ambos os métodos podem ser utilizados para a realização da AFC pelo PLS. Ademais, todos os indicadores apresentaram resultados dentro dos valores de referência.

Dessa maneira, deram-se por encerrados os ajustes do modelo de mensuração e partiuse para a análise do modelo estrutural com objetivo de testar as relações entre as variáveis de $1^{\mathrm{a}}$ ordem (as dimensões) e a variável de $2^{\mathrm{a}}$ ordem. Para isso, utilizou-se o recurso de reamostragem (bootstrap) do SmartPLS. A primeira análise feita foi a avaliação dos coeficientes de determinação de Pearson $\left(R^{2}\right)$. Cohen (1988) recomenda que, para a área de ciências sociais, o $R^{2}=2 \%$ deve ser classificado como efeito pequeno, $R^{2}=13 \%$ como efeito médio e $R^{2}=26 \%$ como efeito grande. Os resultados de $R^{2}$ de cada dimensão estão indicados no quadro 22 e apontam que todo os valores de $R^{2}$ estão acima de $26 \%$. Por isso, considera-se que o efeito de todos os construtos para o modelo são grandes (Cohen, 1988).

\section{Quadro 22 - Valores de $\mathbf{R}^{2}$}

\begin{tabular}{|c|r|}
\hline $\begin{array}{c}\text { Dimensões da escala } \\
\text { (construtos de 1 }\end{array}$ ordem) & R Square \\
\hline Elementos & 0,719 \\
\hline Funcionários & 0,730 \\
\hline Recursos Culturais & 0,707 \\
\hline Recursos Naturais & 0,650 \\
\hline Sentidos & 0,677 \\
\hline
\end{tabular}

Fonte: Elaborado pela autora a partir dos relatórios gerados pelo PLS

Procedeu-se à avaliação das significâncias das correlações e regressões (Hair et al., 2016). Os resultados relacionados no quadro 23 indicaram que todas as relações de correlações entre os construtos e as variáveis e os coeficientes de caminho são significantes. Tal afirmação encontra apoio na análise dos valores entre as relações, fornecidos mediante o teste t de Student, que estão acima do valor de referência de 1,96 (Hair et. al, 2014), sugerindo que os valores-p são menores que $0,05(\mathrm{p}<0,05)$. 
Figura 12 - Modelo estrutural (Boostrap)

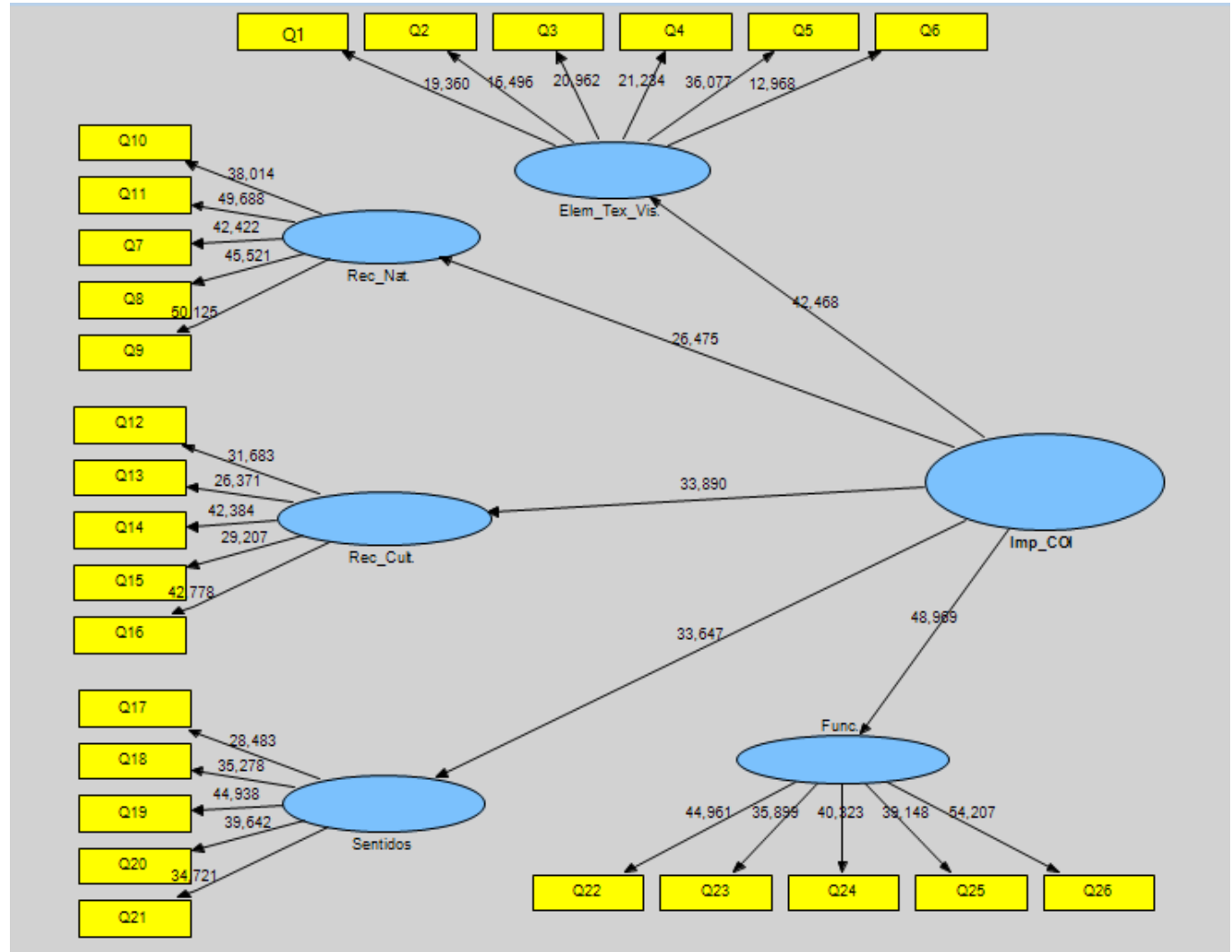

Fonte: SmartPLS

Quadro 23 - Valores t e p das relações causais entre os construtos do modelo ajustado

\begin{tabular}{|l|c|r|}
\hline \multicolumn{1}{|c|}{ Relações Causais } & T-valores & \multicolumn{1}{c|}{ p-valores } \\
\hline BCOI -> Elementos & 42,468 & $8,79 \mathrm{E}-113$ \\
\hline BCOI -> Funcionários & 48,969 & $6,03 \mathrm{E}-126$ \\
\hline BCOI -> Recursos Culturais & 33,890 & $7,60 \mathrm{E}-93$ \\
\hline BCOI -> Recursos Naturais & 26,475 & $9,60 \mathrm{E}-73$ \\
\hline BCOI -> Sentidos & 33,647 & $3,12 \mathrm{E}-92$ \\
\hline
\end{tabular}

Fonte: Elaborado pelos autores a partir dos relatórios gerados pelo PLS

Para estimar a qualidade de ajuste do modelo, foram utilizados dois indicadores:

a) o de validade preditiva $\left(Q^{2}\right)$ que avalia a precisão do modelo ajustado, ou seja, tem como objetivo avaliar o quanto o modelo se aproxima do esperado (Hair et al., 2016), e b) o tamanho do efeito $\left(f^{2}\right)$, que avalia quanto cada variável latente contribui para o ajuste do modelo (Hair et al., 2016), e

b) Os resultados de ambos indicadores foram obtidos empregando-se o módulo Blindfolding do SmartPLS, conforme pode ser observado na figura 13. 
Os resultados dos dois testes $\left(Q^{2} e f^{2}\right)$ - que podem ser analisados no quadro 24 mostram que o modelo tem acurácia (todos os valores de $Q^{2}$ são maiores que zero) e que os construtos são relevantes para o ajuste geral do modelo, pois os valores de $\mathrm{f}^{2}$ são superiores a 0,35 , indicando efeito grande.

Figura 13 - Modelo estrutural (Blindfolding)

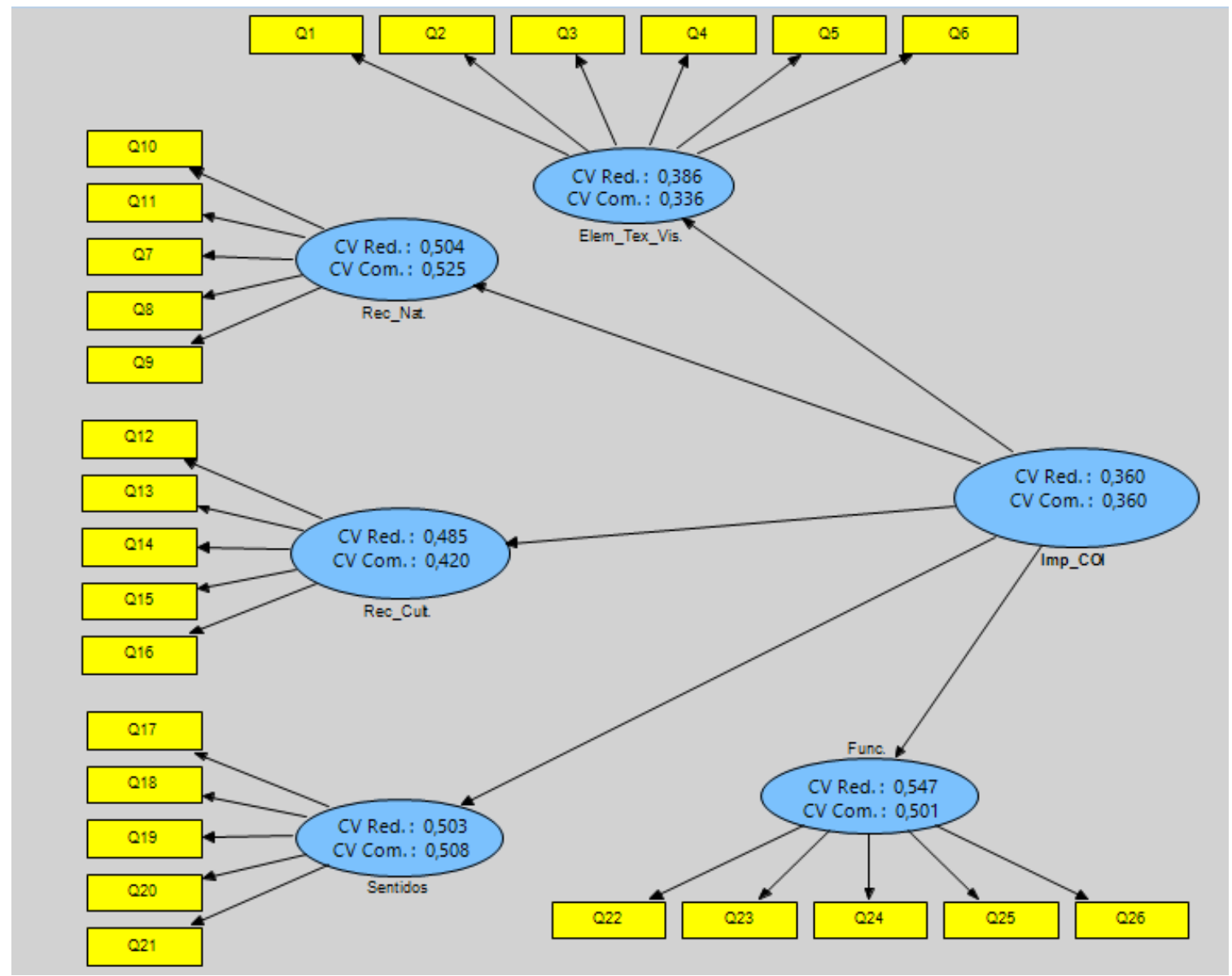

Fonte: SmartPLS

Quadro 24 - Valores dos tamanhos dos efeitos $\left(f^{2}\right)$ e das relevâncias preditivas $\left(Q^{2}\right)$

\begin{tabular}{|c|c|c|}
\hline Construtos & $\mathbf{Q}^{\mathbf{2}}$ & $\mathbf{f}^{\mathbf{2}}$ \\
\hline Elementos & 0,386 & 0,336 \\
\hline Recursos Naturais & 0,504 & 0,525 \\
\hline Recursos Culturais & 0,485 & 0,420 \\
\hline Sentidos & 0,503 & 0,508 \\
\hline Funcionários & 0,547 & 0,501 \\
\hline Valores de referência & & $\begin{array}{c}0,02 ; 0,15 \text { e 0,35 são } \\
\text { considerados pequenos, } \\
\text { médios e grandes }\end{array}$ \\
\hline Aporte teórico & Hair et al. (2016) & Hair et al. (2016) \\
\hline
\end{tabular}

Fonte: Elaborado pela autora a partir dos relatórios gerados pelo PLS 
Com a finalização da avaliação da qualidade de ajuste do modelo, recorreu-se ao último procedimento de validação do modelo: a interpretação dos coeficientes de caminho, a fim de analisar a intensidades das relações causais (Hair et al., 2016). Tais coeficientes são explicados como os betas das regressões lineares simples (Ringle et al., 2014). Os coeficientes de caminho apresentados no quadro 25 dão indicativo de que as relações entre as variáveis de $1^{\mathrm{a}}$ ordem e a de $2^{\mathrm{a}}$ ordem são relevantes.

Quadro 25 - Valores dos coeficientes de caminho do modelo ajustado

\begin{tabular}{|l|c|}
\hline \multicolumn{1}{|c|}{ Relações causais } & Coeficientes de caminho \\
\hline BCOI -> Elementos & 0,848 \\
\hline BCOI -> Funcionários & 0,730 \\
\hline BCOI -> Recursos Culturais & 0,841 \\
\hline BCOI -> Recursos Naturais & 0,805 \\
\hline BCOI -> Sentidos & 0,823 \\
\hline
\end{tabular}

Fonte: Elaborado pela autora a partir dos relatórios gerados pelo PLS

A figura 14 mostra o modelo estrutural ajustado. Tal modelo pode ser considerado válido para mensurar a importância da COI como recurso na estratégia, dado que apresentou validade discriminante, validade convergente e bons índices de confiabilidade.

Figura 14 - MEE ajustada com coeficientes de caminho, $\mathbf{R}^{2}$ e cargas fatoriais

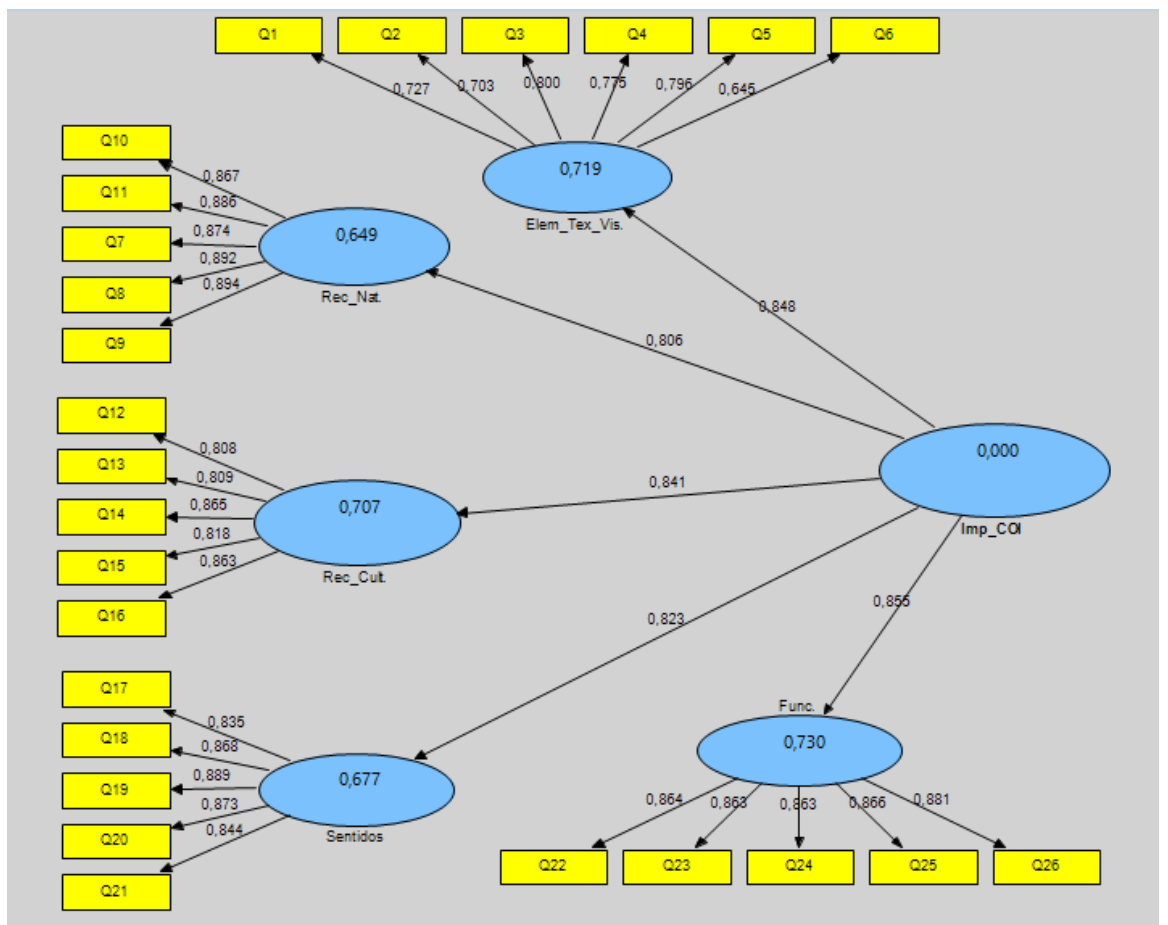

Fonte: SmartPLS 


\subsection{Discussão dos resultados}

Conforme revisado no capítulo 2, a RBT argumenta que a empresa tem recursos de diferentes naturezas e capacidades de níveis variados (Nath et al, 2010). Essa teoria defende também que a sobrevivência da empresa depende de sua capacidade de criar novos recursos, construir uma plataforma de capacidades e fazer com que as capacidades sejam inimitáveis para alcançar uma vantagem competitiva (Day \& Wensley, 1988; Peteraf, 1993). Este estudo partiu do entendimento de que as capacidades de marketing podem criar uma forte imagem de marca (ativo) a qual permite à empresa alcançar desempenho superior (Ruiz-Ortega \& GarcíaVillaverde, 2008). Todavia, por si só, a COI não gera vantagem competitiva. Cabe a empresa fazer uso desse recurso ao combinar e articular com seus recursos organizacionais para a construção de uma capacidade de gestão da marca.

Assim, argumentou-se que um potencial recurso para a empresa utilizar em sua estratégia de marca consiste na COI e, buscou-se construir um instrumento de mensuração para verificar a importância atribuída pelas empresas em processo de internacionalização ao uso da COI por meio da capacidade de marca.

Os resultados das análises da AFE com a subamostra 1 foram satisfatórios. Com isso, cumpriu-se o primeiro objetivo especifico do estudo o de: Propor e refinar uma escala para mensurar a importância da incorporação da COI como recurso na construção da capacidade de marca da empresa em processo de internacionalização, definindo suas dimensões e respectivos indicadores. Os resultados da AFE não apontaram para a exclusão de item. Assim, o modelo conceitual delineado ao longo da etapa de geração de itens e validação de conteúdo permaneceu adequado, e partiu-se para a etapa de AFC com a subamostra 2. Os resultados da AFC, também foram satisfatórios. Desse modo, atendeu-se ao segundo objetivo específico do estudo o de: Testar e validar as escalas propostas para os constructos de $1^{a}$ ordem e as relações deles com o construto de $2^{a}$ ordem.

Após a AFE e AFC, recorreu-se à avaliação do modelo estrutural por meio da MEE. Nessa etapa verificaram-se os coeficientes de determinação, a validação preditiva, o tamanho do efeito, o tamanho e significância dos coeficientes de caminho. Como analisado no item anterior, todos os índices mostraram-se satisfatórios. Importante atentar para a análise dos indicadores das significâncias das correlações e regressões e coeficientes de caminho, pois, ao final do capítulo 2 , foram tecidas hipóteses acerca da relação entre as dimensões (construtos de 
$1^{\mathrm{a}}$ ordem) e a variável BCOI (construto de $2^{\mathrm{a}}$ ordem). Assim sendo, a avaliação de tais indicadores é que poderá dar ou não suporte à confirmação das hipóteses. Conforme pode ser analisado no quadro 26, todas as relações de correlações entre os construtos e as variáveis e os coeficientes de caminho são significantes. Ou seja, os valores fornecidos mediante o teste t de Student estão acima do valor de referência de 1,96 (Hair et. al, 2014), sugerindo que os valoresp são menores que $0,05(\mathrm{p}<0,05)$.

\section{Quadro 26 - Valores t, valores p e coeficientes de caminho das relações causais entre os construtos do modelo ajustado}

\begin{tabular}{|l|c|r|r|}
\hline \multicolumn{1}{|c|}{ Relações Causais } & T-valores & p-valores & $\begin{array}{r}\text { Coeficientes } \\
\text { de caminho }\end{array}$ \\
\hline BCOI -> Elementos & 42,468 & $8,79 \mathrm{E}-113$ & 0,848 \\
\hline BCOI -> Funcionários & 48,969 & $6,03 \mathrm{E}-126$ & 0,730 \\
\hline BCOI -> Recursos Culturais & 33,890 & $7,60 \mathrm{E}-93$ & 0,841 \\
\hline BCOI -> Recursos Naturais & 26,475 & $9,60 \mathrm{E}-73$ & 0,805 \\
\hline BCOI -> Sentidos & 33,647 & $3,12 \mathrm{E}-92$ & 0,823 \\
\hline
\end{tabular}

Fonte: Elaborado pela autora a partir dos relatórios gerados pelo PLS

A análise dos valores do coeficiente de caminho permite ao pesquisador compreender o quanto a variável de $1^{\mathrm{a}}$ ordem (dimensões da escala) aumentará se a variável de $2^{\mathrm{a}}$ ordem (Importância da BCOI) aumentar em um ponto (Ringle et al., 2014). Assim, observa-se que os coeficientes de caminho explicando as relações causais entre a importância da COI e suas dimensões são relativamente altos, pois todos estão acima de 0,73 . Pode-se, portanto, inferir que:

- Quando a variável de $2^{\mathrm{a}}$ ordem BCOI aumentar em 1 ponto, a variável de $1^{\mathrm{a}}$ ordem recursos naturais aumentará em 0,805. Por isso, confirmou-se que a importância da COI como recurso na construção da capacidade de marca manifesta-se por meio da incorporação de recursos naturais do país de origem à capacidade da marca $(\mathrm{H} 1)$;

- De modo bastante expressivo, também se observou que, quando a variável de $2^{\mathrm{a}}$ ordem BCOI aumentar em 1 ponto, a variável de $1^{a}$ ordem recursos culturais aumentará em 0,841. Assim, também confirmou-se que a importância da BCOI como recurso na construção da capacidade de marca da empresa é manifestada por meio da incorporação de recursos culturais do país de origem à capacidade da marca $(\mathrm{H} 2)$; 
- A dimensão elementos textuais e visuais, a qual, a princípio, foi constituída em duas hipóteses, mostrou necessidade de ser unificada, pois poderia causar confusão na mente do respondente. Essa dimensão mostrou uma relação de alta intensidade com a variável de $2^{\mathrm{a}}$ ordem, pois, pela interpretação do resultado do coeficiente de caminho, quando a Importância da BCOI aumentar em 1 ponto, essa variável aumentará em 0,848. Logo, a H3 (a importância da COI como recurso construção da capacidade de marca da empresa é manifestada por meio da incorporação de elementos textuais e visuais do país de origem à capacidade da marca) foi confirmada;

- Com relação à dimensão sentidos, referente a H4, observou-se o coeficiente de caminho de 0,823. Logo, ao se aumentar em 1 a importância da COI como recurso na estratégia da empresa, aumenta-se em 0,823 a dimensão sentidos. Com isso, a H4 (a importância da COI como recurso na estratégia construção da capacidade de marca da empresa é manifestada por meio da utilização de sentidos associados ao país de origem à capacidade da marca) também foi confirmada;

- Por fim, a dimensão funcionários também apresentou coeficiente de caminho alto, ou seja, quando a variável de $2^{\mathrm{a}}$ ordem BCOI aumentar em 1 , a variável de $1^{\mathrm{a}}$ ordem funcionários aumentará em 0,730. Confirmou-se, portanto, que a importância da COI como recurso na estratégia da empresa também é manifestada por meio da incorporação de treinamentos e capacitação dos funcionários sobre o país de origem à construção da capacidade de marca (H5).

A partir dos resultados da pesquisa de campo, foi possível propor uma escala para descrever, analisar e mensurar a importância da BCOI da empresa em processo de internacionalização. Atingiu-se, portanto, o objetivo geral deste estudo e contemplou-se o problema de pesquisa identificado. A escala de BCOI é um construto reflexivo manifestado por meio de outros cinco construtos (figura 15):

- Elementos textuais e visuais: operacionalizado por meio da associação da linguagem do país de origem utilizando o nome de lugares, nome de pontos turísticos, sigla, nome do país, nome de pessoas famosas do país de origem da empresa; assim como a incorporação de aspectos visuais, tais como imagens da bandeira do país, de pessoas famosas, paisagens, imagens de frutos, cores da bandeira - por meio da embalagem dos produtos, no design do produto, na propaganda da empresa; 
- Sentidos: ao se incorporar à marca os demais sentidos (olfato, tato e paladar) por meio de elementos do país de origem (músicas, aromas específicos) na atmosfera do ponto de venda e no design do produto;

- Recursos naturais: por meio da utilização e enaltecimento das matérias-primas típicas e recursos naturais da biodiversidade do país de origem da empresa;

- Recursos culturais: incorporando as heranças culturais, artes, crenças, aspirações, hábitos, costumes, regras, normas, atitudes, valores e mitos mantidos por grande parte da sociedade de um país na marca da empresa;

- Funcionários: capacitação, treinamento e desenvolvimento dos funcionários para falar sobre o país de origem da marca.

Figura 15 - A importância da incorporação da COI na construção da capacidade de marca (BCOI)

Elementos textuais e visuais

Nome de: lugares, pontos turísticos, de pessoas famosas do país de origem da empresa, nome do país, sigla; aspectos visuais, tais como: imagens da bandeira do país, de pessoas famosas, paisagens, imagens de frutos, cores da bandeira

(H3).
Recursos naturais:

Utilização de matérias-primas típicas e recursos naturais da biodiversidade do país de origem da empresa (H1).
Funcionários: capacitação, treinamento e desenvolvimento dos funcionários para falar sobre o país de origem da marca

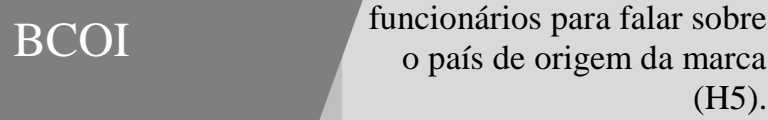

\section{Sentidos:}

Incorporar à marca os demais sentidos (olfato, tato e paladar) por meio de elementos do país de origem (músicas, aromas específicos) na atmosfera do ponto de venda e no design do produto $(\mathrm{H} 4)$.
Recursos culturais: Heranças culturais, artes, crenças, aspirações, hábitos, costumes, regras, normas, atitudes, valores e mitos mantidos por grande parte da sociedade de um país (H2).

Fonte: autora

Para assegurar a validade, a confiabilidade e a dimensionalidade da escala, adotaram-se diversos procedimentos psicométricos conforme destacado por Roth \& Diamantopoulos 
(2009). O processo de desenvolvimento e validação da escala foi realizado em diversas etapas, de modo bastante minucioso, justamente para assegurar que os itens e dimensões representavam o construto que o estudo almejou mensurar. Observa-se que o processo foi positivo, uma vez que a estrutura da escala não sofreu alteração nas fases em que foram utilizadas técnicas estatísticas mais avançadas.

A figura 16 resume as principais fases do estudo e o que foi realizado em cada uma delas.

Figura 16 - Processo de desenvolvimento e validação da escala

\begin{tabular}{|c|c|}
\hline $\begin{array}{c}\text { Etapa } 1 \\
\text { Definição do construto }\end{array}$ & $\begin{array}{r}\text { Intensa revisão da literatura } \\
\text { Definição do construto } \\
\text { Versão primária da escala: } 6 \text { dimensões e } 22 \text { itens }\end{array}$ \\
\hline $\begin{array}{c}\text { Etapa } 2 \\
\text { Geração de item }\end{array}$ & 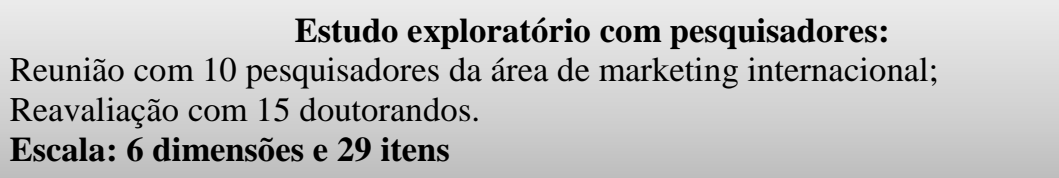 \\
\hline $\begin{array}{l}\text { Etapa } 3 \\
\text { Validação de conteúdo e } \\
\text { purificação inicial }\end{array}$ & $\begin{array}{l}\text { Pesquisa com experts } \\
\text { Validação de conteúdo com } 4 \text { pesquisadores da área de marketing com } \\
\text { experiência em desenvolvimento de escalas. } \\
\text { Escala: } \mathbf{5} \text { dimensões e } 27 \text { itens }\end{array}$ \\
\hline $\begin{array}{l}\text { Etapa } 4 \\
\text { Validação de face e } \\
\text { purificação inicial }\end{array}$ & 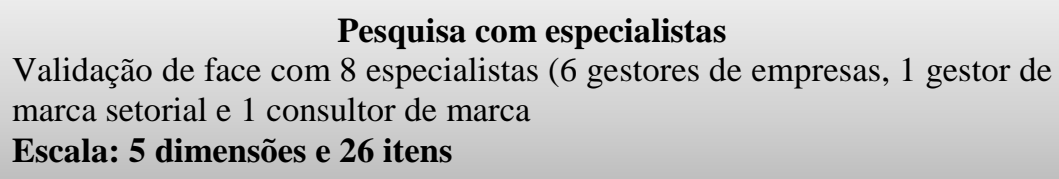 \\
\hline $\begin{array}{c}\text { Etapa } 5 \\
\text { Purificação dos itens }\end{array}$ & 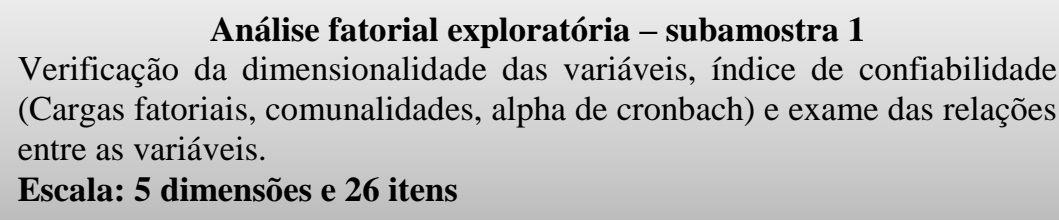 \\
\hline $\begin{array}{c}\text { Etapa } 6 \\
\text { Análise da } \\
\text { confiabilidade e modelo } \\
\text { de mensuração }\end{array}$ & $\begin{array}{l}\quad \text { Análise fatorial confirmatória - subamostra } 2 \\
\text { - Consistência interna (alpha de cronbach e confiabilidade composta) } \\
\text { - Validade convergente (indicador de confiabilidade e variância média } \\
\text { extraída); } \\
\text { - Validade discriminante } \\
\text { Escala: } 5 \text { dimensões e } 26 \text { itens }\end{array}$ \\
\hline $\begin{array}{l}\text { Etapa } 7 \\
\text { Análise do modelo } \\
\text { estrutural e validade } \\
\text { estatística }\end{array}$ & $\begin{array}{l}\text { Modelagem de equações estruturais - subamostra } 2 \\
\text { - Avaliação dos coeficientes de determinação de Pearson }\left(R^{2}\right) \\
\text { - Teste T de Student (verificação das hipóteses); } \\
\text { - Tamanho do efeito }\left(f^{2}\right) \\
\text { - Relevância preditiva }\left(Q^{2}\right) \\
\text { - Coeficiente de caminho (verificação das hipóteses) } \\
\text { Escala: } 5 \text { dimensões e } 26 \text { itens }\end{array}$ \\
\hline
\end{tabular}

Fonte: autora 
Os resultados apontam que a COI pode representar um novo recurso passível de ser utilizado no desenvolvimento e construção de marca (capacidade de marketing) de empresas que estejam em processo de internacionalização. Assim, a relação entre RBT e marketing que se mostrou neste estudo - COI como recurso a ser utilizado pela área de marketing na construção da imagem de empresas que estão se internacionalizando - atende à solicitação Barney et al. (2001) ao mostrar como a área de marketing pode esclarecer a natureza de recursos. O estudo assumiu que tal recurso deve ser desenvolvido por meio das capacidades, processos, ativos físicos, relacionais e intelectuais da área de marketing.

De acordo com Srivastava et al. (2001) qualquer aplicação de RBT ao marketing pode ser considerada ao se identificar recursos que são específicos de marketing (gerados e alavancados pelas atividades de marketing) e que potencialmente manifestem pelo menos um dos atributos desejados na RBT (valioso, raro, difícil de se imitar, difícil de ser utilizado pela organização). A BCOI, por meio de suas dimensões, pode apresentar tais requisitos, pois é um recurso gerado e alavancado pela atividade de marketing - por meio da marca (Samiee, 2011; Samiee et al., 2005) - e mostra-se valioso dependendo do setor e categoria de produto em que é utilizado (Samiee, 2011; Roth \& Romeo, 1992). Bem como, demanda habilidades para ser utilizada pela organização, pois abrange diversos atributos (Spence \& Hamzaoui Essoussi, 2010) e dimensões como funcionários, recursos naturais e culturais, que podem representar verdadeiras barreiras para imitação. 


\section{CONCLUSÕES}

Este estudo argumenta que o país de origem pode estender a teoria baseada em recursos ao ampliar as funcionalidades do COI. Ela defende que o papel do COI não se limita às suas influências no comportamento do consumidor internacional, mas pode, também, servir como um recurso para a empresa ao ser considerado fonte de informação para avaliação de marcas (Đorđević, 2008; Herstein, Berger \& Jaffe, 2014). Enquanto a maioria dos estudos sobre COI investiga o construto pela ótica do consumidor (no B2B e no B2C), a presente tese explorou a temática sob o enfoque da estratégia, mais especificamente sob as lentes da RBT. O estudo atendeu ao seu propósito de desenvolver e vaidar uma escala para mensurar a importância da COI como recurso na estratégia da empresa em processo de internacionalização, definida neste estudo, como a incorporação da COI na capacidade de marca. Esta tese mostra que, apesar do construto país de origem ter um corpo teórico robusto, ele ainda pode ser desenvolvido em novas perspectivas.

A partir da ótica interdisciplinar, recomendada por Roth \& Diamantopoulos (2009) para a temática e, seguindo sugestões de Samiee (2010), Cuervo-Cazurra \& Un (2015) e CuervoCazurra (2011), buscou-se a perspectiva do país de origem na estratégia. Com isso, a abordagem do estudo veio ao encontro de demandas de pesquisadores da área de estratégia para a revitalização e ampliação da teoria baseada em recursos com base em outros campos de estudo, como por exemplo, a área de marketing (Barney et al., 2001; 2014).

Dessa maneira, esta tese desenvolveu e validou uma escala de importância da COI como recurso na estratégia da empresa em processo de internacionalização, dado que não foram encontrados estudos quantitativos e uma escala para mensurar tal construto. Os resultados encontrados por meio da análise dos dados coletados em campo ratificaram as dimensões identificadas na literatura para medir o construto e estimou o modelo para mensurar a BCOI. Os achados indicaram que tal construto é multidimensional, podendo ser operacionalizado por meio de uma escala com 26 itens, estruturada em 5 dimensões (variáveis latentes): recursos naturais, recursos culturais, elementos textuais e visuais, sentidos e funcionários. Os resultados também apontaram que o construto é reflexivo, pois as dimensões da importância da COI como recurso são manifestações do construto. Por isso, considera-se que uma empresa pode reconhecer valor na COI mesmo não utilizando todas as suas dimensões. 
O estudo contribui ao ampliar a estruturação do conhecimento sobre o COO e RBT, atendendo a solicitações de acadêmicos da área de estratégia para revitalizar a RBT (Barney et al, 2011; Barney, 2014) e de marketing internacional avaliando o COI a partir de novas perspectivas (Herz \& Diamantopoulos 2013; Diamantopoulos et al., 2011; Magnusson Westjohn \& Zdravkovic, 2011). Ademais, o estudo relacionou as duas variáveis acatando recomendações de pesquisadores tanto da área de estratégia (Sethi \& Elango, 2000; Cuervo Cazurra \& Un, 2015; Cuervo-Cazurra, 2011) quanto da área de marketing (Baker \& Ballington, 2002; Castro, Giraldi \& Galina, 2014; Samiee, 2011). Esta tese mostra ainda que, apesar da opinião de uma linha de acadêmicos, a COI permanece sendo um tema relevante e pode ser investigada sob diferentes perspectivas e em contextos diferentes dos habituais, como por exemplo, com empresas de mercados emergentes.

A principal contribuição da tese, para as duas linhas de pesquisas envolvidas neste estudo (estratégia e marketing internacional), consiste no desenvolvimento de uma escala para mensurar a COI pela ótica da estratégia, reunindo dimensões sobre a COI passíveis de serem incorporadas à estratégia de marca quando a empresa reconhecer a COI como um recurso. Dessa forma, o estudo contribui ao propor uma escala para COI ple perspectiva empresarial, ou seja, cuja unidade de análise não é o consumidor final e sim a empresa. Ademais, o estudo contribui para a literatura de estratégia, ao apontar potenciais processos de um recurso que podem gerar competitividade às empresas. Como consequência, a contribuição gerencial da pesquisa desdobra-se no fornecimento de subsídios para empresas e gestores de marca desenvolverem estratégias para incorporação e potencialização da utilização COI em transações entre fronteiras, assim como no apontamento de nuances (dimensões) do país de origem que podem fazer parte da identidade da marca.

Importante destacar que o desenvolvimento do instrumento que mensura a importância da COI como recurso na estratégia da empresa em processo de internacionalização permitirá aos pesquisadores de estratégia e de marketing internacional identificar as empresas que utilizam a COI como recurso na estratégia e o modo como operacionalizam essa incorporação, podendo-se, ainda, verificar quais são as dimensões mais relevantes nesse processo e se é um recurso capaz de gerar uma vantagem competitiva sustentável. Sobretudo, ao ser relacionado com outras variáveis, o instrumento permitirá compreender as situações sob as quais a COI mostra-se um recurso valioso e se variáveis como o país de destino, nível de 
internacionalização, apoio do governo e setor exercem papel (influenciador, moderador ou mediador) na atribuição de importância da COI como recurso na ótica da empresa.

Outro aspecto que poderá ser investigado é se a marca-país influencia positivamente na importância atribuída à COI como recurso na estratégia da empresa, podendo assim, incitar uma parceria entre governos e empresas para fortalecimento e disseminação da imagem do país tanto no mercado interno quanto em novos mercados. Portanto, o instrumento proposto nesta tese permitirá que novas perspectivas de estudos sejam desenvolvidas, juntando diferentes esferas acadêmicas, e que novas problemáticas sejam endereçadas. Possibilitará ainda que novas contribuições gerenciais sejam elaboradas, para compreender se a empresa deve ou não mostrar as qualidades do seu país (La et al., 2009). Auxiliará também os gestores de marketing que estão monitorando as impressões que a COI da marca desperta nos seus consumidores para, então, selecionar as dimensões da COI como recurso e os atributos específicos a marca-país para incluir na comunicação com o mercado e, assim, mitigar sinais que possam evocar procedência desfavorável para a marca (D’Antone \& Merunka, 2015).

Recomendam-se estudos futuros que utilizem a escala em empresas em diferentes fases de internacionalização para verificar se há diferença na importância atribuída pela empresa à COI e, também, se tal importância é diferente em função dos aspectos institucionais do país de origem. As seguintes questões poderão ser levantadas: como utilizar ou não a COI? Em quais condições utilizar a COI (dependendo do país de destino, setor da empresa ou mesmo do nível de internacionalização)? Quais dimensões da marca-país devem ser enfatizadas nos processos de incorporação da COI? Sugerem-se estudos futuros para verificar se a importância da COI reconhecida pelas empresas também é valorizada pelo consumidor final e se a importância da COI na estratégia se reverbera ao longo da cadeia de suprimentos da empresa.

O estudo se apoiou em diversos procedimentos psicométricos para assegurar a dimensionalidade do construto (intensa revisão da literatura, pesquisa e reunião com pesquisadores, análise fatorial exploratória), confiabilidade (alfa de cronbach e confiabilidade composta), validade de translação (validade de face e de conteúdo) e validade do construto (validade convergente e discriminante) e técnicas estatísticas avançadas (AFC e MEE). Esses aspectos são recomendados por diversos psicometristas para desenvolvimento de escalas e, em especial, por Roth \& Diamantopoulos (2009) para escalas de COI, pois, conforme constatado por esses autores, a maioria dos estudos sobre desenvolvimento de escalas do tema carece de procedimentos de validação e confiabilidade. No entanto, este é o primeiro estudo que aplica 
essa escala. Logo, seria interessante realizar uma segunda coleta para comparar os resultados da escala (validação cruzada) em outros contextos, de modo a assegurar os seus índices de confiabilidade e validade. Recomendam-se estudos, também, com empresas operando em outros países e de outras nacionalidades, para que se possa explorar tanto as diferenças entre culturas e contextos institucionais, como validar a escala e entre países. 


\section{REFERÊNCIAS}

Aaker, D. A., \& Joachimsthaler, E. (2000). The brand relationship spectrum. California Management Review, 42(4), 8-23.

Acedo, F. J., Barroso, C., \& Galan, J. L. (2006). The resource-based theory: dissemination and main trends. Strategic Management Journal, 27(7), 621-636.

Agrawal, J. \& Kamakura, W. A. (1999). Country of Origin: A competitive advantage? International Journal of Research in Marketing, 16, 255-267.

Ahmed, S. A., \& d'Astous, A. (1995). Comparison of country of origin effects on household and organizational buyers' product perceptions. European Journal of Marketing, 29(3), 35-51.

Al-Sulaiti, K, \& Baker, M. J. (1998). Country of origin effects: a literature review. Marketing Intelligence \& Planning, 16(3), 150-190.

Amit, R., \& Schoemaker, P. J. (1993). Strategic assets and organizational rent. Strategic Management Journal, 14, 33-46.

Bacha Lopes, I., Giraldi, J. de M. E. \& Aguiar, L. K. (2014). An Analysis of Country Image of Brazil and Its Fresh Fruits: A Two Scales Comparison. Journal of Food Products Marketing, 20, 262-282, doi: 10.1080/1045446.2012.726947

Baker, M. J., \& Ballington, L. (2002). Country of origin as a source of competitive advantage. Journal of Strategic Marketing, 10(2), 157-168.

Barney, J. B. \& Hesterly, W. S. (2007). Administração Estratégica e Vantagem Competitiva. São Paulo: Pearson Prentice Hall.

Barney, J. B. (1991). Firm Resources and Sustained Competitive Advantage. Journal of Management, 17(1), 99-120. doi: 10.1177/014920639101700108

Barney, J. B. (1995). Looking inside for competitive advantage. The Academy of Management Executive, 9(4), 49-61.

Barney, J. B., Ketchen, D. J., \& Wright, M. (2011). The future of resource-based theory revitalization or decline?. Journal of management, 37(5), 1299-1315.

Barney, J. B. (2014). How marketing scholars might help address issues in resource-based theory. Journal of the Academy of Marketing Science, 42(1), 24-26.

Barney, J., Wright, M., \& Ketchen, D. J. (2001). The resource-based view of the firm: Ten years after 1991. Journal of management, 27(6), 625-641.

Beverland, M. \& Lindgreen, A. (2002). Using country of origin in strategy: the importance of context and strategic action. Brand Management, 10(2), 147-167.

Bilkey, W. J., \& Nes, E. (1982). Country-of-Origin Effects on Product Evaluations. Journal of International Business Studies, 13(1), 89-100.

Brito, L. A. L., \& Vasconcelos, F. C. de (2005). A Influência do País de Origem no Desempenho das Empresas. RAC, 9(4), 97-118.

Brodie, R. J., Brodie, R. J., Benson-Rea, M., \& Benson-Rea, M. (2016). Country of origin branding: an integrative perspective. Journal of Product \& Brand Management, 25(4), 322336.

Brown, T. A. \& Moore, M. T. (2012). Confirmatory factor analysis. In: Hoyle, R. H. (Ed.). (2012). Handbook of structural equation modeling. Guilford Press. 
Castro, V. A., Giraldi, J. D. M. E., \& Galina, S. V. R. (2014). Revisão Sistemática de Trabalhos Acadêmicos Internacionais sobre Marca-País como Fonte de Vantagem Competitiva. TurismoVisão e Ação, 16(1), 28-60.

Cater, T. (2003). The relevance of four schools of thought on the sources of a firm's competitive advantage: a case of Slovenian firms. Economic and Business Review, 5(4), 309-332.

Cattin, P., Jolibert, A., \& Lohnes, C. (1982). A cross-cultural study of" made in" concepts. Journal of International Business Studies, 131-141.

Carroll, A. (2009). Brand communications in fashion categories using celebrity endorsement. Journal of Brand Management, 17(2), 146-158.

Castro, V. A \& Giraldi, J. M. E. (2015) Estratégias de Marcas para Setores Brasileiros: uma análise das diferenças conceituais entre Indicação Geográfica, Marca Coletiva e Marca Setorial. Anais do VII Encontro de Estudos em Estratégia (3 Es) - ANPAD. 2015.

Cavusgil, S. T., Deligonul, S., \& Yaprak, A. (2005). International Marketing as a Field of Study: A Critical Assessment of Earlier Development and a Look Forward. Journal of International Marketing, 13(4), 1-27. doi:10.1509/jimk.2005.13.4.1

Chao, P., \& Rajendran, K. N. (1993). Consumer profiles and perceptions: country-of-origin effects. International Marketing Review, 10(2).

Chattpadhyay, A., Batra, R., Ozsomer, A. (2012). The New Emerging Market Multinationals: Four Strategies for Disrupting Markets and Building Brands. McGraw Hill.

Cheng, K., Chen, H. P., Lai, W., \& Li, C. (2014). Country Image Effect on Services: A Study of Consumers' Evaluation of Foreign Airlines. Journal of Global Marketing, 27(1), 1-12.

Cheng, J. L. C., Henisz, W., Roth, K., \& Swaminathan, A. 2009. Advancing interdisciplinary research in the field of international business: Prospects, issues, and challenges. Journal of International Business Studies, 40, 1070-1074.

Chin, W.W. (1998). Commentary: Issues and Opinion on Structural Equation Modeling. MIS Quarterly, 7-16.

Churchill Jr, G. A. (1979). A paradigm for developing better measures of marketing constructs. Journal of marketing research, 64-73.

Cohen, J (1988). Statistical Power Analysis for the Behavioral Sciences. 2nd ed. New York: Psychology Press.

Costa, F. J. da (2011). Mensuração e Desenvolvimento de Escalas: Aplicações em Administração. Rio de Janeiro, editora Ciência Moderna Ltda.

Costa, L. A., Cool, K., \& Dierickx, I. (2013). The competitive implications of the deployment of unique resources. Strategic Management Journal, 34(4), 445-463.

Cuervo-Cazurra, A. (2011). Global strategy and global business environment: the direct and indirect influences of the home country on a firm's global strategy. Global Strategy Journal, 1(3-4), 382-386.

Cuervo-Cazurra, A., \& Un, A. (2015, January). Country-of-Origin, Government-and Consumer-Based Advantage \& Disadvantage of Foreignness, and FDI. In Academy of Management Proceedings (Vol. 2015, No. 1, p. 15760). Academy of Management.

D'Antone, S., \& Merunka, D. (2015). The brand origin meaning transfer model (BOMT): an integrative theoretical model. International Marketing Review, 32(6), 713-731. 
d'Astous, A., \& Ahmed, S. A. (1999). The importance of country images in the formation of consumer product perceptions. International Marketing Review, 16(2), 108-126.

d'Astous, A., \& Boujbel, L. (2007). Positioning countries on personality dimensions: Scale development and implications for country marketing.Journal of Business Research, 60(3), 231239.

Day, G. S. (1994). The capabilities of market-driven organizations. The Journal of Marketing, $37-52$.

Day, G. S. (2001). Capabilities for forging customer relationships (No. 118). Marketing Science Institute.

Day, G. S. (2011). Closing the marketing capabilities gap. Journal of Marketing, 75(4), 183195.

Day, G. S. (2014). An outside-in approach to resource-based theories.Journal of the Academy of Marketing Science, 42(1), 27-28.

Day, G. S., \& Wensley, R. (1988). Assessing advantage: a framework for diagnosing competitive superiority. The Journal of Marketing, 1-20.

de Camargo Guerrazzi, L. A., Brandão, M. M., de Campos Junior, H., \& Lourenço, C. E. (2015). Pesquisa em Marketing e Estratégia nos Principais Periódicos Internacionais: Um Estudo Bibliométrico sobre Publicações no Século XXI. Iberoamerican Journal of Strategic Management (IJSM), 14(1), 07-27.

Demirbag, M., Sahadev, S., \& Mellahi, K. (2010). Country image and consumer preference for emerging economy products: the moderating role of consumer materialism. International Marketing Review, 27(2), 141-163.

DeVellis, R. F. (2016). Scale development: Theory and applications (Vol. 26). Sage publications.

Diamantopoulos, A., Schlegelmilch, B. and Palihawadana, D. (2011). The relationship between country-of-origin image and brand image as drivers of purchase intentions: A test of alternative perspectives, International Marketing Review, 28(5), p. 508-524.

Dierickx, I., \& Cool, K. (1989). Asset stock accumulation and sustainability of competitive advantage. Management science, 35(12), 1504-1511.

Đorđević, B. (2008). Corporate strategic branding: How country and corporate brands come together. Ekonomski Anali, 59-89. doi:10.2298/EKA08177059D

Dyer, J. H., \& Singh, H. (1998). The relational view: Cooperative strategy and sources of interorganizational competitive advantage. Academy of management review, 23(4), 660-679.

Fan, Y. (2008). The rise of emerging market multinational and the impact on marketing. Marketing Intelligence \& Planning, 26(4), 353-358.

Faul, F., Erdfelder, E., Buchner, A., \& Lang, A. G. (2009). Statistical power analyses using G* Power 3.1: Tests for correlation and regression analyses.Behavior research methods, 41(4), 1149-1160.

Florek, M., \& Insch, A. (2008). The trademark protection of country brands: insights from New Zealand. Journal of Place Management and Development,1(3), 292-306.

Fornell, C.; Larcker, D.F. (1981). Evaluating structural equation models with unobservable variables and measurement error. Journal of Marketing Research, 18(1), p. 39-50. 
Foss, N. J. (1998). The resource-based perspective: an assessment and diagnosis of problems. Scandinavian Journal of management, 14(3), 133-149.

Forza, C. (2002). Survey research in operations management: a process-based perspective. International Journal of Operations \& Production Management, 22(2), 152-194.

Garson, D. (2012). Partial least squares: regression and path modeling.Asheboro, NC: Statistical Publishing Associates.

Gefen, D., \& Straub, D. (2005). A practical guide to factorial validity using PLS-Graph: Tutorial and annotated example. Communications of the Association for Information systems, 16(1), 5.

Gerbing, D. W., \& Anderson, J. C. (1988). An updated paradigm for scale development incorporating unidimensionality and its assessment. Journal of marketing research, 186-192.

Giraldi, J. M. E., Giraldi, I. M. E., \& Scaduto, A. A. (2011). Brazil's image as social representation process. African Journal of Business Management, 5, 8821-8831.

Gürhan-Canli, Z., \& Maheswaran, D. (2000). Cultural Variations in Country of Origin Effects. Journal of Marketing Research, 37(3), 309-317. doi: 10.1509/jmkr.37.3.309.18778

Hair, J. J. F., Babin, B., Money, A. H., \& Samouel, P. (2005). Fundamentos de métodos de pesquisa em administração. (Tradução: Lene Belon Ribeiro, Ed.). Porto Alegre: Bookman.

Hair, J. F., Black, W. C., Babin, B. J., Anderson, R. E., and Tatham, R. L. (2009). Multivariate data analysis. Bookman Publishing.

Hair, J. F., Sarstedt, M., Ringle, C. M., \& Mena, J. A. (2012). An assessment of the use of partial least squares structural equation modeling in marketing research. Journal of the academy of marketing science, 40(3), 414-433.

Hair, J.F.; Hult, T.M.; Ringle, C.M. e Sarstedt, M. A (2016). Primer on Partial Least Squares Structural Equation Modeling (PLS-SEM). Los Angeles: SAGE.

Hakala, U., Lemmetyinen, A., \& Kantola, S. (2013). Country image as a nation-branding tool. Marketing Intelligence \& Planning, 31(5), 538-556.

Henseler, J., Hubona, G., \& Ray, P. A. (2016). Using PLS path modeling in new technology research: updated guidelines. Industrial Management \& Data Systems, 116(1), 2-20.

Henseler, J., Ringle, C. M., \& Sinkovics, R. R. (2009). The use of partial least squares path modeling in international marketing. Advances in international marketing, 20(1), 277-319.

Herstein, R., Berger, R., \& D. Jaffe, E. (2014). How companies from developing and emerging countries can leverage their brand equity in terms of place branding. Competitiveness Review, 24(4), 293-305.

Herz, M.F. \& Diamantopoulos, A. (2013a). Activation of country stereotypes: automaticity, consonance, and impact, Journal of the Academy of Marketing Science, 41(4), p. 400-417.

Herz, M.F. \& Diamantopoulos, A. (2013b). Country-Specific Associations Made by Consumers: A Dual-Coding Theory Perspective, Journal of International Marketing, 21(3), p. 95-121.

Heslop, L. A., Papadopoulos, N., Dowdles, M., Wall, M., \& Compeau, D. (2004). Who controls the purse strings: A study of consumers' and retail buyers' reactions in an America's FTA environment. Journal of Business Research, 57(10), 1177-1188.

Hooley, G. J., Greenley, G. E., Cadogan, J. W., \& Fahy, J. (2005). The performance impact of marketing resources. Journal of Business Research,58(1), 18-27. 
Hunt, S. D., \& Morgan, R. M. (1995). The comparative advantage theory of competition. The Journal of Marketing, 1-15.

IMR. (2015). Country of Origin Research Revisited: Seeking New Methods and Variables Special issue call for papers from International Marketing Review. Disponível em: http://www.emeraldgrouppublishing.com/products/journals/call_for_papers.htm?id=5673 Data de acesso: 15.03 .2015

Insch, A., \& Florek, M. (2009). Prevalence of country of origin associations on the supermarket shelf. International Journal of Retail \& Distribution Management, 37(5), 453-471.

Jarvis, C. B., Mackenzie, S. B. \& Padsakoff, P. M. (2003). A Critical Review of Construct Indicatores and Measurement Model Misspecification in Marketing and Consumer Research. Journal of Consumer Research, 30, 199-218

Kapferer, J. N. (2003). As marcas: Capital da empresa: criar e desenvolver marcas fortes. Porto Alegre. Boolkman.

Kim, H., \& Hoskosson, R. E. (2015). A Resource Environment View of Competitive Advantage. Forthcoming in Advances in International Management.

Kogut, B., \& Zander, U. (1992). Knowledge of the firm, combinative capabilities, and the replication of technology. Organization science, 3(3), 383-397.

Kotabe, M. (1999). In: Rugman, A. (Ed.): The Oxford Handbook of International Business. Oxford: Oxford University Press, 2001.

Kotler, P. \& Gertner, D. (2002). Country as brand, product, and beyond: a place marketing and brand management perspective. Journal of Brand Management. 9 (4/5), 249-261.

Kozlenkova, I. V., Samaha, S. A., \& Palmatier, R. W. (2014). Resource-based theory in marketing. Journal of the Academy of Marketing Science,42(1), 1-21.

Krush, M. T., Sohi, R. S., \& Saini, A. (2015). Dispersion of marketing capabilities: impact on marketing's influence and business unit outcomes. Journal of the Academy of Marketing Science, 43(1), 32-51.

Kumar, N. \& Steenkamp, J-B. E.M. (2013). Brand breakout: how emerging market brands will go global. Palgrave Macmillan.

La, V., Patterson, P., \& Styles, C. (2009). Client-perceived performance and value in professional B2B services: An international perspective. Journal of International Business Studies, 40(2), 274-300.

Laroche, M., Papadopoulos, N., Heslop, L. A., \& Mourali, M. (2005). The influence of country image structure on consumer evaluations of foreign products. International Marketing Review, 22(1), 96-115.

Lee, N., \& Hooley, G. (2005). The evolution of "classical mythology" within marketing measure development. European Journal of Marketing, 39(3/4), 365-385.

Lippman, S. A., \& Rumelt, R. P. (1982). Uncertain imitability: An analysis of interfirm differences in efficiency under competition. The Bell Journal of Economics, 418-438.

MacKenzie, S. B., Podsakoff, P. M., \& Podsakoff, N. P. (2011). Construct measurement and validation procedures in MIS and behavioral research: Integrating new and existing techniques. MIS quarterly, 35(2), 293-334. 
Magnusson, P.; Haas, S. M. \& Zhao, H. (2008). A Branding Strategy for Emerging Market Firms Entering Developed Markets. Journal of International Consumer Marketing, 20(3-4), 95-106.

Magnusson, P., Westjohn, S.A., and Zdravkovic, S. (2011a). What? I thought Samsung was Japanese": accurate or not, perceived country of origin matters, International Marketing Review, 28(5,) p. 454-472.

Magnusson, P., Westjohn, S.A., and Zdravkovic, S. (2011b). Further clarification on how perceived brand origin affects brand attitude: A reply to Samiee and Usunier, International Marketing Review, 28(5), p. 497-507.

Malhotra, N.K. (2012). Pesquisa de marketing: uma orientação aplicada. 6a ed. Porto Alegre: Bookman.

Manrai, L.A., Lascu, D-N., \& Manrai, A. K. (1998). Interactive effects of country of origin and product category on product evaluations. International Business Review, 7, 591-615.

Makadok, R. (2001). TOWARD A SYNTHESIS OF THE RESOURCE-BASED AND DYNAMIC-CAPABILITY VIEWS OF RENT. Strategic management journal, 22, 387-401.

Martín, M. O., \& Cerviño, J. (2011). Towards an integrative framework of brand country of origen recognition determinants: A cross-classified hierarchical model. International Marketing Review, 28(6), 530-558.

Martins, G. de A., \& Theóphilo, C. R. (2009). Metodologia da Investigação Científica para Ciências Sociais Aplicadas. São Paulo -SP: Atlas.

Medida provisória n. 2.186-16, de 23 de agosto de 2001. Regulamenta o inciso II do § 4o do art. 225 da Constituição, os arts. 1o, 8o, alínea "j", 10, alínea "c", 15 e 16, alíneas 3 e 4 da Convenção sobre Diversidade Biológica, dispõe sobre o acesso ao patrimônio genético, a proteção e o acesso ao conhecimento tradicional associado, a repartição de benefícios e o acesso à tecnologia e transferência de tecnologia para sua conservação e utilização, e dá outras providências. Recuperado de http://www.planalto.gov.br/ccivil_03/mpv/2186-16.htm

Mohd Yasin, N., Nasser Noor, M., \& Mohamad, O. (2007). Does image of country-of-origin matter to brand equity?. Journal of Product \& Brand Management, 16(1), 38-48.

Moradi, H., \& Zarei, A. (2012). Creating consumer-based brand equity for young Iranian consumers via country of origin sub-components effects. Asia Pacific Journal of Marketing and Logistics, 24(3), 394-413.

Morrish, S. C., \& Lee, C. (2011). Country of origin as a source of sustainable competitive advantage: The case for international higher education institutions in New Zealand. Journal of Strategic Marketing, 19(6), 517-529.

Nagashima, A. (1970). A Comparison of Japanese and U. S. Attitudes toward Foreign Products. Journal of Marketing, 34(1), 68-74. doi:10.2307/1250298

. (1977). A Comparative "Made in" Product Image Survey among Japanese Businessmen. Journal of Marketing, 41 (3), 95-100. Doi: 10.2307/1250943

Nath, P., Nachiappan, S., \& Ramanathan, R. (2010). The impact of marketing capability, operations capability and diversification strategy on performance: A resource-based view. Industrial Marketing Management, 39(2), 317-329.

Nebenzahl, I. D., Jaffe E. D. \& Usunier, J-C. (2003). Personifying country of origin research. Management International Review, 43(4), 383-406. 
Netemeyer, R. G., Bearden, W. O., \& Sharma, S. (2003). Scaling procedures: Issues and applications. Sage Publications.

Neto, M. G.; Avrichir, I.; Silva, D. da \& Figueiredo, C. da C. (2016). Adaptação e validação de instrumento de medida de competências interculturais para estudantes universitários brasileiros. REGE - Revista de Gestão, 23(1), 20-30

Newbert, S. L. (2007). Empirical research on the resource-based view of the firm: an assessment and suggestions for future research. Strategic management journal, 28(2), 121-146.

Niederle, P. A. (2012). O mercado vitivinícola e a reorganização do sistema de indicações geográficas na região do Languedoc, França. Organizações Rurais \& Agroindustriais.v. 14(2), 155-173.

Niss, H. (1995). Country of origin marketing over the product life cycle. European Journal of Marketing, 30(3), 6-22.

Ohanian, R. (1990). Construction and validation of a scale to measure celebrity endorsers' perceived expertise, trustworthiness, and attractiveness. Journal of advertising, 19(3), 39-52.

Papadopoulos, N. (1986). Development and organization of a cross-national study: the countryof-origin effect. In: Papadopoulos N, Bradley MF, editors. Proceedings, workshop on international strategy. Brussels: European Institute for Advanced Studies in Management, 4256.

Papadopoulos, N. (2004). Place branding: evolution, meaning and implications. Place branding, 1(1), 36-49.

Papadopoulos, N., Heslop, L. A. \& Bamossy, G. (1990). A comparative image analysis of domestic versus imported products. International Journal of Research in Marketing, 16(7), 283-94. doi:10.1016/0167-8116(90)90005-8

Pappu, R., Quester, P. G., \& Cooksey, R. W. (2005). Consumer-based brand equity: improving the measurement-empirical evidence. Journal of Product \& Brand Management, 14(3), 143154.

Pappu, R., Quester, P. G., \& Cooksey, R. W. (2006). Consumer-based brand equity and country-of-origin relationships: some empirical evidence. European Journal of Marketing, 40(5/6), 696-717.

Pappu, R, Quester, P. G. \& Cooksey, R. W. (2007). Country image and consumer-based brand equity: relationships and implications for international marketing. Journal of International Business Studies, 38(5), 726-745.

Paterlini, M. A., Giraldi, J. D. M. E., \& Amui, L. B. L. (2012). The use of the country of origin information in communication strategies used by Brazilian cosmetics-exporting enterprises in external markets. Journal of Management Research, 4(4), 310-333.

Penrose, E. T. (1959). The Growth of the Firm. Wiley: New York.

Peteraf, M. A. (1993). The cornerstones of competitive advantage: a resource-based view. Strategic management journal, 14(3), 179-191.

Peterson, R. A., \& Jolibert, A. J. P. (1995). A Meta-Analysis of Country-of-Origin Effects. Journal of International Business Studies, 26(4), 883-900. 
Pharr, J. (2005). Synthesizing country-of-origin research from the last decade: is the concept still salient in an era of global brands? Journal of Marketing Theory and Practice,13(4), p. 3445, Retrieved from http://www.jstor.org/stable/40470235

Piehler, R., King, C., Burmann, C., \& Xiong, L. (2016). The importance of employee brand understanding, brand identification, and brand commitment in realizing brand citizenship behaviour. European Journal of Marketing,50(9/10).

Pisharodi, R. M., \& Parameswaran, R. (1992). Confirmatory factor analysis of a country-oforigin scale: initial results. Advances in consumer research,19(1), 706-714.

Quester, P. G., Dzever, S., \& Chetty, S. (2000). Country-of-origin effects on purchasing agents' product perceptions: an international perspective. Journal of Business \& Industrial Marketing, 15(7), 479-489.

Ramamurti, R. (2008). What Have We Learned about Emerging Market MNEs? Insights from a Multi-Country Research Project. In: Conference on Emerging Multinationals: Outward FDI form Emerging and Developing Economies. Copenhagen Business School, Copenhagen, Denmark, October 9010, 2008.

Ramamurti, R. (2012). What is really different about emerging market multinationals? Global Strategy Journal, 2(1), 41-47.

Ray, G., Barney, J. B., \& Muhanna, W. A. (2004). Capabilities, business processes, and competitive advantage: choosing the dependent variable in empirical tests of the resource-based view. Strategic management journal,25(1), 23-37.

Ringle, C. M., Silva, D. D., \& Bido, D. (2014). STRUCTURAL EQUATION MODELING WITH THE SMARTPLS. REMark: Revista Brasileira de Marketing, 13(2).

Rossiter, J. R. (2002). The C-OAR-SE procedure for scale development in marketing. International Journal of Research in Marketing, 19(4), 305-335.

Roth, M. S. \& Romeo, J. B. (1992). Matching Product Category and Country Image Perceptions: A Framework for Managing Country-of-Origin Effects. Journal of International Business Studies, 23(3), 477-497.

Roth, K \& Diamantopoulos, A. (2009). Advancing the country image construct. Journal of Business Research, 62, 726-740.

Samiee, S. (2010). Advancing the country image construct - A commentary essay. Journal of Business Research, 63, p. 442-445. doi: 10.1016/j.jbusres.2008.12.012

Samiee, S. (2011). Resolving the impasse regarding research on the origins of products and brands. International Marketing Review, 28(5), 473-485.

Samiee, S., Shimp, T. A. \& Sharma, S. (2005). Brand origin recognition accurancy: its antecedents and consumers' cognitive limitations. Journal of International Business Studies, 36, 379-397.

Sampieri, R. H., Collado, C. F., \& Lucio, P. B. (2006). Metodologia de Pesquisa. 3a ed., São Paulo: McGraw-Hill.

Schooler, R. D. (1965). Product Bias in the Central American Common Market. Journal of Marketing Research, 2, 394-97.

Schooler, R. D. \& Wildt, A. (1968). Elasticity of Product Bias. Journal of Marketing Research, 5(1), 78-81. doi: 10.2307/3149798 
Senthi, S. P.; \& Elango, B. (2000). The influence of "country of origin" on multinational Corporation global strategy: A conceptual framework. Journal of International Management, 5, 285-298.

Sirmon, D. G., Hitt, M. A., \& Ireland, R. D. (2007). Managing firm resources in dynamic environments to create value: Looking inside the black box. Academy of management review, 32(1), 273-292.

Spence, M., \& Hamzaoui Essoussi, L. (2010). SME brand building and management: an exploratory study. European Journal of Marketing, 44(7/8), 1037-1054.

Srivastava, R. K., \& Shocker, A. D. (1991). Brand equity: a perspective on its meaning and measurement. Marketing Science Institute.

Srivastava, R. K., Shervani, T. A., \& Fahey, L. (1998). Market-based assets and shareholder value: a framework for analysis. The Journal of Marketing, 2-18.

Srivastava, R. K., Shervani, T. A., \& Fahey, L. (1999). Marketing, business processes, and shareholder value: an organizationally embedded view of marketing activities and the discipline of marketing. The Journal of Marketing, 168-179.

Srivastava, R. K., Fahey, L., \& Christensen, H. K. (2001). The resource-based view and marketing: The role of market-based assets in gaining competitive advantage. Journal of management, 27(6), 777-802.

Sutter, M. B., Polo, E. F., \& Maclennan, M. L. F. (2014). Atributos da imagem do país de origem como fonte de vantagem competitiva: estudo no segmento internacional da moda brasileira. InternexT - Revista Eletrônica de Negócios Internacionais da ESPM, 9(2), 75-93.

Sutter, M. B., Polo, E. F., \& Maclennan, M. L. F. (2014). Atributos da imagem do país de origem como fonte de vantagem competitiva: estudo no segmento internacional da moda brasileira. InternexT - Revista Eletrônica de Negócios Internacionais da ESPM, 9(2), 75-93.

Sutter, M. B, Maclennan, M. L. F., Tiscoski, G. P. \& Polo, E. (2015a). Braziliannes: A look at the multiple faces of the Brazilian National Identity. Future Studies Research Journal, 7(1), 130-155.

Sutter, M. B., Barakat, S. R., Massaini, S. A., Porto, M. C., \& Marinho, B. D. L. (2015b). Estudo Sobre a Utilização de Atributos da Identidade Cultural Brasileira como Fonte de Vantagem Competitiva no Segmento de Moda. Revista Administração em Diálogo (RAD), 16(1).

Sutter, M. B., MacLennan, M. L. F., Fernandes, C. C., \& Oliveira Jr, M. M. D. (2015c). Country of Origin Image and Foreign Markets Strategy: Analysis of the Brazilian Cosmetics Company Natura. Revista Brasileira de Marketing e-ISSN: 2177-5184, 14(3), 393-406.

Sutter, M. B, Carmago, M. A. A P.; Strehlau, V. I. \& Crescitelli, E. (2016a). A Apropriação da Imagem de um País Emergente na Construção de uma Marca Europeia: Estudo de Caso L'Occitane au Brésil. Espacios (Caracas), 37, p.1.

Sutter, M. B, Maclennan, M. L. F., Giraldi, J. M. E.; Crescitelli, E. \& Polo, E. (2016b). Incorporating Country-of-Origin Image into International Branding: Evidence from the Cosmetic Industry in Brazil In: Academy of International Business - AIB, 2016, New Orleans. Proceedings of the 2016 Annual Meeting of the Academy of International Business.

Tallman, S. \& Yip, G. (2009).Strategy and the multinational enterprise. In: Rugman, A. (Ed.): The Oxford Handbook of International Business. (2nd edition). Oxford: Oxford University Press, 2009. 
Teece, D. J., Pisano, G., \& Shuen, A. (1997). Dynamic capabilities and strategic management. Strategic management journal, 18(7), 509-533.

Theodosiou, M., Kehagias, J., \& Katsikea, E. (2012). Strategic orientations, marketing capabilities and firm performance: An empirical investigation in the context of frontline managers in service organizations. Industrial Marketing Management, 41(7), 1058-1070.

Thakor, M. V. \& Kohli, C. S. (1996). Brand origin: conceptualization and review. Journal of consumer marketing, 13(3), 27-42.

Thakor, M. V. \& Lavack, A. M. (2003). Effect of perceived brand origin associations on consumer perceptions of quality. Journal of product and brand management, 12(6), 394-407.

Usunier, J-C. (2006). Relevance in business: the case of country-of-origin research in marketing. European Management Review, 3, 60-73.

Usunier, J-C. \& Cestre, G. (2007). Product ethnicity: revisiting the match between products and countries. Journal of International Marketing, 15(3), p. 32-72.

Usunier, J.-C. (2011), The shift from manufacturing to brand origin: suggestions for improving COO relevance, International Marketing Review, 28(5), p. 486-496.

Verlegh, P. M. J. \& Steenkamp, J. B. E. M. (1999). A review and meta-analysis of country-oforigin research. Journal of Economic Psychology, 20(5), 521-546.

Vergara, S. C. (2011). Projetos e relatórios de pesquisa em administração. 13 ed., São Paulo: Atlas.

Yaprak, A. \& Parameswaran, R. (1986). Strategy formulation in multinational marketing: a deductive, paradigm-integrating approach. Advances in International Marketing, 1, 21-45.

Wang, C. L., Li, D., Barnes, B. R., \& Ahn, J. (2012). Country image, product image and consumer purchase intention: Evidence from an emerging economy. International Business Review, 21(6), 1041-1051.

Wen-Cheng, W., Chien-Hung, L. \& Ying-Chien, C. (2011). Types of Competitive Advantage and Analysis. International Journal of Business and Management, 6(5), 100-104.

Wernerfelt, B. (1984). A resource-based view of the firm. Strategic management journal, 5(2), 171-180.

Wernerfelt, B. (1989). From critical resources to corporate strategy. Journal of general management, 14(3), 4-12.

Wernerfelt, B. (1995). The resource-based view of the firm: ten years after.Strategic management journal, 16, 171-171.

Wernerfelt, B. (2014). On the role of the RBV in marketing. Journal of the Academy of Marketing Science, 42(1), 22-23.

Winter, S. G. (1995). Four Rs of profitability: rents, resources, routines, and replication. In Resource-Based and Evolutionary Theories of the Firm, Montegomery CA (ed). Kluwer: Boston, MA; 147-178.

Woodside, A. G., Sullivan, D. P., \& Trappey, R. J. (1999). Assessing relationships among strategic types, distinctive marketing competencies, and organizational performance. Journal of Business research, 45(2), 135-146. 
Zhou, K. Z., Li, J. J., Zhou, N., \& Su, C. (2008). Market orientation, job satisfaction, product quality, and firm performance: evidence from China.Strategic Management Journal, 29(9), 985. 


\section{APÊNDICES}

\section{Apêndice A - Instrumento de coleta de dados}

\section{FEAUSP}

Olá. Gostaria de solicitar sua colaboração para participar de uma pesquisa que faz parte da minha tese de Doutorado na Faculdade de Economia, Administração e Contabilidade (FEA) da USP. O estudo almeja levantar informações sobre estratégias internacionais.

Todas as informações obtidas são confidenciais, não havendo qualquer forma de identificação. Os dados serão utilizados unicamente para fins acadêmicos.

$\mathrm{O}$ preenchimento levará cerca de 5 minutos. Caso tenha alguma dúvida, fique à vontade para entrar em contato comigo pelo e-mail: mbsutter@gmail.com

Muito obrigada pela colaboração!

Prof ${ }^{a}$ Mariana Bassi Sutter

1) A empresa em que você trabalha tem operações internacionais? $\square$ Sim $\square$ Não

2) Como a empresa opera em outros mercados?

$\square$ Trabalho na subsidiária de uma multinacional (empresa estrangeira operando no Brasil).

$\square$ Exportação indireta, por meio de trading ou de empresa comercial exportadora no Brasil.

$\square$ Exportação direta, para distribuidores no exterior ou diretamente para clientes no exterior.

$\square$ Representante exclusivo no exterior, responsável por divulgar, vender e distribuir o

produto no exterior.

Escritórios de comercialização próprios.

Centros de distribuição próprios.

Subsidiárias em outros países.

É nacional e só opera no mercado brasileiro.

Outro (especifique):

3) Qual é a origem (nacionalidade) da empresa? Indique uma opção:

\begin{tabular}{|c|c|c|c|c|}
\hline$\square$ Brasil & $\square$ Angola & $\square$ Alemanha & $\square$ Colômbia & $\square$ Portugal \\
\hline$\square$ Chile & $\square$ Arábia Saudita & $\square$ Nova Zelândia & $\square$ Coréia do Sul & $\square$ Suíça \\
\hline$\square$ França & $\square$ Armênia & $\square$ China & $\square$ Coréia do Norte & $\square$ Itália \\
\hline$\square$ Estados Unidos & $\square$ Aruba & $\square$ Turquia & $\square$ Croácia & $\square$ Japão \\
\hline$\square$ México & $\square$ Austrália & $\square$ Rússia & $\square$ Cuba & $\square$ Espanha \\
\hline$\square$ Argentina & $\square$ Áustria & $\square$ Tailândia & $\square$ Costa Rica & $\square$ Holanda \\
\hline$\square$ Peru & $\square$ Bélgica & $\square$ Grécia & $\square$ Dinamarca & $\square$ Suécia \\
\hline$\square$ Venezuela & $\square$ Bolívia & $\square$ Guatemala & $\square$ Egito & $\square$ Reino Unido \\
\hline$\square$ África do Sul & $\square$ Bulgária & $\square$ Outro (especifique): & & \\
\hline
\end{tabular}

4) Qual o seu cargo atual na empresa?
Coordenador
Gerente
Diretor
Supervisor
$\square$ Vice-presidente $\square$ Presidente
Outro (especifique): 
5) Setor de atuação da empresa (descrição CNAE)

$\square$ Agricultura

$\square$ Indústria de transformação

$\square$ Produção Florestal

$\square$ Eletricidade e gás

$\square$ Indústria extrativa

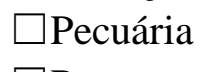

$\square$ Pesca

$\square$ Moda
$\square$ Construção
$\square$ Comércio

$\square$ Transporte
$\square$ Armazenagem

$\square$ Esporte e recreação

$\square$ Alimentação

$\square$ Informação e comunicação

$\square$ Artes e Cultura

$\square$ Correio

$\square$ Reparação de veículos automotores e motocicletas

$\square$ Água, esgoto, atividade de gestão de resíduo e descontinuação

6) Gênero: $\square$ Feminino $\square$ Masculino

7) Área da organização em que trabalha:

$\begin{array}{ll}\square \text { Operações } & \square \text { Marketing } \\ \square \text { Inovação } & \square \text { Finanças }\end{array}$

8) A seguir, encontram-se algumas características de marketing que são compreendidas como os sinais transmitidos pela sua empresa em pontos de contato com o cliente, tais como: propaganda, site, folhetos, uniformes dos funcionários, ambientação de escritórios, ambientação de show room, estande em feiras e no produto que contempla a sua embalagem, design e matéria-prima. 
Pensando no principal produto exportado pela sua empresa, pediria que o Sr./Sra indicasse o grau de concordância atribuído as afirmações abaixo. Considerando a escala 1 até 7, onde 1 Discorda Fortemente e 7 Concorda Fortemente com a afirmação

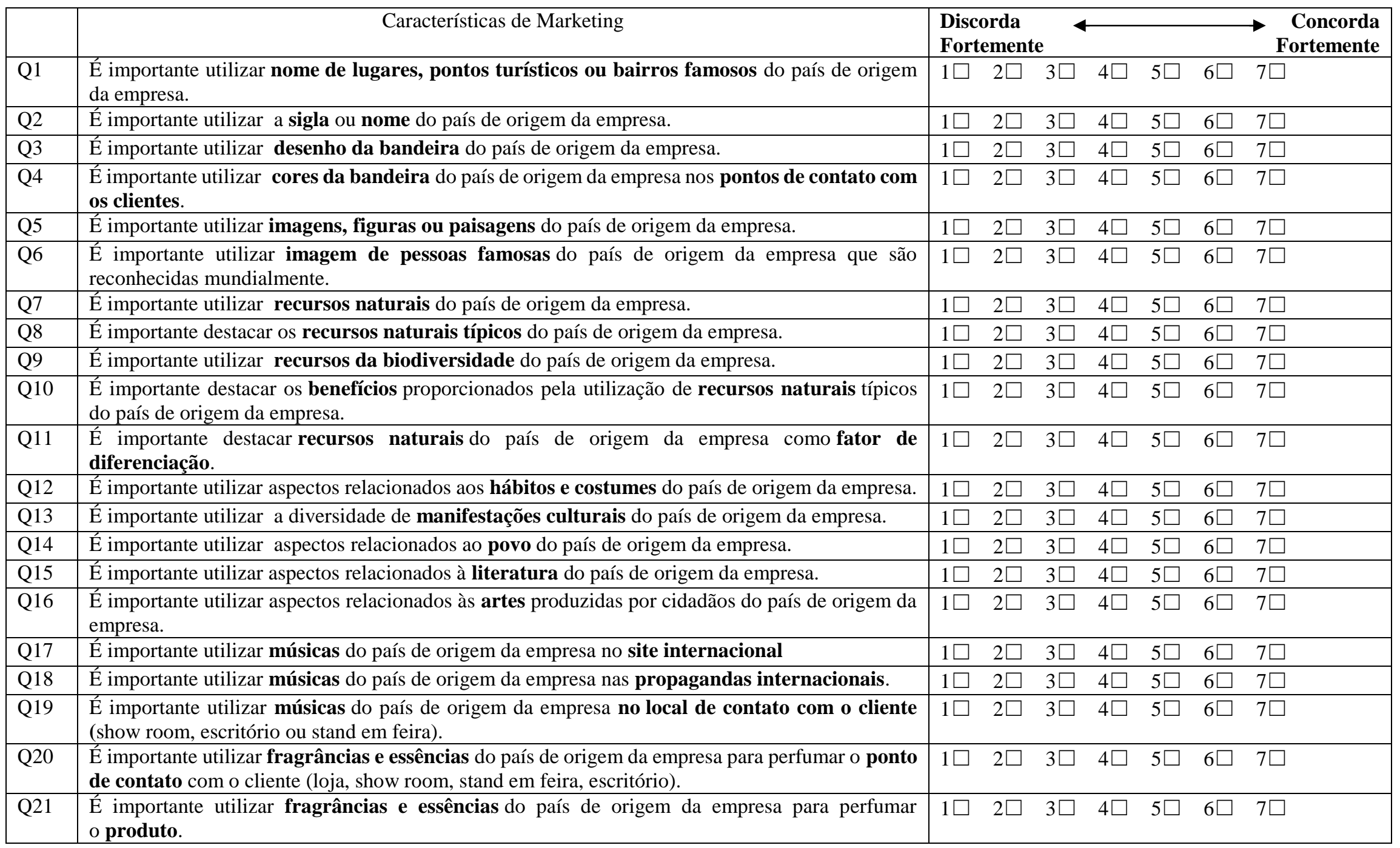




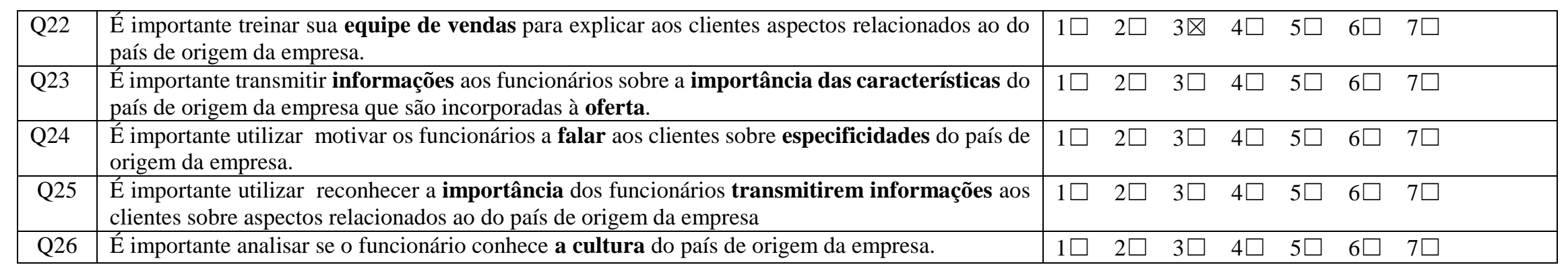




\section{ANEXOS}

Anexo 1 - Resumo das principais escalas analisadas por Roth \& Diamantopoulos (2009)

\begin{tabular}{|c|c|c|c|c|}
\hline Autor(es) & Dimensões do produto & Dimensões do País & Amostra & Origem dos itens \\
\hline $\begin{array}{l}\text { Wang and } \\
\text { Lamb (1980) }\end{array}$ & Não aborda & $\begin{array}{l}\text { A influencia do ambiente estrangeiro: } \\
\text { - O ambiente econômico; } \\
\text { - O ambiente político }\end{array}$ & $\begin{array}{l}\text { Amostra aleatória. } \\
\mathrm{N}=273 \text { famílias e donas de casa }\end{array}$ & Revisão da literatura \\
\hline $\begin{array}{l}\text { ang and } \\
\text { Lamb (1983) }\end{array}$ & Não aborda & $\begin{array}{l}\text { A influencia do ambiente estrangeiro: } \\
\text { - O ambiente político; } \\
\text { - O ambiente cultural; } \\
\text { - O ambiente econômico. }\end{array}$ & $\begin{array}{l}\text { Pré-teste com N = } 94 \text { estudantes; } \\
\text { Validação com N = } 305 \text { famílias } \\
\text { e donas de casa }\end{array}$ & Revisão da literatura \\
\hline $\begin{array}{l}\text { Papadopoulos (1986) validada } \\
\text { por: Papadopoulos } \\
\text { et al. (1990); Heslop \& } \\
\text { Papadopoulos (1993) e outros }\end{array}$ & $\begin{array}{l}\text { - Integridade do produto (7 } \\
\text { itens); } \\
\text { - Preço-valor ( } 2 \text { itens); } \\
\text { - Presença de mercado (4 } \\
\text { itens); } \\
\text { - Sensibilidade ( } 4 \text { itens) }\end{array}$ & $\begin{array}{l}\text { Dimensões sobre as pessoas do país: } \\
\text { - Crenças ( } 3 \text { itens); } \\
\text { - Afeto (4 itens); } \\
\text { - Ligação/elo ( } 2 \text { itens) }\end{array}$ & $\begin{array}{l}\text { Consumidores, amostra de } \\
\text { cluster ou amostra de quota. } \\
\mathrm{N}=2247\end{array}$ & $\begin{array}{l}\text { Nagashima }(1970,1977) \text {; } \\
\text { Darling \& Kraft (1977), } \\
\text { Kelman } \quad(1965) \quad \text { e } \\
\text { literatura } \\
\text { de nobçãa imagem }\end{array}$ \\
\hline $\begin{array}{l}\text { Yaprak et al. (1986); } \\
\text { Parameswaran } \\
\& \text { Yaprak (1987) - (Y\&P); } \\
\text { validado por: Knight and } \\
\text { Calantone }(2000)-(\text { K\&C) }\end{array}$ & $\begin{array}{l}\text { - Atributos gerais do produto } \\
\text { ( } 14 \text { itens); } \\
\text { - Atributos específicos do } \\
\text { produto ( } 9 \text { itens para carros, } 8 \\
\text { itens para câmeras e } 7 \text { itens } \\
\text { para calculadoras). }\end{array}$ & $\begin{array}{l}\text { - Atributos gerais do país (10 itens) - Y\&P; } \\
\text { - Pessoas/povo ( } 9 \text { itens) - K\&C }\end{array}$ & $\begin{array}{l}\text { Y\&P N = } 158 \text { executivos } \\
\text { K\&C N = } 914 \text { donas de casa e } \\
\text { estudantes }\end{array}$ & Revisão da literatura \\
\hline $\begin{array}{l}\text { Schweiger (1988); Schweiger } \\
(1990,1992) ; \text { Schweiger \& } \\
\text { Kurz (1997) e outros }\end{array}$ & Não aborda & $\begin{array}{l}\text { - } 8 \text { dimensões de imagem; } \\
\text { - } 6 \text { atributos emocionais; } \\
-4 \text { atributos objetivos. }\end{array}$ & $\begin{array}{l}\text { Consumidores } \\
\mathrm{N}=14000\end{array}$ & $\begin{array}{l}\text { Associações livres de } \\
\text { consumidores com fotos } \\
\text { de países. }\end{array}$ \\
\hline Desborde (1990) & Não aborda & $\begin{array}{l}\text { - Escala de país de origem de afinidade e } \\
\text { similaridade cultural e política ( } 8 \text { itens); } \\
\text { - Nível de desenvolvimento econômico, } \\
\text { tecnológico e superioridade de produto ( } 5 \\
\text { itens); } \\
\text { - Escala de afeto da imagem do país ( } 10 \\
\text { itens) }\end{array}$ & Donas de casa $\mathrm{N}=709$ & $\begin{array}{l}\text { Abordagem dedutiva e } \\
\text { especialistas }\end{array}$ \\
\hline Ger (1991) & Não aborda & $\begin{array}{l}\text { - Percepções de similaridade (7 dimensões); } \\
\text { - Pensamentos sobre o país (4 dimensões); } \\
\text { - Atitude em relação a países (4 itens) }\end{array}$ & $\begin{array}{l}\text { Estudantes de graduação } \\
\mathrm{N}=119\end{array}$ & Questionários \\
\hline Autor(es) & Dimensões do produto & Dimensões do País & Amostra & Origem dos itens \\
\hline
\end{tabular}




\begin{tabular}{|c|c|c|c|c|}
\hline Weber \& Grundhöfer (1991) & Não aborda & $\begin{array}{l}\text { Dimensões de imagem de país: } \\
\text { Política, Aparência, Cultura, Pessoas e } \\
\text { Economia. }\end{array}$ & $\begin{array}{l}\text { Consumidores } \\
\mathrm{N}=30\end{array}$ & Testes exploratórios \\
\hline $\begin{array}{l}\text { Pisharodi \& Parameswaran } \\
(1992), \quad \text { validada } r \text { por: } \\
\text { Parameswaran \& Pisharodi } \\
(1994,2002)\end{array}$ & $\begin{array}{l}\text { GPA - Atributos gerais do } \\
\text { produto ( } 8 \text { itens): } \\
\text { - GPA1 - atributos negativos } \\
\text { do produto; } \\
\text { - GPA } 2 \text { - aspectos da } \\
\text { distribuição e promoção do } \\
\text { mix de marketing; } \\
\text { - GPA } 3 \text { - imagem do produto. } \\
\text { SPA - Atributos específicos do } \\
\text { produto (10 itens). }\end{array}$ & $\begin{array}{l}\text { Atributos gerais do país ( } 12 \text { itens): } \\
\text { - GCA1 - atributos gerais do país e das } \\
\text { pessoas; } \\
\text { - GCA2 - interação entre o país avaliado e } \\
\text { do respondente ou outro país }\end{array}$ & $\begin{array}{l}\text { Consumidores adultos } \\
\mathrm{N}=678\end{array}$ & $\begin{array}{l}\text { Parameswaran \& Yaprak, } \\
\text { (1987), Yaprak } \\
\text { \& Parameswaran (1986) }\end{array}$ \\
\hline Chao \& Rajendran (1993) & $\begin{array}{l}\text { Escala de personificação: } \\
\text { Essa pessoa... } 10 \text { dimensões } \\
\text { ( } 25 \text { itens). }\end{array}$ & Não aborda & $\begin{array}{l}\text { Estudantes } \\
\mathrm{N}=499\end{array}$ & Estudo piloto e pré-teste \\
\hline Kühn (1993) & $\begin{array}{l}\text { Made-in-image } \\
\text { Atributos de produto ( } 6 \text { itens) }\end{array}$ & $\begin{array}{l}\text { Live-in-image } \\
\text { - Pessoas } \\
\text { - Cultura/sociedade } \\
\text { - Economia/política/políticos } \\
\text { - Situação econômica } \\
\end{array}$ & $\begin{array}{l}\text { Gestores } \\
\mathrm{N}=3347\end{array}$ & Não aborda \\
\hline $\begin{array}{l}\text { Martin \& Eroglu (1993), } \\
\text { validada por Li et al. ( 1997) }\end{array}$ & Não aborda & $\begin{array}{l}\text { Imagem do país: } \\
\text { - Dimensão política; } \\
\text { - Dimensão econômica; } \\
\text { - Dimensão tecnológica. }\end{array}$ & $\begin{array}{l}\text { Estudantes } \\
\text { Inicial } \mathrm{N}=200 ; \\
\text { Revisado: } \mathrm{N}=230 \text { (Estados } \\
\text { Unidos); } 80 \text { (Alemanha) e } 80 \\
\text { (Índia) }\end{array}$ & $\begin{array}{l}\text { Questionário, grupo } \\
\text { focal, julgamento com } \\
\text { experts e pré-test. }\end{array}$ \\
\hline Häubl (1996) & $\begin{array}{l}\text { - Avaliação do modelo de } \\
\text { aparência (3 itens); } \\
\text { - Avaliação das características } \\
\text { do modelo (4 itens); } \\
\text { - Atitude em relação ao modelo } \\
\text { (4 itens); } \\
\text { - Avaliação dos carros feitos no } \\
\text { país (4 itens). }\end{array}$ & $\begin{array}{l}\text { - Avaliação afetiva do país (4 itens); } \\
\text { - Avaliação cognitiva de país (4 itens); } \\
\text { - Avaliação do país da indústria de } \\
\text { automóvel (4 itens) }\end{array}$ & $\begin{array}{l}\text { Donos de carro } \\
N=309 \text { (Alemanha) } \\
N=313 \text { (França) }\end{array}$ & $\begin{array}{l}\text { Parameswaran \& Yaprak, } \\
\text { (1987), McGee \& Spiro } \\
\text { (1991), Pisharodi \& } \\
\text { Parameswaran (1992), } \\
\text { Martin \& Eroglu (1993), } \\
\text { Jaffe \& Nebenzahl } \\
\text { (1993). }\end{array}$ \\
\hline Autor(es) & Dimensões do produto & Dimensões do País & Amostra & Origem dos itens \\
\hline Lebrenz (1996) & Made-in-image & Conhecimento sobre o país: & Estudantes & Não aborda \\
\hline
\end{tabular}




\begin{tabular}{|c|c|c|c|c|}
\hline & Atributos de produto ( 5 itens) & $\begin{array}{l}\text { - Componente afetivo ( } 3 \text { itens); } \\
\text { - Componente cognitivo ( } 12 \text { itens). }\end{array}$ & $N=465$ & \\
\hline Moeller, 1997 & $\begin{array}{l}\text { - Produtos em geral (5 itens) } \\
\text { - Carros ( } 5 \text { itens) } \\
\text { - Moda ( } 2 \text { itens) } \\
\text { (as } 3 \text { categorias de produtos } \\
\text { analisadas no estudo) }\end{array}$ & $\begin{array}{l}\text { Imagem do País: } \\
\text { - Fator 1: cognitivo ( } 6 \text { itens); } \\
\text { - Fator 2: afetivo ( } 2 \text { itens })\end{array}$ & $\begin{array}{l}\text { Pré-teste com estudantes } \mathrm{N}=60 \\
\mathrm{~N}=415 \text { turistas }\end{array}$ & $\begin{array}{l}\text { Literatura sobre imagem } \\
\text { do país de origem }(38 \\
\text { estudos); Spiegel \& } \\
\text { Verlag (1993). }\end{array}$ \\
\hline Allred et al. (1999) & Não aborda & $\begin{array}{l}\text { Imagem do país: } \\
\text { - Ambiente (5 itens); } \\
\text { - Trabalho ( } 6 \text { itens); } \\
\text { - Economia (5 itens); } \\
\text { - Conflito (5 itens); } \\
\text { - Politica (4 itens); } \\
\text { - Formação profissional/vocação (4 itens); } \\
\text { - Cultura no trabalho (2 itens) }\end{array}$ & $\begin{array}{l}\text { Estudantes } \\
\mathrm{N}=214\end{array}$ & $\begin{array}{l}\text { Literatura de marketing e } \\
\text { outros temas, grupo focal. }\end{array}$ \\
\hline Lee \& Ganesh (1999) & $\begin{array}{l}\text { Imagem do produto } \\
\text { Imagem da marca } \\
\text { Avaliação da marca } \\
\text { (15 itens) }\end{array}$ & $\begin{array}{l}\text { - Imagem global/geral do país (4 itens); } \\
\text { - Imagem global/geral das pessoas ( } 7 \text { itens); } \\
\text { - Imagem global/geral do país e das pessoas }\end{array}$ & $\begin{array}{l}\text { Donas de casa } \\
\mathrm{N}=233\end{array}$ & $\begin{array}{l}\text { Parameswaran \& Yaprak } \\
\text { (1987) }\end{array}$ \\
\hline Papadopoulos et al ( 2000) & $\begin{array}{l}\text { Imagem do Produto: } \\
\text { - Integridade do produto (9 } \\
\text { itens); } \\
\text { - Preço ( } 1 \text { item); } \\
\text { - Presença de mercado (5 } \\
\text { itens); } \\
\text { - Resposta/sensibilidade do } \\
\text { comprador (5 itens). }\end{array}$ & $\begin{array}{l}\text { Imagem do país: } \\
\text { - Avanço ( } 7 \text { itens); } \\
\text { - Afeto das pessoas ( } 5 \text { itens); } \\
\text { - Ligações desejadas (4 itens) }\end{array}$ & $\begin{array}{l}\text { Consumidores } \\
\mathrm{N}=6094\end{array}$ & 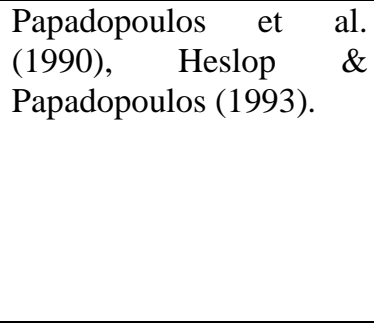 \\
\hline Verlegh (2001) & $\begin{array}{l}\text { Crenças do produto: } \\
\text { - Crenças hedônicas (3 itens); } \\
\text { - Crenças utilitárias }\end{array}$ & $\begin{array}{l}\text { Imagem do país: } \\
\text { - Paisagem natural ( } 2 \text { itens); } \\
\text { - Clima ( } 2 \text { itens); } \\
\text { - Competência ( } 3 \text { itens); } \\
\text { - Criatividade ( } 3 \text { itens); } \\
\text { - Sentimentos positivos ( } 3 \text { itens); } \\
\text { - Sentimentos negativos ( } 3 \text { itens). }\end{array}$ & $\begin{array}{l}\text { Consumidores } \\
N=202 \text { (tomates) } \\
\mathrm{N}=204 \text { (máquina de lavar) }\end{array}$ & 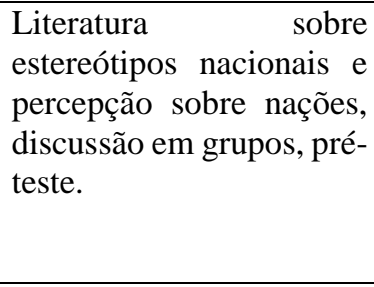 \\
\hline
\end{tabular}




\begin{tabular}{|c|c|c|c|c|}
\hline Autor(es) & Dimensões do produto & Dimensões do País & Amostra & Origem dos itens \\
\hline Ittersum et al. (2003) & $\begin{array}{l}\text { Atributos do produto: } \\
\text { - Qualidade (4 itens); } \\
\text { - Saúde (5 itens); } \\
\text { - Exclusividade (4 itens). }\end{array}$ & $\begin{array}{l}\text { Imagem do produto específica da região: } \\
\text { - Pessoas ( } 4 \text { itens); } \\
\text { - Natureza ( } 2 \text { itens); } \\
\text { - Clima ( } 2 \text { itens) }\end{array}$ & $\begin{array}{l}\text { Donas de casa } \\
\mathrm{N}=130\end{array}$ & $\begin{array}{l}\text { Grupo focal, entrevistas } \\
\text { pessoais e entrevistas } \\
\text { com experts. }\end{array}$ \\
\hline Knight et al. (2003) & $\begin{array}{l}\text { Escala de imagem do país de } \\
\text { origem } \\
\text { - Oferta negativa ( } 2 \text { itens); } \\
\text { - Oferta positiva ( } 2 \text { itens); } \\
\text { - Promoção ( } 1 \text { item); } \\
\text { - Distribuição ( } 1 \text { item); } \\
\text { - Preço ( } 1 \text { item). }\end{array}$ & $\begin{array}{l}\text { Escala de imagem do país de origem } \\
\text { - Povo ( } 2 \text { itens); } \\
\text { - Situação política. }\end{array}$ & $\begin{array}{l}\mathrm{N}=488 \text { estudantes (amostra por } \\
\text { conveniência); } \mathrm{N}=631 \text { donas de } \\
\text { casa (amostra aleatória). }\end{array}$ & $\begin{array}{l}\text { Parameswaran } \\
\text { \& Yaprak (1987) }\end{array}$ \\
\hline Nebenzahl et al. (2003) & $\begin{array}{l}\text { Uma pessoa que compra } \\
\text { produtos feito em (made in) } \\
\text { está } \\
\text { - Buscando qualidade e } \\
\text { satisfação ( } 11 \text { itens); } \\
\text { - Oprimido ( } 11 \text { itens); } \\
\text { - Buscando valor econômico (5 } \\
\text { itens); } \\
\text { - Chauvinista/nacionalista (3 } \\
\text { itens) } \\
\text { Produtos feito em (país) são... } \\
\text { (14 itens). }\end{array}$ & Não aborda & Donas de casa $\mathrm{N}=4200$ & $\begin{array}{l}\text { Jaffe \& Nebenzahl } \\
\text { (1991), questões em } \\
\text { aberto. }\end{array}$ \\
\hline Heslop et al. (2004). & $\begin{array}{l}\text { - Crenças do produto ( } 8 \text { itens); } \\
\text { - Avaliação do produto ( } 4 \\
\text { itens). }\end{array}$ & $\begin{array}{l}\text { - Descrição do país (5 itens); } \\
\text { - Descrição das pessoas (3 itens); } \\
\text { - Competência do país (3 itens); } \\
\text { - Competência das pessoas (3 itens); } \\
\text { - Avaliação do país ( } 2 \text { itens); } \\
\text { - Relacionamentos (5 itens). }\end{array}$ & $\begin{array}{l}\text { Consumidores } \mathrm{N}=312 \\
\text { Varejistas } \mathrm{N}=204\end{array}$ & $\begin{array}{l}\text { Papadopoulos (1993); } \\
\text { Bennet (191) e D’Souza } \\
(1993) .\end{array}$ \\
\hline Laroche et al. (2005). & $\begin{array}{l}\text { - Crenças do produto ( } 3 \text { itens); } \\
\text { - Avaliação do produto }(3 \\
\text { itens). }\end{array}$ & $\begin{array}{l}\text { Imagem do país: } \\
\text { - Crenças do país ( } 3 \text { itens); } \\
\text { - Afeto das pessoas ( } 3 \text { itens); } \\
\text { - Interação desejada (3 itens). }\end{array}$ & Donas de casa $\mathrm{N}=436$ & $\begin{array}{l}\text { Papadopoulos (1986); } \\
\text { Papadopoulos \& Heslop } \\
\text { (2000); Li et al. (1997); } \\
\text { Nagashima (1970). }\end{array}$ \\
\hline
\end{tabular}




\begin{tabular}{|c|c|c|c|c|}
\hline Autor(es) & Dimensões do produto & Dimensões do País & Amostra & Origem dos itens \\
\hline Brijs (2006) & $\begin{array}{l}\text { Atitude com relação ao } \\
\text { produto sob investigação: } \\
\text { - Cognitiva ( } 4 \text { itens); } \\
\text { - Afetiva (3 itens); } \\
\text { - Conativo (3 itens) }\end{array}$ & $\begin{array}{l}\text { Componente cognitivo de imagem de país } \\
\text { - Geo-cultural ( } 3 \text { itens); } \\
\text { - Socioeconômico ( } 3 \text { itens); } \\
\text { - Componente de imagem de país de } \\
\text { sentimentos positivos ( } 6 \text { itens); } \\
\text { - Componentes conativos de imagem de } \\
\text { país ( } 3 \text { itens). }\end{array}$ & $\begin{array}{l}\text { Pré-teste } \mathrm{N}=113 \\
\text { Principal estudantes } \\
\mathrm{N}=616 \text { (Espanha), } 609 \\
\text { (Dinamarca) }\end{array}$ & $\begin{array}{l}\text { Entrevistas exploratórias } \\
\text { e revisão da literatura. }\end{array}$ \\
\hline d'Astous \& Boujbel (2007) & Atitude em relação a produtos & $\begin{array}{l}\text { Dimensões de personalidade: } \\
\text { - Socialização (4 itens); } \\
\text { - Maldade (4 itens) } \\
\text { - Convencimento (4 itens) } \\
\text { - Assiduidade (4 itens) } \\
\text { - Conformidade (4 itens) } \\
\text { - Pertinência (4 itens) } \\
\text { Avaliação como destino de viagem } \\
\text { Familiaridade do país }\end{array}$ & $\begin{array}{l}\text { Consumidores } \\
\text { Pré-teste } \mathrm{N}=174 \\
\text { Donas de casa } \\
\mathrm{N}=170\end{array}$ & $\begin{array}{l}\text { Entrevistas exploratórias } \\
\mathrm{e} \text { escalas } \mathrm{de} \\
\text { personalidade. }\end{array}$ \\
\hline $\begin{array}{l}\text { Pappu, Quester \& Cooksey } \\
(2007)\end{array}$ & $\begin{array}{l}\text { Micro imagem do país: } \\
\text { - Inovação ( } 2 \text { itens); } \\
\text { - Prestígio ( } 3 \text { itens); } \\
\text { - Design ( } 3 \text { itens). }\end{array}$ & $\begin{array}{l}\text { Macro imagem do país: } \\
\text { - Tecnologia ( } 3 \text { itens); } \\
\text { - Economia ( } 3 \text { itens); } \\
\text { - Política ( } 3 \text { itens). }\end{array}$ & $\begin{array}{l}\text { Conveniência } \\
\mathrm{N}=539\end{array}$ & $\begin{array}{l}\text { Martin \& Eroglu (1993); } \\
\text { Nagashima (1970; 1977). }\end{array}$ \\
\hline
\end{tabular}

Fonte: Elaborado a partir de Roth \& Diamantopoulos (2009) e Bacha Lopes \& Giraldi (2014). 